Article

\title{
An Event Study Analysis of Political Events, Disasters, and Accidents for Chinese Tourists to Taiwan
}

\author{
Chia-Lin Chang ${ }^{1,2,3} \mathbb{D}^{-}$, Shu-Han Hsu ${ }^{1}$ and Michael McAleer ${ }^{3,4,5,6,7, *(\mathbb{D})}$ \\ 1 Department of Applied Economics, National Chung Hsing University, Taichung 402, Taiwan; \\ changchialin@email.nchu.edu.tw (C.-L.C.); h31944@gmail.com (S.-H.H.) \\ 2 Department of Finance, National Chung Hsing University, Taichung 402, Taiwan \\ 3 Department of Finance, Asia University, Taichung 41354, Taiwan \\ 4 Discipline of Business Analytics, University of Sydney Business School, Sydney 2006, Australia \\ 5 Econometric Institute, Erasmus School of Economics, Erasmus University Rotterdam, 3000 Rotterdam, \\ The Netherlands \\ 6 Department of Economic Analysis and ICAE, Complutense University of Madrid, 28040 Madrid, Spain \\ 7 Institute of Advanced Sciences, Yokohama National University, Yokohama 240-8501, Japan \\ * Correspondence: michael.mcaleer@gmail.com
}

Received: 23 October 2018; Accepted: 18 November 2018; Published: 20 November 2018

\begin{abstract}
The number of Chinese tourists visiting Taiwan has been closely related to the political relationship across the Taiwan Strait. The occurrence of political events and disasters or accidents have had, and will continue to have, a huge impact on the Taiwan tourism market. To date, there has been relatively little empirical research conducted on this issue. Tourists are characterized as being involved in one of three types of tourism: group tourism (group-type), individual tourism (individual-type), and medical cosmetology (medical-type). We use the fundamental equation in tourism finance to examine the correlation that exists between the rate of change in the number of tourists and the rate of return on tourism. Second, we use the event study method to observe whether the numbers of tourists have changed abnormally before and after the occurrence of major events on both sides of the Strait. Three different types of conditional variance models, namely, the Generalized Autoregressive Conditional Heteroscedasticity, GARCH $(1,1)$, Glosten, Jagannathan and Runkle, GJR $(1,1)$ and Exponential GARCH, EGARCH $(1,1)$, are used to estimate the abnormal rate of change in the number of tourists. The empirical results concerning the major events affecting the changes in the numbers of tourists from China to Taiwan are economically significant, and confirm the types of tourists that are most likely to be affected by such major events.
\end{abstract}

Keywords: event study; abnormal rate of change; Chinese tourists; OLS; GARCH; GJR; EGARCH; tourism finance

JEL: G14; C22; C52; C58

\section{Introduction}

According to statistics compiled by Taiwan's Tourism Bureau under its Ministry of Transportation and Communications for the year 2016, international visitors to Taiwan mostly came from five regions, namely, China and Hong Kong (including Macao), Japan, South Korea, Malaysia, and Singapore. However, from 2010 onwards, with the relaxation of the Cross-Strait tourism policy, the number of tourists to Taiwan from China markedly increased, reaching 3.43 million by the end of 2015, accounting for $45.80 \%$ of the total number of international visitors to Taiwan. The number of Chinese tourists in 2016, nevertheless, appears to have exhibited a significantly downward trend (see Figure 1). 


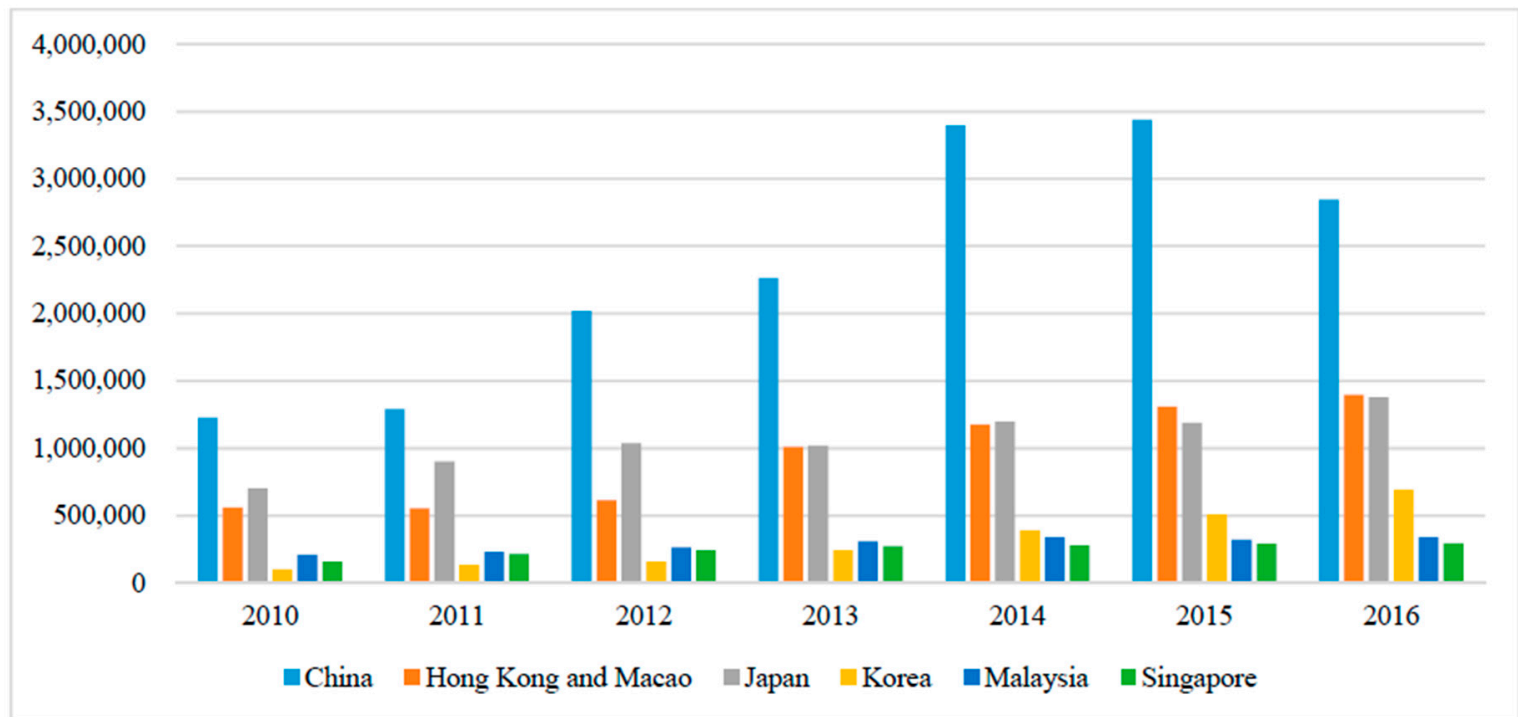

Figure 1. Top five international tourist arrivals to Taiwan, 2010-2016. Sources: Taiwan Tourism Bureau (2017).

The number of Chinese tourists coming to Taiwan has been very closely related to the political relationship across the Taiwan Strait. Beginning in 1949, when the Chinese Communist Party announced the establishment of the People's Republic of China, and the Republic of China relocated to Taiwan, a period of mutual confrontation and division between the two sides ensued, and both sides held fast to the principle of there being only one China. In 1987, after Taiwan announced the lifting of martial law, citizens of Taiwan were allowed to travel to China to visit relatives.

On 1 January 2001, Taiwan piloted its "Three Small Links" policy, whereby mainland Chinese were allowed to apply to visit the offshore islands of Kinmen and Matsu for sightseeing, and passengers on both sides of the Taiwan Strait could travel to and from these islands. On 1 January 2002, mainland Chinese who had gone overseas to study, or who had acquired permanent residence in another foreign country, were allowed to visit Taiwan. On 1 May 2002, mainland Chinese who were allowed to travel on business trips abroad were permitted to visit Taiwan, but they needed to pass through a third country before entering Taiwan.

With the Kuomintang President Ma Ying-Jeou's substantial relaxation of restrictions on Cross-Straits tourism in 2008, group-type tourism by Chinese to visit Taiwan was allowed. On 22 June 2011, the restrictions were further relaxed to allow individual-type travel to Taiwan by Chinese citizens. So far, Taiwan has allowed people in 47 cities in China to apply for individual-type travel to Taiwan, subject to a maximum number of 6000 applications per day. On 1 January 2012, Taiwan relaxed the restrictions on medical-type tourism, so that Chinese citizens could travel to Taiwan for health checks and/or for cosmetic treatments.

In the increasingly competitive tourism market, the willingness of Chinese tourists to travel in Taiwan has not only been affected by the relaxation of tourism policies across the Taiwan Strait, but also by the complicated and close Cross-Straits political relationship and concerns over tourism safety in Taiwan. The occurrence of political events and disasters or accidents have had, and will continue to have, a huge impact on the Taiwan tourism market, although so far, there has been relatively little empirical research conducted on this issue.

For this reason, this paper uses Chinese tourists as the major focus of its analysis to examine whether or not major events that have taken place on both sides of the Strait in the past three years have given rise to abnormal changes in the number of visitors to Taiwan. Moreover, the paper compares the reactions of the group-type, individual-type, and medical-type tourists to these major events.

The important events are divided into political events and disasters/accidents, and tourists are characterized as being involved in one of three types of tourism: group tourism (group-type), 
individual tourism (individual-type), and medical cosmetology (medical-type). First, we use McAleer's [1] fundamental equation in tourism finance to examine the correlation that exists between the rate of change in the number of tourists, and the rate of return on tourism. Second, we use the event study method to observe whether the numbers of tourists have changed abnormally before and after the occurrence of major events on both sides of the Strait.

With regard to the estimation method used to calculate the abnormal changes in the numbers of tourists, in addition to using the Ordinary Least squares (OLS) method that is most commonly used in the historical literature, we also consider the rate of change in the number of tourists and the time-varying variance in the residuals. To this end, we use three different types of conditional variance models, namely Generalized Autoregressive Conditional Heteroscedasticity, GARCH $(1,1)$, Glosten, Jagannathan and Runkle, GJR $(1,1)$ and Exponential GARCH, EGARCH $(1,1)$, to estimate the abnormal rate of change in the number of tourists. In this way, we intend to obtain a more accurate estimate of the abnormal rate of change in the number of tourists.

The empirical results concerning the major events affecting the changes in the numbers of tourists from China to Taiwan are economically significant, and they confirm which types of tourists are more likely to be affected by such major events. These results can serve as a valuable reference to the Taiwan government, and to public and private policy-makers as they formulate new economic and financial tourism policies in the future.

The remainder of the paper is organized as follows. In Section 2, the background and literature are reviewed. In Section 3, the empirical models are presented. The data and variables are described in Section 4. In Section 5, the empirical results are analyzed. Some concluding comments are given in Section 6.

\section{Background and Literature}

It can be difficult to assess the demand for events in tourist destinations. In the following section, we break down the major events of both a political nature, as well as disasters and accidents, to focus our attention on windows in time that are easier to analyze on an individual basis.

\subsection{Identifying the Cross-Strait Events in 2014-2016}

Changes in Cross-Straits political stances and the environment may bring about abnormal changes in the numbers of tourists visiting Taiwan. The political orientation has always been an important event that has plagued the authorities on both sides, especially with the constant strengthening of the subjective consciousness of the Taiwanese and the united consciousness of the mainland Chinese, which has led to an extremely sensitive relationship between the two. After the Kuomintang's presidential candidate Ma Ying-Jeou took office in 2008, the "1992 Consensus, according to which both sides recognize that there is only one China, but have different opinions on what that means" (The "1992 Consensus, where both sides recognize only one China, but have different opinions", developed through the mutual non-recognition of sovereignty, mutual non-denial of each other's jurisdiction, and reciprocity and mutual benefit), was used in the institutionalized consultations between the two sides, in the hope that peaceful and stable development between the two could be maintained.

However, in 2016 there was a switch in the ruling party in Taiwan, with the election of the Democratic Progressive Party's candidate, Tsai Ing-Wen, as the Republic of China's 14th President. While it was still hoped that the peaceful and stable development of the two sides of the Straits would be maintained, in her inaugural presidential speech, President Tsai did not mention the one-China principle, thereby causing China to feel dissatisfied, and the Cross-Straits political relationship was once again affected.

A summary of the important political events that occurred on the two sides of the Taiwan Strait over the 2014-2016 period is provided below. These are also presented in Table 1.

18 March 2014-10 April 2014-The Sunflower Youth Movement: The social movement that resulted in the occupation of the Taiwan legislature by students was mainly in response to the 
opposition to the Kuomintang's forced passing of the review by the committee on the Cross-Straits Agreement on Trade in Services. This led to the formation of a social movement that resulted in the occupation of the Legislative Yuan by Taiwanese students and various civic groups. This event attracted the attention of people from all walks of life, and also impacted the implementation of various Cross-Straits agreements.

Table 1. Literature review of event studies.

\begin{tabular}{lcl}
\hline Disaster and Accident Events & & \\
\hline $\begin{array}{c}\text { Mazzocchi and Montini (2001) } \\
\text { Tao (2014) } \\
\text { Chen et al. (2007) }\end{array}$ & $\begin{array}{c}\text { 26 September 1997 } \\
\text { 20 April 2013 } \\
\text { 22 April 2003 }\end{array}$ & $\begin{array}{l}\text { Magnitude 5.9 earthquake in Umbria (Italy) } \\
\text { Magnitude 7.0 earthquake in Lushan (China) } \\
\text { SARS (Severe Acute Respiratory Syndrome) in Taiwan }\end{array}$ \\
\hline Political Events & & \\
\hline Johnson et al. (2015) & 4 March 2010 & Travel Promotion Act of 2000 \\
\hline Economic Events & & $\begin{array}{l}\text { New hotel openings announcement in Spain } \\
\text { Innovation announcement from tourism enterprises } \\
\text { in Poland }\end{array}$ \\
Nicolau (2002) & 1997-1999 & \\
\hline Szutowski and Bednarska (2014) & & $\begin{array}{l}\text { The Olympic Games announcement } \\
\text { Tokyo 2020 Summer Olympic Games announcement }\end{array}$ \\
\hline International Competitions & 1988-2014 & \\
\hline Ogick and Wang (2010) & 9 September 2013 &
\end{tabular}

29 November 2014-Taiwan's nine-in-one local elections: These were the largest local elections for public officials in Taiwan's political history. The Kuomintang (KMT) won six seats (compared to the 15 seats it held before the election), while the Democratic Progressive Party (DPP) won 13 seats (compared to the six seats it held before the election), and independent candidates won three seats. The KMT (the ruling party) suffered an unprecedented defeat, and former president Ma Ying-jeou resigned as chairman of the KMT. This election outcome had a short-term impact on Cross-Straits relations.

7 November 2015-Ma-Xi Summit: The top leaders of Taiwan and China met at the Shangri-La Hotel in Singapore for the first time since the two sides of the Taiwan Strait became politically separated in 1949. Although the two sides did not sign an agreement or issue a joint statement, the meeting nevertheless constituted a major breakthrough in Cross-Straits relations.

16 January 2016-Taiwan's 14th presidential election and Taiwan's ninth legislative election: In Taiwan's third political party rotation, with Tsai Ing-wen being elected as Taiwan's 14th President, the DPP took charge of the executive administration and controlled over half the seats in the Legislative Yuan, a symbol of the Democratic Progressive Party being totally in power.

20 May 2016-Taiwan 14th Presidential inauguration: At her inauguration ceremony as Taiwan's 14th President, while Tsai Ing-wen advocated the maintenance of goodwill and peace across the Taiwan Strait, she did not clearly express the one-China principle, which again caused China to feel dissatisfied, thereby leading to a stalemate in Cross-Strait relations. As rumors that Chinese officials were setting limits on the numbers of Chinese tourists that would be allowed to visit Taiwan continued to spread, the willingness of Chinese tourists to visit Taiwan was indirectly affected.

18 September 2016-Taiwan mayors visit China: This was a visit by the mayors of eight counties and cities in Taiwan to Beijing to support the cooperation and exchange event to promote "China's eight measures to benefit Taiwan".

In addition to unavoidable natural disasters, tourism safety is also one of the factors that affects tourists' decisions regarding whether or not to visit a country or region. According to the Ministry of Transportation and Communications of the Republic of China, since 2008 when Taiwan relaxed restrictions to allow Chinese tourists to fly directly to and from Taiwan, 90 Chinese tourists have been 
killed and 390 injured in Taiwan. The following is a list of the major accidents on the two sides of the Strait between 2014 and 2016.

31 July 2014-The Kaohsiung Petrochemical gas explosion: This caused serious damage to a number of important roads in Kaohsiung, and resulted in 32 deaths and 321 people injured.

4 September 2014-Taiwan's "gutter oil" scandal: Illegal use by manufacturers of inferior-quality oil products: Taiwan's food safety issues caught the attention of the Chinese government. By immediately going through "Cross-Strait food safety agreement" channels, a comprehensive survey of food products imported into Taiwan has been conducted to maintain food safety.

6 February 2016-Kaohsiung's magnitude 6.6 Meinong earthquake: This resulted in 117 deaths and 551 people injured. The Yongkang District of Tainan suffered the most serious casualties (a total of 115 deaths), with the collapse of a large residential building. In addition, the frequency of the aftershocks following the incident resulted in increased uncertainty regarding the safety of tourists.

1 July 2016-95th Anniversary of the founding of the Communist Party of China: In commemoration of this special day, in the morning of that day, as the Taiwan Navy was conducting training operations, it accidentally fired a Hsiung Feng series 3 anti-ship missile, which resulted in the captain of a Kaohsiung fishing boat being killed and three of his crew members injured. The Taiwan government stressed that this unfortunate incident was due to negligence on the part of staff, and not political factors. This event added to the tensions between the two sides.

During the period 2014-2016, there were two major accidents involving transportation, the first being the crash of TransAsia Airways Flight No. 235 that took place on 4 February 2015; the plane came down in Taipei City, plunging into the Keelung River and killing 43 people, of whom 28 were Chinese tourists. The second major incident took place on 19 July 2016, when a tour bus, in which a tour group from Liaoning in China was travelling, struck a roadside guardrail on the way to Taoyuan Airport and immediately burst into flames, leaving a total of 26 dead.

In summary, over the 2014-2016 period, there were six important political events and disasters/accidents that occurred in Taiwan and China. These important events during 2014-2016 are listed chronologically in Figure 2.

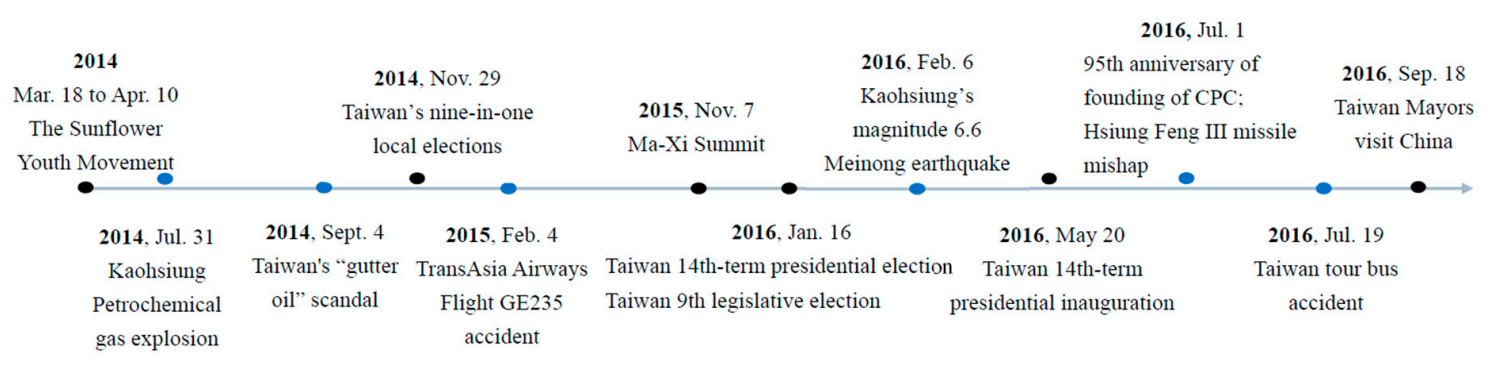

Figure 2. Major Cross-Strait events, 2014-2016.

\subsection{Literature Review of Event Studies}

The event study method dates back to 1933, when Dolley [2] studied the impact of stock segmentation on stock prices. The approach was subsequently widely used in the fields of economics, finance, and accounting (Ball and Brown [3]; Fama et al. [4]; Fama [5]; Boehmer et al. [6]; MacKinlay [7]; Binder [8]; Corrado [9]). The event study method has also been used in tourism research. A summary of the literature on the application of the event study approach to tourism-related issues is provided below.

Mazzocchi and Montini [10] examined the impact of the 26 September 1997 magnitude 5.9 earthquake on the flow of tourists in the Umbria region of central Italy using the event study approach. They used data covering the period January 1988-July 1998, with a particular focus on the months in which visits by tourists stopped, in order to analyze the impact of the earthquake on tourists' total number of visits. In estimation, OLS was used to estimate the average number of visits by tourists, and Patell's [11] standardized residual test was applied to estimate any abnormal changes in the number of these visits. The empirical results showed that the earthquake had a significant abnormal 
impact on the numbers of visits by both local tourists and foreign tourists. The number of visits by local tourists decreased by more than that for foreign tourists. In a comparison of local tourists with foreign tourists in terms of the economic losses brought about by the earthquake, for domestic tourists, the economic losses were also greater than for foreign tourists, amounting to as much as US\$ 5.19 million.

Tao [12] used the event study method to study the economic impact on China's stock market of the magnitude-7.0 earthquake that occurred on 20 April 2013 in Lushan, Sichuan Province, China. The daily trading data for the China stock market included the Shanghai Composite Index, the Shenzhen Component Index, and the CSI 300 Index. Using data covering the period 20 April 2012-19 April 2013, Tao analyzed the impact of the Lushan earthquake on stock market returns. He used OLS to estimate the expected average abnormal returns, and the t-statistic to inspect the abnormal returns. The empirical results showed that the Lushan earthquake did not significantly impact the stock returns of the Shanghai Composite Index, the Shenzhen Component Index, or the CSI 300 Index. Tao attributed the reason for this to the fact that the region where the earthquake struck was not developed, and hence the impact on the economic benefits was not significant.

Nicolau [13] used the event study method to examine the impact of a hotel's announcement that it was opening for business on the stock price returns in the hotel industry. The stock prices and IBEX-35 index daily trading data for 42 newly-opened hotels listed on the Spanish Stock Exchange located in Madrid from 1997-1999 were analyzed. The GARCH $(1,1)$ model was used to estimate the average abnormal stock returns, and Boehmer et al.'s [6] standardized cross-sectional method and Corrado's [14] non-parametric test were used to test the abnormal returns resulting from the changes in stocks. The empirical results showed that the hotel's announcement that it was opening for business had a significantly positive impact on the hotel's stock price on the day, in $61.9 \%$ of the cases.

Chen et al. [15] used the event study approach to examine the impact of the outbreak of SARS (Severe Acute Respiratory Syndrome) on the stock prices of publicly-traded hotel stock. Using the period 2 May 2002-7 April 2003 for estimation, attention was particularly focused on the 10 days and 20 days prior to and after the event date of 22 April 2003. The study used OLS, GARCH(1,1), GJR $(1,1)$ and EGARCH $(1,1)$ to estimate the accumulated average abnormal returns. The empirical results showed that the outbreak of the SARS epidemic after the Taiwan hotel stock price compensation had a significantly negative impact on hotel stock price returns in Taiwan.

Dick and Wang [16] used the event study method to examine the impact of announcements made by the International Olympic Committee (IOC), on which cities would host the games, on the major stock index returns of the winning and losing countries. Data covering the period 1988-2014 in relation to 15 announcements as to which countries would host future Olympic Games were used in the event study. OLS was applied to estimate the cumulative average abnormal returns, and the t-statistic was used to inspect the abnormal returns. The empirical results showed that the announcements regarding the cities that had been selected to host the Olympic Games indicated that the cumulative average abnormal returns of the stock indexes in those countries in which the cities that had placed first in the selection process had increased by about $2 \%$, while the stock index returns of those countries that were ranked last were not significantly affected. Announcements regarding the selection as to which cities would host the Winter Olympics also did not have a significant impact on the respective countries' stock returns.

Ogawa [17] used the event study approach to analyze the impact of large-scale sporting activities on the yields of Japanese Real Estate Investment Trusts (J-REITs). Data were used for a total of 41 J-REITs quoted on the Tokyo Stock Exchange with 18 July 2013-8 September 2013 as the estimation period (there being 37 trading days after holidays were excluded), and 9 September 2013 was regarded as the event date. OLS was used to estimate the average abnormal returns, and the t-statistic was used to examine the abnormal returns. The empirical results showed that Japan's winning the bid to be selected to host the 2020 Olympic Games had both a positive and significant impact on the overall returns to real estate stocks, and the effect on J-REITs, with a particular emphasis on hotels in terms of average abnormal returns, was relatively large. 
Szutowski and Bednarska [18] applied the event study method to examine the impact of tourism business announcements on stock market value. Stock price data obtained from the Warsaw Stock Exchange (WSE) and 34 innovative news reports and seven innovative types in the last six years were used in conducting the analysis. The estimation period was set to cover 250 days before the event, and the event period was established as covering 10 days before and 10 days after the announcement. OLS was used to estimate the cumulative average abnormal returns, and the Szyszka [19] J-statistic was used to check the abnormal returns. The empirical results showed that the impact of the innovative announcements by the tourism businesses on the stock market abnormal returns was $0.63 \%$, and the cumulative average abnormal returns reached $2 \%$ during the five days before and 5 days after the announcement was made.

Johnson et al. [20] used the event study method to examine the impact of the Travel Promotion Act (TPA) of 2000 on stock price returns. They used data obtained from the Center for Research in Security Prices (CRSP), and for Real Estate Investment Trusts (REITs) in performing their analysis. With the estimation period covering 255 trading days in which the event date fell (4 March 2010), and an event period (which covered the day of the event, the day before the event and the day after the event), they used OLS to estimate the cumulative average abnormal returns and the z-statistic to test the cumulative average abnormal returns. The empirical results showed that the US Travel Promotion Act had a significant positive impact on the hotel industry's stock price returns. In addition, the large hotel chains were found to benefit more as a result of the TPA than smaller hotel chains.

In summary, when used in research related to tourism issues, the event study method has mainly been used to examine the impact of changes in the tourism environment on financial markets. The scope of the events considered includes the tourism natural environment (disaster and accident events), tourism cultural environment (political events, economic events, and international competitions), and tourism resources. These studies are classified according to different events, as shown in Table 1 . Furthermore, the results of the studies has indicated that the changes in the tourism environment have a significant impact on both the number of tourist arrivals to a country, as well as its stock market returns. We have not found such connections in other studies.

\section{Models}

\subsection{Defining the Event Study's Period}

An event refers to new relevant information, which through its impact on stock prices determines whether it is a major event or not. Moreover, an event study as a form of empirical research is commonly used to investigate the impact of specific events in terms of abnormal returns in financial markets (MacKinlay [7], Binder [8], Corrado [9]). This method is derived from Fama's [5] efficient markets hypothesis (EMH), which posits that any financially-related information will immediately be reflected in stock prices.

The event study method is used to establish the difference between the counterfactual price that is not affected by the information, and the actual price, in order to estimate the price effect arising from the event (McWilliams and Siegel [21], Binder [8]). This paper uses the event study method to estimate the impact of Cross-Straits political and disaster-related incidents on Chinese tourists travelling to Taiwan.

When using the event study method, it is necessary to determine the event and the date on which the event first occurred $\left(t_{0}\right)$, as well as the part of the estimation period that was not affected by the event $\left(T=t_{2}-t_{1}+1\right)$, and the event period $\left(\mathrm{W}=t_{4}-t_{3}+1\right)$. The event study method does not have a set standard in terms of the period between the estimation period and the event period. From a review of the literature, it can be found that where the daily data are used, the estimation period tends to be in the range of 100 days to 300 days, while the event period is between 2 days and 121 days.

The events considered in this study include both political events and disaster-related incidents. The estimation period for political events ranges from 110 days prior to the date of the event, to 11 days 
before it $\left(t_{1}=-110\right.$ to $\left.t_{2}=-11\right)$, and the event period ranges from 10 days before the political event to 20 days after it $\left(t_{3}=-10\right.$ to $\left.t_{4}=20\right)$. The estimation period for disaster-related incidents ranges from 100 days prior to the event to one day before it $\left(t_{1}=-100\right.$ to $\left.t_{2}=-1\right)$, and the event period ranges from the date of the event to 30 days after it $\left(t_{3}=0\right.$ to $\left.t_{4}=30\right)$. Regardless of whether the events are political or disaster-related, the estimation period is always 100 days, and the event period is 31 days, so that the period under observation covers a total of 131 days.

\subsection{Fundamental Tourism Finance Equation and Tourism Financial Returns}

McAleer [1] developed the fundamental tourism finance equation to connect the growth in the number of tourists and the returns on the associated tourism financial asset. The fundamental equation is used to derive the relationship between the change rate of tourist arrivals and the financial (tourism) returns, which is explained below.

Consider Equation (1), where total daily tourist expenditure, $y_{t}$, is equal to the daily total number of tourist arrivals, $x_{t}$, times the daily average expenditure by tourists, $z_{t}$, which is given by:

$$
y_{t}=x_{t} \times z_{t}
$$

It is argued in McAleer [1] that there is little evidence to suggest that the average daily expenditure by tourists, $z_{t}$, changes on a daily basis, so that $z_{t}$ can be replaced by a constant, $c$, and Equation (1) can be replaced by:

$$
y_{t}=c \times x_{t}
$$

from which it follows that:

$$
\Delta y_{t}=c \times \Delta x_{t} .
$$

where $\Delta$ is the first difference operator. In Equation (2), $\Delta y_{t}$ is the change in total daily tourism expenditure, and $\Delta x_{t}$ is the change in the net daily tourist arrivals, where the net daily tourist arrivals is the total number of daily tourist arrivals minus the daily tourist departures.

Using the lagged version of Equation (1) to divide the left-hand side of Equation (2) by $y_{t-1}$ and the right-hand side of Equation (3) by $x_{t-1}$, gives:

$$
\frac{\Delta Y_{t}}{Y_{t-1}}=\frac{\Delta X_{t}}{X_{t-1}}
$$

in which Equation (3) leads to the fundamental equation in tourism finance. This equation relates the growth in total daily tourism expenditure, or alternatively, the daily returns on total tourism, $\Delta y_{t} / y_{t-1}$, to the net daily tourist arrivals divided by the previous day's total number of tourists, $\Delta x_{t} / x_{t-1}$.

Equation (3) is the fundamental tourism finance equation, which shows that the changes in daily returns on total tourism are approximately equal to the net change rate in daily tourist arrivals. Therefore, we use the change rate of tourist arrivals to be the change rate of the total daily Chinese tourism expenditure for purpose of analysis.

The change rate of tourist arrivals, $R_{t}$, is given as the first difference in log arrivals, and multiplied by 100 , as follows:

$$
R_{t}=\ln \left(A_{t} / A_{t-1}\right) \times 100
$$

where $A_{t}$ and $A_{t-1}$ are the daily tourist arrivals for the time periods $t$ and $t-1$, respectively.

\subsection{Estimating the Expected Rate of Change in Tourist Arrivals}

The market model of Sharpe [22], one of several risk-adjusted returns models, is used to estimate the expected rate of change in the number of Chinese tourists to Taiwan (MacKinlay [7]).

In order to estimate the expected rate of change in the number of Chinese tourists, this paper uses OLS and three frequently applied conditional volatility models, namely, GARCH $(1,1)$, GJR $(1,1)$, and 
EGARCH (1,1), to evaluate the abnormal returns from significant events. The methods of estimation cover the standard OLS approach, whereby the conditional volatilities are constant, and the three most widely used methods, when the conditional volatilities vary dynamically over time.

\subsubsection{OLS}

$$
\begin{gathered}
R_{t}=\phi_{1}+\phi_{2} R_{m t}+\varepsilon_{t}, t \in T=\left[t_{1}, t_{2}\right] \\
E\left(\varepsilon_{t}\right)=0 \\
\operatorname{var}\left(\varepsilon_{t}\right)=\sigma_{\varepsilon}^{2}
\end{gathered}
$$

where $R_{t}$ is the rate of change in the number of tourists; $t=\left[t_{1}, t_{2}\right]$ refers to different time points within the estimation period; $R_{m t}$ is the rate of change in the number of tourists in the market; $\varepsilon_{i t}$ is the error term, where $\varepsilon_{t} \sim N\left(0, \sigma_{\varepsilon}^{2}\right) ; \phi_{1}$ and $\phi_{2}$ are regression coefficients, where $\phi_{1}$ is the intercept, and $\phi_{2}$ is systematic risk, referring to the sensitivity of the rate of change in the number of visits by Chinese tourists as compared to the rate of change in the number of visits by foreign tourists as a whole; $T$ is the length (or number of periods) in the estimation period, where $T=t_{2}-t_{1}+1$.

However, the classical regression model assumes that the variance of the regression error term is a fixed constant, but time series data are mostly characterized by time-varying heteroscedasticity. If OLS is used to estimate the expected rate of change in the number of Chinese tourists visiting Taiwan, the estimation is likely to be biased. To resolve this problem, Engle [23] proposed the Auto-Regressive Conditional Heteroskedasticity (ARCH) model to compensate for the changes in the time series data due to the changes in the time points, as well as for the volatility clustering and heavy tails. Given below are the regression equations for three univariate conditional volatility models that are used to estimate the expected rate of change in the number of Chinese tourists. For a more detailed derivation, the interested reader may refer to McAleer [24] and Chang et al. [25].

\subsubsection{GARCH}

Bollerslev [26] generalized the Auto-Regressive Conditional Heteroskedasticity (ARCH) model, and proposed the Generalized Auto-Regressive Conditional Heteroskedasticity (GARCH) model. At the same time, the concepts of the Auto-Regressive (AR) model and the Moving-Average (MA) model were used in the estimation of the conditional variance. The model uses $\operatorname{GARCH}(1,1)$ to construct the regression equation and conditional mean equation, as follows:

$$
\begin{gathered}
R_{t}=\phi_{1}+\phi_{2} R_{m t}+\varepsilon_{t}, t \in T=\left[t_{1}, t_{2}\right] \\
\varepsilon_{t}=\theta_{t} \varepsilon_{t-1}+\eta_{t} \\
\theta_{t} \sim \operatorname{iid}(0, \alpha) ; \eta_{t} \sim \operatorname{iid}(0, \omega) \\
\eta_{t}=\varepsilon_{t} / \sqrt{h_{t}} \\
h_{t}=E\left(\varepsilon_{t-1}^{2} \mid I_{t-1}\right)=\omega+\alpha \varepsilon_{t-1}^{2}+\beta h_{t-1}
\end{gathered}
$$

where $\varepsilon_{t} \mid I_{t-1} \sim N\left(0, h_{t}\right)$, and $I_{t-1}$ is the information set in period $t-1$. The mean of the conditional distribution of the error terms is zero, the variance is $h_{t}$, and $\eta_{t}$ is the standardized residual. In accordance with Engle's [23] ARCH(1) model, Tsay [27] obtained the $\mathrm{ARCH}(1,1)$ conditional variance equation as shown in Equation (8), with $\beta=0$.

As Equation (8) shows, $h_{t}$ is the conditional volatility, $\alpha$ is the impact of short-term persistence in the ARCH effect, and $(\alpha+\beta)$ is the impact of long-term persistence in the GARCH effect. According to McAleer [24], $\omega>0, \alpha>0$ and $\beta \in[-1,1]$ in Equation (8), in order to satisfy the sufficient condition that $h_{t}>0$. Moreover, from Equation (7), it can be seen that $\omega>0$ and $\alpha>0$. When the condition that $\alpha+\beta<1$ is satisfied, this means that the quasi-maximum likelihood estimates (QMLE) of the parameters in Equation (8) satisfy the sufficient conditions for consistency and asymptotic normality (see Ling and McAleer [28]). 


\subsubsection{GJR}

GARCH is unable to capture the asymmetric effect in financial time series data. In order to capture such asymmetry, Glosten et al. [29] proposed the Threshold or asymmetric GARCH (or GJR) model, using an indexed random variable $\left(I\left(\varepsilon_{t-1}\right)\right)$ to represent different conditions inside and outside the threshold variance values, so that the conditional variation value can exhibit two different phenomena. The regression equation for $\mathrm{GJR}(1,1)$ is as follows:

$$
\begin{gathered}
R_{t}=\phi_{1}+\phi_{2} R_{m t}+\varepsilon_{t}, t \in T=\left[t_{1}, t_{2}\right] \\
\varepsilon_{t}=\theta_{t} \varepsilon_{t-1}+\psi_{t} I\left(\varepsilon_{t-1}\right)+\eta_{t} \\
\theta_{t} \sim \operatorname{iid}(0, \alpha) ; \psi_{t} \sim \operatorname{iid}(0, \gamma) ; \eta_{t} \sim \operatorname{iid}(0, \omega) \\
I\left(\varepsilon_{t-1}\right)=1 \text { when } \varepsilon_{t-1}<0 \\
I\left(\varepsilon_{t-1}\right)=0 \text { when } \varepsilon_{t-1} \geq 0 \\
\eta_{t}=\varepsilon_{t} / \sqrt{h_{t}} \\
h_{t}=E\left(\varepsilon_{t-1}^{2} \mid I_{t-1}\right)=\omega+\alpha \varepsilon_{t-1}^{2}+\gamma I\left(\varepsilon_{t-1}\right)+\beta h_{t-1}
\end{gathered}
$$

where $\gamma$ is the asymmetry parameter; when $\gamma>0$, there is an asymmetric effect inherent within the time series data. $\alpha+\gamma / 2$ is the short-term impact persistence, and $\alpha+\beta+\gamma / 2$ is the long-term impact persistence. As the GARCH model is nested inside the GJR model, with the exception of the asymmetry parameter $(\gamma)$, the coefficients of the two models are explained in the same way. A sufficient condition for the QMLE of the parameters in GJR $(1,1)$ to be consistent and asymptotically normal is $\alpha+\beta+\gamma / 2<0$ (see Ling and McAleer [28]).

\subsubsection{EGARCH}

Nelson [30] proposed the Exponential GARCH (EGARCH) model, in which the conditional variance equation is set as a logarithmic function. The EGARCH model can capture the asymmetric effect in the time series data. The EGARCH $(1,1)$ regression equation may be expressed as follows (for a detailed derivation, see McAleer and Hafner [31]):

$$
\begin{gathered}
R_{t}=\phi_{1}+\phi_{2} R_{m t}+\varepsilon_{t}, t \in T=\left[t_{1}, t_{2}\right] \\
\varepsilon_{t}=\theta_{t} \sqrt{\left|\eta_{t-1}\right|}+\psi_{t} \sqrt{\eta_{t-1}}+\eta_{t} \\
\theta_{t} \sim \operatorname{iid}(0, \alpha) ; \psi_{t} \sim \operatorname{iid}(0, \gamma) ; \eta_{t} \sim \operatorname{iid}(0, \omega)
\end{gathered}
$$

$\sqrt{\eta_{t-1}}$ is a complex-valued function of $\eta_{t-1}$.

$$
\begin{gathered}
\eta_{t}=\varepsilon_{t} / \sqrt{h_{t}} \\
h_{t}=E\left(\varepsilon_{t-1}^{2} \mid I_{t-1}\right)=\omega+\alpha\left|\eta_{t-1}\right|+\gamma \eta_{t-1}+\beta h_{t-1} \\
\log h_{t}=E\left(\varepsilon_{t-1}^{2} \mid I_{t-1}\right)=\omega+\alpha\left|\eta_{t-1}\right|+\gamma \eta_{t-1}+\beta h_{t-1}
\end{gathered}
$$

$\log h_{t}=\log \left(1+\left(h_{t-1}-1\right)\right) \approx h_{t-1}-1$ is an approximation used to replace $h_{t}$ in Equation (14).

\subsection{Calculating the Cumulative Abnormal Change Rate}

By using the OLS, GARCH(1,1), GJR(1,1), and EGARCH(1,1) regression equations mentioned above, we can estimate the regression coefficients $\hat{\phi}_{1}$ and $\hat{\phi}_{2}$, respectively, and $\hat{\phi}_{1}$ and $\hat{\phi}_{2}$ can be brought into the events period data, in order to forecast the rate of change in the number of Chinese tourists visiting Taiwan, as shown in Equation (16) (see McAleer and Hafner [31]):

$$
E R_{E}=\hat{\phi}_{1}+\hat{\phi}_{2} \cdot R_{m E}, E \in W=\left[t_{3}, t_{4}\right]
$$


where $E R_{E}$ is the rate of change in the number of Chinese tourists visiting Taiwan in period $E$ within the event period, $R_{m E}$ is the rate of change in the total number of tourists visiting Taiwan in period $E$ within the event period, and $W$ is the length of the event period (the number of periods), where $W=t_{4}-t_{3}+1$.

The formula used to calculate the abnormal rate of change in the number of Chinese tourists visiting Taiwan is as follows:

$$
A R_{E}=R_{E}-E R_{E}, E \in W=\left[t_{3}, t_{4}\right]
$$

where $A R_{E}$ is the abnormal rate of change in the number of Chinese tourists visiting Taiwan in period $E$ within the event period, $R_{E}$ is the rate of change in the number of Chinese tourists actually visiting Taiwan in period $E$ within the event period, and $E R_{E}$ is the rate of change in the number of Chinese tourists that are expected to visit Taiwan in period $E$ within the event period.

The cumulative abnormal change rate (CAR) is the cumulative abnormal rate of change in the number of tourists between any two periods within the event period. The formula is as follows:

$$
\operatorname{CAR}\left(\tau_{1}, \tau_{2}\right)=\sum_{E=\tau_{1}}^{\tau_{2}} A R_{E},\left[\tau_{1}, \tau_{2}\right] \in W=\left[t_{3}, t_{4}\right]
$$

where $\operatorname{CAR}\left(\tau_{1}, \tau_{2}\right)$ is the abnormal rate of change in the cumulative number of Chinese tourists from period $\tau_{1}$ to $\tau_{2}$ during the event period, and $A R_{E}$ is the abnormal rate of change in the number of Chinese tourists in period $E$ in the event period. $\left[\tau_{1}, \tau_{2}\right]$ represents a total of $m$ periods, from periods $\tau_{1}$ to $\tau_{2}$ during the event period, where $m=\tau_{2}-\tau_{1}+1$, and $t_{4} \geq \tau_{2} \geq \tau_{1} \geq t_{3}$.

\subsection{Testing the Cumulative Abnormal Change Rate}

The traditional method (Brown and Warner [32]) and the standardized-residual method (Patell [11]) are used to test the cumulative abnormal change rate in terms of the number of tourists. The null $\left(H_{0}\right)$ and alternative hypotheses $\left(H_{1}\right)$ are as follows:

$$
\begin{aligned}
& H_{0}: \operatorname{CAR}\left(\tau_{1}, \tau_{2}\right)=0 \\
& H_{1}: \operatorname{CAR}\left(\tau_{1}, \tau_{2}\right) \neq 0
\end{aligned}
$$

The traditional method (hereafter TM) uses the residual variance in the estimation period to simulate the residual variance in the event period. This test assumes that the residual variance in the estimation period is equal to that in the event period. The event will not cause the event-induced variance in the abnormal returns to change in the event period. Moreover, the abnormal returns in the estimation period and the event period will not lead to structural change, indicating that the parameters estimated by the equation for the expected returns in the estimation period will not change in the event period. The test statistic for the cumulative abnormal change rate in terms of the number of tourists is as shown in the following equation:

$$
t^{\mathrm{TM}}=\frac{\operatorname{CAR}\left(\tau_{1}, \tau_{2}\right)}{\sqrt{\operatorname{Var}\left(\mathrm{C} A R\left(\tau_{1}, \tau_{2}\right)\right)}}=\frac{\sum_{E=\tau_{1}}^{\tau_{2}}\left(\frac{A R_{E}}{\sqrt{m}}\right)}{\hat{S}_{i}}
$$

where $\operatorname{CAR}\left(\tau_{1}, \tau_{2}\right)$ is the abnormal change rate in the cumulative number of tourists from period $\tau_{1}$ to $\tau_{2}$ in the event period; $\operatorname{Var}\left(\operatorname{CAR}\left(\tau_{1}, \tau_{2}\right)\right)$ is the variance of the abnormal change rate in the cumulative number of Chinese tourists from period $\tau_{1}$ to $\tau_{2}$ in the event period; $A R_{E}$ refers to the abnormal returns of the Chinese tourists in period $E$ in the event period; $\hat{S}$ is the standardized error of the residual for Chinese tourists in the estimation period, that is:

$$
\hat{S}=\sqrt{\frac{\sum_{t=t_{1}}^{t_{2}}\left(\hat{\varepsilon}_{t}-\sum_{t=t_{1}}^{T} \frac{\hat{\varepsilon}_{t}}{T}\right)^{2}}{T-1}}
$$


$\hat{\varepsilon}_{t}$ is the residual for Chinese tourists in period $t$ in the estimation period, that is, $\hat{\varepsilon}_{t}=R_{t}-E\left(\hat{R}_{t}\right)$, where $T$ is the length of the estimation period (the number of periods), and $T=t_{2}-t_{1}+1$; and $m$ is the length of the estimation period from period $\tau_{1}$ to $\tau_{2}$ in the event period (the number of periods), where $m=\tau_{2}-\tau_{1}+1$.

The standardized-residual method (hereafter SRM) standardizes the abnormal change rate in the number of Chinese tourists, resulting in the distribution of the abnormal change rate in the number of each type of tourist being a unit-normal distribution, thereby ensuring that the abnormal change rate for the cumulative number of tourists is normally distributed. The test statistic for the abnormal change rate in the cumulative number of tourists is as shown in the following equation:

$$
t^{\mathrm{SRM}}=\frac{\operatorname{SCAR}\left(\tau_{1}, \tau_{2}\right)}{\sqrt{\operatorname{Var}\left(\operatorname{SCAR}\left(\tau_{1}, \tau_{2}\right)\right)}}=\frac{\sum_{E=\tau_{1}}^{\tau_{2}}\left(\frac{S A R_{E}}{\sqrt{m}}\right)}{\left[\frac{T-2}{T-4}\right]^{\frac{1}{2}}}
$$

where $\operatorname{SCAR}\left(\tau_{1}, \tau_{2}\right)$ is the abnormal rate of change in the standardized cumulative number of Chinese tourists from period $\tau_{1}$ to $\tau_{2}$ in the event period; $\operatorname{Var}\left(\mathrm{SC} A R \tau_{1}, \tau_{2}\right)$ is the variance of the abnormal rate of change in the standardized cumulative number of Chinese tourists from period $\tau_{1}$ to $\tau_{2}$ in the event period; $S A R_{E}$ is the abnormal rate of change in the standardized cumulative number of Chinese tourists from period $\tau_{1}$ to $\tau_{2}$ in the event period. The formula used to calculate $S A R_{E}$ is as follows:

$$
S A R_{E}=\frac{A R_{E}}{\hat{S} \sqrt{1+\frac{1}{T}+\frac{\left(R_{m E}-\bar{R}_{m T}\right)^{2}}{\sum_{t=t_{1}}^{t_{2}}\left(R_{m t}-\bar{R}_{m T}\right)^{2}}}}
$$

where $\hat{S}$ is the standard deviation of the residuals for the Chinese tourists in the estimation period, as give above, $\hat{\varepsilon}_{t}$ is the residual for the Chinese tourists in period $t$ in the estimation period, that is, $\hat{\varepsilon}_{t}=R_{t}-E\left(\hat{R}_{t}\right) ; R_{m E}$ is the rate of change in the total number of international travelers visiting Taiwan in period $E$ in the event period; $R_{m t}$ is the rate of change in the total number of international travelers visiting Taiwan in period $t$ in the estimation period; $\bar{R}_{m T}$ is the mean of the rate of change in the total number of international travelers visiting Taiwan in period $T$ in the estimation period, that is, $\bar{R}_{m T}=\frac{1}{T} \sum_{t=t_{1}}^{t_{2}} R_{m t} ; T$ is the length of the estimation period (number of periods), that is, $T=t_{2}-t_{1}+1$. In addition, because of the differences in the data, which lead to the observed values of $T$ in each sample period being likely to be different, the expected value of $S A R_{E}$ is equal to zero, and the variance is $(T-2) /(T-4)$. Therefore, the standardized cumulative abnormal rate of change is $\operatorname{SCAR}\left(\tau_{1}, \tau_{2}\right)=\sum_{E=\tau_{1}}^{\tau_{2}} S A R_{E}$. Moreover, the variance of the standardized cumulative abnormal change rate in the number of tourists is $\operatorname{Var}\left(\operatorname{SCAR}\left(\tau_{1}, \tau_{2}\right)\right)=m\left(\frac{T-2}{T-4}\right)$, where $m$ is the length of that part of the event period from period $\tau_{1}$ to $\tau_{2}$ (number of periods), that is, $m=\tau_{2}-\tau_{1}+1$.

In summary, the paper uses the traditional method and the standardized residual method to test the cumulative abnormal rate of change in the number of tourists in the event period. If the test statistic rejects the null hypothesis $\left(H_{0}\right)$, this indicates that abnormal change arising from the event is present.

\section{Data and Variables}

The data set comprises daily tourist arrivals from the world and China to Taiwan for the period 1 January 2014 to 31 October 2016, giving 1035 observations that are obtained from the National Immigration Agency of Taiwan (Taiwan Tourism Bureau, Statistic Data, Retrieved 17 June 2017 from http:/ / admin.taiwan.net.tw/ (in Chinese).

The data were collected by the National Immigration Agency of Taiwan. The original data source comprises daily tourist arrivals from the world and China to Taiwan for the period from 1 January 2014 to 31 October 2016, giving 1035 observations. Based on the original data source from the National 
Immigration Agency of Taiwan, we can disaggregate three types of Chinese tourists to Taiwan, namely Group-type, Individual-type, and Medical-type.

We have selected several of the most important political events, and disaster and accident events, based on public news that highlighted the important events at the time. Given the limitations in obtaining data from the National Immigration Agency in Taiwan, we focus on three different types of Chinese visitors: (1) Group type, (2) Individual type, and (3) Medical type. Figure 3 presents the trend for international tourists and for the three types of Chinese tourists to Taiwan.

The paper examines the effect of six political events and six disaster and accident events on the change rate of Chinese tourist arrivals to Taiwan, using an event study approach. The explanations of each major Cross-Strait event and sample period are given below. Table 2 presents the time period corresponding to each event.

Table 2. Major cross-strait events and sample periods.

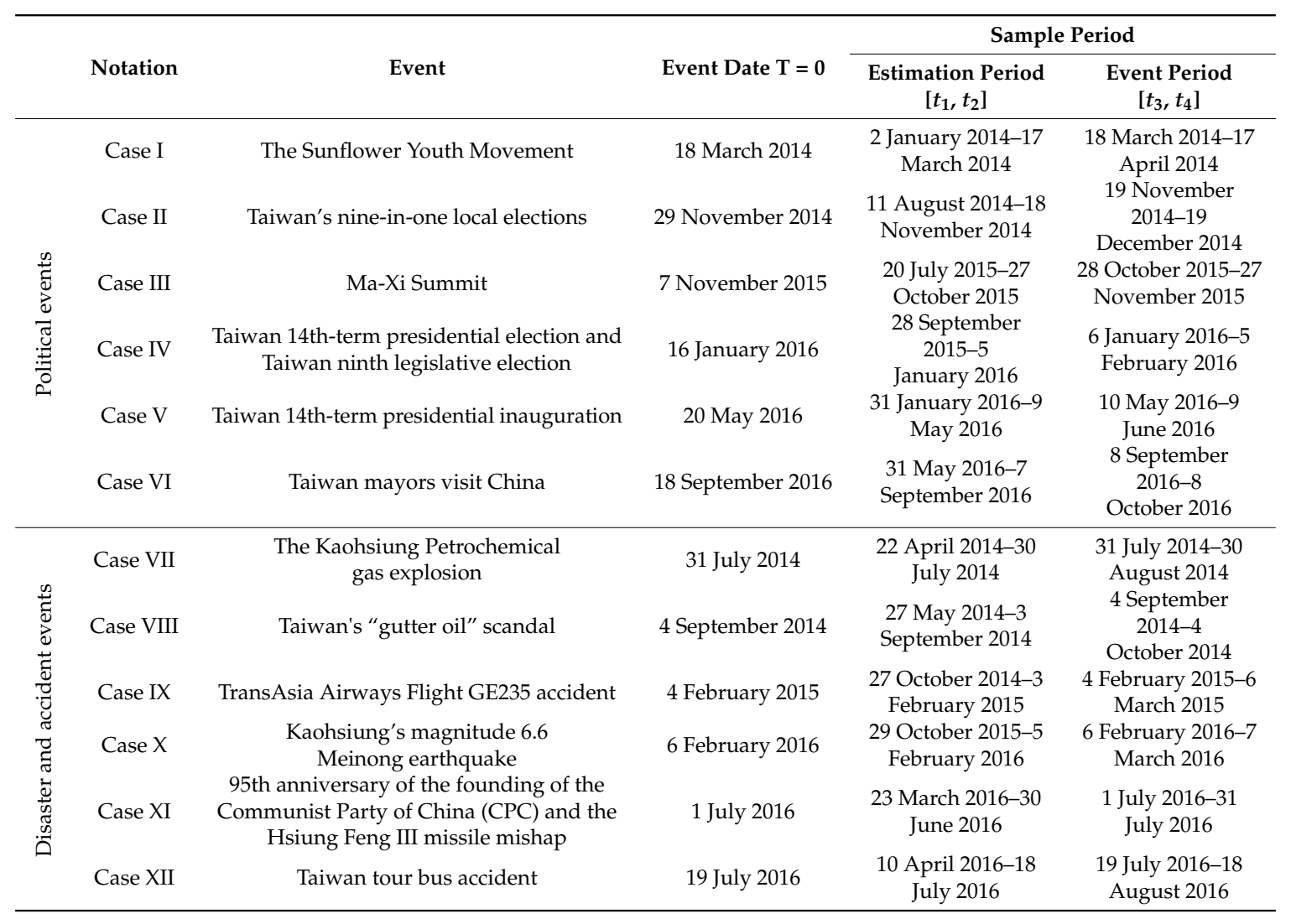

\section{(1) Political Events}

\section{Case I: The Sunflower Youth Movement}

Event date $(\mathrm{t}=0)$ : 18 March 2014

Estimation period: 2 January 2014-17 March 2014 (75 days)

Event period $\left(\tau_{1}=0, \tau_{2}=30\right)$ : 18 March 2014-17 April 2014 (31 days)

\section{Case II: Taiwan's nine-in-one local elections}

Event date $(\mathrm{t}=0)$ : 29 November 2014

Estimation period: 8 November 2014-18 November 2014 (100 days)

Event period $\left(\tau_{1}=-10, \tau_{2}=20\right)$ : 19 November 2014-19 December 2014 (31 days)

\section{Case III: Ma-Xi Summit}

Event date $(t=0): 7$ November 2015 
Estimation period: 20 July 2015-27 October 2015 (100 days)

Event period ( $\left.\tau_{1}=-10, \tau_{2}=20\right)$ : 28 October 2015-27 November 2015 (31 days)

Case IV: Taiwan 14th presidential election and Taiwan ninth legislative election

Event date $(\mathrm{t}=0)$ : 16 January 2016

Estimation period: 28 September 2015-5 January 2016 (100 days)

Event period $\left(\tau_{1}=-10, \tau_{2}=20\right)$ : 6 January 2016-5 February 2016 (31 days)

Case V: Taiwan 14th Presidential inauguration

Event date $(t=0): 20$ May 2016

Estimation period: 31 January 2016-9 May 2016 (100 days)

Event period $\left(\tau_{1}=-10, \tau_{2}=20\right)$ : 10 May 2016-9 June 2016 (31 days)

Case VI: Taiwan mayors visit China

Event date $(t=0)$ : 18 September 2016

Estimation period: 31 May 2016-7 September 2016 (100 days)

Event period $\left(\tau_{1}=-10, \tau_{2}=20\right): 8$ September 2016-8 October 2016 (31 days)

(2) Disaster and Accident Events

Case VII: The Kaohsiung Petrochemical gas explosion

Event date $(t=0)$ : 31 July 2014

Estimation period: 22 April 2014-30 July 2014 (100 days)

Event period $\left(\tau_{1}=0, \tau_{2}=30\right)$ : 31 July 2014-30 August 2014 (31 days)

Case VIII: Taiwan's "gutter oil" scandal

Event date $(t=0)$ : 4 September 2014

Estimation period: 27 May 2014-3 September 2014 (100 days)

Event period $\left(\tau_{1}=0, \tau_{2}=30\right)$ : 4 September 2014-4 October 2014 (31 days)

Case IX: TransAsia Airways Flight GE235 accident

Event date $(\mathrm{t}=0)$ : 4 February 2015

Estimation period: 27 October 2014-3 February 2015 (100 days)

Event period $\left(\tau_{1}=0, \tau_{2}=30\right): 4$ February 2015-6 March 2015 (31 days)

Case X: Kaohsiung's magnitude 6.6 Meinong earthquake

Event date $(t=0): 6$ February 2016

Estimation period: 29 October 2015-5 February 2016 (100 days)

Event period $\left(\tau_{1}=0, \tau_{2}=30\right): 6$ February 2016-7 March 2016 (31 days)

Case XI: 95th anniversary of the founding of the Communist Party of China and the Hsiung Feng III missile mishap

Event date $(t=0): 1$ July 2016

Estimation period: 23 March 2016-30 June 2016 (100 days)

Event period $\left(\tau_{1}=0, \tau_{2}=30\right)$ : 1 July 2016-31 July 2016 (31 days)

Case XII: Taiwan tour bus accident

Event date $(\mathrm{t}=0)$ : 19 July 2016

Estimation period: 10 April 2016-18 July 2016 (100 days)

Event period $\left(\tau_{1}=0, \tau_{2}=30\right)$ : 19 July 2016-18 August 2016 (31 days) 

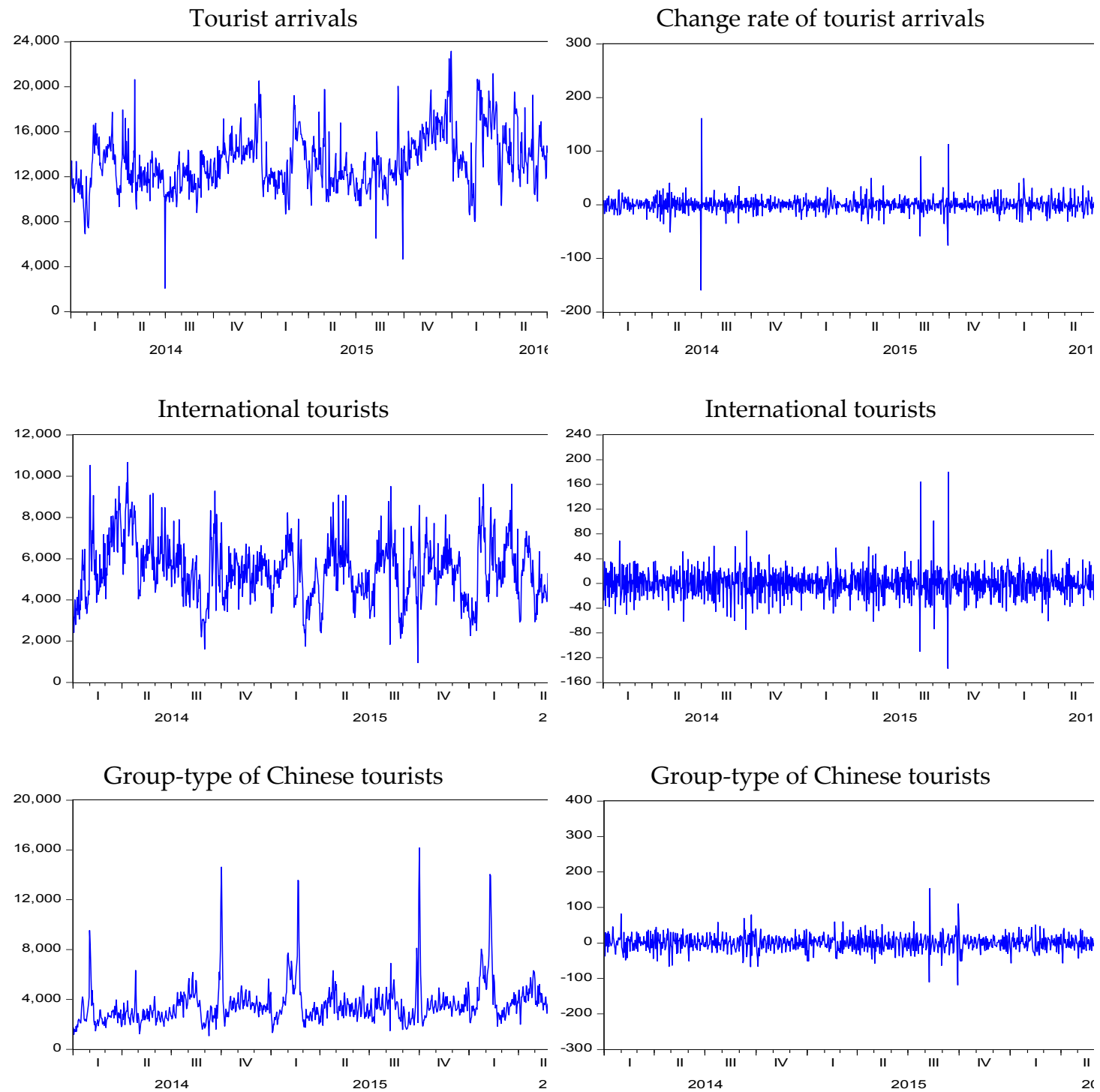

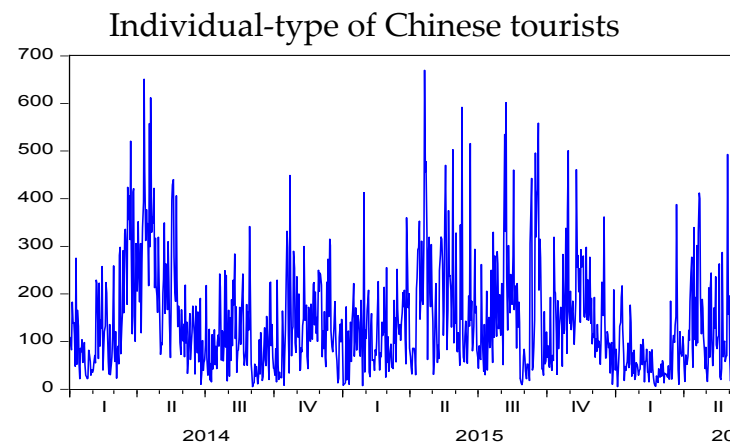

Medical-type of Chinese tourists

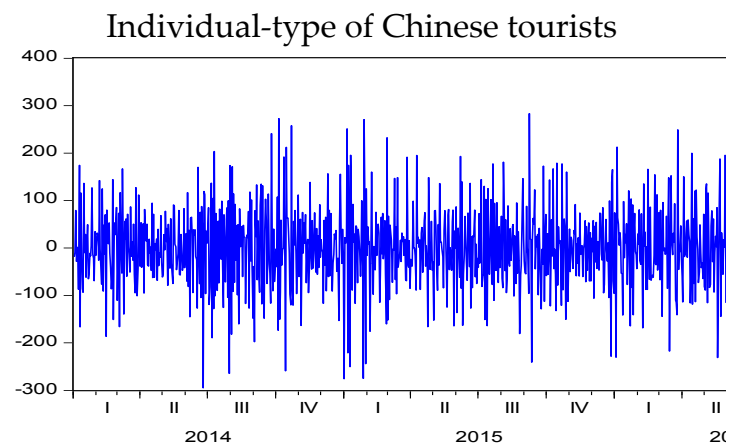

Medical-type of Chinese tourists

Figure 3. Daily tourist arrivals to Taiwan, 1/1/2014-31/10/2016

\section{Empirical Results}

As discussed previously, in this section we use the OLS, GARCH $(1,1)$, GJR $(1,1)$, and EGARCH $(1,1)$ models to estimate the expected number of tourists during the event periods, and we use the difference between the expected number of tourists and the actual number of tourists to calculate the 
average abnormal rate of change and cumulative abnormal rate of change. We extend the analysis to use the traditional method (Brown and Warner [32]) and the standardized residual method (Patell [11]) to determine whether there are abnormal changes in the cumulative numbers of Chinese tourists visiting Taiwan, due to the occurrence of each event in Table 3. For the detailed results of the estimation by OLS, GARCH, GJR, and EGARCH, refer to Tables A1-A48 (in Appendix A). The trend for the cumulative rate of change in the number of tourists is given in Figure 4.

The empirical results can and do differ according to the different political events, and different disasters and accident events, as well as with the different methods of estimation. In order to provide a comprehensive analysis of each type of event, as estimated by alternative methods, a detailed analysis of each combination is required.

The Augmented Dickey-Fuller (ADF) and Phillips-Perron (PP) tests are used to determine whether the data for the rate of change in the number of tourists are stationary. As shown in Table 4, the series for the rate of change in the number of Chinese tourists visiting Taiwan is stationary. The empirical results regarding the tests that were carried out to determine whether the returns to Chinese tourists visiting Taiwan are abnormally affected by the political and disaster-related events are listed sequentially.

Table 3. Results for cumulative abnormal change rate of Chinese tourist arrivals.

\begin{tabular}{|c|c|c|c|c|c|c|c|c|c|}
\hline \multicolumn{10}{|c|}{ Political Events } \\
\hline \multirow{2}{*}{ Event } & \multirow{2}{*}{ Types } & \multicolumn{2}{|c|}{ OLS } & \multicolumn{2}{|c|}{ GARCH(1,1) } & \multicolumn{2}{|c|}{$\operatorname{GJR}(1,1)$} & \multicolumn{2}{|c|}{$\operatorname{EGARCH}(\mathbf{1}, \mathbf{1})$} \\
\hline & & TM & SRM & TM & SRM & TM & SRM & TM & SRM \\
\hline Case I & $\begin{array}{c}\text { Group } \\
\text { Individual } \\
\text { Medical }\end{array}$ & & & & & & & & \\
\hline Case II & $\begin{array}{c}\text { Group } \\
\text { Individual } \\
\text { Medical }\end{array}$ & & & & & & & & \\
\hline Case III & $\begin{array}{c}\text { Group } \\
\text { Individual } \\
\text { Medical }\end{array}$ & & & & & & & & \\
\hline Case IV & $\begin{array}{c}\text { Group } \\
\text { Individual } \\
\text { Medical }\end{array}$ & $\begin{array}{l}+ \\
+\end{array}$ & $\begin{array}{l}+ \\
+\end{array}$ & $\begin{array}{l}+ \\
+\end{array}$ & $\begin{array}{l}+ \\
+\end{array}$ & + & + & + & + \\
\hline Case V & $\begin{array}{c}\text { Group } \\
\text { Individual } \\
\text { Medical }\end{array}$ & - & - & & & & & & \\
\hline Case VI & $\begin{array}{c}\text { Group } \\
\text { Individual } \\
\text { Medical }\end{array}$ & $\begin{array}{l}+ \\
+ \\
-\end{array}$ & $\begin{array}{l}+ \\
+ \\
-\end{array}$ & $\begin{array}{l}+ \\
+\end{array}$ & $\begin{array}{l}+ \\
+\end{array}$ & + & + & + & + \\
\hline \multicolumn{10}{|c|}{ Disaster and Accident Events } \\
\hline \multirow{2}{*}{ Event } & \multirow{2}{*}{ Types } & \multicolumn{2}{|c|}{ OLS } & \multicolumn{2}{|c|}{ GARCH(1,1) } & \multicolumn{2}{|c|}{$\operatorname{GJR}(1,1)$} & \multicolumn{2}{|c|}{ EGARCH(1,1) } \\
\hline & & TM & SRM & $\mathbf{T M}$ & SRM & TM & SRM & TM & SRM \\
\hline Case VII & $\begin{array}{c}\text { Group } \\
\text { Individual } \\
\text { Medical }\end{array}$ & $\begin{array}{l}- \\
- \\
+\end{array}$ & $\begin{array}{l}- \\
- \\
+\end{array}$ & $\begin{array}{l}- \\
- \\
+\end{array}$ & $\begin{array}{l}- \\
- \\
+\end{array}$ & $\begin{array}{l}- \\
- \\
+\end{array}$ & $\begin{array}{l}- \\
- \\
+\end{array}$ & - & - \\
\hline Case VIII & $\begin{array}{c}\text { Group } \\
\text { Individual } \\
\text { Medical }\end{array}$ & $\begin{array}{l}+ \\
+ \\
+\end{array}$ & $\begin{array}{l}+ \\
+ \\
+\end{array}$ & $\begin{array}{l}+ \\
+\end{array}$ & $\begin{array}{l}+ \\
+\end{array}$ & $\begin{array}{l}+ \\
+\end{array}$ & $\begin{array}{l}+ \\
+\end{array}$ & $\begin{array}{l}+ \\
+\end{array}$ & $\begin{array}{l}+ \\
+\end{array}$ \\
\hline
\end{tabular}


Table 3. Cont.

\begin{tabular}{|c|c|c|c|c|c|c|c|c|c|}
\hline \multicolumn{10}{|c|}{ Disaster and Accident Events } \\
\hline \multirow{2}{*}{ Event } & \multirow{2}{*}{ Types } & \multicolumn{2}{|c|}{ OLS } & \multicolumn{2}{|c|}{ GARCH(1,1) } & \multicolumn{2}{|c|}{ GJR(1,1) } & \multicolumn{2}{|c|}{ EGARCH(1,1) } \\
\hline & & TM & SRM & TM & SRM & TM & SRM & TM & SRM \\
\hline \multirow{3}{*}{ Case IX } & Group & - & - & - & - & - & - & - & - \\
\hline & Individual & - & - & - & - & - & - & - & - \\
\hline & Medical & - & - & - & - & & & & \\
\hline \multirow{3}{*}{ Case $X$} & Group & & & & & & & & \\
\hline & Individual & - & - & - & - & - & - & & \\
\hline & Medical & - & - & & & - & - & & \\
\hline \multirow{3}{*}{ Case XI } & Group & & & & & & & & \\
\hline & Individual & & & & & & & & \\
\hline & Medical & & & & & & & & \\
\hline \multirow{3}{*}{ Case XII } & Group & & & & & & & & \\
\hline & Individual & & & & & & & & \\
\hline & Medical & & & & & & & & \\
\hline
\end{tabular}

Notes: (1) Traditional method (TM) is the traditional method proposed by Brown and Warner [32]. (2) SRM is the standardized-residual method proposed by Pattel [11]. (3) - and + denote that the cumulative change rate of Chinese tourist arrivals are negative abnormal and positive abnormal, respectively.

Table 4. Unit root tests.

\begin{tabular}{|c|c|c|c|c|}
\hline \multirow{2}{*}{\multicolumn{2}{|c|}{ Variables }} & \multicolumn{3}{|c|}{ Augmented Dickey-Fuller (ADF) Test } \\
\hline & & $\begin{array}{c}\text { No Trend } \\
\text { and Intercept }\end{array}$ & With Intercept & $\begin{array}{l}\text { With Trend } \\
\text { and Intercept }\end{array}$ \\
\hline \multicolumn{2}{|c|}{ International tourists } & -20.34 * & $-20.34^{*}$ & $-20.33 *$ \\
\hline \multirow{3}{*}{ Chinese tourists } & Group-type & $-14.90 *$ & $-14.90 *$ & $-14.90 *$ \\
\hline & Individual-type & $-15.24 *$ & $-15.23 *$ & $-15.24 *$ \\
\hline & Medical-type & $-19.54 *$ & $-19.53 *$ & $-19.52 *$ \\
\hline \multirow{2}{*}{\multicolumn{2}{|c|}{ Variables }} & \multicolumn{3}{|c|}{ PP test } \\
\hline & & $\begin{array}{c}\text { No Trend } \\
\text { and Intercept }\end{array}$ & With Intercept & $\begin{array}{l}\text { With Trend } \\
\text { and Intercept }\end{array}$ \\
\hline \multicolumn{2}{|c|}{ International tourists } & $-151.73 *$ & $-151.95 *$ & $-151.94 *$ \\
\hline \multirow{3}{*}{ Chinese tourists } & Group-type & $-111.90 *$ & $-112.66 *$ & $-124.12 *$ \\
\hline & Individual-type & $-79.35 *$ & $-79.27 *$ & $-80.91 *$ \\
\hline & Medical-type & $-284.46^{*}$ & $-307.89 *$ & $-377.68 *$ \\
\hline
\end{tabular}

Note: ${ }^{*}$ denotes significant at the $1 \%$ level. 
Case I

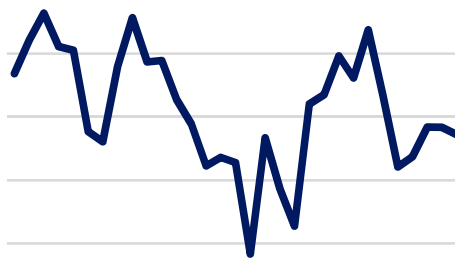

Group-type

Political events

Case II

Case III
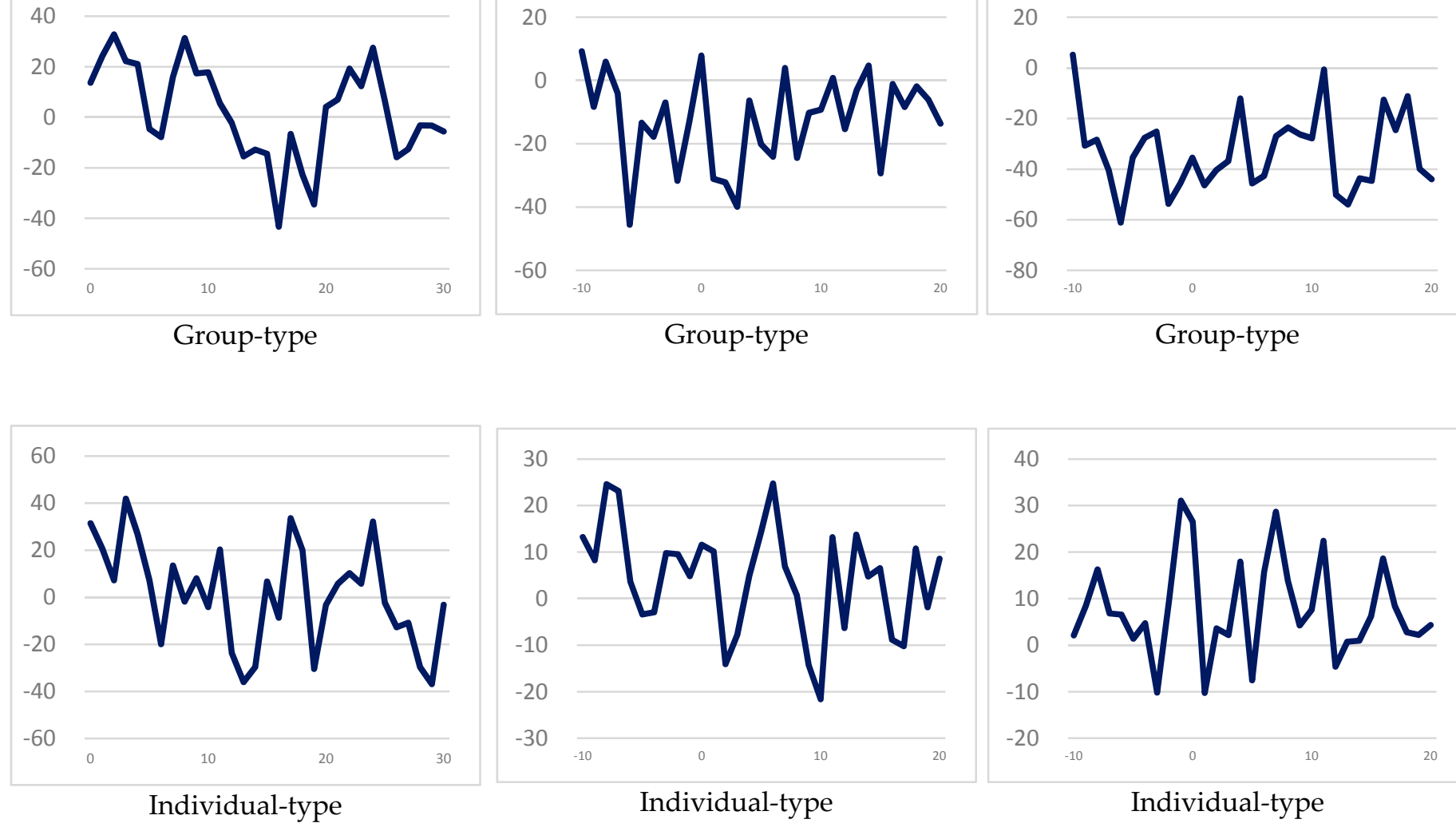

Figure 4. Cont 


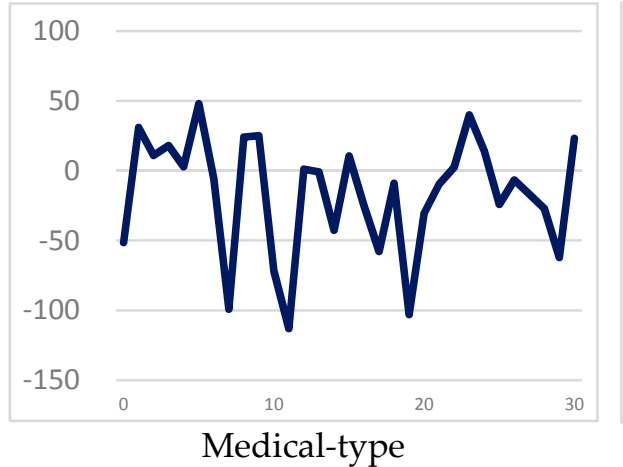

Case IV

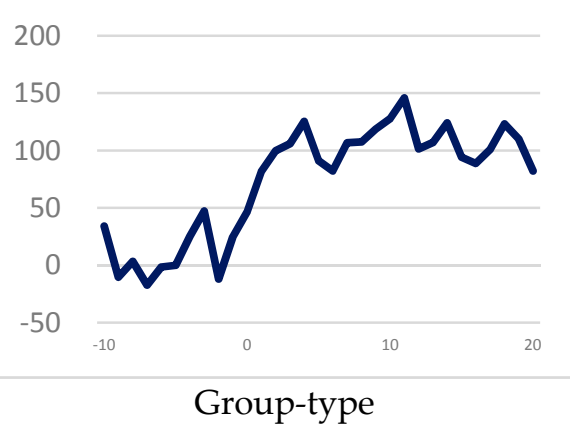

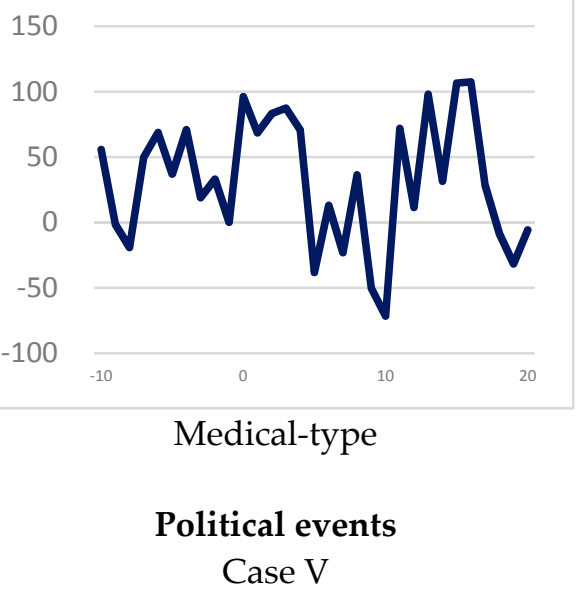

250

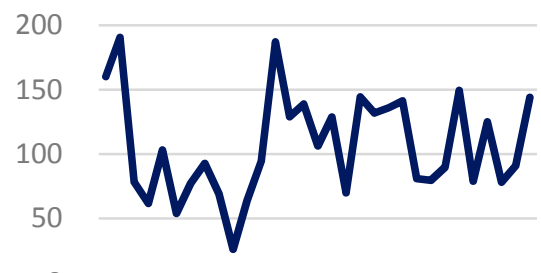

Medical-type

Case VI
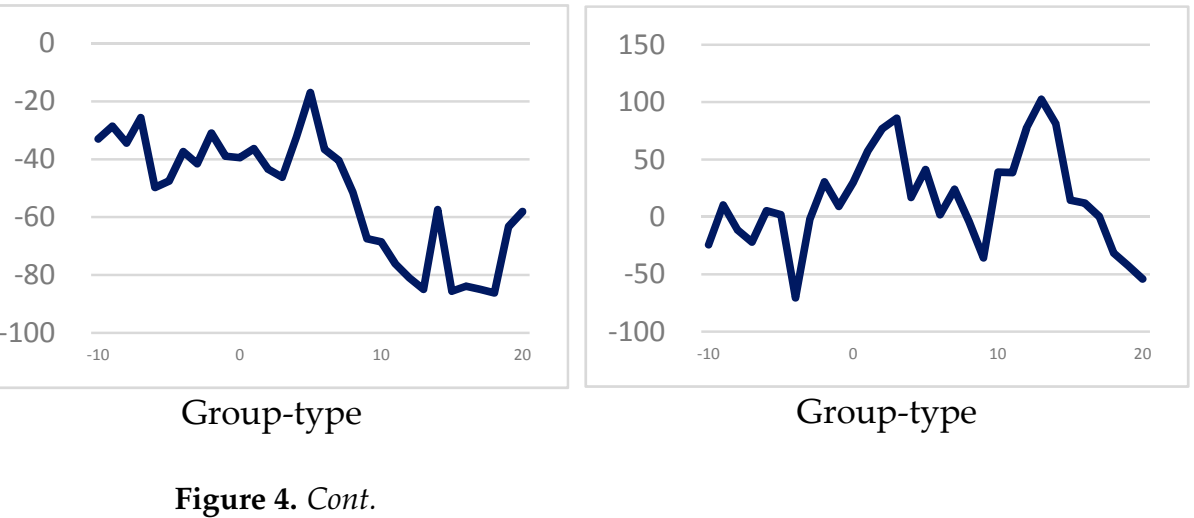

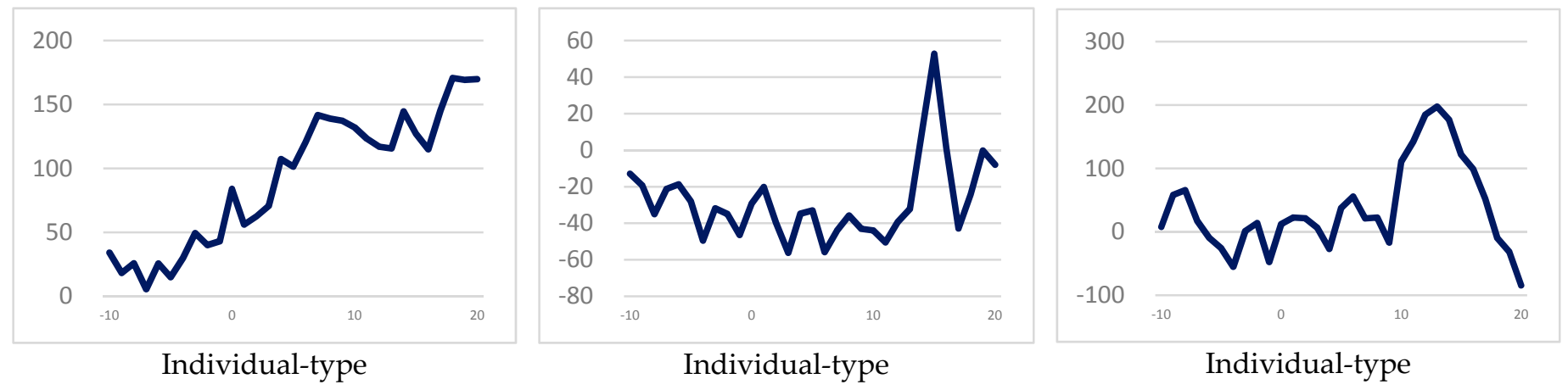

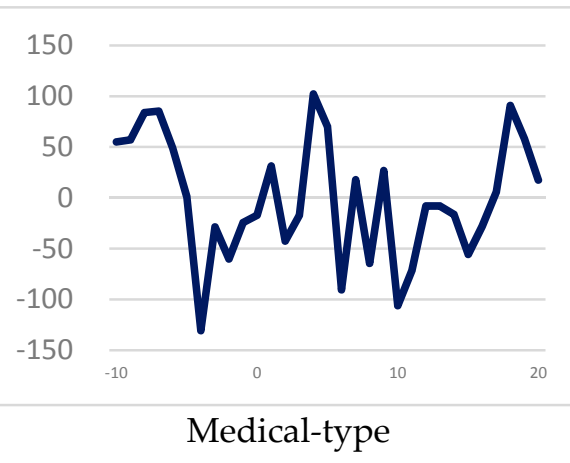

Case VII

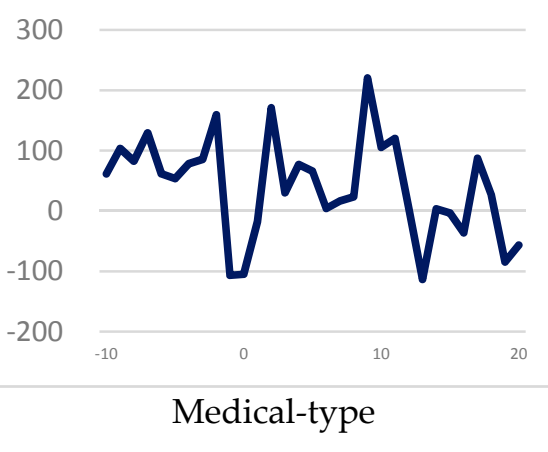

Disaster and Accident Events

$$
\text { Case VIII }
$$

Figure 4. Cont.

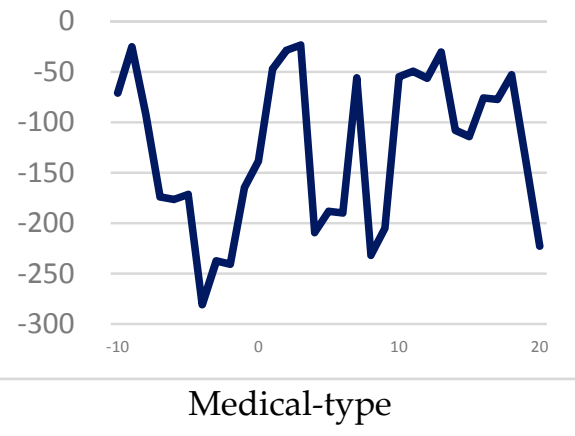

Case IX 

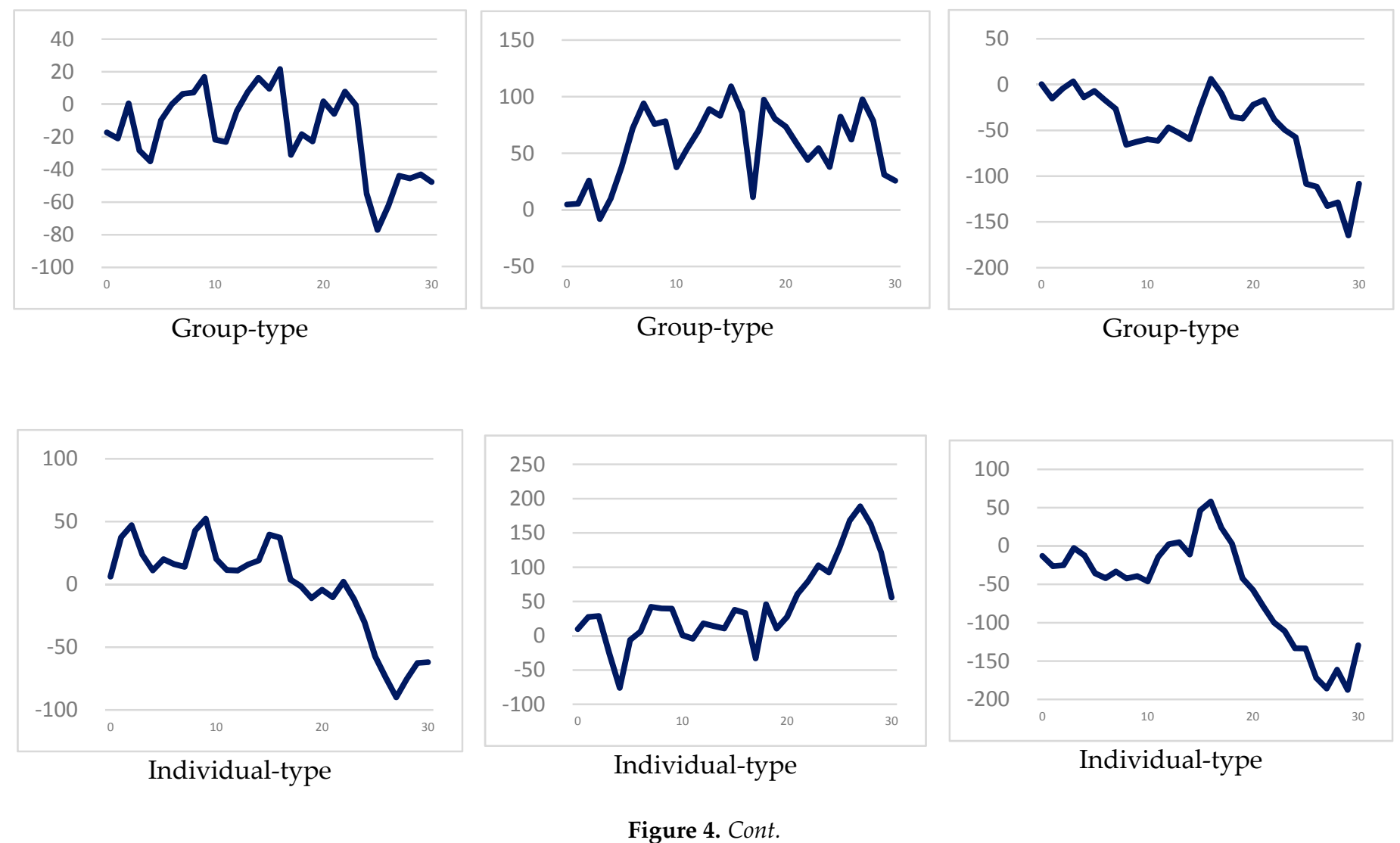


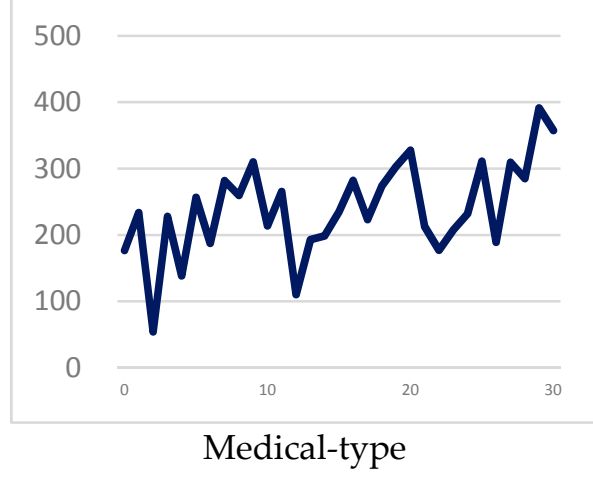

Case X

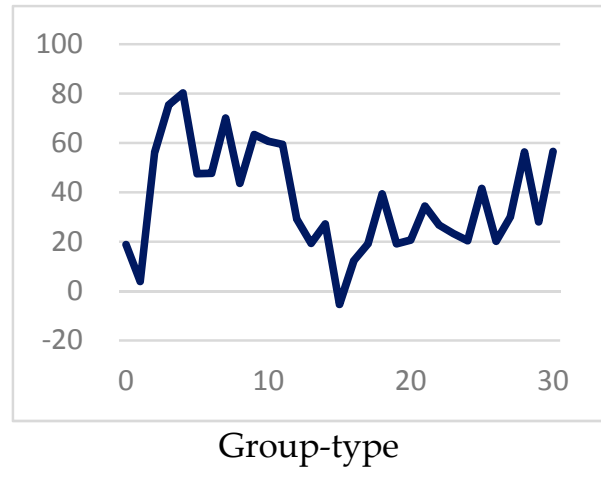

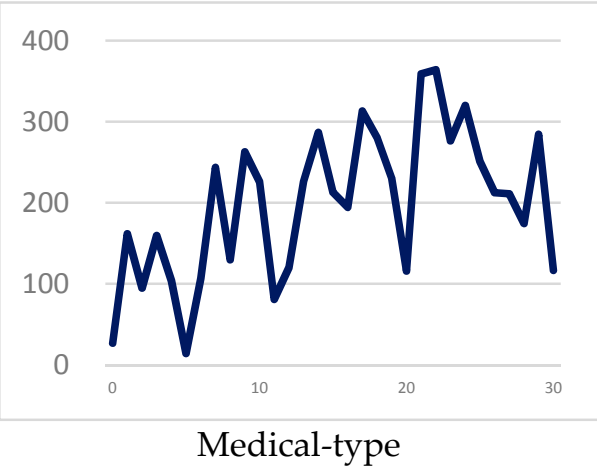

Disaster and Accident Events

$$
\text { Case XI }
$$

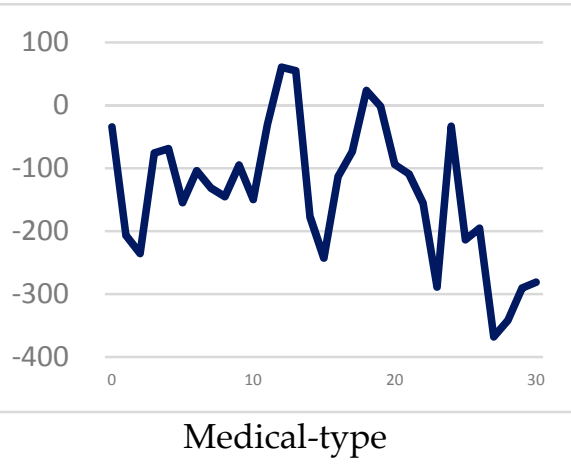

Case XII

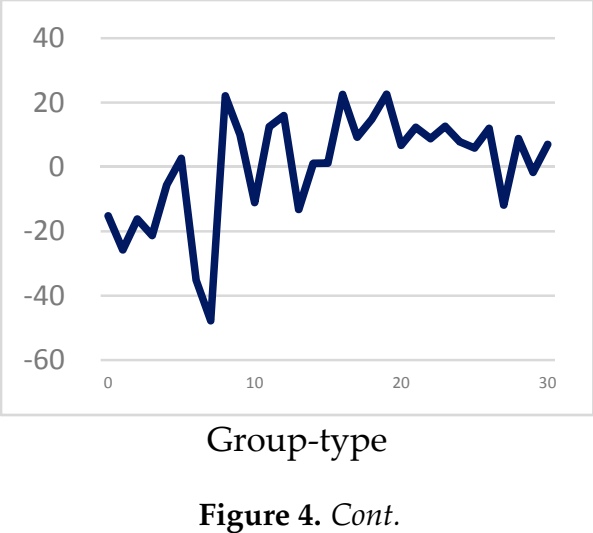

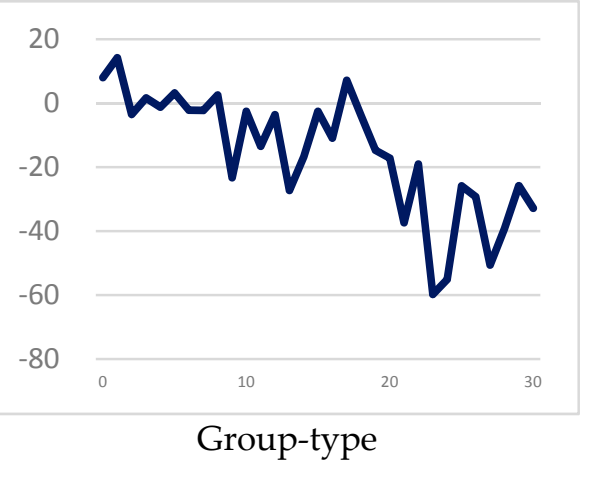



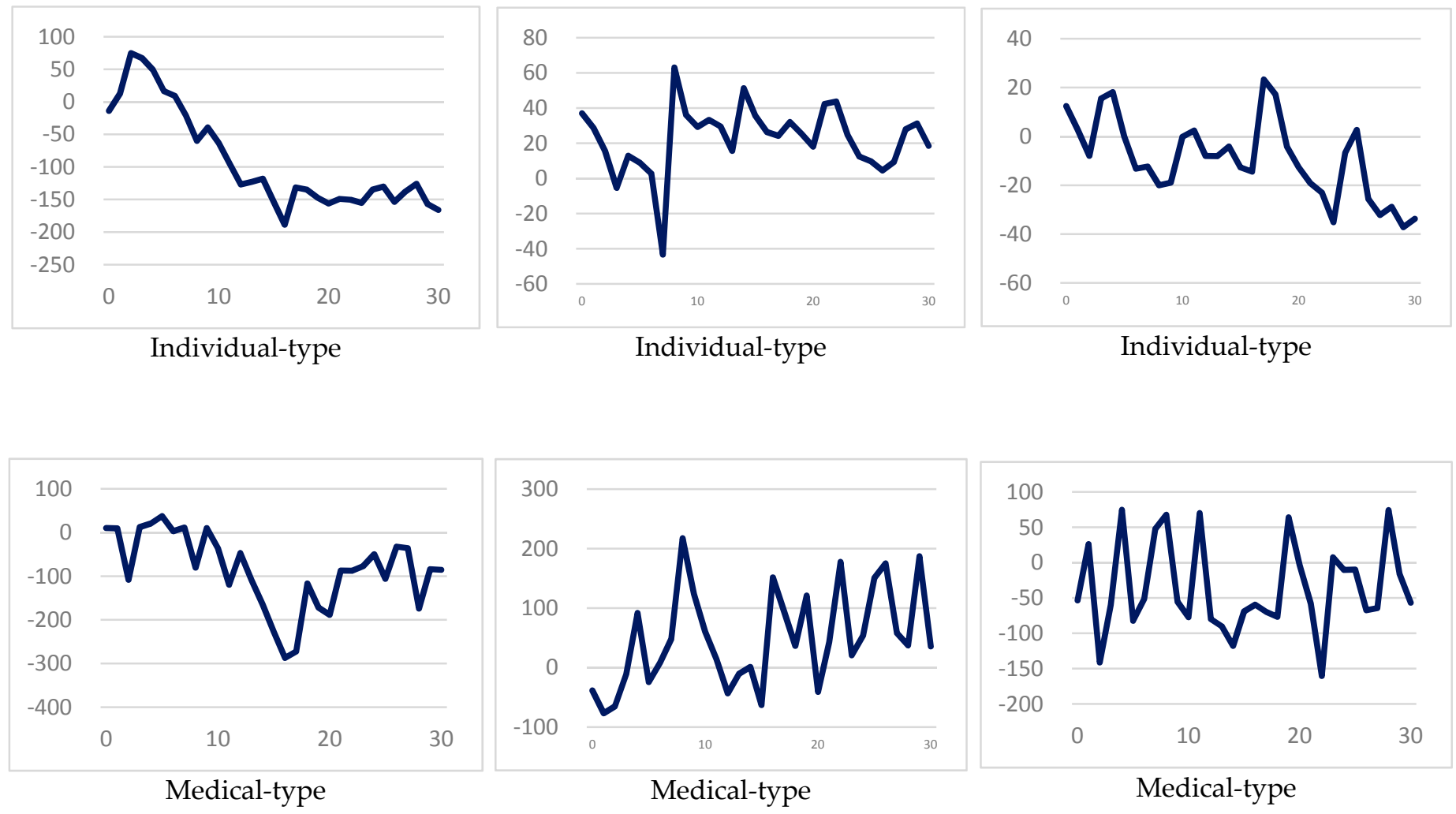

Figure 4. Cumulative abnormal change rate of Chinese tourist arrivals to Taiwan. 


\subsection{Empirical Results for Political Events}

\section{(1) Case I: The Sunflower Youth Movement}

Although the Sunflower movement, which resulted in students and civic groups occupying Taiwan's Legislative Yuan for half a month, raised concerns from people in all walks of life and impacted the implementation of various Cross-Strait agreements, the empirical results did not reveal any significant changes in the number of each group of Chinese tourists visiting Taiwan. For the detailed results of the model parameter estimation, see Tables A1-A4.

The cumulative abnormal change rate (CAR) for three types of Chinese tourist arrivals to Taiwan are given according to four estimation methods, namely OLS, GARCH, GJR, and EGARCH. The empirical results are consistent in that there are no significant factors for any group of Chinese tourist arrivals to Taiwan, regardless of whether the traditional or standardized-residual method is used.

\section{(2) Case II: Taiwan's nine-in-one local elections}

Taiwan's nine-in-one local elections that were held in 2014 resulted in the Kuomintang (KMT) suffering an unprecedented defeat; as a consequence, the former President Ma Ying-jeou resigned as chairman of the KMT party. Although there was much public concern as to what impact the election results might have on future Cross-Straits relationship, the two sides continued to maintain friendly and interactive relations. The empirical results do not show that there was a significant abnormal change in the number of each group of Chinese tourists visiting Taiwan. For the detailed results of the parameter estimation, see Tables A5-A8.

The CAR for three types of Chinese tourist arrivals to Taiwan are given according to four estimation methods. The empirical results are consistent, in that there are no significant factors for any group of Chinese tourist arrivals to Taiwan, regardless of whether the traditional or standardized-residual method is used.

\section{(3) Case III: Ma-Xi Summit}

For the first time since the political separation in 1949 between the two sides of the Taiwan Strait, the top leaders of Taiwan and China met in Singapore. Although the meeting symbolized a major breakthrough in Cross-Strait relations, the two sides did not sign an agreement or issue a joint statement. For this reason, the empirical results did not exhibit a significant abnormal change in the number of each group of Chinese tourists visiting Taiwan. See Tables A9-A12 for the detailed results of the model estimation.

The CAR for three types of Chinese tourist arrivals to Taiwan are given according to four estimation methods. As in Cases I and II, the empirical results are consistent in that there are no significant factors for any group of Chinese tourist arrivals to Taiwan, regardless of whether the traditional or standardized-residual method is used.

\section{(4) Case IV: Taiwan 14th Presidential election and Taiwan ninth legislative election}

President Tsai Ing-wen's speech on 4 June 2015, prior to the presidential election and the 12 December 2015 subsequent political statements made on 22 December 2015, stated that the status quo would be maintained in the Cross-Strait relationship, and that good Cross-Strait interactions and goodwill would also continue. The results for all models show that there was a significant abnormal increase in the number of Group-type tourists from China after the event took place, and the results of OLS and GARCH $(1,1)$ estimation indicate that the number of Individual-type tourists from China also increased abnormally after the event. The Medical-type tourists from China did not, however, experience any abnormal changes. These results show that the number of both Group-type and Individual-type tourists increased abnormally (with + effects) after the Taiwan 14th Presidential 
election and the Taiwan ninth legislative election. However, Medical-type tourists do not seem to have been affected by this event. See Tables A13-A16 for the detailed results of the model estimation.

These empirical results are important as they show that CAR varies according to the type of Chinese tourists, as well as the method of estimation, and whether the traditional or standardized-residual method is used.

\section{(5) Case V: Taiwan 14th Presidential inauguration}

OLS estimates showed that the number of Group-type tourists significantly and abnormally declined following the incident, but the numbers of Individual-type and Medical-type tourists did not experience any abnormal changes. As President Tsai Ing-wen did not mention the 1992 Consensus in her inaugural address, the Chinese government expressed dissatisfaction and Cross-Strait relations stalled, affecting interactions between the two sides. It was rumored that the Chinese government had decided to limit the numbers of Group-type tourists visiting Taiwan. The empirical results confirm the above statements. However, the numbers of Individual-type tourists visiting Taiwan did not decline abnormally. Since the quality of Taiwan's medical treatment is high and its cost is low, the numbers of Medical-type tourists, who mainly come to Taiwan for medical check-ups or cosmetic treatments, were not affected by the political events. See Tables A17-A20 for the detailed results of the model estimation.

The CAR for three types of Chinese tourist arrivals to Taiwan are given, according to four estimation methods. As in Cases I, II, and III, the empirical results are consistent in that there are no significant factors for any groups of Chinese tourist arrivals to Taiwan, regardless of whether the traditional or standardized-residual method is used, with the sole exception being OLS for the Group-type tourists, with decreasing CAR (with - effects). It is worth noting that there are no dynamic effects from estimating conditional volatility.

\section{(6) Case VI: Taiwan mayors visit China}

The OLS and GARCH $(1,1)$ estimates reveal that Group-type tourists experienced a significant abnormal increase following this event. The results of the four models all showed that the numbers of Individual-type tourists increased significantly after the event. Only the OLS estimates indicated that Medical-type tourists experienced a significant abnormal increase prior to the event's occurrence. These results show that the visit by the mayors of eight counties and cities in Taiwan to Beijing, to support the cooperation and exchange event to promote "China's eight measures to benefit Taiwan", had a relatively more significant impact on Individual-type tourists. For the detailed results of the model estimation, see Tables A21-A24.

These results show that the numbers of both Group-type and Individual-type tourists increased abnormally (with + effects) after the Taiwan mayors visited China, for two and four methods of estimation, respectively. However, Medical-type tourists had a decreasing CAR (with - effects) for OLS, but not for the three time-varying conditional volatility models.

These empirical results are important as they show that CAR varies according to the type of Chinese tourists, as well as according to the method of estimation.

\subsection{Empirical Results for Disaster and Accident Events}

\section{(1) Case VII: The Kaohsiung Petrochemical gas explosion}

The results of the OLS, GARCH $(1,1)$, and GJR $(1,1)$ estimates showed that the numbers of Group-type tourists experienced a significant abnormal decrease following the occurrence of the event. The results of all four models revealed that Individual-type tourists also declined significantly. However, the results of the OLS, GARCH $(1,1)$, and GJR $(1,1)$ estimates showed that the numbers of Medical-type tourists significantly increased. According to the above results, the Kaohsiung Petrochemical gas explosion event had a relatively large impact on Group-type and Individual-type 
tourists, but it did not affect the Medical-type tourists who came to Taiwan for medical treatment. See Tables A25-A28 for the detailed results of model estimation.

These results show that the number of both Group-type and Individual-type tourists decreased abnormally (with - effects), for three and four methods of estimation, respectively. However, Medical-type tourists had an increasing CAR (with + effects) for three methods of estimation.

These empirical results are important as they show that CAR varies according to the type of Chinese tourists, as well as with the method of estimation.

\section{(2) Case VIII: Taiwan's “gutter oil” scandal}

The results of the four different kinds of models show that the numbers of Group-type and Individual-type tourists experienced significant abnormal increases following the event, but that the numbers of Medical-type tourists only increased significantly when OLS was used. As the time when the contaminated cooking oil scandal occurred in Taiwan was simultaneous to the Chinese national holidays (1 October 2014-7 October 2014), there was no impact on the willingness of Chinese tourists to visit Taiwan. On the contrary, due to the long holiday, the number of each group of Chinese visitors to Taiwan during that period was actually higher than expected, and therefore they exhibited abnormal increases. See Tables A29-A32 for the detailed results of model estimation.

These results show that the number of Group-type, Individual-type, and Medical-type tourists increased abnormally (with + effects), for four, four, and one methods of estimation, respectively. Only Medical-type tourists showed no dynamic effects from time-varying conditional volatility.

These empirical results are important as they show that CAR varies consistently and positively for all three types of Chinese tourists, as well as for the method of estimation.

\section{(3) Case IX: TransAsia Airways Flight GE235 accident}

The estimates of the four models showed that there was a significant abnormal decline in the numbers of Group-type and Individual-type tourists following the event, but only the results of OLS and GARCH $(1,1)$ indicated that the numbers of Medical-type tourists declined significantly. From these results, it can be inferred that the crash of TransAsia Airways Flight 235 impacted the willingness of each group of Chinese tourists to visit Taiwan, due to their concerns over flight safety. The detailed results of the model estimates are given in Tables A33-A36.

These results are the polar opposite of Case VIII in that the numbers of Group-type, Individual-type, and Medical-type tourists were decreased abnormally (with - effects), for four, four, and two methods of estimation, respectively.

These empirical results are important as they show that CAR varies consistently and negatively for all three types of Chinese tourists, as well as for the method of estimation.

\section{(4) Case X: Kaohsiung's magnitude 6.6 Meinong earthquake}

While the number of Group-type tourists was not abnormally changed, the results of the OLS, GARCH $(1,1)$ and GJR $(1,1)$ estimates showed that the number of Individual-type tourists was significantly and abnormally reduced after the event occurred, as was the number of Medical-type tourists from the results of OLS and GJR $(1,1)$. As the 6.6 magnitude Meinong, Kaohsiung earthquake struck at the same time as the Chinese Lunar New Year holiday (7 February 2016-13 February 2016), and the area where it happened was not a tourist attraction, Group-type tourists were not affected. However, after the Chinese New Year holiday, the numbers of Individual-type and Medical-type tourists declined significantly. See Tables A37-A40 for the detailed results of model estimation.

These results show that the number of Individual-type and Medical-type tourists decreased abnormally (with - effects), for three and one methods of estimation, respectively. Only Group-type tourists showed no significant constant or dynamic effects of time-varying conditional volatility.

These empirical results are important as they show that CAR varies consistently and negatively for two types of Chinese tourists, as well as with the method of estimation. 
(5) Case XI: 95th anniversary of the founding of the Communist Party of China and the Hsiung Feng III missile mishap

The results for the four models all show that the numbers of Group-type, Individual-type, and Medical-type tourists were not affected by this accident. The Taiwan government issued a statement immediately after the mishap to point out that the incident occurred due to negligence in personnel training, and not because of political factors. It was for this reason that the willingness of each group of Chinese tourists to visit Taiwan from the mainland was not affected. See Tables A41-A44 for the detailed results of the model estimation.

As in Cases I, II, and III, the empirical results are consistent in that there are no significant factors for any group of Chinese tourist arrivals to Taiwan, regardless of the method of estimation, and whether the traditional or standardized-residual method is used.

\section{(6) Case XII: Taiwan tour bus accident}

The results for all four models showed that the numbers of Group-type, Individual-type, and Medical type tourists from China were not affected by this accident. From the empirical results, it can be seen that the tour bus accident that resulted in the deaths of tourists from Liaoning, China was due to human factors, and that the likelihood of such an incident recurring was low. In addition, the accident victims were part of a tour bus tour group, and the unfortunate event had no effect on Individual-type tourists who made their own arrangements regarding their itinerary and transportation. See Tables A45-A48 for the detailed results of the model estimation.

As in Cases I, II, III, and XI, the empirical results are consistent in that there are no significant factors for any group of Chinese tourist arrivals to Taiwan, regardless of the method of estimation, and whether the traditional or standardized-residual method is used.

\section{Conclusions}

The Cross-Strait relationship has long been a major focus of attention among the general public, not only in Taiwan and China, but also throughout the entire Asia-Pacific region, having become one of the more important issues of concern to the global community. The different official political stances on the two sides of the Taiwan Strait have indirectly affected private sector exchanges. Since 2008, when President Ma Ying-jeou relaxed the Cross-Strait policy, mainland Chinese have been allowed to apply to travel to Taiwan as Group-type tourists, without having to transit through a third country. With the relaxation of the conditions for Cross-Strait tourism, increasing numbers of Chinese tourists have been attracted to visit Taiwan. From 2010 onwards, Chinese tourists have accounted for the largest proportion of international tourists visiting Taiwan (though both China and Taiwan sometimes regard such tourism as domestic).

In 2016, Taiwan's 14th President Tsai Ing-wen's Cross-Strait policy was unable to satisfy the expectations for one China, which led to a gradual stalemate in Cross-Strait relations. Rumors circulated that the Chinese government had limited the number of Chinese tourists that could visit Taiwan. The data also indicated that the number of Chinese tourists visiting Taiwan was also exhibiting a clear downward trend. In addition to political factors, Taiwan's tourism environment in relation to facilities and safety considerations was also affecting the willingness of Chinese tourists to visit Taiwan.

Previous studies have rarely examined the impact of political and disaster-related events on tourism demand from China to Taiwan. In this research, an approach that has frequently been applied in financial studies, namely the event study methodology, was adopted to analyze the effects of changes in the number of three types of Chinese tourists to Taiwan caused by political events, and by disaster and accident events.

The purpose of this study was to demonstrate a potential application of the event study method to tourism data, which could be applied to analyze the impact of such detailed information on tourism. This research has used data on the numbers of Chinese tourists visiting Taiwan over the period 
1 January 2014-31 October 2016 to examine the impact of Cross-Strait political events, and disaster and accident events, on the numbers of Chinese tourists visiting Taiwan during the period 2014-2016.

Major political events and increased uncertainty regarding the Cross-Strait relationship have affected the numbers of Chinese tourists visiting Taiwan. The empirical results of this paper show that President Tsai Ing-wen's lack of a specific mention of the "1992 Consensus" Cross-Strait policy resulted in an abnormal reduction in the number of Group-type Chinese tourists visiting Taiwan, an outcome that confirms the rumors that the Chinese government has limited the numbers of its citizens that can visit Taiwan.

The visit by eight of Taiwan's county and city mayors to Beijing, China, and the ensuing agreement between the two sides to jointly promote the "Eight measures to benefit Taiwan" in Taiwan and China through exchange and cooperation, resulted in the numbers of both Group-type and Individual-type tourists increasing abnormally. This paper confirms that political events have had relatively little impact on the numbers of Medical-type tourists visiting Taiwan, mainly because Medical-type tourists come to Taiwan for health checks or cosmetic treatments, and are thereby not generally affected by political events.

Given the restrictions in obtaining (daily) data from the National Immigration Agency in Taiwan, the data used in the paper focused on daily Chinese and international tourist arrivals data from 1 January 2014 to 31 October 2016.

Overall, we have focused on two major issues that affect Chinese tourists to travel to Taiwan, namely political events, and disaster and accident events. Based on the data sources, we can verify the impacts from different political events, and disaster and accident events, for three types of Chinese tourists to Taiwan, four methods of estimation, and the traditional and standardized-residual methods.

From the results of the disaster-related event research, it has been found that the impact of disasters and accidents on the number of Chinese tourists visiting Taiwan mainly depends on the level of an incident's impact. For example, the Kaohsiung Petrochemical gas explosion resulted in a significant abnormal reduction in the numbers of Group-type and Individual-type Chinese tourists visiting Taiwan.

The TransAsia Airways Flight 235 crash incident directly affected the tourists' concerns over travel safety and hence their willingness to travel, so that the numbers of each type of tourist exhibited a significant abnormal reduction. The accidental firing of a missile by the Taiwan Navy and the accident involving a Chinese tour group travelling on a tour bus did not affect the numbers of Chinese tourists visiting Taiwan.

In the cases where the events occurred on a national holiday, there was not an abnormal change in the number of Chinese tourists visiting Taiwan. If the incident took place during the Chinese New Year holiday, while it did not affect the numbers of Group-type tourists; after the holidays were over, the numbers of Individual-type and Medical-type tourists did in fact experience a significant abnormal reduction.

Based on the above empirical results, we estimated the impacts from different political events, and disaster and accident events, for three types of Chinese tourists to Taiwan. For political events, Group-type tourists are the most sensitive to the impact of Cross-Strait political events, but Individual-type and Medical-type tourists are seemingly not affected by political events.

In the past, in order to attract Chinese tourists to visit Taiwan, Taiwan businesses adopted low-cost group price competition as their business model. This not only undermined the quality of tourism in Taiwan, but also gave rise to bad money driving out good money, with the exclusion of international travelers with high spending power who would otherwise have been willing to visit Taiwan.

For disaster-related events, different levels of an incident generate different effects on the rate of change in the numbers of different types of Chinese tourists to Taiwan. These empirical results should serve as a valuable reference to the Taiwan Government, as well as to public and private policy-makers, as they formulate new economic and financial tourism policies and strategies for the future. 
Therefore, in the future, tourism businesses in Taiwan should enhance their own competitiveness, and extricate themselves from the vicious cycle of price competition. The Taiwan government should also actively promote a unique style of tourism, establish tourism groups with specific purposes, and create a friendly and safe tourism environment. It should also enhance the quality of tourism in Taiwan, strengthen the depth of tourism, attract tourists with high spending power, and create new sources of tourism revenue.

Future research would also use additional data from leading tourism source countries to Taiwan, such as Hong Kong and Macao, Japan, South Korea, Singapore, Malaysia, and USA. This would enable a greater understanding of the effects of tourism demand to Taiwan caused by major events. Additionally, further research would also examine the effects of further information and factors that affect tourism demand movements.

Author Contributions: Conceptualization, C.-L.C.; Data curation, S.-H.H.; Formal analysis, C.-L.C. and M.M.; Funding acquisition, C.-L.C. and M.M.; Investigation, C.-L.C., S.-H.H. and M.M.; Methodology, M.M.; Project administration, C.-L.C.; Software, S.-H.H.; Supervision, C.-L.C. and M.M.; Validation, S.-H.H.; Writing-original draft, C.-L.C. and S.-H.H.; Writing-review \& editing, M.M.

Funding: This research received no external funding.

Acknowledgments: The authors are most grateful to three reviewers for very helpful comments and suggestions. For financial support, the first author wishes to thank the Ministry of Science and Technology (MOST), Taiwan, and the third author acknowledges the Australian Research Council and the Ministry of Science and Technology (MOST), Taiwan.

Conflicts of Interest: The authors declare no conflict of interest.

\section{Appendix A.}

Table A1. Case I: OLS-Cumulative abnormal change rate of Chinese tourist arrivals.

\begin{tabular}{|c|c|c|c|c|c|c|c|c|c|}
\hline \multirow{3}{*}{ Event Period $\left[\tau_{1}, \tau_{2}\right]$} & \multicolumn{3}{|c|}{ Group-Type } & \multicolumn{3}{|c|}{ Individual-Type } & \multicolumn{3}{|c|}{ Medical-Type } \\
\hline & \multirow{2}{*}{ CAR } & \multicolumn{2}{|c|}{ t-Value } & \multirow{2}{*}{ CAR } & \multicolumn{2}{|c|}{ t-Value } & \multirow{2}{*}{ CAR } & \multicolumn{2}{|c|}{ t-Value } \\
\hline & & TM & SRM & & TM & SRM & & TM & SRM \\
\hline$[0,0]$ & 13.66 & 0.54 & 0.53 & 31.44 & 0.84 & 0.82 & -51.38 & -0.69 & -0.67 \\
\hline$[0,1]$ & 24.20 & 0.96 & 0.94 & 20.65 & 0.55 & 0.54 & 30.91 & 0.41 & 0.40 \\
\hline$[0,2]$ & 32.79 & 1.31 & 1.27 & 7.25 & 0.19 & 0.19 & 10.87 & 0.15 & 0.14 \\
\hline$[0,3]$ & 22.26 & 0.89 & 0.85 & 41.95 & 1.13 & 1.08 & 17.94 & 0.24 & 0.23 \\
\hline$[0,4]$ & 21.08 & 0.84 & 0.82 & 26.77 & 0.72 & 0.70 & 2.82 & 0.04 & 0.04 \\
\hline$[0,5]$ & -4.61 & -0.18 & -0.18 & 7.26 & 0.20 & 0.19 & 47.95 & 0.64 & 0.62 \\
\hline$[0,6]$ & -7.84 & -0.31 & -0.31 & -19.91 & -0.53 & -0.52 & -5.90 & -0.08 & -0.08 \\
\hline$[0,7]$ & 15.89 & 0.63 & 0.62 & 13.55 & 0.36 & 0.36 & -99.14 & -1.33 & -1.30 \\
\hline$[0,8]$ & 31.35 & 1.25 & 1.22 & -1.80 & -0.05 & -0.05 & 24.10 & 0.32 & 0.31 \\
\hline$[0,9]$ & 17.39 & 0.69 & 0.68 & 8.08 & 0.22 & 0.21 & 25.03 & 0.34 & 0.33 \\
\hline$[0,10]$ & 17.85 & 0.71 & 0.70 & -4.17 & -0.11 & -0.11 & -71.81 & -0.96 & -0.94 \\
\hline$[0,11]$ & 5.54 & 0.22 & 0.22 & 20.30 & 0.55 & 0.53 & -113.08 & -1.51 & -1.48 \\
\hline$[0,12]$ & -2.25 & -0.09 & -0.09 & -23.66 & -0.64 & -0.62 & 1.11 & 0.01 & 0.01 \\
\hline$[0,13]$ & -15.50 & -0.62 & -0.60 & -36.02 & -0.97 & -0.94 & -0.83 & -0.01 & -0.01 \\
\hline$[0,14]$ & -12.78 & -0.51 & -0.50 & -29.60 & -0.80 & -0.78 & -42.67 & -0.57 & -0.56 \\
\hline$[0,15]$ & -14.42 & -0.57 & -0.56 & 6.77 & 0.18 & 0.18 & 10.41 & 0.14 & 0.14 \\
\hline$[0,16]$ & -43.32 & -1.73 & -1.67 & -8.64 & -0.23 & -0.22 & -25.34 & -0.34 & -0.33 \\
\hline$[0,17]$ & -6.60 & -0.26 & -0.26 & 33.69 & 0.90 & 0.88 & -57.86 & -0.77 & -0.76 \\
\hline$[0,18]$ & -22.73 & -0.91 & -0.89 & 20.09 & 0.54 & 0.53 & -9.03 & -0.12 & -0.12 \\
\hline$[0,19]$ & -34.47 & -1.37 & -1.34 & -30.43 & -0.82 & -0.80 & -103.00 & -1.38 & -1.34 \\
\hline$[0,20]$ & 4.05 & 0.16 & 0.16 & -3.21 & -0.09 & -0.08 & -30.57 & -0.41 & -0.40 \\
\hline$[0,21]$ & 7.00 & 0.28 & 0.27 & 5.70 & 0.15 & 0.15 & -9.71 & -0.13 & -0.13 \\
\hline$[0,22]$ & 19.26 & 0.77 & 0.75 & 10.29 & 0.28 & 0.27 & 2.34 & 0.03 & 0.03 \\
\hline$[0,23]$ & 12.32 & 0.49 & 0.47 & 5.85 & 0.16 & 0.15 & 39.83 & 0.53 & 0.51 \\
\hline$[0,24]$ & 27.48 & 1.10 & 1.07 & 32.14 & 0.86 & 0.84 & 14.09 & 0.19 & 0.18 \\
\hline$[0,25]$ & 6.59 & 0.26 & 0.26 & -2.22 & -0.06 & -0.06 & -24.09 & -0.32 & -0.32 \\
\hline
\end{tabular}


Table A1. Cont.

\begin{tabular}{|c|c|c|c|c|c|c|c|c|c|}
\hline \multirow{3}{*}{ Event Period $\left[\tau_{1}, \tau_{2}\right]$} & \multicolumn{3}{|c|}{ Group-Type } & \multicolumn{3}{|c|}{ Individual-Type } & \multicolumn{3}{|c|}{ Medical-Type } \\
\hline & \multirow{2}{*}{ CAR } & \multicolumn{2}{|c|}{ t-Value } & \multirow{2}{*}{ CAR } & \multicolumn{2}{|c|}{ t-Value } & \multirow{2}{*}{ CAR } & \multicolumn{2}{|c|}{ t-Value } \\
\hline & & TM & SRM & & TM & SRM & & TM & SRM \\
\hline$[0,26]$ & -15.79 & -0.63 & -0.62 & -12.66 & -0.34 & -0.33 & -6.66 & -0.09 & -0.09 \\
\hline$[0,27]$ & -12.56 & -0.50 & -0.49 & -10.79 & -0.29 & -0.28 & -16.85 & -0.23 & -0.22 \\
\hline$[0,28]$ & -3.24 & -0.13 & -0.12 & -29.64 & -0.80 & -0.77 & -27.12 & -0.36 & -0.35 \\
\hline$[0,29]$ & -3.31 & -0.13 & -0.13 & -36.86 & -0.99 & -0.97 & -62.19 & -0.83 & -0.81 \\
\hline$[0,30]$ & -5.63 & -0.22 & -0.22 & -3.13 & -0.08 & -0.08 & 23.12 & 0.31 & 0.30 \\
\hline
\end{tabular}

Table A2. Case I: GARCH(1,1)—Cumulative abnormal change rate of Chinese tourist arrivals.

\begin{tabular}{|c|c|c|c|c|c|c|c|c|c|}
\hline \multirow{3}{*}{ Event Period $\left[\tau_{1}, \tau_{2}\right]$} & \multicolumn{3}{|c|}{ Group-Type } & \multicolumn{3}{|c|}{ Individual-Type } & \multicolumn{3}{|c|}{ Medical-Type } \\
\hline & \multirow{2}{*}{ CAR } & \multicolumn{2}{|c|}{ t-Value } & \multirow{2}{*}{ CAR } & \multicolumn{2}{|c|}{ t-Value } & \multirow{2}{*}{ CAR } & \multicolumn{2}{|c|}{ t-Value } \\
\hline & & TM & SRM & & TM & SRM & & TM & SRM \\
\hline$[0,0]$ & 13.86 & 0.43 & 0.41 & 32.38 & 0.48 & 0.47 & -52.80 & -0.63 & -0.61 \\
\hline$[0,1]$ & 24.51 & 0.75 & 0.73 & 21.25 & 0.32 & 0.31 & 28.30 & 0.34 & 0.33 \\
\hline$[0,2]$ & 33.25 & 1.02 & 0.99 & 8.14 & 0.12 & 0.12 & 6.97 & 0.08 & 0.08 \\
\hline$[0,3]$ & 22.78 & 0.70 & 0.67 & 42.01 & 0.62 & 0.60 & 12.97 & 0.15 & 0.15 \\
\hline$[0,4]$ & 22.07 & 0.68 & 0.66 & 31.31 & 0.46 & 0.45 & -4.29 & -0.05 & -0.05 \\
\hline$[0,5]$ & -3.54 & -0.11 & -0.11 & 11.15 & 0.17 & 0.16 & 39.73 & 0.47 & 0.46 \\
\hline$[0,6]$ & -6.51 & -0.20 & -0.20 & -14.39 & -0.21 & -0.21 & -15.70 & -0.19 & -0.18 \\
\hline$[0,7]$ & 17.47 & 0.54 & 0.52 & 20.64 & 0.31 & 0.30 & -110.49 & -1.31 & -1.28 \\
\hline$[0,8]$ & 33.05 & 1.01 & 0.99 & 5.12 & 0.08 & 0.07 & 11.54 & 0.14 & 0.13 \\
\hline$[0,9]$ & 19.28 & 0.59 & 0.58 & 15.87 & 0.24 & 0.23 & 11.06 & 0.13 & 0.13 \\
\hline$[0,10]$ & 20.06 & 0.62 & 0.60 & 6.11 & 0.09 & 0.09 & -87.52 & -1.04 & -1.02 \\
\hline$[0,11]$ & 8.01 & 0.25 & 0.24 & 32.09 & 0.48 & 0.47 & -130.34 & -1.55 & -1.51 \\
\hline$[0,12]$ & 0.48 & 0.01 & 0.01 & -10.02 & -0.15 & -0.15 & -17.76 & -0.21 & -0.21 \\
\hline$[0,13]$ & -12.56 & -0.39 & -0.38 & -21.48 & -0.32 & -0.31 & -21.12 & -0.25 & -0.24 \\
\hline$[0,14]$ & -9.71 & -0.30 & -0.29 & -15.10 & -0.22 & -0.22 & -64.20 & -0.76 & -0.74 \\
\hline$[0,15]$ & -11.15 & -0.34 & -0.33 & 22.22 & 0.33 & 0.32 & -12.55 & -0.15 & -0.15 \\
\hline$[0,16]$ & -39.71 & -1.22 & -1.18 & 9.53 & 0.14 & 0.14 & -50.09 & -0.59 & -0.57 \\
\hline$[0,17]$ & -2.98 & -0.09 & -0.09 & 50.43 & 0.75 & 0.73 & -83.56 & -0.99 & -0.97 \\
\hline$[0,18]$ & -18.95 & -0.58 & -0.57 & 37.12 & 0.55 & 0.54 & -36.03 & -0.43 & -0.42 \\
\hline$[0,19]$ & -30.45 & -0.93 & -0.91 & -11.88 & -0.18 & -0.17 & -131.55 & -1.56 & -1.52 \\
\hline$[0,20]$ & 8.06 & 0.25 & 0.24 & 13.51 & 0.20 & 0.20 & -59.99 & -0.71 & -0.70 \\
\hline$[0,21]$ & 11.15 & 0.34 & 0.33 & 22.56 & 0.34 & 0.33 & -40.39 & -0.48 & -0.47 \\
\hline$[0,22]$ & 23.55 & 0.72 & 0.71 & 27.39 & 0.41 & 0.40 & -29.63 & -0.35 & -0.34 \\
\hline$[0,23]$ & 16.50 & 0.51 & 0.48 & 19.92 & 0.30 & 0.28 & 7.24 & 0.09 & 0.08 \\
\hline$[0,24]$ & 32.11 & 0.99 & 0.96 & 50.31 & 0.75 & 0.73 & -20.58 & -0.24 & -0.24 \\
\hline$[0,25]$ & 11.44 & 0.35 & 0.34 & 17.12 & 0.25 & 0.25 & -60.24 & -0.71 & -0.70 \\
\hline$[0,26]$ & -10.77 & -0.33 & -0.32 & 7.30 & 0.11 & 0.11 & -44.17 & -0.52 & -0.51 \\
\hline$[0,27]$ & -7.32 & -0.22 & -0.22 & 10.33 & 0.15 & 0.15 & -55.83 & -0.66 & -0.65 \\
\hline$[0,28]$ & 1.90 & 0.06 & 0.06 & -11.43 & -0.17 & -0.16 & -66.76 & -0.79 & -0.76 \\
\hline$[0,29]$ & 2.36 & 0.07 & 0.07 & -13.68 & -0.20 & -0.20 & -104.07 & -1.23 & -1.21 \\
\hline$[0,30]$ & 0.02 & 0.00 & 0.00 & 18.24 & 0.27 & 0.26 & -19.63 & -0.23 & -0.23 \\
\hline
\end{tabular}


Table A3. Case I: GJR(1,1)—Cumulative abnormal change rate of Chinese tourist arrivals.

\begin{tabular}{|c|c|c|c|c|c|c|c|c|c|}
\hline \multirow{3}{*}{ Event Period $\left[\tau_{1}, \tau_{2}\right]$} & \multicolumn{3}{|c|}{ Group-Type } & \multicolumn{3}{|c|}{ Individual-Type } & \multicolumn{3}{|c|}{ Medical-Type } \\
\hline & \multirow{2}{*}{ CAR } & \multicolumn{2}{|c|}{ t-Value } & \multirow{2}{*}{ CAR } & \multicolumn{2}{|c|}{ t-Value } & \multirow{2}{*}{ CAR } & \multicolumn{2}{|c|}{ t-Value } \\
\hline & & TM & SRM & & TM & SRM & & TM & SRM \\
\hline$[0,0]$ & 10.16 & 0.11 & 0.11 & 32.28 & 0.67 & 0.65 & -51.27 & -0.14 & -0.14 \\
\hline$[0,1]$ & 18.30 & 0.20 & 0.20 & 21.38 & 0.44 & 0.43 & 22.53 & 0.06 & 0.06 \\
\hline$[0,2]$ & 23.95 & 0.27 & 0.26 & 8.34 & 0.17 & 0.17 & -1.76 & 0.00 & 0.00 \\
\hline$[0,3]$ & 11.44 & 0.13 & 0.12 & 42.56 & 0.88 & 0.84 & -6.54 & -0.02 & -0.02 \\
\hline$[0,4]$ & 3.70 & 0.04 & 0.04 & 30.86 & 0.64 & 0.62 & 2.30 & 0.01 & 0.01 \\
\hline$[0,5]$ & -24.12 & -0.27 & -0.26 & 11.01 & 0.23 & 0.22 & 36.81 & 0.10 & 0.10 \\
\hline$[0,6]$ & -31.46 & -0.35 & -0.34 & -14.80 & -0.31 & -0.30 & -12.22 & -0.03 & -0.03 \\
\hline$[0,7]$ & -11.76 & -0.13 & -0.13 & 19.97 & 0.41 & 0.40 & -101.12 & -0.28 & -0.27 \\
\hline$[0,8]$ & 1.15 & 0.01 & 0.01 & 4.64 & 0.10 & 0.09 & 14.76 & 0.04 & 0.04 \\
\hline$[0,9]$ & -16.25 & -0.18 & -0.18 & 15.31 & 0.32 & 0.31 & 15.32 & 0.04 & 0.04 \\
\hline$[0,10]$ & -20.65 & -0.23 & -0.23 & 5.06 & 0.10 & 0.10 & -70.88 & -0.19 & -0.19 \\
\hline$[0,11]$ & -36.94 & -0.41 & -0.40 & 30.80 & 0.64 & 0.62 & -108.24 & -0.30 & -0.29 \\
\hline$[0,12]$ & -49.03 & -0.55 & -0.53 & -11.64 & -0.24 & -0.23 & 12.23 & 0.03 & 0.03 \\
\hline$[0,13]$ & -65.75 & -0.73 & -0.72 & -23.19 & -0.48 & -0.47 & 10.16 & 0.03 & 0.03 \\
\hline$[0,14]$ & -65.68 & -0.73 & -0.72 & -16.66 & -0.34 & -0.34 & -38.18 & -0.10 & -0.10 \\
\hline$[0,15]$ & -70.83 & -0.79 & -0.77 & 20.56 & 0.42 & 0.41 & 15.06 & 0.04 & 0.04 \\
\hline$[0,16]$ & -104.78 & -1.17 & -1.13 & 7.32 & 0.15 & 0.15 & -8.55 & -0.02 & -0.02 \\
\hline$[0,17]$ & -69.52 & -0.78 & -0.76 & 48.73 & 1.01 & 0.98 & -56.89 & -0.16 & -0.15 \\
\hline$[0,18]$ & -88.58 & -0.99 & -0.97 & 35.49 & 0.73 & 0.72 & -12.39 & -0.03 & -0.03 \\
\hline$[0,19]$ & -104.34 & -1.17 & -1.14 & -13.76 & -0.28 & -0.28 & -102.32 & -0.28 & -0.27 \\
\hline$[0,20]$ & -66.91 & -0.75 & -0.73 & 12.25 & 0.25 & 0.25 & -48.49 & -0.13 & -0.13 \\
\hline$[0,21]$ & -66.78 & -0.75 & -0.73 & 21.40 & 0.44 & 0.43 & -32.87 & -0.09 & -0.09 \\
\hline$[0,22]$ & -57.42 & -0.64 & -0.63 & 26.31 & 0.54 & 0.53 & -25.48 & -0.07 & -0.07 \\
\hline$[0,23]$ & -64.43 & -0.72 & -0.69 & 19.75 & 0.41 & 0.39 & -14.64 & -0.04 & -0.04 \\
\hline$[0,24]$ & -55.51 & -0.62 & -0.61 & 49.25 & 1.02 & 0.99 & -18.94 & -0.05 & -0.05 \\
\hline$[0,25]$ & -80.10 & -0.89 & -0.87 & 15.89 & 0.33 & 0.32 & -55.45 & -0.15 & -0.15 \\
\hline$[0,26]$ & -105.72 & -1.18 & -1.15 & 6.07 & 0.13 & 0.12 & -40.01 & -0.11 & -0.11 \\
\hline$[0,27]$ & -106.17 & -1.19 & -1.16 & 8.94 & 0.18 & 0.18 & -48.68 & -0.13 & -0.13 \\
\hline$[0,28]$ & -97.03 & -1.08 & -1.04 & -11.93 & -0.25 & -0.24 & -84.80 & -0.23 & -0.22 \\
\hline$[0,29]$ & -104.08 & -1.16 & -1.14 & -15.31 & -0.32 & -0.31 & -92.51 & -0.25 & -0.25 \\
\hline$[0,30]$ & -107.54 & -1.20 & -1.17 & 17.21 & 0.36 & 0.35 & -25.61 & -0.07 & -0.07 \\
\hline
\end{tabular}


Table A4. Case I: EGARCH(1,1)—Cumulative abnormal change rate of Chinese tourist arrivals.

\begin{tabular}{|c|c|c|c|c|c|c|c|c|c|}
\hline \multirow{3}{*}{ Event Period $\left[\tau_{1}, \tau_{2}\right]$} & \multicolumn{3}{|c|}{ Group-Type } & \multicolumn{3}{|c|}{ Individual-Type } & \multicolumn{3}{|c|}{ Medical-Type } \\
\hline & \multirow{2}{*}{ CAR } & \multicolumn{2}{|c|}{ t-Value } & \multirow{2}{*}{ CAR } & \multicolumn{2}{|c|}{ t-Value } & \multirow{2}{*}{ CAR } & \multicolumn{2}{|c|}{ t-Value } \\
\hline & & TM & SRM & & TM & SRM & & TM & SRM \\
\hline$[0,0]$ & 8.92 & 0.08 & 0.08 & 33.31 & 0.82 & 0.80 & -51.76 & -0.68 & -0.67 \\
\hline$[0,1]$ & 15.58 & 0.14 & 0.13 & 19.85 & 0.49 & 0.48 & 32.95 & 0.44 & 0.42 \\
\hline$[0,2]$ & 19.87 & 0.18 & 0.17 & 6.01 & 0.15 & 0.14 & 13.97 & 0.18 & 0.18 \\
\hline$[0,3]$ & 5.78 & 0.05 & 0.05 & 36.27 & 0.90 & 0.86 & 24.56 & 0.32 & 0.31 \\
\hline$[0,4]$ & -2.51 & -0.02 & -0.02 & 35.57 & 0.88 & 0.86 & 1.25 & 0.02 & 0.02 \\
\hline$[0,5]$ & -31.87 & -0.28 & -0.28 & 12.27 & 0.30 & 0.30 & 49.51 & 0.65 & 0.64 \\
\hline$[0,6]$ & -40.31 & -0.36 & -0.35 & -10.54 & -0.26 & -0.25 & -6.28 & -0.08 & -0.08 \\
\hline$[0,7]$ & -21.73 & -0.19 & -0.19 & 27.03 & 0.67 & 0.65 & -101.28 & -1.34 & -1.31 \\
\hline$[0,8]$ & -10.27 & -0.09 & -0.09 & 9.61 & 0.24 & 0.23 & 24.02 & 0.32 & 0.31 \\
\hline$[0,9]$ & -28.92 & -0.26 & -0.25 & 21.11 & 0.52 & 0.51 & 24.73 & 0.33 & 0.32 \\
\hline$[0,10]$ & -34.25 & -0.30 & -0.30 & 16.29 & 0.40 & 0.39 & -75.95 & -1.00 & -0.98 \\
\hline$[0,11]$ & -51.67 & -0.46 & -0.45 & 44.65 & 1.11 & 1.08 & -118.85 & -1.57 & -1.54 \\
\hline$[0,12]$ & -64.81 & -0.58 & -0.56 & 5.82 & 0.14 & 0.14 & -7.06 & -0.09 & -0.09 \\
\hline$[0,13]$ & -82.77 & -0.73 & -0.72 & -4.79 & -0.12 & -0.12 & -9.31 & -0.12 & -0.12 \\
\hline$[0,14]$ & -84.13 & -0.75 & -0.73 & 0.01 & 0.00 & 0.00 & -49.38 & -0.65 & -0.64 \\
\hline$[0,15]$ & -90.52 & -0.80 & -0.78 & 38.28 & 0.95 & 0.92 & 3.30 & 0.04 & 0.04 \\
\hline$[0,16]$ & -125.35 & -1.11 & -1.07 & 31.11 & 0.77 & 0.74 & -36.77 & -0.49 & -0.47 \\
\hline$[0,17]$ & -91.79 & -0.81 & -0.80 & 66.88 & 1.66 & 1.62 & -64.45 & -0.85 & -0.83 \\
\hline$[0,18]$ & -112.21 & -1.00 & -0.97 & 52.82 & 1.31 & 1.28 & -14.55 & -0.19 & -0.19 \\
\hline$[0,19]$ & -129.09 & -1.15 & -1.12 & 6.24 & 0.15 & 0.15 & -110.20 & -1.46 & -1.42 \\
\hline$[0,20]$ & -93.44 & -0.83 & -0.81 & 25.45 & 0.63 & 0.62 & -32.02 & -0.42 & -0.41 \\
\hline$[0,21]$ & -94.70 & -0.84 & -0.82 & 33.40 & 0.83 & 0.81 & -9.79 & -0.13 & -0.13 \\
\hline$[0,22]$ & -86.71 & -0.77 & -0.75 & 37.35 & 0.92 & 0.90 & 3.43 & 0.05 & 0.04 \\
\hline$[0,23]$ & -95.73 & -0.85 & -0.81 & 20.62 & 0.51 & 0.49 & 49.32 & 0.65 & 0.62 \\
\hline$[0,24]$ & -87.43 & -0.78 & -0.76 & 60.07 & 1.49 & 1.45 & 16.19 & 0.21 & 0.21 \\
\hline$[0,25]$ & -113.20 & -1.00 & -0.98 & 28.41 & 0.70 & 0.69 & -22.88 & -0.30 & -0.30 \\
\hline$[0,26]$ & -140.12 & -1.24 & -1.22 & 18.73 & 0.46 & 0.45 & -5.15 & -0.07 & -0.07 \\
\hline$[0,27]$ & -141.77 & -1.26 & -1.23 & 23.23 & 0.57 & 0.56 & -16.19 & -0.21 & -0.21 \\
\hline$[0,28]$ & -134.61 & -1.19 & -1.15 & -7.48 & -0.19 & -0.18 & -18.34 & -0.24 & -0.23 \\
\hline$[0,29]$ & -142.12 & -1.26 & -1.23 & 1.58 & 0.04 & 0.04 & -62.72 & -0.83 & -0.81 \\
\hline$[0,30]$ & -147.34 & -1.31 & -1.27 & 27.39 & 0.68 & 0.66 & 28.28 & 0.37 & 0.36 \\
\hline
\end{tabular}


Table A5. Case II: OLS—Cumulative abnormal change rate of Chinese tourist arrivals.

\begin{tabular}{|c|c|c|c|c|c|c|c|c|c|}
\hline \multirow{3}{*}{ Event Period $\left[\tau_{1}, \tau_{2}\right]$} & \multicolumn{3}{|c|}{ Group-Type } & \multicolumn{3}{|c|}{ Individual-Type } & \multicolumn{3}{|c|}{ Medical-Type } \\
\hline & \multirow{2}{*}{ CAR } & \multicolumn{2}{|c|}{ t-Value } & \multirow{2}{*}{ CAR } & \multicolumn{2}{|c|}{ t-Value } & \multirow{2}{*}{ CAR } & \multicolumn{2}{|c|}{ t-Value } \\
\hline & & TM & SRM & & TM & SRM & & TM & SRM \\
\hline$[-10,-10]$ & 9.27 & 0.33 & 0.33 & 13.21 & 0.31 & 0.31 & 55.70 & 0.61 & 0.60 \\
\hline$[-10,-9]$ & -8.31 & -0.30 & -0.29 & 8.25 & 0.20 & 0.19 & -1.36 & -0.01 & -0.01 \\
\hline$[-10,-8]$ & 5.94 & 0.21 & 0.21 & 24.61 & 0.58 & 0.56 & -19.03 & -0.21 & -0.20 \\
\hline$[-10,-7]$ & -4.03 & -0.15 & -0.14 & 23.11 & 0.55 & 0.52 & 49.90 & 0.55 & 0.52 \\
\hline$[-10,-6]$ & -45.58 & -1.64 & -1.60 & 3.64 & 0.09 & 0.08 & 68.84 & 0.75 & 0.73 \\
\hline$[-10,-5]$ & -13.37 & -0.48 & -0.47 & -3.39 & -0.08 & -0.08 & 37.01 & 0.41 & 0.40 \\
\hline$[-10,-4]$ & -17.77 & -0.64 & -0.63 & -2.93 & -0.07 & -0.07 & 70.98 & 0.78 & 0.76 \\
\hline$[-10,-3]$ & -6.93 & -0.25 & -0.25 & 9.78 & 0.23 & 0.23 & 18.99 & 0.21 & 0.20 \\
\hline$[-10,-2]$ & -31.69 & -1.14 & -1.11 & 9.55 & 0.23 & 0.22 & 33.19 & 0.36 & 0.35 \\
\hline$[-10,-1]$ & -12.91 & -0.47 & -0.46 & 4.84 & 0.11 & 0.11 & 0.24 & 0.00 & 0.00 \\
\hline$[-10,0]$ & 7.89 & 0.28 & 0.28 & 11.58 & 0.27 & 0.27 & 96.21 & 1.05 & 1.04 \\
\hline$[-10,1]$ & -31.06 & -1.12 & -1.10 & 10.14 & 0.24 & 0.23 & 68.48 & 0.75 & 0.73 \\
\hline$[-10,2]$ & -32.15 & -1.16 & -1.13 & -14.08 & -0.33 & -0.33 & 83.34 & 0.91 & 0.89 \\
\hline$[-10,3]$ & -39.89 & -1.44 & -1.41 & -7.76 & -0.18 & -0.18 & 87.41 & 0.96 & 0.94 \\
\hline$[-10,4]$ & -6.31 & -0.23 & -0.22 & 4.91 & 0.12 & 0.11 & 70.98 & 0.78 & 0.76 \\
\hline$[-10,5]$ & -20.15 & -0.73 & -0.71 & 14.34 & 0.34 & 0.33 & -38.17 & -0.42 & -0.41 \\
\hline$[-10,6]$ & -24.07 & -0.87 & -0.85 & 24.75 & 0.59 & 0.57 & 13.04 & 0.14 & 0.14 \\
\hline$[-10,7]$ & 3.94 & 0.14 & 0.14 & 6.93 & 0.16 & 0.16 & -23.09 & -0.25 & -0.25 \\
\hline$[-10,8]$ & -24.44 & -0.88 & -0.85 & 0.71 & 0.02 & 0.02 & 36.32 & 0.40 & 0.39 \\
\hline$[-10,9]$ & -10.19 & -0.37 & -0.36 & -14.26 & -0.34 & -0.33 & -49.92 & -0.55 & -0.53 \\
\hline$[-10,10]$ & -9.20 & -0.33 & -0.33 & -21.61 & -0.51 & -0.50 & -71.42 & -0.78 & -0.77 \\
\hline$[-10,11]$ & 0.84 & 0.03 & 0.03 & 13.20 & 0.31 & 0.30 & 71.94 & 0.79 & 0.77 \\
\hline$[-10,12]$ & -15.34 & -0.55 & -0.54 & -6.32 & -0.15 & -0.15 & 11.52 & 0.13 & 0.12 \\
\hline$[-10,13]$ & -2.99 & -0.11 & -0.11 & 13.75 & 0.33 & 0.32 & 97.96 & 1.07 & 1.05 \\
\hline$[-10,14]$ & 4.71 & 0.17 & 0.16 & 4.77 & 0.11 & 0.11 & 31.61 & 0.35 & 0.34 \\
\hline$[-10,15]$ & -29.35 & -1.06 & -1.03 & 6.56 & 0.16 & 0.15 & 106.55 & 1.17 & 1.14 \\
\hline$[-10,16]$ & -1.09 & -0.04 & -0.04 & -8.82 & -0.21 & -0.20 & 107.58 & 1.18 & 1.15 \\
\hline$[-10,17]$ & -8.37 & -0.30 & -0.30 & -10.22 & -0.24 & -0.24 & 28.71 & 0.31 & 0.31 \\
\hline$[-10,18]$ & -1.84 & -0.07 & -0.07 & 10.77 & 0.26 & 0.25 & -8.52 & -0.09 & -0.09 \\
\hline$[-10,19]$ & -6.10 & -0.22 & -0.21 & -1.86 & -0.04 & -0.04 & -31.73 & -0.35 & -0.34 \\
\hline$[-10,20]$ & -13.63 & -0.49 & -0.48 & 8.57 & 0.20 & 0.20 & -5.68 & -0.06 & -0.06 \\
\hline
\end{tabular}


Table A6. Case II: GARCH(1,1)—Cumulative abnormal change rate of Chinese tourist arrivals.

\begin{tabular}{|c|c|c|c|c|c|c|c|c|c|}
\hline \multirow{3}{*}{ Event Period $\left[\tau_{1}, \tau_{2}\right]$} & \multicolumn{3}{|c|}{ Group-Type } & \multicolumn{3}{|c|}{ Individual-Type } & \multicolumn{3}{|c|}{ Medical-Type } \\
\hline & \multirow{2}{*}{ CAR } & \multicolumn{2}{|c|}{ t-Value } & \multirow{2}{*}{ CAR } & \multicolumn{2}{|c|}{ t-Value } & \multirow{2}{*}{ CAR } & \multicolumn{2}{|c|}{ t-Value } \\
\hline & & TM & SRM & & TM & SRM & & TM & SRM \\
\hline$[-10,-10]$ & 7.18 & 0.10 & 0.09 & 15.05 & 0.23 & 0.22 & 54.85 & 0.57 & 0.56 \\
\hline$[-10,-9]$ & -11.39 & -0.15 & -0.15 & 14.63 & 0.22 & 0.21 & 0.88 & 0.01 & 0.01 \\
\hline$[-10,-8]$ & 1.16 & 0.02 & 0.01 & 33.80 & 0.51 & 0.49 & -16.22 & -0.17 & -0.16 \\
\hline$[-10,-7]$ & -10.63 & -0.14 & -0.14 & 34.81 & 0.52 & 0.50 & 52.84 & 0.55 & 0.52 \\
\hline$[-10,-6]$ & -56.08 & -0.75 & -0.73 & 12.68 & 0.19 & 0.19 & 64.35 & 0.67 & 0.65 \\
\hline$[-10,-5]$ & -27.90 & -0.37 & -0.37 & 2.70 & 0.04 & 0.04 & 24.68 & 0.26 & 0.25 \\
\hline$[-10,-4]$ & -33.95 & -0.46 & -0.45 & 6.08 & 0.09 & 0.09 & 59.37 & 0.62 & 0.60 \\
\hline$[-10,-3]$ & -25.76 & -0.35 & -0.34 & 19.26 & 0.29 & 0.28 & 4.53 & 0.05 & 0.05 \\
\hline$[-10,-2]$ & -51.80 & -0.70 & -0.68 & 22.85 & 0.34 & 0.33 & 20.77 & 0.22 & 0.21 \\
\hline$[-10,-1]$ & -36.09 & -0.48 & -0.48 & 17.56 & 0.26 & 0.26 & -16.56 & -0.17 & -0.17 \\
\hline$[-10,0]$ & -18.01 & -0.24 & -0.24 & 24.60 & 0.37 & 0.36 & 76.32 & 0.79 & 0.78 \\
\hline$[-10,1]$ & -58.56 & -0.79 & -0.77 & 26.20 & 0.39 & 0.39 & 49.50 & 0.51 & 0.50 \\
\hline$[-10,2]$ & -61.72 & -0.83 & -0.81 & 3.84 & 0.06 & 0.06 & 63.51 & 0.66 & 0.64 \\
\hline$[-10,3]$ & -72.27 & -0.97 & -0.95 & 10.25 & 0.15 & 0.15 & 64.18 & 0.67 & 0.65 \\
\hline$[-10,4]$ & -40.38 & -0.54 & -0.53 & 25.73 & 0.39 & 0.38 & 48.32 & 0.50 & 0.49 \\
\hline$[-10,5]$ & -57.24 & -0.77 & -0.75 & 34.69 & 0.52 & 0.51 & -65.06 & -0.68 & -0.66 \\
\hline$[-10,6]$ & -62.82 & -0.84 & -0.82 & 48.00 & 0.72 & 0.70 & -13.15 & -0.14 & -0.13 \\
\hline$[-10,7]$ & -37.12 & -0.50 & -0.49 & 31.45 & 0.47 & 0.46 & -50.95 & -0.53 & -0.52 \\
\hline$[-10,8]$ & -67.31 & -0.90 & -0.88 & 27.79 & 0.42 & 0.41 & 8.65 & 0.09 & 0.09 \\
\hline$[-10,9]$ & -55.76 & -0.75 & -0.73 & 13.16 & 0.20 & 0.19 & -80.63 & -0.84 & -0.82 \\
\hline$[-10,10]$ & -58.21 & -0.78 & -0.77 & 4.30 & 0.06 & 0.06 & -107.88 & -1.12 & -1.10 \\
\hline$[-10,11]$ & -49.28 & -0.66 & -0.64 & 43.35 & 0.65 & 0.63 & 38.15 & 0.40 & 0.39 \\
\hline$[-10,12]$ & -67.78 & -0.91 & -0.89 & 25.12 & 0.38 & 0.37 & -23.94 & -0.25 & -0.24 \\
\hline$[-10,13]$ & -58.35 & -0.78 & -0.77 & 44.96 & 0.68 & 0.66 & 58.63 & 0.61 & 0.60 \\
\hline$[-10,14]$ & -52.26 & -0.70 & -0.68 & 39.00 & 0.59 & 0.57 & -6.84 & -0.07 & -0.07 \\
\hline$[-10,15]$ & -88.82 & -1.19 & -1.16 & 41.60 & 0.62 & 0.61 & 65.75 & 0.68 & 0.66 \\
\hline$[-10,16]$ & -63.36 & -0.85 & -0.83 & 26.33 & 0.40 & 0.39 & 63.39 & 0.66 & 0.64 \\
\hline$[-10,17]$ & -74.02 & -0.99 & -0.98 & 23.57 & 0.35 & 0.35 & -21.01 & -0.22 & -0.21 \\
\hline$[-10,18]$ & -69.29 & -0.93 & -0.91 & 47.11 & 0.71 & 0.69 & -58.05 & -0.60 & -0.59 \\
\hline$[-10,19]$ & -74.96 & -1.01 & -0.98 & 38.00 & 0.57 & 0.56 & -79.65 & -0.83 & -0.81 \\
\hline$[-10,20]$ & -84.46 & -1.13 & -1.10 & 50.54 & 0.76 & 0.74 & -54.07 & -0.56 & -0.54 \\
\hline
\end{tabular}


Table A7. Case II: GJR(1,1)—Cumulative abnormal change rate of Chinese tourist arrivals.

\begin{tabular}{|c|c|c|c|c|c|c|c|c|c|}
\hline \multirow{3}{*}{ Event Period $\left[\tau_{1}, \tau_{2}\right]$} & \multicolumn{3}{|c|}{ Group-Type } & \multicolumn{3}{|c|}{ Individual-Type } & \multicolumn{3}{|c|}{ Medical-Type } \\
\hline & \multirow{2}{*}{ CAR } & \multicolumn{2}{|c|}{ t-Value } & \multirow{2}{*}{ CAR } & \multicolumn{2}{|c|}{ t-Value } & \multirow{2}{*}{ CAR } & \multicolumn{2}{|c|}{ t-Value } \\
\hline & & TM & SRM & & TM & SRM & & TM & SRM \\
\hline$[-10,-10]$ & 10.33 & 0.30 & 0.29 & 13.35 & 0.31 & 0.30 & 66.30 & 0.23 & 0.23 \\
\hline$[-10,-9]$ & -4.86 & -0.14 & -0.13 & 8.74 & 0.20 & 0.20 & 28.97 & 0.10 & 0.10 \\
\hline$[-10,-8]$ & 10.93 & 0.31 & 0.30 & 25.31 & 0.59 & 0.56 & 25.18 & 0.09 & 0.09 \\
\hline$[-10,-7]$ & 2.35 & 0.07 & 0.06 & 24.01 & 0.56 & 0.53 & 106.97 & 0.38 & 0.36 \\
\hline$[-10,-6]$ & -40.33 & -1.15 & -1.12 & 4.31 & 0.10 & 0.10 & 121.23 & 0.43 & 0.42 \\
\hline$[-10,-5]$ & -9.40 & -0.27 & -0.26 & -2.99 & -0.07 & -0.07 & 83.80 & 0.30 & 0.29 \\
\hline$[-10,-4]$ & -12.21 & -0.35 & -0.34 & -2.31 & -0.05 & -0.05 & 132.01 & 0.47 & 0.46 \\
\hline$[-10,-3]$ & -0.97 & -0.03 & -0.03 & 10.42 & 0.24 & 0.24 & 85.97 & 0.30 & 0.30 \\
\hline$[-10,-2]$ & -23.70 & -0.68 & -0.66 & 10.50 & 0.24 & 0.24 & 117.45 & 0.41 & 0.40 \\
\hline$[-10,-1]$ & -5.04 & -0.14 & -0.14 & 5.72 & 0.13 & 0.13 & 86.91 & 0.31 & 0.30 \\
\hline$[-10,0]$ & 16.07 & 0.46 & 0.45 & 12.47 & 0.29 & 0.28 & 188.27 & 0.66 & 0.65 \\
\hline$[-10,1]$ & -21.22 & -0.61 & -0.59 & 11.26 & 0.26 & 0.25 & 175.21 & 0.62 & 0.60 \\
\hline$[-10,2]$ & -21.24 & -0.61 & -0.59 & -12.82 & -0.30 & -0.29 & 200.69 & 0.71 & 0.69 \\
\hline$[-10,3]$ & -28.77 & -0.82 & -0.81 & -6.50 & -0.15 & -0.15 & 209.42 & 0.74 & 0.72 \\
\hline$[-10,4]$ & 6.35 & 0.18 & 0.18 & 6.37 & 0.15 & 0.14 & 206.88 & 0.73 & 0.71 \\
\hline$[-10,5]$ & -7.56 & -0.22 & -0.21 & 15.75 & 0.36 & 0.36 & 100.49 & 0.35 & 0.35 \\
\hline$[-10,6]$ & -9.89 & -0.28 & -0.28 & 26.38 & 0.61 & 0.59 & 165.88 & 0.59 & 0.57 \\
\hline$[-10,7]$ & 18.91 & 0.54 & 0.53 & 8.65 & 0.20 & 0.19 & 138.43 & 0.49 & 0.48 \\
\hline$[-10,8]$ & -8.06 & -0.23 & -0.22 & 2.63 & 0.06 & 0.06 & 210.85 & 0.74 & 0.72 \\
\hline$[-10,9]$ & 6.52 & 0.19 & 0.18 & -12.33 & -0.29 & -0.28 & 130.13 & 0.46 & 0.45 \\
\hline$[-10,10]$ & 6.94 & 0.20 & 0.19 & -19.83 & -0.46 & -0.45 & 107.86 & 0.38 & 0.37 \\
\hline$[-10,11]$ & 19.22 & 0.55 & 0.53 & 15.32 & 0.35 & 0.34 & 269.96 & 0.95 & 0.93 \\
\hline$[-10,12]$ & 3.83 & 0.11 & 0.11 & -4.11 & -0.09 & -0.09 & 218.24 & 0.77 & 0.75 \\
\hline$[-10,13]$ & 16.24 & 0.46 & 0.45 & 15.92 & 0.37 & 0.36 & 308.27 & 1.09 & 1.06 \\
\hline$[-10,14]$ & 25.58 & 0.73 & 0.71 & 7.17 & 0.17 & 0.16 & 256.52 & 0.90 & 0.88 \\
\hline$[-10,15]$ & -7.92 & -0.23 & -0.22 & 9.01 & 0.21 & 0.20 & 338.58 & 1.19 & 1.16 \\
\hline$[-10,16]$ & 20.56 & 0.59 & 0.57 & -6.37 & -0.15 & -0.14 & 344.31 & 1.21 & 1.19 \\
\hline$[-10,17]$ & 12.78 & 0.37 & 0.36 & -7.90 & -0.18 & -0.18 & 265.18 & 0.94 & 0.92 \\
\hline$[-10,18]$ & 20.72 & 0.59 & 0.58 & 13.28 & 0.31 & 0.30 & 240.96 & 0.85 & 0.83 \\
\hline$[-10,19]$ & 18.35 & 0.52 & 0.51 & 0.93 & 0.02 & 0.02 & 234.04 & 0.83 & 0.80 \\
\hline$[-10,20]$ & 12.02 & 0.34 & 0.33 & 11.52 & 0.27 & 0.26 & 271.57 & 0.96 & 0.93 \\
\hline
\end{tabular}


Table A8. Case II: EGARCH(1,1)—Cumulative abnormal change rate of Chinese tourist arrivals.

\begin{tabular}{|c|c|c|c|c|c|c|c|c|c|}
\hline \multirow{3}{*}{ Event Period $\left[\tau_{1}, \tau_{2}\right]$} & \multicolumn{3}{|c|}{ Group-Type } & \multicolumn{3}{|c|}{ Individual-Type } & \multicolumn{3}{|c|}{ Medical-Type } \\
\hline & \multirow{2}{*}{ CAR } & \multicolumn{2}{|c|}{ t-Value } & \multirow{2}{*}{ CAR } & \multicolumn{2}{|c|}{ t-Value } & \multirow{2}{*}{ CAR } & \multicolumn{2}{|c|}{ t-Value } \\
\hline & & TM & SRM & & TM & SRM & & TM & SRM \\
\hline$[-10,-10]$ & 8.66 & 0.23 & 0.23 & 12.69 & 0.32 & 0.32 & 61.71 & 0.30 & 0.29 \\
\hline$[-10,-9]$ & -8.69 & -0.23 & -0.23 & 7.15 & 0.18 & 0.18 & 10.45 & 0.05 & 0.05 \\
\hline$[-10,-8]$ & 5.25 & 0.14 & 0.14 & 22.97 & 0.58 & 0.56 & -1.29 & -0.01 & -0.01 \\
\hline$[-10,-7]$ & -5.13 & -0.14 & -0.13 & 20.95 & 0.53 & 0.51 & 73.61 & 0.35 & 0.34 \\
\hline$[-10,-6]$ & -48.66 & -1.31 & -1.28 & 1.06 & 0.03 & 0.03 & 98.91 & 0.47 & 0.46 \\
\hline$[-10,-5]$ & -18.54 & -0.50 & -0.49 & -6.39 & -0.16 & -0.16 & 73.45 & 0.35 & 0.35 \\
\hline$[-10,-4]$ & -23.21 & -0.63 & -0.61 & -6.47 & -0.16 & -0.16 & 113.35 & 0.54 & 0.53 \\
\hline$[-10,-3]$ & -13.40 & -0.36 & -0.35 & 5.76 & 0.15 & 0.14 & 67.48 & 0.32 & 0.32 \\
\hline$[-10,-2]$ & -38.16 & -1.03 & -1.00 & 4.97 & 0.13 & 0.12 & 87.54 & 0.42 & 0.41 \\
\hline$[-10,-1]$ & -20.73 & -0.56 & -0.55 & -0.20 & -0.01 & -0.01 & 60.79 & 0.29 & 0.29 \\
\hline$[-10,0]$ & -1.02 & -0.03 & -0.03 & 6.05 & 0.15 & 0.15 & 162.89 & 0.78 & 0.77 \\
\hline$[-10,1]$ & -40.20 & -1.08 & -1.06 & 4.06 & 0.10 & 0.10 & 141.08 & 0.68 & 0.66 \\
\hline$[-10,2]$ & -41.89 & -1.13 & -1.10 & -20.67 & -0.52 & -0.51 & 161.94 & 0.78 & 0.76 \\
\hline$[-10,3]$ & -50.78 & -1.37 & -1.34 & -14.82 & -0.38 & -0.37 & 172.16 & 0.83 & 0.81 \\
\hline$[-10,4]$ & -17.50 & -0.47 & -0.46 & -2.70 & -0.07 & -0.07 & 161.66 & 0.77 & 0.76 \\
\hline$[-10,5]$ & -32.67 & -0.88 & -0.86 & 6.27 & 0.16 & 0.16 & 58.70 & 0.28 & 0.28 \\
\hline$[-10,6]$ & -36.87 & -0.99 & -0.97 & 16.14 & 0.41 & 0.40 & 115.84 & 0.56 & 0.54 \\
\hline$[-10,7]$ & -9.63 & -0.26 & -0.25 & -2.19 & -0.06 & -0.05 & 85.77 & 0.41 & 0.40 \\
\hline$[-10,8]$ & -38.40 & -1.03 & -1.00 & -8.94 & -0.23 & -0.22 & 151.14 & 0.72 & 0.70 \\
\hline$[-10,9]$ & -25.23 & -0.68 & -0.66 & -24.40 & -0.62 & -0.60 & 71.02 & 0.34 & 0.33 \\
\hline$[-10,10]$ & -25.87 & -0.70 & -0.68 & -32.19 & -0.82 & -0.80 & 55.79 & 0.27 & 0.26 \\
\hline$[-10,11]$ & -15.70 & -0.42 & -0.41 & 2.05 & 0.05 & 0.05 & 204.98 & 0.98 & 0.96 \\
\hline$[-10,12]$ & -32.66 & -0.88 & -0.86 & -17.97 & -0.46 & -0.44 & 150.61 & 0.72 & 0.70 \\
\hline$[-10,13]$ & -21.55 & -0.58 & -0.57 & 1.62 & 0.04 & 0.04 & 243.22 & 1.17 & 1.14 \\
\hline$[-10,14]$ & -14.10 & -0.38 & -0.37 & -7.90 & -0.20 & -0.19 & 182.79 & 0.88 & 0.85 \\
\hline$[-10,15]$ & -49.08 & -1.32 & -1.29 & -6.60 & -0.17 & -0.16 & 263.82 & 1.26 & 1.23 \\
\hline$[-10,16]$ & -21.96 & -0.59 & -0.58 & -22.46 & -0.57 & -0.56 & 270.99 & 1.30 & 1.27 \\
\hline$[-10,17]$ & -30.83 & -0.83 & -0.82 & -24.31 & -0.62 & -0.61 & 198.39 & 0.95 & 0.94 \\
\hline$[-10,18]$ & -24.69 & -0.66 & -0.65 & -3.85 & -0.10 & -0.10 & 167.11 & 0.80 & 0.79 \\
\hline$[-10,19]$ & -29.04 & -0.78 & -0.76 & -17.04 & -0.43 & -0.42 & 149.78 & 0.72 & 0.70 \\
\hline$[-10,20]$ & -37.09 & -1.00 & -0.97 & -7.12 & -0.18 & -0.18 & 181.82 & 0.87 & 0.85 \\
\hline
\end{tabular}


Table A9. Case III: OLS-Cumulative abnormal change rate of Chinese tourist arrivals.

\begin{tabular}{|c|c|c|c|c|c|c|c|c|c|}
\hline \multirow{3}{*}{ Event Period $\left[\tau_{1}, \tau_{2}\right]$} & \multicolumn{3}{|c|}{ Group-Type } & \multicolumn{3}{|c|}{ Individual-Type } & \multicolumn{3}{|c|}{ Medical-Type } \\
\hline & \multirow{2}{*}{ CAR } & \multicolumn{2}{|c|}{ t-Value } & \multirow{2}{*}{ CAR } & \multicolumn{2}{|c|}{ t-Value } & \multirow{2}{*}{ CAR } & \multicolumn{2}{|c|}{ t-Value } \\
\hline & & TM & SRM & & TM & SRM & & TM & SRM \\
\hline$[-10,-10]$ & 5.16 & 0.19 & 0.19 & 2.09 & 0.05 & 0.05 & 160.17 & 1.79 & 1.75 \\
\hline$[-10,-9]$ & -30.70 & -1.14 & -1.12 & 8.41 & 0.20 & 0.20 & 190.49 & 2.13 & 2.09 \\
\hline$[-10,-8]$ & -28.43 & -1.06 & -1.04 & 16.27 & 0.39 & 0.38 & 78.31 & 0.87 & 0.86 \\
\hline$[-10,-7]$ & -40.46 & -1.51 & -1.47 & 6.80 & 0.16 & 0.16 & 61.67 & 0.69 & 0.67 \\
\hline$[-10,-6]$ & -61.14 & -2.28 & -2.24 & 6.58 & 0.16 & 0.16 & 102.99 & 1.15 & 1.13 \\
\hline$[-10,-5]$ & -35.51 & -1.32 & -1.30 & 1.40 & 0.03 & 0.03 & 53.78 & 0.60 & 0.59 \\
\hline$[-10,-4]$ & -27.64 & -1.03 & -1.01 & 4.72 & 0.11 & 0.11 & 77.14 & 0.86 & 0.85 \\
\hline$[-10,-3]$ & -25.18 & -0.94 & -0.91 & -10.21 & -0.25 & -0.24 & 92.73 & 1.04 & 1.01 \\
\hline$[-10,-2]$ & -53.66 & -2.00 & -1.95 & 9.42 & 0.23 & 0.22 & 69.13 & 0.77 & 0.75 \\
\hline$[-10,-1]$ & -45.53 & -1.70 & -1.65 & 31.06 & 0.75 & 0.73 & 26.10 & 0.29 & 0.28 \\
\hline$[-10,0]$ & -35.49 & -1.32 & -1.29 & 26.53 & 0.64 & 0.62 & 63.90 & 0.71 & 0.70 \\
\hline$[-10,1]$ & -46.41 & -1.73 & -1.69 & -10.25 & -0.25 & -0.24 & 94.44 & 1.05 & 1.03 \\
\hline$[-10,2]$ & -40.34 & -1.50 & -1.47 & 3.59 & 0.09 & 0.08 & 186.93 & 2.09 & 2.04 \\
\hline$[-10,3]$ & -36.82 & -1.37 & -1.35 & 2.18 & 0.05 & 0.05 & 128.85 & 1.44 & 1.41 \\
\hline$[-10,4]$ & -12.10 & -0.45 & -0.44 & 17.94 & 0.43 & 0.42 & 138.84 & 1.55 & 1.52 \\
\hline$[-10,5]$ & -45.64 & -1.70 & -1.65 & -7.53 & -0.18 & -0.18 & 106.35 & 1.19 & 1.15 \\
\hline$[-10,6]$ & -42.65 & -1.59 & -1.55 & 15.72 & 0.38 & 0.37 & 128.75 & 1.44 & 1.40 \\
\hline$[-10,7]$ & -26.97 & -1.01 & -0.98 & 28.67 & 0.69 & 0.67 & 69.94 & 0.78 & 0.76 \\
\hline$[-10,8]$ & -23.51 & -0.88 & -0.85 & 13.84 & 0.33 & 0.32 & 144.21 & 1.61 & 1.57 \\
\hline$[-10,9]$ & -26.28 & -0.98 & -0.96 & 4.25 & 0.10 & 0.10 & 131.81 & 1.47 & 1.44 \\
\hline$[-10,10]$ & -27.82 & -1.04 & -1.01 & 7.61 & 0.18 & 0.18 & 135.79 & 1.52 & 1.48 \\
\hline$[-10,11]$ & -0.64 & -0.02 & -0.02 & 22.39 & 0.54 & 0.52 & 141.20 & 1.58 & 1.54 \\
\hline$[-10,12]$ & -50.16 & -1.87 & -1.81 & -4.61 & -0.11 & -0.11 & 80.84 & 0.90 & 0.87 \\
\hline$[-10,13]$ & -53.98 & -2.01 & -1.93 & 0.73 & 0.02 & 0.02 & 79.65 & 0.89 & 0.85 \\
\hline$[-10,14]$ & -43.62 & -1.63 & -1.55 & 0.96 & 0.02 & 0.02 & 89.81 & 1.00 & 0.96 \\
\hline$[-10,15]$ & -44.63 & -1.66 & -1.62 & 6.23 & 0.15 & 0.15 & 149.34 & 1.67 & 1.62 \\
\hline$[-10,16]$ & -12.59 & -0.47 & -0.46 & 18.62 & 0.45 & 0.44 & 78.99 & 0.88 & 0.86 \\
\hline$[-10,17]$ & -24.56 & -0.92 & -0.90 & 8.40 & 0.20 & 0.20 & 124.89 & 1.39 & 1.37 \\
\hline$[-10,18]$ & -11.21 & -0.42 & -0.41 & 2.78 & 0.07 & 0.07 & 78.18 & 0.87 & 0.85 \\
\hline$[-10,19]$ & -39.86 & -1.49 & -1.44 & 2.22 & 0.05 & 0.05 & 90.85 & 1.01 & 0.99 \\
\hline$[-10,20]$ & -43.98 & -1.64 & -1.58 & 4.30 & 0.10 & 0.10 & 143.90 & 1.61 & 1.55 \\
\hline
\end{tabular}


Table A10. Case III: GARCH(1,1)—Cumulative abnormal change rate of Chinese tourist arrivals.

\begin{tabular}{|c|c|c|c|c|c|c|c|c|c|}
\hline \multirow{3}{*}{ Event Period $\left[\tau_{1}, \tau_{2}\right]$} & \multicolumn{3}{|c|}{ Group-Type } & \multicolumn{3}{|c|}{ Individual-Type } & \multicolumn{3}{|c|}{ Medical-Type } \\
\hline & \multirow{2}{*}{ CAR } & \multicolumn{2}{|c|}{ t-Value } & \multirow{2}{*}{ CAR } & \multicolumn{2}{|c|}{ t-Value } & \multirow{2}{*}{ CAR } & \multicolumn{2}{|c|}{ t-Value } \\
\hline & & TM & SRM & & TM & SRM & & TM & SRM \\
\hline$[-10,-10]$ & 5.33 & 0.10 & 0.10 & 2.16 & 0.05 & 0.05 & 149.85 & 0.48 & 0.47 \\
\hline$[-10,-9]$ & -32.51 & -0.63 & -0.62 & 8.28 & 0.20 & 0.20 & 170.02 & 0.55 & 0.54 \\
\hline$[-10,-8]$ & -30.78 & -0.60 & -0.58 & 16.13 & 0.39 & 0.38 & 47.57 & 0.15 & 0.15 \\
\hline$[-10,-7]$ & -43.16 & -0.84 & -0.82 & 6.66 & 0.16 & 0.16 & 20.65 & 0.07 & 0.06 \\
\hline$[-10,-6]$ & -66.74 & -1.29 & -1.27 & 6.13 & 0.15 & 0.15 & 51.91 & 0.17 & 0.16 \\
\hline$[-10,-5]$ & -42.96 & -0.83 & -0.82 & 0.78 & 0.02 & 0.02 & -7.45 & -0.02 & -0.02 \\
\hline$[-10,-4]$ & -36.58 & -0.71 & -0.70 & 3.96 & 0.10 & 0.09 & 5.73 & 0.02 & 0.02 \\
\hline$[-10,-3]$ & -32.74 & -0.63 & -0.62 & -10.75 & -0.26 & -0.25 & 10.88 & 0.04 & 0.03 \\
\hline$[-10,-2]$ & -63.10 & -1.22 & -1.19 & 8.69 & 0.21 & 0.21 & -22.87 & -0.07 & -0.07 \\
\hline$[-10,-1]$ & -55.94 & -1.08 & -1.05 & 30.26 & 0.73 & 0.71 & -76.13 & -0.25 & -0.24 \\
\hline$[-10,0]$ & -48.00 & -0.93 & -0.91 & 25.52 & 0.62 & 0.60 & -48.45 & -0.16 & -0.15 \\
\hline$[-10,1]$ & -59.88 & -1.16 & -1.13 & -11.33 & -0.27 & -0.27 & -28.15 & -0.09 & -0.09 \\
\hline$[-10,2]$ & -55.45 & -1.08 & -1.05 & 2.36 & 0.06 & 0.06 & 54.18 & 0.17 & 0.17 \\
\hline$[-10,3]$ & -53.77 & -1.04 & -1.02 & 0.78 & 0.02 & 0.02 & -14.06 & -0.05 & -0.04 \\
\hline$[-10,4]$ & -30.76 & -0.60 & -0.59 & 16.37 & 0.40 & 0.39 & -14.23 & -0.05 & -0.05 \\
\hline$[-10,5]$ & -63.64 & -1.23 & -1.20 & -8.97 & -0.22 & -0.21 & -57.09 & -0.18 & -0.18 \\
\hline$[-10,6]$ & -62.77 & -1.22 & -1.19 & 14.07 & 0.34 & 0.33 & -44.82 & -0.14 & -0.14 \\
\hline$[-10,7]$ & -48.16 & -0.93 & -0.91 & 26.93 & 0.65 & 0.64 & -113.85 & -0.37 & -0.36 \\
\hline$[-10,8]$ & -45.88 & -0.89 & -0.87 & 12.01 & 0.29 & 0.28 & -49.79 & -0.16 & -0.16 \\
\hline$[-10,9]$ & -51.23 & -0.99 & -0.97 & 2.15 & 0.05 & 0.05 & -72.27 & -0.23 & -0.23 \\
\hline$[-10,10]$ & -53.40 & -1.04 & -1.01 & 5.48 & 0.13 & 0.13 & -78.55 & -0.25 & -0.25 \\
\hline$[-10,11]$ & -27.11 & -0.53 & -0.51 & 20.20 & 0.49 & 0.48 & -83.38 & -0.27 & -0.26 \\
\hline$[-10,12]$ & -77.08 & -1.49 & -1.45 & -6.80 & -0.16 & -0.16 & -154.02 & -0.50 & -0.48 \\
\hline$[-10,13]$ & -81.48 & -1.58 & -1.52 & -1.49 & -0.04 & -0.03 & -165.47 & -0.53 & -0.51 \\
\hline$[-10,14]$ & -71.64 & -1.39 & -1.32 & -1.27 & -0.03 & -0.03 & -165.58 & -0.53 & -0.51 \\
\hline$[-10,15]$ & -76.29 & -1.48 & -1.44 & 3.60 & 0.09 & 0.08 & -116.05 & -0.37 & -0.36 \\
\hline$[-10,16]$ & -46.62 & -0.90 & -0.89 & 15.75 & 0.38 & 0.37 & -196.50 & -0.63 & -0.62 \\
\hline$[-10,17]$ & -59.84 & -1.16 & -1.14 & 5.43 & 0.13 & 0.13 & -160.80 & -0.52 & -0.51 \\
\hline$[-10,18]$ & -47.05 & -0.91 & -0.89 & -0.22 & -0.01 & -0.01 & -217.78 & -0.70 & -0.69 \\
\hline$[-10,19]$ & -76.59 & -1.48 & -1.44 & -0.84 & -0.02 & -0.02 & -215.34 & -0.70 & -0.68 \\
\hline$[-10,20]$ & -81.07 & -1.57 & -1.51 & 1.25 & 0.03 & 0.03 & -172.57 & -0.56 & -0.54 \\
\hline
\end{tabular}


Table A11. Case III: GJR(1,1)—Cumulative abnormal change rate of Chinese tourist arrivals.

\begin{tabular}{|c|c|c|c|c|c|c|c|c|c|}
\hline \multirow{3}{*}{ Event Period $\left[\tau_{1}, \tau_{2}\right]$} & \multicolumn{3}{|c|}{ Group-Type } & \multicolumn{3}{|c|}{ Individual-Type } & \multicolumn{3}{|c|}{ Medical-Type } \\
\hline & \multirow{2}{*}{ CAR } & \multicolumn{2}{|c|}{ t-Value } & \multirow{2}{*}{ CAR } & \multicolumn{2}{|c|}{ t-Value } & \multirow{2}{*}{ CAR } & \multicolumn{2}{|c|}{ t-Value } \\
\hline & & TM & SRM & & TM & SRM & & TM & SRM \\
\hline$[-10,-10]$ & 7.11 & 0.24 & 0.23 & -0.34 & -0.01 & -0.01 & 157.94 & 1.49 & 1.46 \\
\hline$[-10,-9]$ & -28.60 & -0.96 & -0.95 & 4.67 & 0.08 & 0.08 & 186.43 & 1.75 & 1.72 \\
\hline$[-10,-8]$ & -24.97 & -0.84 & -0.82 & 10.46 & 0.17 & 0.17 & 72.15 & 0.68 & 0.67 \\
\hline$[-10,-7]$ & -35.49 & -1.19 & -1.16 & -1.17 & -0.02 & -0.02 & 53.38 & 0.50 & 0.49 \\
\hline$[-10,-6]$ & -56.78 & -1.91 & -1.88 & -2.23 & -0.04 & -0.04 & 93.04 & 0.88 & 0.86 \\
\hline$[-10,-5]$ & -30.89 & -1.04 & -1.02 & -8.79 & -0.15 & -0.14 & 41.98 & 0.39 & 0.39 \\
\hline$[-10,-4]$ & -22.45 & -0.76 & -0.74 & -7.04 & -0.12 & -0.11 & 63.42 & 0.60 & 0.59 \\
\hline$[-10,-3]$ & -17.04 & -0.57 & -0.56 & -25.03 & -0.42 & -0.40 & 76.55 & 0.72 & 0.70 \\
\hline$[-10,-2]$ & -45.28 & -1.52 & -1.49 & -6.77 & -0.11 & -0.11 & 51.10 & 0.48 & 0.47 \\
\hline$[-10,-1]$ & -36.15 & -1.22 & -1.18 & 13.03 & 0.22 & 0.21 & 6.05 & 0.06 & 0.06 \\
\hline$[-10,0]$ & -26.06 & -0.88 & -0.86 & 7.25 & 0.12 & 0.12 & 42.05 & 0.40 & 0.39 \\
\hline$[-10,1]$ & -35.97 & -1.21 & -1.18 & -31.37 & -0.52 & -0.51 & 70.57 & 0.66 & 0.65 \\
\hline$[-10,2]$ & -29.46 & -0.99 & -0.97 & -19.02 & -0.32 & -0.31 & 161.17 & 1.52 & 1.48 \\
\hline$[-10,3]$ & -25.67 & -0.86 & -0.85 & -21.82 & -0.36 & -0.35 & 101.23 & 0.95 & 0.93 \\
\hline$[-10,4]$ & -0.57 & -0.02 & -0.02 & -7.51 & -0.12 & -0.12 & 109.35 & 1.03 & 1.01 \\
\hline$[-10,5]$ & -31.75 & -1.07 & -1.04 & -35.67 & -0.59 & -0.57 & 74.53 & 0.70 & 0.68 \\
\hline$[-10,6]$ & -28.73 & -0.97 & -0.94 & -13.65 & -0.23 & -0.22 & 95.13 & 0.90 & 0.87 \\
\hline$[-10,7]$ & -12.13 & -0.41 & -0.40 & -2.50 & -0.04 & -0.04 & 34.32 & 0.32 & 0.31 \\
\hline$[-10,8]$ & -7.85 & -0.26 & -0.26 & -19.06 & -0.32 & -0.31 & 106.61 & 1.00 & 0.98 \\
\hline$[-10,9]$ & -10.96 & -0.37 & -0.36 & -29.65 & -0.49 & -0.48 & 92.50 & 0.87 & 0.85 \\
\hline$[-10,10]$ & -11.22 & -0.38 & -0.37 & -28.31 & -0.47 & -0.46 & 94.40 & 0.89 & 0.87 \\
\hline$[-10,11]$ & 17.03 & 0.57 & 0.56 & -15.41 & -0.26 & -0.25 & 97.77 & 0.92 & 0.90 \\
\hline$[-10,12]$ & -31.07 & -1.05 & -1.01 & -44.51 & -0.74 & -0.71 & 35.29 & 0.33 & 0.32 \\
\hline$[-10,13]$ & -33.57 & -1.13 & -1.09 & -41.21 & -0.68 & -0.66 & 32.02 & 0.30 & 0.29 \\
\hline$[-10,14]$ & -21.83 & -0.73 & -0.70 & -43.06 & -0.71 & -0.68 & 40.07 & 0.38 & 0.36 \\
\hline$[-10,15]$ & -24.07 & -0.81 & -0.79 & -38.25 & -0.63 & -0.62 & 98.08 & 0.92 & 0.90 \\
\hline$[-10,16]$ & 7.80 & 0.26 & 0.26 & -26.96 & -0.45 & -0.44 & 25.99 & 0.24 & 0.24 \\
\hline$[-10,17]$ & -3.40 & -0.11 & -0.11 & -38.87 & -0.65 & -0.63 & 69.92 & 0.66 & 0.64 \\
\hline$[-10,18]$ & 11.29 & 0.38 & 0.37 & -46.55 & -0.77 & -0.75 & 21.11 & 0.20 & 0.19 \\
\hline$[-10,19]$ & -16.30 & -0.55 & -0.53 & -48.99 & -0.81 & -0.79 & 31.75 & 0.30 & 0.29 \\
\hline$[-10,20]$ & -18.91 & -0.64 & -0.61 & -49.06 & -0.81 & -0.78 & 82.67 & 0.78 & 0.75 \\
\hline
\end{tabular}


Table A12. Case III: EGARCH(1,1)—Cumulative abnormal change rate of Chinese tourist arrivals.

\begin{tabular}{|c|c|c|c|c|c|c|c|c|c|}
\hline \multirow{3}{*}{ Event Period $\left[\tau_{1}, \tau_{2}\right]$} & \multicolumn{3}{|c|}{ Group-Type } & \multicolumn{3}{|c|}{ Individual-Type } & \multicolumn{3}{|c|}{ Medical-Type } \\
\hline & \multirow{2}{*}{ CAR } & \multicolumn{2}{|c|}{ t-Value } & \multirow{2}{*}{ CAR } & \multicolumn{2}{|c|}{ t-Value } & \multirow{2}{*}{ CAR } & \multicolumn{2}{|c|}{ t-Value } \\
\hline & & TM & SRM & & TM & SRM & & TM & SRM \\
\hline$[-10,-10]$ & 8.83 & 0.28 & 0.28 & 0.79 & 0.02 & 0.02 & 160.50 & 1.50 & 1.47 \\
\hline$[-10,-9]$ & -29.20 & -0.94 & -0.92 & 5.95 & 0.12 & 0.11 & 193.68 & 1.81 & 1.78 \\
\hline$[-10,-8]$ & -25.17 & -0.81 & -0.79 & 12.55 & 0.25 & 0.24 & 82.66 & 0.77 & 0.76 \\
\hline$[-10,-7]$ & -34.93 & -1.12 & -1.10 & 1.81 & 0.04 & 0.03 & 66.96 & 0.63 & 0.61 \\
\hline$[-10,-6]$ & -60.25 & -1.94 & -1.90 & 0.49 & 0.01 & 0.01 & 112.23 & 1.05 & 1.03 \\
\hline$[-10,-5]$ & -36.43 & -1.17 & -1.15 & -5.85 & -0.11 & -0.11 & 65.74 & 0.61 & 0.60 \\
\hline$[-10,-4]$ & -29.38 & -0.95 & -0.93 & -3.73 & -0.07 & -0.07 & 91.39 & 0.85 & 0.84 \\
\hline$[-10,-3]$ & -19.98 & -0.64 & -0.62 & -20.04 & -0.39 & -0.38 & 105.87 & 0.99 & 0.96 \\
\hline$[-10,-2]$ & -50.35 & -1.62 & -1.58 & -1.58 & -0.03 & -0.03 & 85.02 & 0.80 & 0.78 \\
\hline$[-10,-1]$ & -41.63 & -1.34 & -1.30 & 18.83 & 0.37 & 0.36 & 43.66 & 0.41 & 0.40 \\
\hline$[-10,0]$ & -34.07 & -1.10 & -1.07 & 13.15 & 0.26 & 0.25 & 84.48 & 0.79 & 0.77 \\
\hline$[-10,1]$ & -44.36 & -1.43 & -1.39 & -24.85 & -0.49 & -0.47 & 116.67 & 1.09 & 1.06 \\
\hline$[-10,2]$ & -39.54 & -1.27 & -1.24 & -12.20 & -0.24 & -0.23 & 211.63 & 1.98 & 1.93 \\
\hline$[-10,3]$ & -37.78 & -1.22 & -1.19 & -14.77 & -0.29 & -0.28 & 156.24 & 1.46 & 1.43 \\
\hline$[-10,4]$ & -14.50 & -0.47 & -0.46 & -0.19 & 0.00 & 0.00 & 168.79 & 1.58 & 1.55 \\
\hline$[-10,5]$ & -43.05 & -1.39 & -1.34 & -27.00 & -0.53 & -0.51 & 136.05 & 1.27 & 1.23 \\
\hline$[-10,6]$ & -42.59 & -1.37 & -1.34 & -4.90 & -0.10 & -0.09 & 161.48 & 1.51 & 1.47 \\
\hline$[-10,7]$ & -26.58 & -0.86 & -0.83 & 6.83 & 0.13 & 0.13 & 104.45 & 0.98 & 0.95 \\
\hline$[-10,8]$ & -23.11 & -0.74 & -0.72 & -9.21 & -0.18 & -0.18 & 180.65 & 1.69 & 1.64 \\
\hline$[-10,9]$ & -29.67 & -0.96 & -0.94 & -19.92 & -0.39 & -0.38 & 171.83 & 1.61 & 1.57 \\
\hline$[-10,10]$ & -29.69 & -0.96 & -0.93 & -17.81 & -0.35 & -0.34 & 177.08 & 1.66 & 1.62 \\
\hline$[-10,11]$ & -1.70 & -0.05 & -0.05 & -4.26 & -0.08 & -0.08 & 184.05 & 1.72 & 1.68 \\
\hline$[-10,12]$ & -49.26 & -1.59 & -1.53 & -32.52 & -0.64 & -0.61 & 124.76 & 1.17 & 1.13 \\
\hline$[-10,13]$ & -51.44 & -1.66 & -1.59 & -28.44 & -0.56 & -0.53 & 124.78 & 1.17 & 1.12 \\
\hline$[-10,14]$ & -39.25 & -1.26 & -1.20 & -29.47 & -0.58 & -0.55 & 136.07 & 1.27 & 1.21 \\
\hline$[-10,15]$ & -46.92 & -1.51 & -1.47 & -25.25 & -0.49 & -0.48 & 200.43 & 1.87 & 1.82 \\
\hline$[-10,16]$ & -18.11 & -0.58 & -0.57 & -13.99 & -0.27 & -0.27 & 133.43 & 1.25 & 1.22 \\
\hline$[-10,17]$ & -30.24 & -0.97 & -0.95 & -25.41 & -0.50 & -0.49 & 181.33 & 1.70 & 1.66 \\
\hline$[-10,18]$ & -15.20 & -0.49 & -0.48 & -32.29 & -0.63 & -0.61 & 135.80 & 1.27 & 1.24 \\
\hline$[-10,19]$ & -43.04 & -1.39 & -1.35 & -34.09 & -0.67 & -0.65 & 150.05 & 1.40 & 1.36 \\
\hline$[-10,20]$ & -44.94 & -1.45 & -1.39 & -33.27 & -0.65 & -0.63 & 204.05 & 1.91 & 1.84 \\
\hline
\end{tabular}


Table A13. Case IV: OLS-Cumulative abnormal change rate of Chinese tourist arrivals.

\begin{tabular}{|c|c|c|c|c|c|c|c|c|c|}
\hline \multirow{3}{*}{ Event Period $\left[\tau_{1}, \tau_{2}\right]$} & \multicolumn{3}{|c|}{ Group-Type } & \multicolumn{3}{|c|}{ Individual-Type } & \multicolumn{3}{|c|}{ Medical-Type } \\
\hline & \multirow{2}{*}{ CAR } & \multicolumn{2}{|c|}{ t-Value } & \multirow{2}{*}{ CAR } & \multicolumn{2}{|c|}{ t-Value } & \multirow{2}{*}{ CAR } & \multicolumn{2}{|c|}{ t-Value } \\
\hline & & TM & SRM & & TM & SRM & & TM & SRM \\
\hline$[-10,-10]$ & 34.16 & 1.54 & 1.52 & 34.15 & 0.91 & 0.90 & 54.99 & 0.78 & 0.77 \\
\hline$[-10,-9]$ & -10.42 & -0.47 & -0.46 & 18.30 & 0.49 & 0.48 & 57.01 & 0.81 & 0.80 \\
\hline$[-10,-8]$ & 3.44 & 0.16 & 0.15 & 25.86 & 0.69 & 0.68 & 83.84 & 1.19 & 1.17 \\
\hline$[-10,-7]$ & -17.28 & -0.78 & -0.77 & 5.60 & 0.15 & 0.15 & 85.41 & 1.21 & 1.19 \\
\hline$[-10,-6]$ & -1.56 & -0.07 & -0.07 & 25.75 & 0.69 & 0.67 & 48.79 & 0.69 & 0.68 \\
\hline$[-10,-5]$ & 0.02 & 0.00 & 0.00 & 14.94 & 0.40 & 0.39 & 0.91 & 0.01 & 0.01 \\
\hline$[-10,-4]$ & 25.15 & 1.14 & 1.12 & 29.92 & 0.80 & 0.78 & -130.89 & -1.85 & -1.82 \\
\hline$[-10,-3]$ & 47.40 & 2.14 & 2.11 & 49.47 & 1.32 & 1.30 & -28.62 & -0.41 & -0.40 \\
\hline$[-10,-2]$ & -12.05 & -0.54 & -0.53 & 40.07 & 1.07 & 1.05 & -60.18 & -0.85 & -0.84 \\
\hline$[-10,-1]$ & 24.56 & 1.11 & 1.09 & 43.11 & 1.15 & 1.13 & -24.37 & -0.35 & -0.34 \\
\hline$[-10,0]$ & 46.52 & 2.10 & 2.07 & 83.99 & 2.24 & 2.20 & -17.14 & -0.24 & -0.24 \\
\hline$[-10,1]$ & 81.60 & $3.69 *$ & $3.63 *$ & 56.07 & 1.49 & 1.47 & 31.27 & 0.44 & 0.44 \\
\hline$[-10,2]$ & 99.79 & $4.51^{* *}$ & $4.44^{* *}$ & 62.56 & 1.67 & 1.64 & -42.54 & -0.60 & -0.59 \\
\hline$[-10,3]$ & 106.06 & $4.79 * *$ & $4.71 * *$ & 70.71 & 1.88 & 1.85 & -17.11 & -0.24 & -0.24 \\
\hline$[-10,4]$ & 125.32 & $5.66^{* *}$ & $5.58 * *$ & 107.40 & 2.86 & 2.82 & 102.25 & 1.45 & 1.43 \\
\hline$[-10,5]$ & 91.15 & $4.12 *$ & $4.05^{*}$ & 101.34 & 2.70 & 2.65 & 70.06 & 0.99 & 0.98 \\
\hline$[-10,6]$ & 82.22 & 3.72 * & $3.66^{*}$ & 120.37 & 3.21 * & $3.16^{*}$ & -90.69 & -1.28 & -1.27 \\
\hline$[-10,7]$ & 106.70 & $4.82^{* *}$ & $4.75^{* *}$ & 141.77 & $3.78 *$ & $3.72 *$ & 17.59 & 0.25 & 0.25 \\
\hline$[-10,8]$ & 107.43 & $4.86^{* *}$ & $4.78^{* *}$ & 138.98 & $3.70 *$ & $3.65 *$ & -64.56 & -0.91 & -0.90 \\
\hline$[-10,9]$ & 118.65 & $5.36^{* *}$ & $5.28 * *$ & 137.37 & $3.66 *$ & $3.60 *$ & 26.75 & 0.38 & 0.37 \\
\hline$[-10,10]$ & 127.78 & $5.78^{* *}$ & $5.68^{* *}$ & 132.07 & $3.52 *$ & $3.46^{*}$ & -106.14 & -1.50 & -1.48 \\
\hline$[-10,11]$ & 145.84 & $6.59 * *$ & $6.49 * *$ & 123.24 & 3.28 * & 3.23 * & -71.55 & -1.01 & -1.00 \\
\hline$[-10,12]$ & 101.45 & $4.59^{* *}$ & $4.51^{* *}$ & 116.94 & 3.12 * & 3.06 * & -8.19 & -0.12 & -0.11 \\
\hline$[-10,13]$ & 107.00 & $4.84^{* *}$ & $4.76^{* *}$ & 115.69 & $3.08 *$ & $3.03 *$ & -8.08 & -0.11 & -0.11 \\
\hline$[-10,14]$ & 124.09 & $5.61^{* *}$ & $5.52 * *$ & 144.69 & $3.85 *$ & $3.79 *$ & -16.41 & -0.23 & -0.23 \\
\hline$[-10,15]$ & 94.22 & $4.26^{*}$ & $4.19^{*}$ & 127.17 & $3.39 *$ & $3.34 *$ & -55.82 & -0.79 & -0.78 \\
\hline$[-10,16]$ & 88.80 & $4.01 *$ & $3.95 *$ & 114.97 & $3.06 *$ & $3.02 *$ & -27.97 & -0.40 & -0.39 \\
\hline$[-10,17]$ & 100.93 & $4.56^{* *}$ & $4.44^{* *}$ & 145.31 & 3.87 * & $3.76^{*}$ & 5.77 & 0.08 & 0.08 \\
\hline$[-10,18]$ & 123.14 & $5.56^{* *}$ & $5.48 *$ & 170.81 & $4.55^{* *}$ & $4.48 * *$ & 90.92 & 1.29 & 1.27 \\
\hline$[-10,19]$ & 110.07 & $4.97^{* *}$ & $4.89 *$ & 169.21 & $4.51^{* *}$ & $4.44^{* *}$ & 58.15 & 0.82 & 0.81 \\
\hline$[-10,20]$ & 82.15 & $3.71 *$ & $3.65 *$ & 169.72 & $4.52 * *$ & $4.45^{* *}$ & 17.53 & 0.25 & 0.24 \\
\hline
\end{tabular}


Table A14. Case IV: GARCH(1,1)—Cumulative abnormal change rate of Chinese tourist arrivals.

\begin{tabular}{|c|c|c|c|c|c|c|c|c|c|}
\hline \multirow{3}{*}{ Event Period $\left[\tau_{1}, \tau_{2}\right]$} & \multicolumn{3}{|c|}{ Group-Type } & \multicolumn{3}{|c|}{ Individual-Type } & \multicolumn{3}{|c|}{ Medical-Type } \\
\hline & \multirow{2}{*}{ CAR } & \multicolumn{2}{|c|}{ t-Value } & \multirow{2}{*}{ CAR } & \multicolumn{2}{|c|}{ t-Value } & \multirow{2}{*}{ CAR } & \multicolumn{2}{|c|}{ t-Value } \\
\hline & & TM & SRM & & TM & SRM & & TM & SRM \\
\hline$[-10,-10]$ & 31.30 & 1.21 & 1.19 & 32.32 & 1.09 & 1.08 & 54.44 & 0.76 & 0.75 \\
\hline$[-10,-9]$ & -9.14 & -0.35 & -0.35 & 17.20 & 0.58 & 0.57 & 57.47 & 0.80 & 0.79 \\
\hline$[-10,-8]$ & 9.99 & 0.39 & 0.38 & 25.89 & 0.88 & 0.86 & 85.57 & 1.20 & 1.18 \\
\hline$[-10,-7]$ & -1.56 & -0.06 & -0.06 & 8.20 & 0.28 & 0.27 & 89.26 & 1.25 & 1.23 \\
\hline$[-10,-6]$ & 1.68 & 0.06 & 0.06 & 23.00 & 0.78 & 0.76 & 49.95 & 0.70 & 0.68 \\
\hline$[-10,-5]$ & -0.57 & -0.02 & -0.02 & 10.01 & 0.34 & 0.33 & 1.30 & 0.02 & 0.02 \\
\hline$[-10,-4]$ & 17.97 & 0.69 & 0.68 & 21.79 & 0.74 & 0.72 & -131.88 & -1.84 & -1.81 \\
\hline$[-10,-3]$ & 37.93 & 1.47 & 1.44 & 39.72 & 1.34 & 1.32 & -30.03 & -0.42 & -0.41 \\
\hline$[-10,-2]$ & -11.83 & -0.46 & -0.45 & 33.06 & 1.12 & 1.10 & -59.34 & -0.83 & -0.82 \\
\hline$[-10,-1]$ & 20.21 & 0.78 & 0.77 & 33.66 & 1.14 & 1.12 & -24.46 & -0.34 & -0.34 \\
\hline$[-10,0]$ & 46.18 & 1.78 & 1.76 & 75.21 & 2.54 & 2.51 & -16.25 & -0.23 & -0.22 \\
\hline$[-10,1]$ & 84.72 & $3.27 *$ & $3.22 *$ & 47.78 & 1.62 & 1.59 & 33.02 & 0.46 & 0.45 \\
\hline$[-10,2]$ & 101.58 & $3.93 *$ & $3.87 *$ & 52.99 & 1.79 & 1.77 & -41.01 & -0.57 & -0.56 \\
\hline$[-10,3]$ & 101.68 & $3.93 *$ & $3.86^{*}$ & 58.09 & 1.97 & 1.93 & -16.87 & -0.24 & -0.23 \\
\hline$[-10,4]$ & 122.97 & $4.75^{* *}$ & $4.68^{* *}$ & 94.75 & $3.21 *$ & $3.16^{*}$ & 103.04 & 1.44 & 1.42 \\
\hline$[-10,5]$ & 96.84 & $3.74 *$ & $3.68 *$ & 90.84 & $3.07 *$ & $3.02 *$ & 72.72 & 1.02 & 1.00 \\
\hline$[-10,6]$ & 85.91 & 3.32 * & 3.27 * & 108.34 & $3.67^{*}$ & $3.61 *$ & -88.38 & -1.24 & -1.22 \\
\hline$[-10,7]$ & 107.62 & $4.16^{*}$ & $4.09 *$ & 127.94 & $4.33 *$ & $4.26^{*}$ & 19.37 & 0.27 & 0.27 \\
\hline$[-10,8]$ & 108.40 & $4.19 *$ & $4.12 *$ & 124.39 & $4.21 *$ & 4.14 * & -62.69 & -0.88 & -0.86 \\
\hline$[-10,9]$ & 120.44 & $4.65^{* *}$ & $4.58^{* *}$ & 122.30 & $4.14^{*}$ & $4.07^{*}$ & 28.90 & 0.40 & 0.40 \\
\hline$[-10,10]$ & 124.09 & $4.79^{* *}$ & $4.72 * *$ & 114.20 & $3.86^{*}$ & $3.80 *$ & -105.13 & -1.47 & -1.45 \\
\hline$[-10,11]$ & 139.54 & $5.39 * *$ & $5.31 * *$ & 103.63 & $3.51 *$ & 3.45 * & -71.03 & -0.99 & -0.98 \\
\hline$[-10,12]$ & 103.87 & 4.01 * & 3.94 * & 99.73 & $3.37 *$ & $3.32 *$ & -5.64 & -0.08 & -0.08 \\
\hline$[-10,13]$ & 104.47 & $4.04 *$ & $3.97 *$ & 95.89 & $3.24 *$ & $3.19 *$ & -6.55 & -0.09 & -0.09 \\
\hline$[-10,14]$ & 117.73 & $4.55^{* *}$ & $4.48^{* *}$ & 122.69 & $4.15^{*}$ & $4.09 *$ & -15.64 & -0.22 & -0.22 \\
\hline$[-10,15]$ & 85.30 & $3.30 *$ & $3.25^{*}$ & 103.46 & $3.50 *$ & $3.45^{*}$ & -55.53 & -0.78 & -0.76 \\
\hline$[-10,16]$ & 82.36 & $3.18 *$ & $3.13^{*}$ & 91.37 & $3.09 *$ & $3.04 *$ & -27.05 & -0.38 & -0.37 \\
\hline$[-10,17]$ & 74.54 & 2.88 & 2.80 & 113.63 & $3.84 *$ & $3.74 *$ & 2.33 & 0.03 & 0.03 \\
\hline$[-10,18]$ & 94.14 & $3.64 *$ & $3.58 *$ & 137.40 & $4.65^{* *}$ & $4.58 * *$ & 86.99 & 1.22 & 1.20 \\
\hline$[-10,19]$ & 87.01 & 3.36 * & 3.31 * & 137.18 & $4.64^{* *}$ & $4.57 * *$ & 55.63 & 0.78 & 0.77 \\
\hline$[-10,20]$ & 65.04 & 2.51 & 2.47 & 139.08 & $4.71^{* *}$ & $4.63^{* *}$ & 16.43 & 0.23 & 0.23 \\
\hline
\end{tabular}


Table A15. Case IV: GJR(1,1)—Cumulative abnormal change rate of Chinese tourist arrivals.

\begin{tabular}{|c|c|c|c|c|c|c|c|c|c|}
\hline \multirow{3}{*}{ Event Period $\left[\tau_{1}, \tau_{2}\right]$} & \multicolumn{3}{|c|}{ Group-Type } & \multicolumn{3}{|c|}{ Individual-Type } & \multicolumn{3}{|c|}{ Medical-Type } \\
\hline & \multirow{2}{*}{ CAR } & \multicolumn{2}{|c|}{$\mathrm{t}$-Value } & \multirow{2}{*}{ CAR } & \multicolumn{2}{|c|}{ t-Value } & \multirow{2}{*}{ CAR } & \multicolumn{2}{|c|}{ t-Value } \\
\hline & & TM & SRM & & TM & SRM & & TM & SRM \\
\hline$[-10,-10]$ & 31.65 & 1.02 & 1.01 & 29.23 & 0.43 & 0.42 & 61.21 & 0.28 & 0.27 \\
\hline$[-10,-9]$ & -8.44 & -0.27 & -0.27 & 12.57 & 0.18 & 0.18 & 71.19 & 0.32 & 0.32 \\
\hline$[-10,-8]$ & 11.02 & 0.36 & 0.35 & 19.97 & 0.29 & 0.29 & 106.27 & 0.48 & 0.47 \\
\hline$[-10,-7]$ & -0.19 & -0.01 & -0.01 & 1.85 & 0.03 & 0.03 & 117.05 & 0.53 & 0.52 \\
\hline$[-10,-6]$ & 3.42 & 0.11 & 0.11 & 11.44 & 0.17 & 0.16 & 84.26 & 0.38 & 0.37 \\
\hline$[-10,-5]$ & 1.52 & 0.05 & 0.05 & -4.86 & -0.07 & -0.07 & 42.35 & 0.19 & 0.19 \\
\hline$[-10,-4]$ & 20.42 & 0.66 & 0.65 & 3.01 & 0.04 & 0.04 & -84.15 & -0.38 & -0.37 \\
\hline$[-10,-3]$ & 40.73 & 1.32 & 1.30 & 17.98 & 0.26 & 0.26 & 24.48 & 0.11 & 0.11 \\
\hline$[-10,-2]$ & -8.70 & -0.28 & -0.28 & 11.01 & 0.16 & 0.16 & 2.27 & 0.01 & 0.01 \\
\hline$[-10,-1]$ & 23.70 & 0.77 & 0.76 & 8.14 & 0.12 & 0.12 & 43.87 & 0.20 & 0.19 \\
\hline$[-10,0]$ & 50.01 & 1.62 & 1.59 & 48.12 & 0.71 & 0.69 & 59.03 & 0.27 & 0.26 \\
\hline$[-10,1]$ & 88.90 & 2.88 & 2.83 & 18.99 & 0.28 & 0.27 & 115.24 & 0.52 & 0.51 \\
\hline$[-10,2]$ & 106.11 & $3.44 *$ & $3.38 *$ & 21.45 & 0.31 & 0.31 & 48.02 & 0.22 & 0.21 \\
\hline$[-10,3]$ & 106.56 & $3.45 *$ & $3.39 *$ & 22.74 & 0.33 & 0.33 & 78.85 & 0.36 & 0.35 \\
\hline$[-10,4]$ & 128.20 & $4.15^{*}$ & $4.09 *$ & 57.38 & 0.84 & 0.83 & 205.65 & 0.93 & 0.91 \\
\hline$[-10,5]$ & 102.41 & 3.32 * & $3.26 *$ & 52.80 & 0.77 & 0.76 & 182.39 & 0.82 & 0.81 \\
\hline$[-10,6]$ & 91.83 & $2.97 *$ & $2.93 *$ & 67.40 & 0.99 & 0.97 & 28.08 & 0.13 & 0.12 \\
\hline$[-10,7]$ & 113.89 & 3.69 * & $3.63 *$ & 83.94 & 1.23 & 1.21 & 142.60 & 0.64 & 0.63 \\
\hline$[-10,8]$ & 115.02 & 3.72 * & $3.67 *$ & 77.93 & 1.14 & 1.13 & 67.39 & 0.30 & 0.30 \\
\hline$[-10,9]$ & 127.40 & $4.12 *$ & $4.06^{*}$ & 73.57 & 1.08 & 1.06 & 165.84 & 0.75 & 0.74 \\
\hline$[-10,10]$ & 131.41 & $4.25 *$ & $4.18^{*}$ & 61.80 & 0.91 & 0.89 & 38.51 & 0.17 & 0.17 \\
\hline$[-10,11]$ & 147.21 & $4.77^{* *}$ & $4.69^{* *}$ & 48.20 & 0.71 & 0.70 & 79.39 & 0.36 & 0.35 \\
\hline$[-10,12]$ & 111.88 & $3.62 *$ & 3.56 * & 43.78 & 0.64 & 0.63 & 151.85 & 0.68 & 0.67 \\
\hline$[-10,13]$ & 112.83 & $3.65 *$ & $3.59 *$ & 36.39 & 0.53 & 0.53 & 157.66 & 0.71 & 0.70 \\
\hline$[-10,14]$ & 126.44 & $4.09 *$ & $4.03 *$ & 59.88 & 0.88 & 0.86 & 155.31 & 0.70 & 0.69 \\
\hline$[-10,15]$ & 94.37 & $3.06 *$ & $3.01 *$ & 37.63 & 0.55 & 0.54 & 122.20 & 0.55 & 0.54 \\
\hline$[-10,16]$ & 91.78 & $2.97 *$ & $2.93 *$ & 23.63 & 0.35 & 0.34 & 157.60 & 0.71 & 0.70 \\
\hline$[-10,17]$ & 84.33 & 2.73 & 2.66 & 39.03 & 0.57 & 0.56 & 193.29 & 0.87 & 0.85 \\
\hline$[-10,18]$ & 104.28 & $3.38 *$ & $3.32 *$ & 59.76 & 0.88 & 0.86 & 284.73 & 1.28 & 1.26 \\
\hline$[-10,19]$ & 97.49 & $3.16^{*}$ & $3.11 *$ & 58.40 & 0.86 & 0.84 & 260.37 & 1.17 & 1.15 \\
\hline$[-10,20]$ & 75.86 & 2.46 & 2.42 & 59.15 & 0.87 & 0.85 & 228.17 & 1.03 & 1.01 \\
\hline
\end{tabular}


Table A16. Case IV: EGARCH(1,1)—Cumulative abnormal change rate of Chinese tourist arrivals.

\begin{tabular}{|c|c|c|c|c|c|c|c|c|c|}
\hline \multirow{3}{*}{ Event Period $\left[\tau_{1}, \tau_{2}\right]$} & \multicolumn{3}{|c|}{ Group-Type } & \multicolumn{3}{|c|}{ Individual-Type } & \multicolumn{3}{|c|}{ Medical-Type } \\
\hline & \multirow{2}{*}{ CAR } & \multicolumn{2}{|c|}{ t-Value } & \multirow{2}{*}{ CAR } & \multicolumn{2}{|c|}{ t-Value } & \multirow{2}{*}{ CAR } & \multicolumn{2}{|c|}{ t-Value } \\
\hline & & TM & SRM & & TM & SRM & & TM & SRM \\
\hline$[-10,-10]$ & 32.49 & 0.84 & 0.82 & 29.71 & 0.46 & 0.46 & 66.87 & 0.18 & 0.17 \\
\hline$[-10,-9]$ & -7.68 & -0.20 & -0.19 & 12.84 & 0.20 & 0.20 & 82.37 & 0.22 & 0.21 \\
\hline$[-10,-8]$ & 11.57 & 0.30 & 0.29 & 19.93 & 0.31 & 0.31 & 122.95 & 0.32 & 0.32 \\
\hline$[-10,-7]$ & -0.38 & -0.01 & -0.01 & 1.11 & 0.02 & 0.02 & 139.15 & 0.37 & 0.36 \\
\hline$[-10,-6]$ & 5.33 & 0.14 & 0.13 & 12.11 & 0.19 & 0.18 & 112.21 & 0.30 & 0.29 \\
\hline$[-10,-5]$ & 4.40 & 0.11 & 0.11 & -3.61 & -0.06 & -0.06 & 75.99 & 0.20 & 0.20 \\
\hline$[-10,-4]$ & 24.63 & 0.63 & 0.62 & 5.10 & 0.08 & 0.08 & -44.78 & -0.12 & -0.12 \\
\hline$[-10,-3]$ & 45.71 & 1.18 & 1.16 & 20.49 & 0.32 & 0.31 & 69.50 & 0.18 & 0.18 \\
\hline$[-10,-2]$ & -4.52 & -0.12 & -0.11 & 12.77 & 0.20 & 0.20 & 52.70 & 0.14 & 0.14 \\
\hline$[-10,-1]$ & 28.94 & 0.75 & 0.73 & 10.54 & 0.16 & 0.16 & 100.00 & 0.26 & 0.26 \\
\hline$[-10,0]$ & 55.19 & 1.42 & 1.40 & 50.33 & 0.78 & 0.77 & 120.68 & 0.32 & 0.31 \\
\hline$[-10,1]$ & 94.09 & 2.42 & 2.39 & 21.06 & 0.33 & 0.32 & 182.42 & 0.48 & 0.47 \\
\hline$[-10,2]$ & 111.95 & 2.88 & 2.84 & 23.85 & 0.37 & 0.37 & 120.84 & 0.32 & 0.31 \\
\hline$[-10,3]$ & 113.67 & 2.93 * & 2.88 & 25.94 & 0.40 & 0.40 & 157.39 & 0.41 & 0.41 \\
\hline$[-10,4]$ & 135.52 & 3.49 * & $3.44 *$ & 60.58 & 0.94 & 0.93 & 289.75 & 0.76 & 0.75 \\
\hline$[-10,5]$ & 109.14 & 2.81 & 2.76 & 55.41 & 0.86 & 0.85 & 271.93 & 0.72 & 0.70 \\
\hline$[-10,6]$ & 99.28 & 2.56 & 2.52 & 70.41 & 1.10 & 1.08 & 123.27 & 0.32 & 0.32 \\
\hline$[-10,7]$ & 122.17 & $3.15 *$ & $3.10 *$ & 87.41 & 1.36 & 1.34 & 243.45 & 0.64 & 0.63 \\
\hline$[-10,8]$ & 123.77 & $3.19 *$ & 3.14 * & 81.60 & 1.27 & 1.25 & 173.84 & 0.46 & 0.45 \\
\hline$[-10,9]$ & 136.51 & $3.52 *$ & $3.46^{*}$ & 77.35 & 1.20 & 1.19 & 277.88 & 0.73 & 0.72 \\
\hline$[-10,10]$ & 141.70 & $3.65 *$ & $3.59 *$ & 66.33 & 1.03 & 1.02 & 156.27 & 0.41 & 0.41 \\
\hline$[-10,11]$ & 158.32 & 4.08 * & $4.01 *$ & 53.18 & 0.83 & 0.82 & 202.81 & 0.53 & 0.53 \\
\hline$[-10,12]$ & 122.30 & 3.15 * & 3.10 * & 48.10 & 0.75 & 0.74 & 280.69 & 0.74 & 0.73 \\
\hline$[-10,13]$ & 124.38 & $3.20 *$ & $3.15^{*}$ & 41.39 & 0.64 & 0.63 & 292.21 & 0.77 & 0.76 \\
\hline$[-10,14]$ & 138.96 & $3.58 *$ & $3.52 *$ & 65.46 & 1.02 & 1.00 & 295.54 & 0.78 & 0.77 \\
\hline$[-10,15]$ & 107.68 & 2.77 & 2.73 & 43.65 & 0.68 & 0.67 & 268.08 & 0.71 & 0.70 \\
\hline$[-10,16]$ & 105.23 & 2.71 & 2.67 & 29.61 & 0.46 & 0.45 & 309.03 & 0.81 & 0.80 \\
\hline$[-10,17]$ & 100.86 & 2.60 & 2.53 & 47.15 & 0.73 & 0.71 & 350.74 & 0.92 & 0.90 \\
\hline$[-10,18]$ & 121.62 & 3.13 * & $3.08 *$ & 68.33 & 1.06 & 1.05 & 447.83 & 1.18 & 1.16 \\
\hline$[-10,19]$ & 114.52 & 2.95 * & 2.90 * & 66.59 & 1.04 & 1.02 & 428.95 & 1.13 & 1.11 \\
\hline$[-10,20]$ & 92.58 & 2.38 & 2.35 & 66.97 & 1.04 & 1.03 & 402.24 & 1.06 & 1.04 \\
\hline
\end{tabular}


Table A17. Case V: OLS-Cumulative abnormal change rate of Chinese tourist arrivals.

\begin{tabular}{|c|c|c|c|c|c|c|c|c|c|}
\hline \multirow{3}{*}{ Event Period $\left[\tau_{1}, \tau_{2}\right]$} & \multicolumn{3}{|c|}{ Group-Type } & \multicolumn{3}{|c|}{ Individual-Type } & \multicolumn{3}{|c|}{ Medical-Type } \\
\hline & \multirow{2}{*}{ CAR } & \multicolumn{2}{|c|}{$\mathrm{t}$-Value } & \multirow{2}{*}{ CAR } & \multicolumn{2}{|c|}{ t-Value } & \multirow{2}{*}{ CAR } & \multicolumn{2}{|c|}{ t-Value } \\
\hline & & TM & SRM & & TM & SRM & & TM & SRM \\
\hline$[-10,-10]$ & -32.96 & -1.36 & -1.33 & -12.93 & -0.32 & -0.31 & 61.37 & 0.62 & 0.61 \\
\hline$[-10,-9]$ & -28.58 & -1.18 & -1.13 & -19.31 & -0.47 & -0.46 & 103.52 & 1.04 & 1.01 \\
\hline$[-10,-8]$ & -34.42 & -1.42 & -1.39 & -34.99 & -0.86 & -0.84 & 82.38 & 0.83 & 0.82 \\
\hline$[-10,-7]$ & -25.58 & -1.05 & -1.03 & -21.17 & -0.52 & -0.51 & 129.40 & 1.31 & 1.28 \\
\hline$[-10,-6]$ & -49.76 & -2.05 & -2.00 & -18.73 & -0.46 & -0.45 & 61.36 & 0.62 & 0.60 \\
\hline$[-10,-5]$ & -47.51 & -1.96 & -1.93 & -27.98 & -0.68 & -0.67 & 53.56 & 0.54 & 0.53 \\
\hline$[-10,-4]$ & -37.33 & -1.54 & -1.51 & -49.55 & -1.21 & -1.19 & 78.26 & 0.79 & 0.78 \\
\hline$[-10,-3]$ & -41.53 & -1.71 & -1.68 & -31.87 & -0.78 & -0.77 & 85.57 & 0.86 & 0.85 \\
\hline$[-10,-2]$ & -30.93 & -1.27 & -1.25 & -34.90 & -0.85 & -0.84 & 159.54 & 1.61 & 1.58 \\
\hline$[-10,-1]$ & -38.94 & -1.60 & -1.55 & -46.41 & -1.14 & -1.10 & -106.69 & -1.08 & -1.04 \\
\hline$[-10,0]$ & -39.42 & -1.62 & -1.58 & -29.24 & -0.72 & -0.70 & -105.01 & -1.06 & -1.03 \\
\hline$[-10,1]$ & -36.34 & -1.50 & -1.47 & -20.13 & -0.49 & -0.48 & -17.77 & -0.18 & -0.18 \\
\hline$[-10,2]$ & -43.42 & -1.79 & -1.76 & -39.64 & -0.97 & -0.96 & 170.96 & 1.72 & 1.70 \\
\hline$[-10,3]$ & -46.19 & -1.90 & -1.87 & -56.16 & -1.38 & -1.35 & 29.96 & 0.30 & 0.30 \\
\hline$[-10,4]$ & -32.28 & -1.33 & -1.30 & -34.72 & -0.85 & -0.83 & 77.10 & 0.78 & 0.76 \\
\hline$[-10,5]$ & -16.99 & -0.70 & -0.68 & -32.96 & -0.81 & -0.79 & 66.08 & 0.67 & 0.65 \\
\hline$[-10,6]$ & -36.57 & -1.50 & -1.48 & -55.84 & -1.37 & -1.35 & 3.99 & 0.04 & 0.04 \\
\hline$[-10,7]$ & -40.35 & -1.66 & -1.63 & -44.23 & -1.08 & -1.07 & 16.75 & 0.17 & 0.17 \\
\hline$[-10,8]$ & -51.49 & -2.12 & -2.09 & -35.77 & -0.88 & -0.86 & 23.60 & 0.24 & 0.23 \\
\hline$[-10,9]$ & -67.44 & -2.78 & -2.73 & -43.04 & -1.05 & -1.04 & 220.30 & 2.22 & 2.19 \\
\hline$[-10,10]$ & -68.55 & -2.82 & -2.78 & -43.96 & -1.08 & -1.06 & 105.48 & 1.06 & 1.05 \\
\hline$[-10,11]$ & -76.15 & $-3.13 *$ & $-3.08^{*}$ & -50.54 & -1.24 & -1.22 & 120.17 & 1.21 & 1.19 \\
\hline$[-10,12]$ & -81.02 & $-3.33 *$ & $-3.28 *$ & -39.36 & -0.96 & -0.95 & 4.94 & 0.05 & 0.05 \\
\hline$[-10,13]$ & -84.93 & -3.49 * & $-3.43 *$ & -32.21 & -0.79 & -0.77 & -113.75 & -1.15 & -1.13 \\
\hline$[-10,14]$ & -57.46 & -2.36 & -2.26 & 10.51 & 0.26 & 0.25 & 3.50 & 0.04 & 0.03 \\
\hline$[-10,15]$ & -85.57 & $-3.52 *$ & $-3.42 *$ & 52.75 & 1.29 & 1.25 & -3.43 & -0.03 & -0.03 \\
\hline$[-10,16]$ & -83.87 & $-3.45^{*}$ & $-3.37^{*}$ & 1.17 & 0.03 & 0.03 & -36.17 & -0.36 & -0.36 \\
\hline$[-10,17]$ & -84.93 & $-3.49 *$ & $-3.42 *$ & -42.91 & -1.05 & -1.03 & 87.49 & 0.88 & 0.86 \\
\hline$[-10,18]$ & -86.15 & -3.55 * & $-3.49 *$ & -24.12 & -0.59 & -0.58 & 26.67 & 0.27 & 0.26 \\
\hline$[-10,19]$ & -63.30 & -2.60 & -2.56 & -0.24 & -0.01 & -0.01 & -84.63 & -0.85 & -0.84 \\
\hline$[-10,20]$ & -58.10 & -2.39 & -2.34 & -8.00 & -0.20 & -0.19 & -56.51 & -0.57 & -0.56 \\
\hline
\end{tabular}

Note: * denotes significance at the $10 \%$ level. 
Table A18. Case V: GARCH(1,1)—Cumulative abnormal change rate of Chinese tourist arrivals.

\begin{tabular}{|c|c|c|c|c|c|c|c|c|c|}
\hline \multirow{3}{*}{ Event Period $\left[\tau_{1}, \tau_{2}\right]$} & \multicolumn{3}{|c|}{ Group-Type } & \multicolumn{3}{|c|}{ Individual-Type } & \multicolumn{3}{|c|}{ Medical-Type } \\
\hline & \multirow{2}{*}{ CAR } & \multicolumn{2}{|c|}{ t-Value } & \multirow{2}{*}{ CAR } & \multicolumn{2}{|c|}{ t-Value } & \multirow{2}{*}{ CAR } & \multicolumn{2}{|c|}{ t-Value } \\
\hline & & TM & SRM & & TM & SRM & & TM & SRM \\
\hline$[-10,-10]$ & -32.40 & -1.07 & -1.05 & -14.71 & -0.29 & -0.29 & 62.53 & 0.57 & 0.55 \\
\hline$[-10,-9]$ & -26.94 & -0.89 & -0.86 & -20.83 & -0.42 & -0.40 & 90.48 & 0.82 & 0.79 \\
\hline$[-10,-8]$ & -32.15 & -1.06 & -1.04 & -38.02 & -0.76 & -0.75 & 68.39 & 0.62 & 0.61 \\
\hline$[-10,-7]$ & -22.46 & -0.74 & -0.73 & -24.82 & -0.49 & -0.49 & 107.86 & 0.97 & 0.96 \\
\hline$[-10,-6]$ & -46.17 & -1.52 & -1.48 & -24.58 & -0.49 & -0.48 & 44.04 & 0.40 & 0.39 \\
\hline$[-10,-5]$ & -43.22 & -1.42 & -1.40 & -35.06 & -0.70 & -0.69 & 33.29 & 0.30 & 0.30 \\
\hline$[-10,-4]$ & -32.33 & -1.07 & -1.05 & -57.83 & -1.15 & -1.14 & 54.64 & 0.49 & 0.49 \\
\hline$[-10,-3]$ & -35.86 & -1.18 & -1.16 & -41.52 & -0.83 & -0.81 & 60.03 & 0.54 & 0.53 \\
\hline$[-10,-2]$ & -24.43 & -0.81 & -0.79 & -45.29 & -0.90 & -0.89 & 127.28 & 1.15 & 1.13 \\
\hline$[-10,-1]$ & -31.38 & -1.03 & -1.00 & -56.59 & -1.13 & -1.09 & -152.70 & -1.38 & -1.33 \\
\hline$[-10,0]$ & -31.43 & -1.04 & -1.01 & -41.73 & -0.83 & -0.81 & -145.95 & -1.32 & -1.28 \\
\hline$[-10,1]$ & -27.72 & -0.91 & -0.90 & -34.15 & -0.68 & -0.67 & -59.50 & -0.54 & -0.53 \\
\hline$[-10,2]$ & -34.10 & -1.12 & -1.11 & -54.90 & -1.09 & -1.08 & 126.28 & 1.14 & 1.12 \\
\hline$[-10,3]$ & -36.18 & -1.19 & -1.17 & -72.73 & -1.45 & -1.43 & -17.11 & -0.15 & -0.15 \\
\hline$[-10,4]$ & -21.72 & -0.72 & -0.70 & -53.07 & -1.06 & -1.04 & 31.14 & 0.28 & 0.28 \\
\hline$[-10,5]$ & -5.53 & -0.18 & -0.18 & -51.78 & -1.03 & -1.01 & 11.37 & 0.10 & 0.10 \\
\hline$[-10,6]$ & -24.33 & -0.80 & -0.79 & -75.59 & -1.51 & -1.48 & -56.00 & -0.51 & -0.50 \\
\hline$[-10,7]$ & -27.35 & -0.90 & -0.89 & -64.98 & -1.30 & -1.28 & -47.93 & -0.43 & -0.43 \\
\hline$[-10,8]$ & -37.83 & -1.25 & -1.23 & -57.93 & -1.15 & -1.14 & -42.76 & -0.39 & -0.38 \\
\hline$[-10,9]$ & -53.09 & -1.75 & -1.72 & -66.45 & -1.32 & -1.30 & 151.09 & 1.37 & 1.34 \\
\hline$[-10,10]$ & -53.48 & -1.76 & -1.74 & -68.55 & -1.37 & -1.35 & 32.85 & 0.30 & 0.29 \\
\hline$[-10,11]$ & -60.29 & -1.99 & -1.96 & -76.02 & -1.52 & -1.49 & 41.99 & 0.38 & 0.37 \\
\hline$[-10,12]$ & -64.41 & -2.12 & -2.09 & -65.83 & -1.31 & -1.29 & -78.00 & -0.70 & -0.69 \\
\hline$[-10,13]$ & -67.75 & -2.23 & -2.19 & -60.50 & -1.21 & -1.18 & -195.37 & -1.77 & -1.73 \\
\hline$[-10,14]$ & -39.14 & -1.29 & -1.23 & -17.27 & -0.34 & -0.33 & -94.16 & -0.85 & -0.81 \\
\hline$[-10,15]$ & -66.85 & -2.20 & -2.14 & 22.58 & 0.45 & 0.44 & -95.37 & -0.86 & -0.84 \\
\hline$[-10,16]$ & -64.64 & -2.13 & -2.08 & -31.02 & -0.62 & -0.60 & -125.22 & -1.13 & -1.11 \\
\hline$[-10,17]$ & -65.19 & -2.15 & -2.10 & -77.12 & -1.54 & -1.50 & 1.41 & 0.01 & 0.01 \\
\hline$[-10,18]$ & -65.72 & -2.17 & -2.13 & -59.58 & -1.19 & -1.17 & -62.30 & -0.56 & -0.55 \\
\hline$[-10,19]$ & -42.09 & -1.39 & -1.37 & -36.61 & -0.73 & -0.72 & -179.05 & -1.62 & -1.59 \\
\hline$[-10,20]$ & -36.01 & -1.19 & -1.16 & -44.92 & -0.90 & -0.88 & -159.05 & -1.44 & -1.41 \\
\hline
\end{tabular}


Table A19. Case V: GJR(1,1)—Cumulative abnormal change rate of Chinese tourist arrivals.

\begin{tabular}{|c|c|c|c|c|c|c|c|c|c|}
\hline \multirow{3}{*}{ Event Period $\left[\tau_{1}, \tau_{2}\right]$} & \multicolumn{3}{|c|}{ Group-Type } & \multicolumn{3}{|c|}{ Individual-Type } & \multicolumn{3}{|c|}{ Medical-Type } \\
\hline & \multirow{2}{*}{ CAR } & \multicolumn{2}{|c|}{ t-Value } & \multirow{2}{*}{ CAR } & \multicolumn{2}{|c|}{ t-Value } & \multirow{2}{*}{ CAR } & \multicolumn{2}{|c|}{ t-Value } \\
\hline & & TM & SRM & & TM & SRM & & TM & SRM \\
\hline$[-10,-10]$ & -34.20 & -0.62 & -0.61 & -14.18 & -0.35 & -0.35 & 73.79 & 0.25 & 0.25 \\
\hline$[-10,-9]$ & -32.38 & -0.59 & -0.56 & -16.97 & -0.42 & -0.41 & 113.70 & 0.39 & 0.38 \\
\hline$[-10,-8]$ & -39.65 & -0.72 & -0.71 & -33.24 & -0.83 & -0.81 & 102.96 & 0.35 & 0.35 \\
\hline$[-10,-7]$ & -32.81 & -0.59 & -0.58 & -17.93 & -0.45 & -0.44 & 154.09 & 0.53 & 0.52 \\
\hline$[-10,-6]$ & -57.97 & -1.05 & -1.02 & -17.71 & -0.44 & -0.43 & 101.39 & 0.35 & 0.34 \\
\hline$[-10,-5]$ & -57.31 & -1.04 & -1.02 & -26.91 & -0.67 & -0.66 & 102.09 & 0.35 & 0.34 \\
\hline$[-10,-4]$ & -48.76 & -0.88 & -0.87 & -48.32 & -1.20 & -1.18 & 134.90 & 0.46 & 0.46 \\
\hline$[-10,-3]$ & -54.47 & -0.98 & -0.97 & -30.92 & -0.77 & -0.76 & 151.69 & 0.52 & 0.51 \\
\hline$[-10,-2]$ & -45.79 & -0.83 & -0.81 & -32.72 & -0.81 & -0.80 & 230.56 & 0.79 & 0.78 \\
\hline$[-10,-1]$ & -56.32 & -1.02 & -0.98 & -40.78 & -1.01 & -0.98 & -37.48 & -0.13 & -0.12 \\
\hline$[-10,0]$ & -57.71 & -1.04 & -1.01 & -26.10 & -0.65 & -0.63 & -19.65 & -0.07 & -0.07 \\
\hline$[-10,1]$ & -56.05 & -1.01 & -1.00 & -17.63 & -0.44 & -0.43 & 78.15 & 0.27 & 0.26 \\
\hline$[-10,2]$ & -64.72 & -1.17 & -1.15 & -37.10 & -0.92 & -0.91 & 275.38 & 0.94 & 0.93 \\
\hline$[-10,3]$ & -69.04 & -1.25 & -1.23 & -53.76 & -1.34 & -1.32 & 143.41 & 0.49 & 0.48 \\
\hline$[-10,4]$ & -56.39 & -1.02 & -1.00 & -33.56 & -0.83 & -0.82 & 202.92 & 0.70 & 0.68 \\
\hline$[-10,5]$ & -43.19 & -0.78 & -0.76 & -29.92 & -0.74 & -0.73 & 194.86 & 0.67 & 0.65 \\
\hline$[-10,6]$ & -64.57 & -1.17 & -1.15 & -52.02 & -1.29 & -1.27 & 139.04 & 0.48 & 0.47 \\
\hline$[-10,7]$ & -70.09 & -1.27 & -1.25 & -39.82 & -0.99 & -0.97 & 158.64 & 0.54 & 0.54 \\
\hline$[-10,8]$ & -82.72 & -1.50 & -1.47 & -31.72 & -0.79 & -0.78 & 175.20 & 0.60 & 0.59 \\
\hline$[-10,9]$ & -100.26 & -1.81 & -1.78 & -38.97 & -0.97 & -0.95 & 380.49 & 1.31 & 1.29 \\
\hline$[-10,10]$ & -103.00 & -1.86 & -1.83 & -39.71 & -0.99 & -0.97 & 273.72 & 0.94 & 0.92 \\
\hline$[-10,11]$ & -112.42 & -2.03 & -2.00 & -45.43 & -1.13 & -1.11 & 294.42 & 1.01 & 0.99 \\
\hline$[-10,12]$ & -119.05 & -2.15 & -2.12 & -33.63 & -0.84 & -0.82 & 185.96 & 0.64 & 0.63 \\
\hline$[-10,13]$ & -124.19 & -2.24 & -2.20 & -27.79 & -0.69 & -0.68 & 79.84 & 0.27 & 0.27 \\
\hline$[-10,14]$ & -99.44 & -1.80 & -1.72 & 19.10 & 0.47 & 0.45 & 193.09 & 0.66 & 0.63 \\
\hline$[-10,15]$ & -128.41 & -2.32 & -2.25 & 58.65 & 1.46 & 1.41 & 202.93 & 0.70 & 0.68 \\
\hline$[-10,16]$ & -127.80 & -2.31 & -2.26 & 5.27 & 0.13 & 0.13 & 184.26 & 0.63 & 0.62 \\
\hline$[-10,17]$ & -129.95 & -2.35 & -2.30 & -40.63 & -1.01 & -0.99 & 322.07 & 1.11 & 1.08 \\
\hline$[-10,18]$ & -132.77 & -2.40 & -2.36 & -21.82 & -0.54 & -0.53 & 269.81 & 0.93 & 0.91 \\
\hline$[-10,19]$ & -111.73 & -2.02 & -1.99 & 2.88 & 0.07 & 0.07 & 164.61 & 0.56 & 0.56 \\
\hline$[-10,20]$ & -108.56 & -1.96 & -1.92 & -3.20 & -0.08 & -0.08 & 196.30 & 0.67 & 0.66 \\
\hline
\end{tabular}


Table A20. Case V: EGARCH(1,1)—Cumulative abnormal change rate of Chinese tourist arrivals.

\begin{tabular}{|c|c|c|c|c|c|c|c|c|c|}
\hline \multirow{3}{*}{ Event Period $\left[\tau_{1}, \tau_{2}\right]$} & \multicolumn{3}{|c|}{ Group-Type } & \multicolumn{3}{|c|}{ Individual-Type } & \multicolumn{3}{|c|}{ Medical-Type } \\
\hline & \multirow{2}{*}{ CAR } & \multicolumn{2}{|c|}{ t-Value } & \multirow{2}{*}{ CAR } & \multicolumn{2}{|c|}{ t-Value } & \multirow{2}{*}{ CAR } & \multicolumn{2}{|c|}{ t-Value } \\
\hline & & TM & SRM & & TM & SRM & & TM & SRM \\
\hline$[-10,-10]$ & -34.56 & -0.46 & -0.45 & -14.24 & -0.34 & -0.34 & 74.59 & 0.24 & 0.23 \\
\hline$[-10,-9]$ & -34.31 & -0.46 & -0.44 & -16.37 & -0.40 & -0.38 & 115.61 & 0.37 & 0.35 \\
\hline$[-10,-8]$ & -42.11 & -0.56 & -0.56 & -32.60 & -0.79 & -0.78 & 105.72 & 0.33 & 0.33 \\
\hline$[-10,-7]$ & -36.31 & -0.49 & -0.48 & -16.94 & -0.41 & -0.40 & 157.82 & 0.50 & 0.49 \\
\hline$[-10,-6]$ & -61.59 & -0.83 & -0.80 & -16.91 & -0.41 & -0.40 & 105.86 & 0.33 & 0.33 \\
\hline$[-10,-5]$ & -61.62 & -0.83 & -0.81 & -25.99 & -0.63 & -0.62 & 107.45 & 0.34 & 0.33 \\
\hline$[-10,-4]$ & -53.78 & -0.72 & -0.71 & -47.24 & -1.14 & -1.13 & 141.15 & 0.45 & 0.44 \\
\hline$[-10,-3]$ & -60.10 & -0.81 & -0.79 & -29.75 & -0.72 & -0.71 & 158.80 & 0.50 & 0.49 \\
\hline$[-10,-2]$ & -52.40 & -0.70 & -0.69 & -31.25 & -0.76 & -0.74 & 238.63 & 0.76 & 0.74 \\
\hline$[-10,-1]$ & -64.46 & -0.86 & -0.83 & -38.67 & -0.94 & -0.90 & -28.30 & -0.09 & -0.09 \\
\hline$[-10,0]$ & -65.90 & -0.88 & -0.86 & -24.23 & -0.59 & -0.57 & -9.75 & -0.03 & -0.03 \\
\hline$[-10,1]$ & -64.75 & -0.87 & -0.85 & -15.72 & -0.38 & -0.37 & 88.89 & 0.28 & 0.28 \\
\hline$[-10,2]$ & -74.11 & -0.99 & -0.98 & -35.06 & -0.85 & -0.84 & 287.00 & 0.91 & 0.89 \\
\hline$[-10,3]$ & -79.07 & -1.06 & -1.04 & -51.60 & -1.25 & -1.23 & 155.91 & 0.49 & 0.49 \\
\hline$[-10,4]$ & -66.77 & -0.90 & -0.88 & -31.46 & -0.76 & -0.75 & 216.22 & 0.68 & 0.67 \\
\hline$[-10,5]$ & -54.72 & -0.73 & -0.72 & -27.42 & -0.66 & -0.65 & 209.16 & 0.66 & 0.65 \\
\hline$[-10,6]$ & -76.97 & -1.03 & -1.02 & -49.28 & -1.19 & -1.18 & 154.27 & 0.49 & 0.48 \\
\hline$[-10,7]$ & -83.31 & -1.12 & -1.10 & -36.87 & -0.89 & -0.88 & 174.79 & 0.55 & 0.54 \\
\hline$[-10,8]$ & -96.52 & -1.29 & -1.27 & -28.69 & -0.70 & -0.68 & 192.21 & 0.61 & 0.60 \\
\hline$[-10,9]$ & -114.74 & -1.54 & -1.52 & -35.81 & -0.87 & -0.85 & 398.38 & 1.26 & 1.24 \\
\hline$[-10,10]$ & -118.20 & -1.59 & -1.56 & -36.39 & -0.88 & -0.87 & 292.50 & 0.93 & 0.91 \\
\hline$[-10,11]$ & -128.51 & -1.72 & -1.70 & -41.85 & -1.01 & -1.00 & 314.15 & 0.99 & 0.98 \\
\hline$[-10,12]$ & -135.96 & -1.82 & -1.79 & -29.84 & -0.72 & -0.71 & 206.61 & 0.65 & 0.64 \\
\hline$[-10,13]$ & -141.45 & -1.90 & -1.86 & -24.06 & -0.58 & -0.57 & 101.28 & 0.32 & 0.31 \\
\hline$[-10,14]$ & -118.41 & -1.59 & -1.52 & 23.57 & 0.57 & 0.55 & 215.68 & 0.68 & 0.65 \\
\hline$[-10,15]$ & -147.38 & -1.98 & -1.92 & 62.85 & 1.52 & 1.48 & 226.24 & 0.72 & 0.69 \\
\hline$[-10,16]$ & -146.99 & -1.97 & -1.93 & 9.33 & 0.23 & 0.22 & 208.33 & 0.66 & 0.64 \\
\hline$[-10,17]$ & -149.36 & -2.00 & -1.96 & -36.71 & -0.89 & -0.87 & 346.90 & 1.10 & 1.07 \\
\hline$[-10,18]$ & -152.86 & -2.05 & -2.02 & -17.76 & -0.43 & -0.42 & 295.52 & 0.94 & 0.92 \\
\hline$[-10,19]$ & -132.70 & -1.78 & -1.75 & 7.19 & 0.17 & 0.17 & 191.26 & 0.61 & 0.60 \\
\hline$[-10,20]$ & -130.63 & -1.75 & -1.72 & 1.48 & 0.04 & 0.04 & 223.94 & 0.71 & 0.69 \\
\hline
\end{tabular}


Table A21. Case VI: OLS-Cumulative abnormal change rate of Chinese tourist arrivals.

\begin{tabular}{|c|c|c|c|c|c|c|c|c|c|}
\hline \multirow{3}{*}{ Event Period $\left[\tau_{1}, \tau_{2}\right]$} & \multicolumn{3}{|c|}{ Group-Type } & \multicolumn{3}{|c|}{ Individual-Type } & \multicolumn{3}{|c|}{ Medical-Type } \\
\hline & \multirow{2}{*}{ CAR } & \multicolumn{2}{|c|}{ t-Value } & \multirow{2}{*}{ CAR } & \multicolumn{2}{|c|}{ t-Value } & \multirow{2}{*}{ CAR } & \multicolumn{2}{|c|}{ t-Value } \\
\hline & & TM & SRM & & TM & SRM & & TM & SRM \\
\hline$[-10,-10]$ & -24.32 & -0.81 & -0.80 & 7.76 & 0.30 & 0.29 & -70.72 & -0.86 & -0.85 \\
\hline$[-10,-9]$ & 10.40 & 0.35 & 0.34 & 58.26 & 2.25 & 2.21 & -25.18 & -0.31 & -0.30 \\
\hline$[-10,-8]$ & -11.30 & -0.38 & -0.37 & 65.74 & 2.53 & 2.47 & -92.40 & -1.12 & -1.10 \\
\hline$[-10,-7]$ & -21.85 & -0.73 & -0.72 & 17.20 & 0.66 & 0.65 & -173.94 & -2.12 & -2.08 \\
\hline$[-10,-6]$ & 5.36 & 0.18 & 0.18 & -9.47 & -0.36 & -0.36 & -176.40 & -2.15 & -2.11 \\
\hline$[-10,-5]$ & 1.89 & 0.06 & 0.06 & -25.76 & -0.99 & -0.98 & -171.38 & -2.09 & -2.05 \\
\hline$[-10,-4]$ & -70.65 & -2.36 & -2.33 & -55.13 & -2.13 & -2.09 & -280.66 & $-3.42^{*}$ & $-3.36^{*}$ \\
\hline$[-10,-3]$ & -1.99 & -0.07 & -0.06 & 1.47 & 0.06 & 0.05 & -237.28 & -2.89 & -2.78 \\
\hline$[-10,-2]$ & 30.52 & 1.02 & 1.00 & 14.08 & 0.54 & 0.53 & -240.59 & $-2.93^{*}$ & -2.87 \\
\hline$[-10,-1]$ & 9.21 & 0.31 & 0.30 & -47.44 & -1.83 & -1.80 & -164.63 & -2.00 & -1.97 \\
\hline$[-10,0]$ & 30.07 & 1.01 & 0.98 & 12.36 & 0.48 & 0.47 & -138.47 & -1.69 & -1.65 \\
\hline$[-10,1]$ & 57.50 & 1.92 & 1.89 & 22.56 & 0.87 & 0.86 & -47.02 & -0.57 & -0.56 \\
\hline$[-10,2]$ & 76.82 & 2.57 & 2.53 & 21.41 & 0.83 & 0.81 & -28.55 & -0.35 & -0.34 \\
\hline$[-10,3]$ & 85.86 & 2.87 & 2.81 & 6.47 & 0.25 & 0.24 & -23.41 & -0.28 & -0.28 \\
\hline$[-10,4]$ & 16.91 & 0.57 & 0.53 & -26.98 & -1.04 & -0.98 & -209.17 & -2.55 & -2.41 \\
\hline$[-10,5]$ & 41.20 & 1.38 & 1.36 & 37.75 & 1.46 & 1.43 & -188.17 & -2.29 & -2.26 \\
\hline$[-10,6]$ & 1.79 & 0.06 & 0.06 & 55.76 & 2.15 & 2.12 & -189.74 & -2.31 & -2.27 \\
\hline$[-10,7]$ & 24.03 & 0.80 & 0.79 & 21.28 & 0.82 & 0.81 & -55.95 & -0.68 & -0.67 \\
\hline$[-10,8]$ & -4.04 & -0.14 & -0.13 & 22.59 & 0.87 & 0.86 & -231.67 & -2.82 & -2.78 \\
\hline$[-10,9]$ & -35.66 & -1.19 & -0.72 & -16.96 & -0.65 & -0.40 & -205.18 & -2.50 & -1.51 \\
\hline$[-10,10]$ & 38.92 & 1.30 & 1.25 & 110.78 & $4.27 *$ & $4.10^{*}$ & -54.61 & -0.66 & -0.64 \\
\hline$[-10,11]$ & 38.62 & 1.29 & 1.25 & 142.38 & $5.49 * *$ & $5.32 * *$ & -49.38 & -0.60 & -0.58 \\
\hline$[-10,12]$ & 77.89 & 2.60 & 2.55 & 184.77 & $7.12 * *$ & $6.96 * *$ & -56.23 & -0.68 & -0.67 \\
\hline$[-10,13]$ & 102.38 & $3.42 *$ & 3.34 * & 197.50 & $7.61^{* *}$ & $7.43^{* *}$ & -30.23 & -0.37 & -0.36 \\
\hline$[-10,14]$ & 81.26 & 2.72 & 2.66 & 176.59 & $6.81 * *$ & $6.67 * *$ & -107.71 & -1.31 & -1.29 \\
\hline$[-10,15]$ & 14.57 & 0.49 & 0.48 & 121.64 & $4.69^{* *}$ & $4.61 * *$ & -114.08 & -1.39 & -1.37 \\
\hline$[-10,16]$ & 12.02 & 0.40 & 0.40 & 98.97 & $3.81 *$ & $3.76^{*}$ & -75.79 & -0.92 & -0.91 \\
\hline$[-10,17]$ & 0.16 & 0.01 & 0.01 & 52.26 & 2.01 & 1.98 & -77.20 & -0.94 & -0.93 \\
\hline$[-10,18]$ & -31.51 & -1.05 & -1.03 & -9.70 & -0.37 & -0.37 & -52.78 & -0.64 & -0.63 \\
\hline$[-10,19]$ & -42.43 & -1.42 & -1.37 & -31.32 & -1.21 & -1.16 & -136.38 & -1.66 & -1.60 \\
\hline$[-10,20]$ & -54.12 & -1.81 & -1.71 & -84.43 & -3.25 & -3.08 & -222.72 & -2.71 & -2.56 \\
\hline
\end{tabular}


Table A22. Case VI: GARCH(1,1)—Cumulative abnormal change rate of Chinese tourist arrivals.

\begin{tabular}{|c|c|c|c|c|c|c|c|c|c|}
\hline \multirow{3}{*}{ Event Period $\left[\tau_{1}, \tau_{2}\right]$} & \multicolumn{3}{|c|}{ Group-Type } & \multicolumn{3}{|c|}{ Individual-Type } & \multicolumn{3}{|c|}{ Medical-Type } \\
\hline & \multirow{2}{*}{ CAR } & \multicolumn{2}{|c|}{ t-Value } & \multirow{2}{*}{ CAR } & \multicolumn{2}{|c|}{ t-Value } & \multirow{2}{*}{ CAR } & \multicolumn{2}{|c|}{ t-Value } \\
\hline & & TM & SRM & & TM & SRM & & TM & SRM \\
\hline$[-10,-10]$ & -24.57 & -0.78 & -0.77 & 10.83 & 0.24 & 0.24 & -66.73 & -0.51 & -0.50 \\
\hline$[-10,-9]$ & 9.91 & 0.31 & 0.31 & 62.18 & 1.39 & 1.36 & -17.66 & -0.13 & -0.13 \\
\hline$[-10,-8]$ & -12.05 & -0.38 & -0.37 & 74.04 & 1.65 & 1.61 & -80.61 & -0.61 & -0.60 \\
\hline$[-10,-7]$ & -22.82 & -0.72 & -0.71 & 22.98 & 0.51 & 0.50 & -159.34 & -1.21 & -1.19 \\
\hline$[-10,-6]$ & 4.15 & 0.13 & 0.13 & -5.55 & -0.12 & -0.12 & -158.84 & -1.21 & -1.19 \\
\hline$[-10,-5]$ & 0.42 & 0.01 & 0.01 & -18.30 & -0.41 & -0.40 & -149.72 & -1.14 & -1.12 \\
\hline$[-10,-4]$ & -72.35 & -2.30 & -2.26 & -46.54 & -1.04 & -1.02 & -255.42 & -1.94 & -1.91 \\
\hline$[-10,-3]$ & -3.97 & -0.13 & -0.12 & 19.43 & 0.43 & 0.42 & -206.73 & -1.57 & -1.51 \\
\hline$[-10,-2]$ & 28.32 & 0.90 & 0.88 & 27.67 & 0.62 & 0.61 & -207.60 & -1.58 & -1.55 \\
\hline$[-10,-1]$ & 6.78 & 0.22 & 0.21 & -37.33 & -0.83 & -0.82 & -129.02 & -0.98 & -0.96 \\
\hline$[-10,0]$ & 27.40 & 0.87 & 0.85 & 20.12 & 0.45 & 0.44 & -100.01 & -0.76 & -0.74 \\
\hline$[-10,1]$ & 54.58 & 1.73 & 1.71 & 34.78 & 0.78 & 0.76 & -4.27 & -0.03 & -0.03 \\
\hline$[-10,2]$ & 73.65 & 2.34 & 2.30 & 37.81 & 0.84 & 0.83 & 18.42 & 0.14 & 0.14 \\
\hline$[-10,3]$ & 82.44 & 2.62 & 2.56 & 27.67 & 0.62 & 0.60 & 27.92 & 0.21 & 0.21 \\
\hline$[-10,4]$ & 13.22 & 0.42 & 0.40 & 2.63 & 0.06 & 0.06 & -152.73 & -1.16 & -1.10 \\
\hline$[-10,5]$ & 37.30 & 1.18 & 1.17 & 57.25 & 1.28 & 1.26 & -130.50 & -0.99 & -0.98 \\
\hline$[-10,6]$ & -2.36 & -0.07 & -0.07 & 77.33 & 1.73 & 1.70 & -128.29 & -0.97 & -0.96 \\
\hline$[-10,7]$ & 19.64 & 0.62 & 0.61 & 45.04 & 1.00 & 0.99 & 9.32 & 0.07 & 0.07 \\
\hline$[-10,8]$ & -8.67 & -0.28 & -0.27 & 46.25 & 1.03 & 1.02 & -163.08 & -1.24 & -1.22 \\
\hline$[-10,9]$ & -40.38 & -1.28 & -0.77 & -46.82 & -1.04 & -0.63 & -144.47 & -1.10 & -0.66 \\
\hline$[-10,10]$ & 33.77 & 1.07 & 1.03 & 145.33 & 3.24 * & $3.11 *$ & 22.96 & 0.17 & 0.17 \\
\hline$[-10,11]$ & 33.24 & 1.06 & 1.02 & 176.07 & 3.93 * & 3.81 * & 31.36 & 0.24 & 0.23 \\
\hline$[-10,12]$ & 72.28 & 2.30 & 2.24 & 217.51 & $4.85^{* *}$ & $4.74^{* *}$ & 27.66 & 0.21 & 0.21 \\
\hline$[-10,13]$ & 96.52 & 3.07 * & $2.99 *$ & 231.88 & $5.17^{* *}$ & $5.05^{* *}$ & 57.36 & 0.44 & 0.43 \\
\hline$[-10,14]$ & 75.16 & 2.39 & 2.34 & 210.81 & $4.70^{* *}$ & $4.61 * *$ & -16.81 & -0.13 & -0.13 \\
\hline$[-10,15]$ & 8.23 & 0.26 & 0.26 & 155.46 & $3.47^{*}$ & $3.41 *$ & -19.92 & -0.15 & -0.15 \\
\hline$[-10,16]$ & 5.45 & 0.17 & 0.17 & 130.98 & $2.92 *$ & 2.88 & 21.34 & 0.16 & 0.16 \\
\hline$[-10,17]$ & -6.66 & -0.21 & -0.21 & 85.37 & 1.90 & 1.88 & 23.51 & 0.18 & 0.18 \\
\hline$[-10,18]$ & -38.59 & -1.23 & -1.20 & 29.29 & 0.65 & 0.64 & 52.51 & 0.40 & 0.39 \\
\hline$[-10,19]$ & -49.77 & -1.58 & -1.52 & 13.92 & 0.31 & 0.30 & -26.42 & -0.20 & -0.19 \\
\hline$[-10,20]$ & -61.71 & -1.96 & -1.85 & -34.58 & -0.77 & -0.73 & -108.45 & -0.82 & -0.78 \\
\hline
\end{tabular}


Table A23. Case VI: GJR(1,1)—Cumulative abnormal change rate of Chinese tourist arrivals.

\begin{tabular}{|c|c|c|c|c|c|c|c|c|c|}
\hline \multirow{3}{*}{ Event Period $\left[\tau_{1}, \tau_{2}\right]$} & \multicolumn{3}{|c|}{ Group-Type } & \multicolumn{3}{|c|}{ Individual-Type } & \multicolumn{3}{|c|}{ Medical-Type } \\
\hline & \multirow{2}{*}{ CAR } & \multicolumn{2}{|c|}{ t-Value } & \multirow{2}{*}{ CAR } & \multicolumn{2}{|c|}{ t-Value } & \multirow{2}{*}{ CAR } & \multicolumn{2}{|c|}{ t-Value } \\
\hline & & TM & SRM & & TM & SRM & & TM & SRM \\
\hline$[-10,-10]$ & -21.70 & -0.33 & -0.32 & 11.64 & 0.17 & 0.17 & -61.71 & -0.24 & -0.23 \\
\hline$[-10,-9]$ & 15.06 & 0.23 & 0.22 & 63.98 & 0.93 & 0.91 & -7.62 & -0.03 & -0.03 \\
\hline$[-10,-8]$ & -3.67 & -0.06 & -0.05 & 76.55 & 1.11 & 1.08 & -65.54 & -0.25 & -0.24 \\
\hline$[-10,-7]$ & -13.08 & -0.20 & -0.19 & 26.72 & 0.39 & 0.38 & -139.27 & -0.53 & -0.52 \\
\hline$[-10,-6]$ & 15.44 & 0.23 & 0.23 & -0.62 & -0.01 & -0.01 & -133.77 & -0.51 & -0.50 \\
\hline$[-10,-5]$ & 14.72 & 0.22 & 0.22 & -12.60 & -0.18 & -0.18 & -119.63 & -0.46 & -0.45 \\
\hline$[-10,-4]$ & -55.71 & -0.84 & -0.83 & -39.88 & -0.58 & -0.57 & -220.31 & -0.84 & -0.83 \\
\hline$[-10,-3]$ & 17.24 & 0.26 & 0.25 & 26.42 & 0.38 & 0.37 & -166.56 & -0.64 & -0.61 \\
\hline$[-10,-2]$ & 50.40 & 0.76 & 0.75 & 36.04 & 0.52 & 0.51 & -162.44 & -0.62 & -0.61 \\
\hline$[-10,-1]$ & 29.98 & 0.45 & 0.45 & -27.65 & -0.40 & -0.39 & -78.88 & -0.30 & -0.30 \\
\hline$[-10,0]$ & 52.02 & 0.79 & 0.77 & 31.02 & 0.45 & 0.44 & -44.87 & -0.17 & -0.17 \\
\hline$[-10,1]$ & 82.44 & 1.25 & 1.23 & 46.39 & 0.67 & 0.66 & 55.90 & 0.21 & 0.21 \\
\hline$[-10,2]$ & 104.68 & 1.58 & 1.56 & 50.15 & 0.73 & 0.71 & 83.63 & 0.32 & 0.31 \\
\hline$[-10,3]$ & 116.81 & 1.77 & 1.73 & 40.69 & 0.59 & 0.58 & 98.16 & 0.38 & 0.37 \\
\hline$[-10,4]$ & 51.89 & 0.78 & 0.74 & 16.05 & 0.23 & 0.22 & -77.44 & -0.30 & -0.28 \\
\hline$[-10,5]$ & 75.31 & 1.14 & 1.12 & 72.48 & 1.05 & 1.03 & -50.25 & -0.19 & -0.19 \\
\hline$[-10,6]$ & 38.26 & 0.58 & 0.57 & 93.45 & 1.35 & 1.33 & -43.02 & -0.16 & -0.16 \\
\hline$[-10,7]$ & 62.89 & 0.95 & 0.93 & 62.04 & 0.90 & 0.88 & 99.61 & 0.38 & 0.37 \\
\hline$[-10,8]$ & 36.60 & 0.55 & 0.54 & 64.30 & 0.93 & 0.92 & -67.78 & -0.26 & -0.26 \\
\hline$[-10,9]$ & -7.40 & -0.11 & -0.07 & -23.68 & -0.34 & -0.21 & -44.44 & -0.17 & -0.10 \\
\hline$[-10,10]$ & 86.06 & 1.30 & 1.25 & 164.65 & 2.38 & 2.29 & 128.34 & 0.49 & 0.47 \\
\hline$[-10,11]$ & 87.35 & 1.32 & 1.28 & 196.49 & 2.84 & 2.76 & 141.74 & 0.54 & 0.53 \\
\hline$[-10,12]$ & 128.18 & 1.94 & 1.89 & 239.06 & 3.46 * & $3.38 *$ & 143.05 & 0.55 & 0.53 \\
\hline$[-10,13]$ & 154.92 & 2.34 & 2.29 & 254.35 & 3.68 * & 3.59 * & 177.76 & 0.68 & 0.66 \\
\hline$[-10,14]$ & 135.56 & 2.05 & 2.01 & 234.33 & 3.39 * & $3.32 *$ & 108.60 & 0.42 & 0.41 \\
\hline$[-10,15]$ & 70.57 & 1.07 & 1.05 & 180.05 & 2.61 & 2.56 & 110.50 & 0.42 & 0.42 \\
\hline$[-10,16]$ & 69.35 & 1.05 & 1.03 & 156.75 & 2.27 & 2.23 & 156.76 & 0.60 & 0.59 \\
\hline$[-10,17]$ & 59.59 & 0.90 & 0.89 & 112.11 & 1.62 & 1.60 & 163.95 & 0.63 & 0.62 \\
\hline$[-10,18]$ & 31.29 & 0.47 & 0.46 & 56.62 & 0.82 & 0.80 & 197.99 & 0.76 & 0.74 \\
\hline$[-10,19]$ & 23.83 & 0.36 & 0.35 & 41.82 & 0.61 & 0.58 & 124.09 & 0.47 & 0.46 \\
\hline$[-10,20]$ & 15.18 & 0.23 & 0.22 & -5.97 & -0.09 & -0.08 & 47.10 & 0.18 & 0.17 \\
\hline
\end{tabular}


Table A24. Case VI: EGARCH(1,1)—Cumulative abnormal change rate of Chinese tourist arrivals.

\begin{tabular}{|c|c|c|c|c|c|c|c|c|c|}
\hline \multirow{3}{*}{ Event Period $\left[\tau_{1}, \tau_{2}\right]$} & \multicolumn{3}{|c|}{ Group-Type } & \multicolumn{3}{|c|}{ Individual-Type } & \multicolumn{3}{|c|}{ Medical-Type } \\
\hline & \multirow{2}{*}{ CAR } & \multicolumn{2}{|c|}{ t-Value } & \multirow{2}{*}{ CAR } & \multicolumn{2}{|c|}{ t-Value } & \multirow{2}{*}{ CAR } & \multicolumn{2}{|c|}{ t-Value } \\
\hline & & TM & SRM & & TM & SRM & & TM & SRM \\
\hline$[-10,-10]$ & -21.43 & -0.27 & -0.26 & 11.60 & 0.16 & 0.16 & -55.27 & -0.12 & -0.12 \\
\hline$[-10,-9]$ & 15.90 & 0.20 & 0.20 & 64.02 & 0.91 & 0.89 & 5.84 & 0.01 & 0.01 \\
\hline$[-10,-8]$ & -2.74 & -0.03 & -0.03 & 76.48 & 1.08 & 1.06 & -46.00 & -0.10 & -0.10 \\
\hline$[-10,-7]$ & -11.11 & -0.14 & -0.14 & 26.91 & 0.38 & 0.37 & -111.80 & -0.25 & -0.24 \\
\hline$[-10,-6]$ & 18.35 & 0.23 & 0.23 & -0.20 & 0.00 & 0.00 & -98.54 & -0.22 & -0.21 \\
\hline$[-10,-5]$ & 17.83 & 0.22 & 0.22 & -12.24 & -0.17 & -0.17 & -78.09 & -0.17 & -0.17 \\
\hline$[-10,-4]$ & -52.06 & -0.65 & -0.64 & -39.45 & -0.56 & -0.55 & -171.82 & -0.38 & -0.37 \\
\hline$[-10,-3]$ & 20.29 & 0.25 & 0.24 & 26.46 & 0.37 & 0.36 & -113.33 & -0.25 & -0.24 \\
\hline$[-10,-2]$ & 54.74 & 0.69 & 0.67 & 36.44 & 0.52 & 0.51 & -100.79 & -0.22 & -0.22 \\
\hline$[-10,-1]$ & 35.49 & 0.45 & 0.44 & -26.92 & -0.38 & -0.38 & -9.04 & -0.02 & -0.02 \\
\hline$[-10,0]$ & 58.54 & 0.73 & 0.72 & 32.00 & 0.45 & 0.44 & 32.86 & 0.07 & 0.07 \\
\hline$[-10,1]$ & 89.04 & 1.12 & 1.10 & 47.26 & 0.67 & 0.66 & 139.69 & 0.31 & 0.30 \\
\hline$[-10,2]$ & 111.40 & 1.40 & 1.38 & 50.92 & 0.72 & 0.71 & 173.55 & 0.38 & 0.37 \\
\hline$[-10,3]$ & 123.55 & 1.55 & 1.52 & 41.32 & 0.58 & 0.57 & 194.05 & 0.43 & 0.42 \\
\hline$[-10,4]$ & 58.17 & 0.73 & 0.69 & 16.35 & 0.23 & 0.22 & 23.45 & 0.05 & 0.05 \\
\hline$[-10,5]$ & 83.67 & 1.05 & 1.03 & 73.47 & 1.04 & 1.02 & 60.61 & 0.13 & 0.13 \\
\hline$[-10,6]$ & 47.02 & 0.59 & 0.58 & 94.45 & 1.34 & 1.32 & 74.54 & 0.16 & 0.16 \\
\hline$[-10,7]$ & 72.04 & 0.90 & 0.89 & 63.04 & 0.89 & 0.88 & 223.83 & 0.49 & 0.48 \\
\hline$[-10,8]$ & 46.46 & 0.58 & 0.57 & 65.44 & 0.93 & 0.91 & 63.72 & 0.14 & 0.14 \\
\hline$[-10,9]$ & 10.50 & 0.13 & 0.08 & -19.46 & -0.28 & -0.17 & 108.67 & 0.24 & 0.14 \\
\hline$[-10,10]$ & 95.80 & 1.20 & 1.15 & 165.44 & 2.34 & 2.25 & 271.43 & 0.59 & 0.57 \\
\hline$[-10,11]$ & 97.89 & 1.23 & 1.19 & 197.46 & 2.80 & 2.71 & 292.32 & 0.64 & 0.62 \\
\hline$[-10,12]$ & 139.55 & 1.75 & 1.71 & 240.21 & 3.40 * & $3.32 *$ & 301.14 & 0.66 & 0.65 \\
\hline$[-10,13]$ & 166.74 & 2.09 & 2.04 & 255.53 & $3.62 *$ & 3.53 * & 342.66 & 0.75 & 0.73 \\
\hline$[-10,14]$ & 148.10 & 1.86 & 1.82 & 235.65 & 3.34 * & 3.27 * & 280.81 & 0.62 & 0.60 \\
\hline$[-10,15]$ & 83.85 & 1.05 & 1.03 & 181.53 & 2.57 & 2.53 & 290.07 & 0.64 & 0.63 \\
\hline$[-10,16]$ & 83.58 & 1.05 & 1.03 & 158.46 & 2.24 & 2.21 & 344.07 & 0.75 & 0.74 \\
\hline$[-10,17]$ & 74.36 & 0.93 & 0.92 & 113.88 & 1.61 & 1.59 & 358.22 & 0.79 & 0.77 \\
\hline$[-10,18]$ & 45.93 & 0.58 & 0.57 & 58.20 & 0.82 & 0.81 & 397.93 & 0.87 & 0.86 \\
\hline$[-10,19]$ & 38.31 & 0.48 & 0.46 & 43.18 & 0.61 & 0.59 & 329.62 & 0.72 & 0.70 \\
\hline$[-10,20]$ & 29.71 & 0.37 & 0.35 & -4.74 & -0.07 & -0.06 & 258.64 & 0.57 & 0.54 \\
\hline
\end{tabular}


Table A25. Case VII: OLS—Cumulative abnormal change rate of Chinese tourist arrivals.

\begin{tabular}{|c|c|c|c|c|c|c|c|c|c|}
\hline \multirow{3}{*}{ Event Period $\left[\tau_{1}, \tau_{2}\right]$} & \multicolumn{3}{|c|}{ Group-Type } & \multicolumn{3}{|c|}{ Individual-Type } & \multicolumn{3}{|c|}{ Medical-Type } \\
\hline & \multirow{2}{*}{ CAR } & \multicolumn{2}{|c|}{ t-Value } & \multirow{2}{*}{ CAR } & \multicolumn{2}{|c|}{ t-Value } & \multirow{2}{*}{ CAR } & \multicolumn{2}{|c|}{ t-Value } \\
\hline & & TM & SRM & & TM & SRM & & TM & SRM \\
\hline$[0,0]$ & -17.29 & -0.88 & -0.86 & 6.24 & 0.27 & 0.26 & 176.65 & 2.15 & 2.11 \\
\hline$[0,1]$ & -20.93 & -1.06 & -1.05 & 37.49 & 1.60 & 1.58 & 233.85 & 2.84 & 2.80 \\
\hline$[0,2]$ & 0.56 & 0.03 & 0.03 & 47.07 & 2.01 & 1.98 & 53.96 & 0.66 & 0.65 \\
\hline$[0,3]$ & -28.25 & -1.43 & -1.41 & 23.73 & 1.02 & 1.00 & 227.76 & 2.77 & 2.73 \\
\hline$[0,4]$ & -34.92 & -1.77 & -1.74 & 11.10 & 0.47 & 0.47 & 138.31 & 1.68 & 1.66 \\
\hline$[0,5]$ & -9.64 & -0.49 & -0.48 & 20.04 & 0.86 & 0.84 & 256.74 & $3.12 *$ & $3.07 *$ \\
\hline$[0,6]$ & 0.01 & 0.00 & 0.00 & 16.08 & 0.69 & 0.68 & 187.34 & 2.28 & 2.24 \\
\hline$[0,7]$ & 6.44 & 0.33 & 0.32 & 13.94 & 0.60 & 0.59 & 281.62 & $3.42 *$ & 3.37 * \\
\hline$[0,8]$ & 7.16 & 0.36 & 0.36 & 42.80 & 1.83 & 1.80 & 259.33 & $3.15 *$ & $3.10 *$ \\
\hline$[0,9]$ & 16.77 & 0.85 & 0.84 & 52.25 & 2.24 & 2.20 & 309.96 & $3.77^{*}$ & $3.71 *$ \\
\hline$[0,10]$ & -21.75 & -1.10 & -1.09 & 20.16 & 0.86 & 0.85 & 213.71 & 2.60 & 2.56 \\
\hline$[0,11]$ & -23.03 & -1.17 & -1.15 & 11.32 & 0.48 & 0.48 & 265.44 & 3.23 * & 3.18 * \\
\hline$[0,12]$ & -4.07 & -0.21 & -0.20 & 10.95 & 0.47 & 0.46 & 110.16 & 1.34 & 1.32 \\
\hline$[0,13]$ & 7.58 & 0.38 & 0.38 & 15.90 & 0.68 & 0.67 & 193.00 & 2.35 & 2.30 \\
\hline$[0,14]$ & 16.32 & 0.83 & 0.82 & 19.06 & 0.82 & 0.80 & 198.66 & 2.41 & 2.38 \\
\hline$[0,15]$ & 9.57 & 0.49 & 0.47 & 39.59 & 1.69 & 1.65 & 234.78 & 2.85 & 2.79 \\
\hline$[0,16]$ & 21.61 & 1.10 & 1.08 & 37.16 & 1.59 & 1.56 & 282.05 & 3.43 * & 3.37 * \\
\hline$[0,17]$ & -30.99 & -1.57 & -1.55 & 3.80 & 0.16 & 0.16 & 222.94 & 2.71 & 2.67 \\
\hline$[0,18]$ & -18.37 & -0.93 & -0.92 & -1.60 & -0.07 & -0.07 & 274.04 & 3.33 * & 3.28 * \\
\hline$[0,19]$ & -22.77 & -1.16 & -1.14 & -11.07 & -0.47 & -0.47 & 303.07 & $3.68 *$ & $3.62 *$ \\
\hline$[0,20]$ & 1.76 & 0.09 & 0.09 & -4.33 & -0.19 & -0.18 & 327.69 & $3.98 *$ & $3.92 *$ \\
\hline$[0,21]$ & -5.85 & -0.30 & -0.29 & -10.32 & -0.44 & -0.43 & 212.75 & 2.59 & 2.55 \\
\hline$[0,22]$ & 7.78 & 0.39 & 0.39 & 2.08 & 0.09 & 0.09 & 177.01 & 2.15 & 2.12 \\
\hline$[0,23]$ & -0.50 & -0.03 & -0.02 & -11.78 & -0.50 & -0.50 & 207.81 & 2.53 & 2.49 \\
\hline$[0,24]$ & -54.74 & -2.78 & -2.74 & -30.23 & -1.29 & -1.27 & 231.82 & 2.82 & 2.77 \\
\hline$[0,25]$ & -77.00 & $-3.91 *$ & $-3.85 *$ & -57.37 & -2.45 & -2.42 & 311.12 & $3.78^{*}$ & $3.72 *$ \\
\hline$[0,26]$ & -62.26 & $-3.16^{*}$ & $-3.11 *$ & -74.21 & $-3.17 *$ & $-3.12 *$ & 188.75 & 2.29 & 2.26 \\
\hline$[0,27]$ & -43.88 & -2.23 & -2.19 & -89.98 & $-3.85 *$ & $-3.79 *$ & 309.29 & $3.76^{*}$ & 3.70 * \\
\hline$[0,28]$ & -45.40 & -2.30 & -2.27 & -75.29 & $-3.22 *$ & $-3.17^{*}$ & 284.92 & $3.46^{*}$ & 3.41 * \\
\hline$[0,29]$ & -42.96 & -2.18 & -2.14 & -62.63 & -2.68 & -2.63 & 391.41 & $4.76^{* *}$ & $4.68^{* *}$ \\
\hline$[0,30]$ & -47.64 & -2.42 & -2.38 & -62.01 & -2.65 & -2.61 & 357.44 & $4.34^{* *}$ & $4.28 *$ \\
\hline
\end{tabular}


Table A26. Case VII: GARCH(1,1)—Cumulative abnormal change rate of Chinese tourist arrivals.

\begin{tabular}{|c|c|c|c|c|c|c|c|c|c|}
\hline \multirow{3}{*}{ Event Period $\left[\tau_{1}, \tau_{2}\right]$} & \multicolumn{3}{|c|}{ Group-Type } & \multicolumn{3}{|c|}{ Individual-Type } & \multicolumn{3}{|c|}{ Medical-Type } \\
\hline & \multirow{2}{*}{ CAR } & \multicolumn{2}{|c|}{ t-Value } & \multirow{2}{*}{ CAR } & \multicolumn{2}{|c|}{ t-Value } & \multirow{2}{*}{ CAR } & \multicolumn{2}{|c|}{ t-Value } \\
\hline & & TM & SRM & & TM & SRM & & TM & SRM \\
\hline$[0,0]$ & -18.31 & -0.54 & -0.53 & 5.71 & 0.20 & 0.20 & 176.75 & 2.11 & 2.08 \\
\hline$[0,1]$ & -23.24 & -0.68 & -0.67 & 36.48 & 1.29 & 1.27 & 234.01 & 2.80 & 2.76 \\
\hline$[0,2]$ & -2.57 & -0.08 & -0.07 & 45.51 & 1.61 & 1.58 & 54.24 & 0.65 & 0.64 \\
\hline$[0,3]$ & -32.35 & -0.95 & -0.94 & 21.63 & 0.76 & 0.75 & 228.14 & 2.73 & 2.69 \\
\hline$[0,4]$ & -39.96 & -1.18 & -1.16 & 8.46 & 0.30 & 0.29 & 138.78 & 1.66 & 1.63 \\
\hline$[0,5]$ & -16.17 & -0.48 & -0.47 & 16.95 & 0.60 & 0.59 & 257.26 & $3.08 *$ & $3.03 *$ \\
\hline$[0,6]$ & -7.72 & -0.23 & -0.22 & 12.49 & 0.44 & 0.43 & 187.93 & 2.25 & 2.21 \\
\hline$[0,7]$ & -2.18 & -0.06 & -0.06 & 9.80 & 0.35 & 0.34 & 282.33 & $3.38 *$ & $3.32 *$ \\
\hline$[0,8]$ & -2.75 & -0.08 & -0.08 & 38.18 & 1.35 & 1.33 & 260.11 & $3.11 *$ & $3.06 *$ \\
\hline$[0,9]$ & 5.61 & 0.17 & 0.16 & 47.14 & 1.66 & 1.64 & 310.80 & $3.72 *$ & $3.66 *$ \\
\hline$[0,10]$ & -33.88 & -1.00 & -0.98 & 14.52 & 0.51 & 0.50 & 214.65 & 2.57 & 2.53 \\
\hline$[0,11]$ & -36.25 & -1.07 & -1.05 & 5.16 & 0.18 & 0.18 & 266.46 & 3.19 * & $3.14 *$ \\
\hline$[0,12]$ & -18.87 & -0.56 & -0.55 & 4.34 & 0.15 & 0.15 & 111.23 & 1.33 & 1.31 \\
\hline$[0,13]$ & -7.60 & -0.22 & -0.22 & 8.68 & 0.31 & 0.30 & 194.22 & 2.32 & 2.28 \\
\hline$[0,14]$ & -0.08 & 0.00 & 0.00 & 11.34 & 0.40 & 0.39 & 199.96 & 2.39 & 2.35 \\
\hline$[0,15]$ & -9.27 & -0.27 & -0.27 & 31.54 & 1.11 & 1.09 & 236.03 & 2.82 & 2.76 \\
\hline$[0,16]$ & 1.98 & 0.06 & 0.06 & 28.56 & 1.01 & 0.99 & 283.41 & 3.39 * & 3.33 * \\
\hline$[0,17]$ & -51.32 & -1.51 & -1.49 & -5.37 & -0.19 & -0.19 & 224.44 & 2.68 & 2.64 \\
\hline$[0,18]$ & -39.87 & -1.17 & -1.16 & -11.28 & -0.40 & -0.39 & 275.61 & 3.30 * & $3.25 *$ \\
\hline$[0,19]$ & -46.02 & -1.36 & -1.33 & -21.16 & -0.75 & -0.73 & 304.66 & $3.64 *$ & $3.58 *$ \\
\hline$[0,20]$ & -22.37 & -0.66 & -0.65 & -14.97 & -0.53 & -0.52 & 329.39 & 3.94 * & 3.88 * \\
\hline$[0,21]$ & -30.93 & -0.91 & -0.90 & -21.49 & -0.76 & -0.75 & 214.56 & 2.57 & 2.53 \\
\hline$[0,22]$ & -18.96 & -0.56 & -0.55 & -9.53 & -0.34 & -0.33 & 178.85 & 2.14 & 2.10 \\
\hline$[0,23]$ & -28.40 & -0.84 & -0.82 & -23.89 & -0.84 & -0.83 & 209.72 & 2.51 & 2.47 \\
\hline$[0,24]$ & -83.61 & -2.46 & -2.42 & -42.88 & -1.51 & -1.49 & 233.84 & 2.80 & 2.75 \\
\hline$[0,25]$ & -106.71 & $-3.14 *$ & $-3.09^{*}$ & -70.57 & -2.49 & -2.45 & 313.24 & $3.75 *$ & 3.69 * \\
\hline$[0,26]$ & -93.56 & -2.76 & -2.71 & -87.85 & $-3.10 *$ & $-3.05 *$ & 190.91 & 2.28 & 2.25 \\
\hline$[0,27]$ & -76.17 & -2.24 & -2.21 & -104.15 & $-3.67 *$ & $-3.62 *$ & 311.54 & 3.73 * & 3.67 * \\
\hline$[0,28]$ & -78.85 & -2.32 & -2.29 & -89.97 & $-3.17 *$ & $-3.13 *$ & 287.26 & $3.43 *$ & $3.38 *$ \\
\hline$[0,29]$ & -78.12 & -2.30 & -2.26 & -77.73 & -2.74 & -2.70 & 393.77 & $4.71^{* *}$ & $4.63^{* *}$ \\
\hline$[0,30]$ & -84.34 & -2.48 & -2.44 & -77.56 & -2.74 & -2.69 & 359.84 & 4.30 * & 4.23 * \\
\hline
\end{tabular}


Table A27. Case VII: GJR(1,1)—Cumulative abnormal change rate of Chinese tourist arrivals.

\begin{tabular}{|c|c|c|c|c|c|c|c|c|c|}
\hline \multirow{3}{*}{ Event Period $\left[\tau_{1}, \tau_{2}\right]$} & \multicolumn{3}{|c|}{ Group-Type } & \multicolumn{3}{|c|}{ Individual-Type } & \multicolumn{3}{|c|}{ Medical-Type } \\
\hline & \multirow{2}{*}{ CAR } & \multicolumn{2}{|c|}{ t-Value } & \multirow{2}{*}{ CAR } & \multicolumn{2}{|c|}{ t-Value } & \multirow{2}{*}{ CAR } & \multicolumn{2}{|c|}{ t-Value } \\
\hline & & TM & SRM & & TM & SRM & & TM & SRM \\
\hline$[0,0]$ & -17.09 & -0.81 & -0.79 & 6.27 & 0.27 & 0.26 & 178.17 & 1.56 & 1.54 \\
\hline$[0,1]$ & -20.64 & -0.97 & -0.96 & 37.61 & 1.61 & 1.59 & 236.91 & 2.08 & 2.04 \\
\hline$[0,2]$ & 1.12 & 0.05 & 0.05 & 47.19 & 2.02 & 1.99 & 58.52 & 0.51 & 0.50 \\
\hline$[0,3]$ & -27.47 & -1.30 & -1.28 & 23.87 & 1.02 & 1.01 & 233.84 & 2.05 & 2.02 \\
\hline$[0,4]$ & -33.91 & -1.60 & -1.57 & 11.25 & 0.48 & 0.47 & 145.90 & 1.28 & 1.26 \\
\hline$[0,5]$ & -8.62 & -0.41 & -0.40 & 20.32 & 0.87 & 0.86 & 265.89 & 2.33 & 2.29 \\
\hline$[0,6]$ & 1.16 & 0.05 & 0.05 & 16.43 & 0.70 & 0.69 & 198.02 & 1.73 & 1.71 \\
\hline$[0,7]$ & 7.84 & 0.37 & 0.36 & 14.30 & 0.61 & 0.60 & 293.81 & 2.57 & 2.53 \\
\hline$[0,8]$ & 8.65 & 0.41 & 0.40 & 43.25 & 1.85 & 1.82 & 273.07 & 2.39 & 2.36 \\
\hline$[0,9]$ & 18.37 & 0.87 & 0.85 & 52.77 & 2.26 & 2.23 & 325.24 & 2.85 & 2.81 \\
\hline$[0,10]$ & -19.94 & -0.94 & -0.93 & 20.71 & 0.89 & 0.87 & 230.50 & 2.02 & 1.99 \\
\hline$[0,11]$ & -21.05 & -0.99 & -0.98 & 11.91 & 0.51 & 0.50 & 283.75 & 2.49 & 2.45 \\
\hline$[0,12]$ & -2.11 & -0.10 & -0.10 & 11.68 & 0.50 & 0.49 & 130.05 & 1.14 & 1.12 \\
\hline$[0,13]$ & 9.99 & 0.47 & 0.46 & 16.55 & 0.71 & 0.70 & 214.34 & 1.88 & 1.84 \\
\hline$[0,14]$ & 18.85 & 0.89 & 0.88 & 19.77 & 0.85 & 0.83 & 221.55 & 1.94 & 1.91 \\
\hline$[0,15]$ & 11.73 & 0.55 & 0.54 & 40.61 & 1.74 & 1.70 & 259.31 & 2.27 & 2.22 \\
\hline$[0,16]$ & 24.06 & 1.13 & 1.12 & 38.17 & 1.64 & 1.61 & 308.08 & 2.70 & 2.66 \\
\hline$[0,17]$ & -28.21 & -1.33 & -1.31 & 4.79 & 0.21 & 0.20 & 250.47 & 2.19 & 2.16 \\
\hline$[0,18]$ & -15.45 & -0.73 & -0.72 & -0.56 & -0.02 & -0.02 & 303.09 & 2.66 & 2.62 \\
\hline$[0,19]$ & -19.95 & -0.94 & -0.92 & -9.85 & -0.42 & -0.41 & 333.71 & $2.92^{*}$ & 2.87 \\
\hline$[0,20]$ & 4.84 & 0.23 & 0.22 & -3.10 & -0.13 & -0.13 & 359.83 & $3.15^{*}$ & $3.10^{*}$ \\
\hline$[0,21]$ & -2.55 & -0.12 & -0.12 & -9.07 & -0.39 & -0.38 & 246.41 & 2.16 & 2.13 \\
\hline$[0,22]$ & 11.02 & 0.52 & 0.51 & 3.48 & 0.15 & 0.15 & 212.25 & 1.86 & 1.83 \\
\hline$[0,23]$ & 2.89 & 0.14 & 0.13 & -10.31 & -0.44 & -0.44 & 244.58 & 2.14 & 2.11 \\
\hline$[0,24]$ & -51.14 & -2.41 & -2.37 & -28.74 & -1.23 & -1.21 & 270.10 & 2.37 & 2.33 \\
\hline$[0,25]$ & -73.13 & -3.45 * & $-3.39 *$ & -55.88 & -2.39 & -2.36 & 350.90 & 3.07 * & 3.03 * \\
\hline$[0,26]$ & -58.41 & -2.75 & -2.71 & -72.58 & $-3.11 *$ & $-3.06 *$ & 230.10 & 2.02 & 1.98 \\
\hline$[0,27]$ & -39.82 & -1.88 & -1.85 & -88.32 & $-3.78 *$ & $-3.73 *$ & 352.16 & 3.09 * & 3.04 * \\
\hline$[0,28]$ & -41.21 & -1.94 & -1.91 & -73.57 & $-3.15^{*}$ & $-3.10 *$ & 329.32 & 2.89 & 2.84 \\
\hline$[0,29]$ & -38.85 & -1.83 & -1.80 & -60.74 & -2.60 & -2.56 & 437.39 & $3.83 *$ & $3.77 *$ \\
\hline$[0,30]$ & -43.53 & -2.05 & -2.02 & -59.98 & -2.57 & -2.53 & 404.99 & 3.55 * & 3.49 * \\
\hline
\end{tabular}


Table A28. Case VII: EGARCH(1,1)-Cumulative Abnormal Change Rate of Chinese Tourist Arrivals.

\begin{tabular}{|c|c|c|c|c|c|c|c|c|c|}
\hline \multirow{3}{*}{ Event Period $\left[\tau_{1}, \tau_{2}\right]$} & \multicolumn{3}{|c|}{ Group-Type } & \multicolumn{3}{|c|}{ Individual-Type } & \multicolumn{3}{|c|}{ Medical-Type } \\
\hline & \multirow{2}{*}{ CAR } & \multicolumn{2}{|c|}{ t-Value } & \multirow{2}{*}{ CAR } & \multicolumn{2}{|c|}{ t-Value } & \multirow{2}{*}{ CAR } & \multicolumn{2}{|c|}{ t-Value } \\
\hline & & TM & SRM & & TM & SRM & & TM & SRM \\
\hline$[0,0]$ & -16.75 & -0.53 & -0.53 & 6.32 & 0.27 & 0.27 & 178.17 & 0.51 & 0.50 \\
\hline$[0,1]$ & -19.62 & -0.63 & -0.62 & 37.74 & 1.61 & 1.58 & 236.91 & 0.67 & 0.66 \\
\hline$[0,2]$ & 2.23 & 0.07 & 0.07 & 47.34 & 2.02 & 1.99 & 58.52 & 0.17 & 0.16 \\
\hline$[0,3]$ & -26.08 & -0.83 & -0.82 & 24.06 & 1.03 & 1.01 & 233.84 & 0.66 & 0.65 \\
\hline$[0,4]$ & -32.28 & -1.03 & -1.01 & 11.48 & 0.49 & 0.48 & 145.90 & 0.41 & 0.41 \\
\hline$[0,5]$ & -6.05 & -0.19 & -0.19 & 20.66 & 0.88 & 0.87 & 265.89 & 0.75 & 0.74 \\
\hline$[0,6]$ & 4.30 & 0.14 & 0.14 & 16.85 & 0.72 & 0.71 & 198.02 & 0.56 & 0.55 \\
\hline$[0,7]$ & 11.15 & 0.36 & 0.35 & 14.74 & 0.63 & 0.62 & 293.81 & 0.83 & 0.82 \\
\hline$[0,8]$ & 12.64 & 0.40 & 0.40 & 43.77 & 1.87 & 1.84 & 273.07 & 0.77 & 0.76 \\
\hline$[0,9]$ & 23.00 & 0.73 & 0.72 & 53.38 & 2.28 & 2.24 & 325.24 & 0.92 & 0.91 \\
\hline$[0,10]$ & -15.02 & -0.48 & -0.47 & 21.36 & 0.91 & 0.90 & 230.50 & 0.65 & 0.64 \\
\hline$[0,11]$ & -15.71 & -0.50 & -0.49 & 12.62 & 0.54 & 0.53 & 283.75 & 0.80 & 0.79 \\
\hline$[0,12]$ & 4.28 & 0.14 & 0.13 & 12.52 & 0.53 & 0.53 & 130.05 & 0.37 & 0.36 \\
\hline$[0,13]$ & 15.92 & 0.51 & 0.50 & 17.34 & 0.74 & 0.73 & 214.34 & 0.61 & 0.60 \\
\hline$[0,14]$ & 25.36 & 0.81 & 0.80 & 20.64 & 0.88 & 0.87 & 221.55 & 0.63 & 0.62 \\
\hline$[0,15]$ & 20.37 & 0.65 & 0.63 & 41.73 & 1.78 & 1.74 & 259.31 & 0.74 & 0.72 \\
\hline$[0,16]$ & 32.76 & 1.05 & 1.03 & 39.31 & 1.68 & 1.65 & 308.08 & 0.87 & 0.86 \\
\hline$[0,17]$ & -19.58 & -0.63 & -0.61 & 5.92 & 0.25 & 0.25 & 250.47 & 0.71 & 0.70 \\
\hline$[0,18]$ & -6.29 & -0.20 & -0.20 & 0.65 & 0.03 & 0.03 & 303.09 & 0.86 & 0.85 \\
\hline$[0,19]$ & -9.52 & -0.30 & -0.30 & -8.49 & -0.36 & -0.36 & 333.71 & 0.95 & 0.93 \\
\hline$[0,20]$ & 15.44 & 0.49 & 0.49 & -1.72 & -0.07 & -0.07 & 359.83 & 1.02 & 1.00 \\
\hline$[0,21]$ & 8.30 & 0.26 & 0.26 & -7.65 & -0.33 & -0.32 & 246.41 & 0.70 & 0.69 \\
\hline$[0,22]$ & 23.01 & 0.73 & 0.72 & 5.04 & 0.22 & 0.21 & 212.25 & 0.60 & 0.59 \\
\hline$[0,23]$ & 15.41 & 0.49 & 0.48 & -8.69 & -0.37 & -0.36 & 244.58 & 0.69 & 0.68 \\
\hline$[0,24]$ & -38.34 & -1.22 & -1.21 & -27.07 & -1.15 & -1.14 & 270.10 & 0.77 & 0.75 \\
\hline$[0,25]$ & -60.23 & -1.92 & -1.89 & -54.19 & -2.31 & -2.27 & 350.90 & 0.99 & 0.98 \\
\hline$[0,26]$ & -44.44 & -1.42 & -1.40 & -70.76 & $-3.02 *$ & $-2.97 *$ & 230.10 & 0.65 & 0.64 \\
\hline$[0,27]$ & -25.55 & -0.82 & -0.80 & -86.46 & $-3.69 *$ & $-3.63 *$ & 352.16 & 1.00 & 0.98 \\
\hline$[0,28]$ & -26.42 & -0.84 & -0.83 & -71.64 & $-3.05^{*}$ & $-3.01 *$ & 329.32 & 0.93 & 0.92 \\
\hline$[0,29]$ & -22.84 & -0.73 & -0.72 & -58.66 & -2.50 & -2.46 & 437.39 & 1.24 & 1.22 \\
\hline$[0,30]$ & -26.52 & -0.85 & -0.83 & -57.78 & -2.46 & -2.42 & 404.99 & 1.15 & 1.13 \\
\hline
\end{tabular}


Table A29. Case VIII: OLS—Cumulative abnormal change rate of Chinese tourist arrivals.

\begin{tabular}{|c|c|c|c|c|c|c|c|c|c|}
\hline \multirow{3}{*}{ Event Period $\left[\tau_{1}, \tau_{2}\right]$} & \multicolumn{3}{|c|}{ Group-Type } & \multicolumn{3}{|c|}{ Individual-Type } & \multicolumn{3}{|c|}{ Medical-Type } \\
\hline & \multirow{2}{*}{ CAR } & \multicolumn{2}{|c|}{$\mathrm{t}$-Value } & \multirow{2}{*}{ CAR } & \multicolumn{2}{|c|}{$\mathrm{t}$-Value } & \multirow{2}{*}{ CAR } & \multicolumn{2}{|c|}{ t-Value } \\
\hline & & TM & SRM & & TM & SRM & & TM & SRM \\
\hline$[0,0]$ & 4.72 & 0.21 & 0.20 & 9.73 & 0.31 & 0.30 & 26.95 & 0.25 & 0.24 \\
\hline$[0,1]$ & 5.36 & 0.23 & 0.23 & 27.43 & 0.86 & 0.85 & 161.67 & 1.48 & 1.45 \\
\hline$[0,2]$ & 25.92 & 1.13 & 1.11 & 28.94 & 0.91 & 0.90 & 94.68 & 0.86 & 0.85 \\
\hline$[0,3]$ & -8.18 & -0.36 & -0.35 & -25.21 & -0.79 & -0.78 & 159.44 & 1.46 & 1.43 \\
\hline$[0,4]$ & 10.22 & 0.45 & 0.44 & -75.97 & -2.39 & -2.35 & 103.78 & 0.95 & 0.93 \\
\hline$[0,5]$ & 38.10 & 1.66 & 1.63 & -6.14 & -0.19 & -0.19 & 14.05 & 0.13 & 0.13 \\
\hline$[0,6]$ & 72.00 & $3.14 *$ & $3.09 *$ & 6.18 & 0.19 & 0.19 & 106.84 & 0.98 & 0.96 \\
\hline$[0,7]$ & 94.02 & $4.09 *$ & $4.03 *$ & 42.28 & 1.33 & 1.31 & 243.60 & 2.22 & 2.19 \\
\hline$[0,8]$ & 75.79 & 3.30 * & 3.25 * & 39.93 & 1.26 & 1.24 & 129.57 & 1.18 & 1.16 \\
\hline$[0,9]$ & 78.19 & $3.41 *$ & 3.35 * & 39.50 & 1.24 & 1.22 & 262.72 & 2.40 & 2.36 \\
\hline$[0,10]$ & 37.63 & 1.64 & 1.61 & 0.74 & 0.02 & 0.02 & 225.73 & 2.06 & 2.03 \\
\hline$[0,11]$ & 54.47 & 2.37 & 2.34 & -4.25 & -0.13 & -0.13 & 80.91 & 0.74 & 0.73 \\
\hline$[0,12]$ & 69.67 & $3.03 *$ & $2.99 *$ & 18.10 & 0.57 & 0.56 & 120.24 & 1.10 & 1.08 \\
\hline$[0,13]$ & 88.94 & $3.87^{*}$ & $3.81 *$ & 14.16 & 0.45 & 0.44 & 226.26 & 2.07 & 2.03 \\
\hline$[0,14]$ & 83.04 & $3.62 *$ & $3.56^{*}$ & 10.67 & 0.34 & 0.33 & 286.53 & 2.62 & 2.58 \\
\hline$[0,15]$ & 109.07 & $4.75^{* *}$ & $4.67^{* *}$ & 37.86 & 1.19 & 1.17 & 212.78 & 1.94 & 1.91 \\
\hline$[0,16]$ & 86.05 & 3.75 * & $3.69 *$ & 33.31 & 1.05 & 1.03 & 194.44 & 1.78 & 1.75 \\
\hline$[0,17]$ & 11.28 & 0.49 & 0.48 & -33.07 & -1.04 & -1.02 & 313.07 & 2.86 & 2.81 \\
\hline$[0,18]$ & 97.33 & $4.24^{*}$ & $4.17^{*}$ & 45.76 & 1.44 & 1.42 & 280.25 & 2.56 & 2.52 \\
\hline$[0,19]$ & 80.53 & $3.51 *$ & $3.45 *$ & 10.36 & 0.33 & 0.32 & 230.22 & 2.10 & 2.07 \\
\hline$[0,20]$ & 73.53 & $3.20 *$ & $3.15^{*}$ & 27.48 & 0.87 & 0.85 & 115.74 & 1.06 & 1.04 \\
\hline$[0,21]$ & 58.35 & 2.54 & 2.50 & 60.78 & 1.92 & 1.88 & 358.75 & 3.28 * & $3.22 *$ \\
\hline$[0,22]$ & 44.11 & 1.92 & 1.89 & 79.54 & 2.51 & 2.47 & 363.99 & 3.32 * & 3.27 * \\
\hline$[0,23]$ & 54.46 & 2.37 & 2.34 & 102.67 & 3.23 * & 3.19 * & 276.45 & 2.52 & 2.48 \\
\hline$[0,24]$ & 37.85 & 1.65 & 1.62 & 92.36 & 2.91 & 2.86 & 320.12 & $2.92 *$ & 2.88 \\
\hline$[0,25]$ & 82.27 & $3.58 *$ & $3.53 *$ & 127.84 & $4.03 *$ & $3.97 *$ & 251.14 & 2.29 & 2.26 \\
\hline$[0,26]$ & 62.06 & 2.70 & 2.66 & 168.10 & $5.30^{* *}$ & $5.21 * *$ & 212.45 & 1.94 & 1.91 \\
\hline$[0,27]$ & 97.53 & $4.25 *$ & $4.18^{*}$ & 188.72 & $5.95^{* *}$ & $5.85 * *$ & 211.11 & 1.93 & 1.90 \\
\hline$[0,28]$ & 78.33 & $3.41 *$ & $3.36^{*}$ & 162.72 & $5.13^{* *}$ & $5.05^{* *}$ & 174.28 & 1.59 & 1.57 \\
\hline$[0,29]$ & 31.03 & 1.35 & 1.33 & 121.60 & 3.83 * & $3.77^{*}$ & 284.24 & 2.59 & 2.55 \\
\hline$[0,30]$ & 25.77 & 1.12 & 1.10 & 56.03 & 1.77 & 1.74 & 116.45 & 1.06 & 1.05 \\
\hline
\end{tabular}


Table A30. Case VIII: GARCH(1,1)—Cumulative abnormal change rate of Chinese tourist arrivals.

\begin{tabular}{|c|c|c|c|c|c|c|c|c|c|}
\hline \multirow{3}{*}{ Event Period $\left[\tau_{1}, \tau_{2}\right]$} & \multicolumn{3}{|c|}{ Group-Type } & \multicolumn{3}{|c|}{ Individual-Type } & \multicolumn{3}{|c|}{ Medical-Type } \\
\hline & \multirow{2}{*}{ CAR } & \multicolumn{2}{|c|}{ t-Value } & \multirow{2}{*}{ CAR } & \multicolumn{2}{|c|}{ t-Value } & \multirow{2}{*}{ CAR } & \multicolumn{2}{|c|}{ t-Value } \\
\hline & & $\mathbf{T M}$ & SRM & & TM & SRM & & TM & SRM \\
\hline$[0,0]$ & 4.75 & 0.21 & 0.20 & 9.47 & 0.32 & 0.31 & 30.58 & 0.15 & 0.15 \\
\hline$[0,1]$ & 5.60 & 0.25 & 0.24 & 26.91 & 0.90 & 0.88 & 168.37 & 0.82 & 0.80 \\
\hline$[0,2]$ & 26.54 & 1.16 & 1.14 & 28.17 & 0.94 & 0.92 & 103.94 & 0.50 & 0.49 \\
\hline$[0,3]$ & -8.18 & -0.36 & -0.35 & -26.25 & -0.88 & -0.86 & 174.31 & 0.84 & 0.83 \\
\hline$[0,4]$ & 10.94 & 0.48 & 0.47 & -77.26 & -2.58 & -2.53 & 120.20 & 0.58 & 0.57 \\
\hline$[0,5]$ & 38.71 & 1.69 & 1.67 & -7.69 & -0.26 & -0.25 & 34.50 & 0.17 & 0.16 \\
\hline$[0,6]$ & 72.61 & $3.18 *$ & $3.13 *$ & 4.37 & 0.15 & 0.14 & 130.99 & 0.63 & 0.62 \\
\hline$[0,7]$ & 94.80 & $4.15^{*}$ & $4.08^{*}$ & 40.22 & 1.34 & 1.32 & 270.95 & 1.31 & 1.29 \\
\hline$[0,8]$ & 76.46 & 3.34 * & $3.29 *$ & 37.60 & 1.25 & 1.24 & 161.01 & 0.78 & 0.77 \\
\hline$[0,9]$ & 79.04 & $3.46^{*}$ & $3.40^{*}$ & 36.92 & 1.23 & 1.21 & 297.33 & 1.44 & 1.42 \\
\hline$[0,10]$ & 38.33 & 1.68 & 1.65 & -2.11 & -0.07 & -0.07 & 264.49 & 1.28 & 1.26 \\
\hline$[0,11]$ & 55.16 & 2.41 & 2.38 & -7.36 & -0.25 & -0.24 & 123.40 & 0.60 & 0.59 \\
\hline$[0,12]$ & 70.43 & $3.08 *$ & $3.03 *$ & 14.73 & 0.49 & 0.48 & 166.25 & 0.81 & 0.79 \\
\hline$[0,13]$ & 89.73 & $3.93 *$ & $3.87^{*}$ & 10.54 & 0.35 & 0.35 & 275.87 & 1.34 & 1.32 \\
\hline$[0,14]$ & 83.79 & $3.67^{*}$ & $3.61 *$ & 6.78 & 0.23 & 0.22 & 340.00 & 1.65 & 1.62 \\
\hline$[0,15]$ & 110.11 & $4.82 * *$ & $4.74^{* *}$ & 33.72 & 1.13 & 1.11 & 269.11 & 1.30 & 1.28 \\
\hline$[0,16]$ & 87.00 & 3.81 * & 3.75 * & 28.91 & 0.96 & 0.95 & 254.73 & 1.23 & 1.22 \\
\hline$[0,17]$ & 11.97 & 0.52 & 0.51 & -37.73 & -1.26 & -1.24 & 377.86 & 1.83 & 1.80 \\
\hline$[0,18]$ & 98.32 & $4.30 *$ & 4.24 * & 40.84 & 1.36 & 1.34 & 347.88 & 1.69 & 1.66 \\
\hline$[0,19]$ & 81.48 & $3.56^{*}$ & $3.51 *$ & 5.18 & 0.17 & 0.17 & 301.66 & 1.46 & 1.44 \\
\hline$[0,20]$ & 74.66 & $3.27 *$ & $3.22 *$ & 22.04 & 0.74 & 0.72 & 190.36 & 0.92 & 0.91 \\
\hline$[0,21]$ & 59.65 & 2.61 & 2.57 & 55.09 & 1.84 & 1.81 & 436.57 & 2.11 & 2.08 \\
\hline$[0,22]$ & 45.22 & 1.98 & 1.95 & 73.59 & 2.46 & 2.42 & 446.12 & 2.16 & 2.13 \\
\hline$[0,23]$ & 55.57 & 2.43 & 2.39 & 96.45 & $3.22 *$ & $3.17^{*}$ & 362.27 & 1.75 & 1.73 \\
\hline$[0,24]$ & 38.89 & 1.70 & 1.67 & 85.89 & 2.87 & 2.82 & 409.86 & 1.99 & 1.95 \\
\hline$[0,25]$ & 83.50 & $3.65 *$ & $3.60 *$ & 121.10 & $4.04^{*}$ & $3.98^{*}$ & 344.06 & 1.67 & 1.64 \\
\hline$[0,26]$ & 63.23 & 2.77 & 2.72 & 161.11 & $5.38^{* *}$ & $5.29 * *$ & 309.24 & 1.50 & 1.47 \\
\hline$[0,27]$ & 99.02 & $4.33^{*}$ & $4.26^{*}$ & 181.47 & $6.06^{* *}$ & $5.96^{* *}$ & 310.68 & 1.50 & 1.48 \\
\hline$[0,28]$ & 79.89 & $3.49 *$ & $3.44^{*}$ & 155.21 & $5.18^{* *}$ & $5.10^{* *}$ & 277.36 & 1.34 & 1.32 \\
\hline$[0,29]$ & 32.68 & 1.43 & 1.41 & 113.84 & 3.80 * & 3.74 * & 390.76 & 1.89 & 1.86 \\
\hline$[0,30]$ & 27.01 & 1.18 & 1.16 & 48.00 & 1.60 & 1.58 & 227.88 & 1.10 & 1.09 \\
\hline
\end{tabular}


Table A31. Case VIII: GJR(1,1)—Cumulative abnormal change rate of Chinese tourist arrivals.

\begin{tabular}{|c|c|c|c|c|c|c|c|c|c|}
\hline \multirow{3}{*}{ Event Period $\left[\tau_{1}, \tau_{2}\right]$} & \multicolumn{3}{|c|}{ Group-Type } & \multicolumn{3}{|c|}{ Individual-Type } & \multicolumn{3}{|c|}{ Medical-Type } \\
\hline & \multirow{2}{*}{ CAR } & \multicolumn{2}{|c|}{$\mathrm{t}$-Value } & \multirow{2}{*}{ CAR } & \multicolumn{2}{|c|}{$\mathrm{t}$-Value } & \multirow{2}{*}{ CAR } & \multicolumn{2}{|c|}{ t-Value } \\
\hline & & TM & SRM & & TM & SRM & & TM & SRM \\
\hline$[0,0]$ & 5.33 & 0.20 & 0.19 & 10.60 & 0.35 & 0.34 & 30.91 & 0.15 & 0.15 \\
\hline$[0,1]$ & 6.76 & 0.25 & 0.24 & 29.14 & 0.96 & 0.94 & 169.08 & 0.82 & 0.81 \\
\hline$[0,2]$ & 28.25 & 1.04 & 1.02 & 31.50 & 1.03 & 1.02 & 105.07 & 0.51 & 0.50 \\
\hline$[0,3]$ & -5.84 & -0.21 & -0.21 & -21.72 & -0.71 & -0.70 & 175.61 & 0.85 & 0.83 \\
\hline$[0,4]$ & 13.81 & 0.51 & 0.50 & -71.68 & -2.35 & -2.31 & 122.01 & 0.59 & 0.58 \\
\hline$[0,5]$ & 42.17 & 1.55 & 1.52 & -0.97 & -0.03 & -0.03 & 36.60 & 0.18 & 0.17 \\
\hline$[0,6]$ & 76.67 & 2.81 & 2.77 & 12.22 & 0.40 & 0.39 & 133.42 & 0.65 & 0.64 \\
\hline$[0,7]$ & 99.43 & $3.65 *$ & $3.58 *$ & 49.18 & 1.61 & 1.59 & 273.75 & 1.33 & 1.30 \\
\hline$[0,8]$ & 81.67 & $2.99 *$ & 2.95 * & 47.71 & 1.57 & 1.54 & 164.10 & 0.79 & 0.78 \\
\hline$[0,9]$ & 84.83 & $3.11 *$ & $3.06 *$ & 48.14 & 1.58 & 1.55 & 300.80 & 1.46 & 1.43 \\
\hline$[0,10]$ & 44.71 & 1.64 & 1.61 & 10.26 & 0.34 & 0.33 & 268.24 & 1.30 & 1.28 \\
\hline$[0,11]$ & 62.13 & 2.28 & 2.24 & 6.14 & 0.20 & 0.20 & 127.48 & 0.62 & 0.61 \\
\hline$[0,12]$ & 77.98 & 2.86 & 2.82 & 29.36 & 0.96 & 0.95 & 170.66 & 0.83 & 0.81 \\
\hline$[0,13]$ & 97.87 & 3.59 * & $3.53 *$ & 26.29 & 0.86 & 0.85 & 280.62 & 1.36 & 1.34 \\
\hline$[0,14]$ & 92.52 & 3.39 * & 3.34 * & 23.67 & 0.78 & 0.77 & 345.06 & 1.67 & 1.65 \\
\hline$[0,15]$ & 119.40 & $4.38^{* *}$ & $4.31^{* *}$ & 51.71 & 1.70 & 1.67 & 274.56 & 1.33 & 1.31 \\
\hline$[0,16]$ & 96.88 & 3.55 * & 3.50 * & 48.04 & 1.58 & 1.55 & 260.49 & 1.26 & 1.24 \\
\hline$[0,17]$ & 22.45 & 0.82 & 0.81 & -17.44 & -0.57 & -0.56 & 383.88 & 1.86 & 1.83 \\
\hline$[0,18]$ & 109.36 & $4.01 *$ & 3.95 * & 62.23 & 2.04 & 2.01 & 354.31 & 1.72 & 1.69 \\
\hline$[0,19]$ & 93.11 & $3.41 *$ & 3.36 * & 27.71 & 0.91 & 0.90 & 308.40 & 1.49 & 1.47 \\
\hline$[0,20]$ & 86.87 & $3.19 *$ & $3.14 *$ & 45.68 & 1.50 & 1.48 & 197.47 & 0.96 & 0.94 \\
\hline$[0,21]$ & 72.43 & 2.66 & 2.61 & 79.84 & 2.62 & 2.58 & 444.04 & 2.15 & 2.12 \\
\hline$[0,22]$ & 58.59 & 2.15 & 2.12 & 99.49 & 3.26 & 3.22 & 453.87 & 2.20 & 2.16 \\
\hline$[0,23]$ & 69.53 & 2.55 & 2.51 & 123.49 & $4.05 *$ & $3.99 *$ & 370.35 & 1.79 & 1.77 \\
\hline$[0,24]$ & 53.44 & 1.96 & 1.93 & 114.06 & $3.74 *$ & $3.68 *$ & 418.25 & 2.03 & 1.99 \\
\hline$[0,25]$ & 98.62 & $3.62 *$ & $3.56^{*}$ & 150.39 & $4.94 * *$ & $4.86^{* *}$ & 352.82 & 1.71 & 1.68 \\
\hline$[0,26]$ & 78.95 & 2.89 & 2.85 & 191.53 & $6.29^{* *}$ & $6.19 * *$ & 318.31 & 1.54 & 1.52 \\
\hline$[0,27]$ & 115.29 & $4.23 *$ & $4.16^{*}$ & 212.99 & $6.99 * *$ & $6.88 * *$ & 320.15 & 1.55 & 1.53 \\
\hline$[0,28]$ & 96.74 & $3.55 *$ & $3.49 *$ & 187.86 & $6.16^{* *}$ & $6.07^{* *}$ & 287.17 & 1.39 & 1.37 \\
\hline$[0,29]$ & 50.11 & 1.84 & 1.81 & 147.61 & $4.84^{* *}$ & $4.77^{* *}$ & 400.92 & 1.94 & 1.91 \\
\hline$[0,30]$ & 45.06 & 1.65 & 1.62 & 82.95 & 2.72 & 2.68 & 238.27 & 1.15 & 1.13 \\
\hline
\end{tabular}


Table A32. Case VIII: EGARCH(1,1)—Cumulative abnormal change rate of Chinese tourist arrivals.

\begin{tabular}{|c|c|c|c|c|c|c|c|c|c|}
\hline \multirow{3}{*}{ Event Period $\left[\tau_{1}, \tau_{2}\right]$} & \multicolumn{3}{|c|}{ Group-Type } & \multicolumn{3}{|c|}{ Individual-Type } & \multicolumn{3}{|c|}{ Medical-Type } \\
\hline & \multirow{2}{*}{ CAR } & \multicolumn{2}{|c|}{$\mathrm{t}$-Value } & \multirow{2}{*}{ CAR } & \multicolumn{2}{|c|}{$\mathrm{t}$-Value } & \multirow{2}{*}{ CAR } & \multicolumn{2}{|c|}{ t-Value } \\
\hline & & TM & SRM & & TM & SRM & & TM & SRM \\
\hline$[0,0]$ & 4.22 & 0.15 & 0.15 & 9.63 & 0.31 & 0.31 & 31.89 & 0.14 & 0.13 \\
\hline$[0,1]$ & 5.42 & 0.19 & 0.19 & 27.20 & 0.88 & 0.87 & 171.50 & 0.73 & 0.72 \\
\hline$[0,2]$ & 27.53 & 0.99 & 0.97 & 28.57 & 0.93 & 0.91 & 109.34 & 0.47 & 0.46 \\
\hline$[0,3]$ & -10.86 & -0.39 & -0.38 & -25.57 & -0.83 & -0.81 & 179.26 & 0.77 & 0.75 \\
\hline$[0,4]$ & 11.01 & 0.40 & 0.39 & -76.54 & -2.48 & -2.44 & 128.32 & 0.55 & 0.54 \\
\hline$[0,5]$ & 37.63 & 1.35 & 1.33 & -6.78 & -0.22 & -0.22 & 43.58 & 0.19 & 0.18 \\
\hline$[0,6]$ & 70.89 & 2.54 & 2.51 & 5.44 & 0.18 & 0.17 & 141.32 & 0.60 & 0.59 \\
\hline$[0,7]$ & 93.21 & $3.35 *$ & $3.29 *$ & 41.43 & 1.34 & 1.32 & 282.97 & 1.21 & 1.19 \\
\hline$[0,8]$ & 73.61 & 2.64 & 2.60 & 39.00 & 1.26 & 1.24 & 173.94 & 0.74 & 0.73 \\
\hline$[0,9]$ & 76.39 & 2.74 & 2.70 & 38.46 & 1.25 & 1.23 & 311.99 & 1.33 & 1.31 \\
\hline$[0,10]$ & 34.33 & 1.23 & 1.21 & -0.37 & -0.01 & -0.01 & 280.00 & 1.20 & 1.18 \\
\hline$[0,11]$ & 50.46 & 1.81 & 1.78 & -5.45 & -0.18 & -0.17 & 140.13 & 0.60 & 0.59 \\
\hline$[0,12]$ & 65.39 & 2.35 & 2.31 & 16.80 & 0.54 & 0.54 & 184.40 & 0.79 & 0.78 \\
\hline$[0,13]$ & 84.20 & 3.02 * & $2.98 *$ & 12.76 & 0.41 & 0.41 & 295.36 & 1.26 & 1.24 \\
\hline$[0,14]$ & 77.37 & 2.78 & 2.74 & 9.19 & 0.30 & 0.29 & 360.60 & 1.54 & 1.52 \\
\hline$[0,15]$ & 104.36 & 3.75 * & 3.69 * & 36.24 & 1.17 & 1.16 & 291.70 & 1.25 & 1.23 \\
\hline$[0,16]$ & 80.20 & 2.88 & 2.84 & 31.62 & 1.02 & 1.01 & 278.35 & 1.19 & 1.17 \\
\hline$[0,17]$ & 3.26 & 0.12 & 0.11 & -34.81 & -1.13 & -1.11 & 402.01 & 1.72 & 1.69 \\
\hline$[0,18]$ & 90.32 & 3.24 * & $3.19 *$ & 43.88 & 1.42 & 1.40 & 374.06 & 1.60 & 1.57 \\
\hline$[0,19]$ & 72.67 & 2.61 & 2.57 & 8.40 & 0.27 & 0.27 & 328.99 & 1.41 & 1.38 \\
\hline$[0,20]$ & 66.04 & 2.37 & 2.33 & 25.40 & 0.82 & 0.81 & 219.41 & 0.94 & 0.92 \\
\hline$[0,21]$ & 51.18 & 1.84 & 1.81 & 58.58 & 1.90 & 1.87 & 467.32 & 2.00 & 1.97 \\
\hline$[0,22]$ & 35.14 & 1.26 & 1.24 & 77.28 & 2.50 & 2.47 & 477.58 & 2.04 & 2.01 \\
\hline$[0,23]$ & 44.86 & 1.61 & 1.59 & 100.32 & $3.25 *$ & 3.20 * & 394.98 & 1.69 & 1.66 \\
\hline$[0,24]$ & 27.18 & 0.98 & 0.96 & 89.93 & 2.91 & 2.87 & 443.63 & 1.90 & 1.87 \\
\hline$[0,25]$ & 71.97 & 2.58 & 2.54 & 125.29 & $4.06 *$ & $4.00 *$ & 379.55 & 1.62 & 1.60 \\
\hline$[0,26]$ & 50.80 & 1.82 & 1.80 & 165.47 & $5.36^{* *}$ & $5.28 * *$ & 345.83 & 1.48 & 1.46 \\
\hline$[0,27]$ & 87.40 & 3.14 * & $3.09 *$ & 185.95 & $6.02 * *$ & $5.93 * *$ & 349.34 & 1.49 & 1.47 \\
\hline$[0,28]$ & 67.93 & 2.44 & 2.40 & 159.85 & $5.18^{* *}$ & $5.10 * *$ & 317.45 & 1.36 & 1.34 \\
\hline$[0,29]$ & 20.48 & 0.74 & 0.72 & 118.63 & $3.84 *$ & $3.78 *$ & 432.33 & 1.85 & 1.82 \\
\hline$[0,30]$ & 12.26 & 0.44 & 0.43 & 53.03 & 1.72 & 1.69 & 269.62 & 1.15 & 1.13 \\
\hline
\end{tabular}


Table A33. Case IX: OLS-Cumulative abnormal change rate of Chinese tourist arrivals.

\begin{tabular}{|c|c|c|c|c|c|c|c|c|c|}
\hline \multirow{3}{*}{ Event Period $\left[\tau_{1}, \tau_{2}\right]$} & \multicolumn{3}{|c|}{ Group-Type } & \multicolumn{3}{|c|}{ Individual-Type } & \multicolumn{3}{|c|}{ Medical-Type } \\
\hline & \multirow{2}{*}{ CAR } & \multicolumn{2}{|c|}{ t-Value } & \multirow{2}{*}{ CAR } & \multicolumn{2}{|c|}{ t-Value } & \multirow{2}{*}{ CAR } & \multicolumn{2}{|c|}{ t-Value } \\
\hline & & TM & SRM & & TM & SRM & & TM & SRM \\
\hline$[0,0]$ & 0.39 & 0.01 & 0.01 & -12.89 & -0.47 & -0.46 & -34.37 & -0.42 & -0.41 \\
\hline$[0,1]$ & -15.28 & -0.56 & -0.55 & -26.34 & -0.96 & -0.95 & -206.67 & -2.51 & -2.48 \\
\hline$[0,2]$ & -4.47 & -0.16 & -0.16 & -25.11 & -0.92 & -0.90 & -235.45 & -2.86 & -2.82 \\
\hline$[0,3]$ & 3.48 & 0.13 & 0.12 & -2.73 & -0.10 & -0.10 & -75.79 & -0.92 & -0.91 \\
\hline$[0,4]$ & -13.91 & -0.51 & -0.50 & -12.41 & -0.45 & -0.45 & -68.70 & -0.84 & -0.82 \\
\hline$[0,5]$ & -7.10 & -0.26 & -0.25 & -35.59 & -1.30 & -1.28 & -154.55 & -1.88 & -1.85 \\
\hline$[0,6]$ & -16.97 & -0.62 & -0.60 & -41.95 & -1.53 & -1.50 & -103.91 & -1.26 & -1.23 \\
\hline$[0,7]$ & -26.45 & -0.96 & -0.95 & -33.35 & -1.22 & -1.20 & -131.33 & -1.60 & -1.57 \\
\hline$[0,8]$ & -65.79 & -2.40 & -2.35 & -42.39 & -1.55 & -1.52 & -145.12 & -1.77 & -1.73 \\
\hline$[0,9]$ & -62.43 & -2.27 & -2.23 & -39.33 & -1.44 & -1.41 & -94.88 & -1.15 & -1.13 \\
\hline$[0,10]$ & -59.72 & -2.18 & -2.13 & -46.32 & -1.69 & -1.66 & -149.71 & -1.82 & -1.78 \\
\hline$[0,11]$ & -61.38 & -2.24 & -2.13 & -14.47 & -0.53 & -0.51 & -30.49 & -0.37 & -0.35 \\
\hline$[0,12]$ & -46.84 & -1.71 & -1.67 & 2.17 & 0.08 & 0.08 & 60.71 & 0.74 & 0.72 \\
\hline$[0,13]$ & -52.86 & -1.93 & -1.89 & 4.84 & 0.18 & 0.17 & 55.12 & 0.67 & 0.66 \\
\hline$[0,14]$ & -59.78 & -2.18 & -2.02 & -10.99 & -0.40 & -0.37 & -176.64 & -2.15 & -2.00 \\
\hline$[0,15]$ & -25.70 & -0.94 & -0.92 & 46.52 & 1.70 & 1.68 & -242.71 & $-2.95 *$ & -2.91 \\
\hline$[0,16]$ & 6.29 & 0.23 & 0.22 & 58.06 & 2.12 & 2.05 & -113.18 & -1.38 & -1.33 \\
\hline$[0,17]$ & -9.88 & -0.36 & -0.35 & 23.93 & 0.88 & 0.85 & -73.47 & -0.89 & -0.87 \\
\hline$[0,18]$ & -35.13 & -1.28 & -1.26 & 3.26 & 0.12 & 0.12 & 23.43 & 0.28 & 0.28 \\
\hline$[0,19]$ & -37.25 & -1.36 & -1.34 & -42.08 & -1.54 & -1.52 & -1.48 & -0.02 & -0.02 \\
\hline$[0,20]$ & -22.02 & -0.80 & -0.76 & -57.13 & -2.09 & -1.97 & -93.89 & -1.14 & -1.08 \\
\hline$[0,21]$ & -17.07 & -0.62 & -0.60 & -79.14 & -2.90 & -2.79 & -108.85 & -1.32 & -1.27 \\
\hline$[0,22]$ & -38.23 & -1.39 & -1.37 & -99.91 & $-3.66^{*}$ & $-3.60 *$ & -155.53 & -1.89 & -1.86 \\
\hline$[0,23]$ & -49.72 & -1.81 & -1.78 & -110.71 & $-4.05^{*}$ & $-3.98 *$ & -288.68 & $-3.51 *$ & $-3.45^{*}$ \\
\hline$[0,24]$ & -57.53 & -2.10 & -2.06 & -133.39 & $-4.88^{* *}$ & $-4.80 * *$ & -33.24 & -0.40 & -0.40 \\
\hline$[0,25]$ & -108.41 & $-3.95 *$ & $-3.88 *$ & -133.59 & $-4.89^{* *}$ & $-4.80 * *$ & -213.51 & -2.60 & -2.55 \\
\hline$[0,26]$ & -111.51 & $-4.06 *$ & $-3.96^{*}$ & -171.75 & $-6.28^{* *}$ & $-6.12 * *$ & -195.14 & -2.37 & -2.31 \\
\hline$[0,27]$ & -132.55 & $-4.83 * *$ & $-4.67^{* *}$ & -185.87 & $-6.80^{* *}$ & $-6.58 * *$ & -367.89 & $-4.47^{* *}$ & $-4.33 *$ \\
\hline$[0,28]$ & -128.69 & $-4.69^{* *}$ & $-4.61^{* *}$ & -161.39 & $-5.91^{* *}$ & $-5.80^{* *}$ & -341.62 & -4.16 * & -4.08 * \\
\hline$[0,29]$ & -164.70 & $-6.00 * *$ & $-5.90 * *$ & -187.69 & $-6.87^{* *}$ & $-6.75^{* *}$ & -290.17 & $-3.53 *$ & -3.47 * \\
\hline$[0,30]$ & -108.27 & -3.94 * & $-3.88^{*}$ & -129.58 & $-4.74^{* *}$ & $-4.67^{* *}$ & -281.02 & $-3.42 *$ & -3.37 * \\
\hline
\end{tabular}

Note: ${ }^{* *}$ and $*$ denote significance at the $5 \%$ and $10 \%$ levels, respectively. 
Table A34. Case IX: GARCH(1,1)—Cumulative abnormal change rate of Chinese tourist arrivals.

\begin{tabular}{|c|c|c|c|c|c|c|c|c|c|}
\hline \multirow{3}{*}{ Event Period $\left[\tau_{1}, \tau_{2}\right]$} & \multicolumn{3}{|c|}{ Group-Type } & \multicolumn{3}{|c|}{ Individual-Type } & \multicolumn{3}{|c|}{ Medical-Type } \\
\hline & \multirow{2}{*}{ CAR } & \multicolumn{2}{|c|}{ t-Value } & \multirow{2}{*}{ CAR } & \multicolumn{2}{|c|}{ t-Value } & \multirow{2}{*}{ CAR } & \multicolumn{2}{|c|}{ t-Value } \\
\hline & & TM & SRM & & TM & SRM & & TM & SRM \\
\hline$[0,0]$ & 0.02 & 0.00 & 0.00 & -11.31 & -0.38 & -0.37 & -26.86 & -0.34 & -0.33 \\
\hline$[0,1]$ & -15.22 & -0.71 & -0.70 & -24.82 & -0.83 & -0.82 & -195.94 & -2.47 & -2.43 \\
\hline$[0,2]$ & -3.98 & -0.19 & -0.18 & -23.66 & -0.79 & -0.78 & -221.55 & -2.79 & -2.75 \\
\hline$[0,3]$ & 4.34 & 0.20 & 0.20 & -1.21 & -0.04 & -0.04 & -58.36 & -0.73 & -0.72 \\
\hline$[0,4]$ & -12.89 & -0.60 & -0.59 & -10.40 & -0.35 & -0.34 & -46.62 & -0.59 & -0.58 \\
\hline$[0,5]$ & -5.53 & -0.26 & -0.25 & -33.89 & -1.13 & -1.12 & -129.97 & -1.64 & -1.61 \\
\hline$[0,6]$ & -14.29 & -0.67 & -0.65 & -41.71 & -1.39 & -1.36 & -79.83 & -1.01 & -0.98 \\
\hline$[0,7]$ & -23.82 & -1.11 & -1.09 & -32.19 & -1.08 & -1.06 & -101.45 & -1.28 & -1.25 \\
\hline$[0,8]$ & -62.27 & -2.91 & -2.86 & -42.21 & -1.41 & -1.38 & -114.51 & -1.44 & -1.41 \\
\hline$[0,9]$ & -58.93 & -2.76 & -2.71 & -38.30 & -1.28 & -1.26 & -58.65 & -0.74 & -0.73 \\
\hline$[0,10]$ & -56.45 & -2.64 & -2.58 & -43.99 & -1.47 & -1.44 & -106.69 & -1.34 & -1.31 \\
\hline$[0,11]$ & -56.42 & -2.64 & -2.52 & -14.79 & -0.49 & -0.47 & 8.86 & 0.11 & 0.11 \\
\hline$[0,12]$ & -40.88 & -1.91 & -1.87 & 0.61 & 0.02 & 0.02 & 100.12 & 1.26 & 1.23 \\
\hline$[0,13]$ & -47.09 & -2.20 & -2.16 & 4.49 & 0.15 & 0.15 & 101.09 & 1.27 & 1.25 \\
\hline$[0,14]$ & -55.45 & -2.59 & -2.41 & -7.55 & -0.25 & -0.23 & -117.28 & -1.48 & -1.37 \\
\hline$[0,15]$ & -21.11 & -0.99 & -0.97 & 50.24 & 1.68 & 1.65 & -179.26 & -2.26 & -2.22 \\
\hline$[0,16]$ & 12.25 & 0.57 & 0.55 & 59.80 & 2.00 & 1.93 & -51.64 & -0.65 & -0.63 \\
\hline$[0,17]$ & -2.74 & -0.13 & -0.12 & 24.06 & 0.80 & 0.78 & -12.84 & -0.16 & -0.16 \\
\hline$[0,18]$ & -27.24 & -1.27 & -1.25 & 2.67 & 0.09 & 0.09 & 85.52 & 1.08 & 1.06 \\
\hline$[0,19]$ & -29.02 & -1.36 & -1.34 & -42.55 & -1.42 & -1.40 & 64.25 & 0.81 & 0.80 \\
\hline$[0,20]$ & -14.95 & -0.70 & -0.66 & -54.39 & -1.82 & -1.72 & -16.30 & -0.21 & -0.19 \\
\hline$[0,21]$ & -10.75 & -0.50 & -0.48 & -74.03 & -2.47 & -2.38 & -21.63 & -0.27 & -0.26 \\
\hline$[0,22]$ & -31.41 & -1.47 & -1.45 & -95.00 & $-3.18^{*}$ & $-3.13 *$ & -65.49 & -0.82 & -0.81 \\
\hline$[0,23]$ & -42.12 & -1.97 & -1.93 & -106.61 & $-3.56^{*}$ & $-3.50 *$ & -197.43 & -2.49 & -2.44 \\
\hline$[0,24]$ & -49.19 & -2.30 & -2.26 & -129.98 & $-4.34 *$ & -4.27 * & 59.54 & 0.75 & 0.74 \\
\hline$[0,25]$ & -100.14 & $-4.68^{* *}$ & $-4.60^{* *}$ & -129.22 & $-4.32 *$ & $-4.24 *$ & -114.83 & -1.45 & -1.42 \\
\hline$[0,26]$ & -103.62 & $-4.85^{* *}$ & $-4.72^{* *}$ & -165.76 & $-5.54^{* *}$ & -5.40 ** & -88.83 & -1.12 & -1.09 \\
\hline$[0,27]$ & -125.27 & $-5.86^{* *}$ & $-5.67^{* *}$ & -177.79 & $-5.94 * *$ & $-5.75^{* *}$ & -252.71 & $-3.18 *$ & -3.08 * \\
\hline$[0,28]$ & -121.38 & $-5.68^{* *}$ & $-5.58 * *$ & -152.56 & $-5.10^{* *}$ & $-5.01 * *$ & -221.10 & -2.78 & -2.74 \\
\hline$[0,29]$ & -156.69 & -7.33 ** & $-7.20^{* *}$ & -179.50 & $-6.00^{* *}$ & $-5.90 * *$ & -167.97 & -2.12 & -2.08 \\
\hline$[0,30]$ & -99.98 & $-4.68^{* *}$ & $-4.61^{* *}$ & -121.12 & $-4.05^{*}$ & $-3.99 *$ & -154.76 & -1.95 & -1.92 \\
\hline
\end{tabular}

Note: ${ }^{* *}$ and ${ }^{*}$ denote significance at the $5 \%$ and $10 \%$ levels, respectively. 
Table A35. Case IX: GJR(1,1)—Cumulative abnormal change rate of Chinese tourist arrivals.

\begin{tabular}{|c|c|c|c|c|c|c|c|c|c|}
\hline \multirow{3}{*}{ Event Period $\left[\tau_{1}, \tau_{2}\right]$} & \multicolumn{3}{|c|}{ Group-Type } & \multicolumn{3}{|c|}{ Individual-Type } & \multicolumn{3}{|c|}{ Medical-Type } \\
\hline & \multirow{2}{*}{ CAR } & \multicolumn{2}{|c|}{ t-Value } & \multirow{2}{*}{ CAR } & \multicolumn{2}{|c|}{ t-Value } & \multirow{2}{*}{ CAR } & \multicolumn{2}{|c|}{ t-Value } \\
\hline & & TM & SRM & & TM & SRM & & TM & SRM \\
\hline$[0,0]$ & 0.52 & 0.03 & 0.03 & -11.51 & -0.35 & -0.34 & -6.10 & -0.02 & -0.02 \\
\hline$[0,1]$ & -14.44 & -0.74 & -0.73 & -25.22 & -0.76 & -0.75 & -165.91 & -0.48 & -0.47 \\
\hline$[0,2]$ & -2.92 & -0.15 & -0.15 & -24.26 & -0.73 & -0.72 & -182.40 & -0.53 & -0.52 \\
\hline$[0,3]$ & 5.69 & 0.29 & 0.29 & -2.02 & -0.06 & -0.06 & -9.13 & -0.03 & -0.03 \\
\hline$[0,4]$ & -11.19 & -0.57 & -0.56 & -11.41 & -0.34 & -0.34 & 15.71 & 0.05 & 0.04 \\
\hline$[0,5]$ & -3.57 & -0.18 & -0.18 & -35.11 & -1.05 & -1.04 & -60.29 & -0.17 & -0.17 \\
\hline$[0,6]$ & -12.24 & -0.63 & -0.61 & -43.14 & -1.29 & -1.26 & -10.90 & -0.03 & -0.03 \\
\hline$[0,7]$ & -21.36 & -1.10 & -1.08 & -33.82 & -1.01 & -1.00 & -16.36 & -0.05 & -0.05 \\
\hline$[0,8]$ & -59.66 & $-3.06^{*}$ & $-3.00 *$ & -44.06 & -1.32 & -1.30 & -26.81 & -0.08 & -0.08 \\
\hline$[0,9]$ & -55.92 & -2.87 & -2.82 & -40.34 & -1.21 & -1.19 & 44.74 & 0.13 & 0.13 \\
\hline$[0,10]$ & -52.98 & -2.72 & -2.66 & -46.22 & -1.39 & -1.36 & 15.54 & 0.05 & 0.04 \\
\hline$[0,11]$ & -53.01 & -2.72 & -2.59 & -17.26 & -0.52 & -0.49 & 121.83 & 0.35 & 0.34 \\
\hline$[0,12]$ & -37.35 & -1.92 & -1.87 & -2.08 & -0.06 & -0.06 & 213.90 & 0.62 & 0.61 \\
\hline$[0,13]$ & -43.11 & -2.21 & -2.17 & 1.61 & 0.05 & 0.05 & 233.08 & 0.68 & 0.66 \\
\hline$[0,14]$ & -50.68 & -2.60 & -2.42 & -10.61 & -0.32 & -0.30 & 51.23 & 0.15 & 0.14 \\
\hline$[0,15]$ & -16.01 & -0.82 & -0.81 & 46.99 & 1.41 & 1.39 & 0.87 & 0.00 & 0.00 \\
\hline$[0,16]$ & 17.37 & 0.89 & 0.86 & 56.32 & 1.69 & 1.63 & 123.97 & 0.36 & 0.35 \\
\hline$[0,17]$ & 2.46 & 0.13 & 0.12 & 20.36 & 0.61 & 0.59 & 160.94 & 0.47 & 0.45 \\
\hline$[0,18]$ & -21.86 & -1.12 & -1.10 & -1.23 & -0.04 & -0.04 & 263.85 & 0.77 & 0.75 \\
\hline$[0,19]$ & -23.33 & -1.20 & -1.18 & -46.67 & -1.40 & -1.38 & 252.98 & 0.73 & 0.72 \\
\hline$[0,20]$ & -8.54 & -0.44 & -0.41 & -58.68 & -1.76 & -1.66 & 204.86 & 0.59 & 0.56 \\
\hline$[0,21]$ & -3.74 & -0.19 & -0.18 & -78.51 & -2.36 & -2.27 & 225.97 & 0.66 & 0.63 \\
\hline$[0,22]$ & -24.14 & -1.24 & -1.22 & -99.68 & $-2.99 *$ & $-2.94 *$ & 190.29 & 0.55 & 0.54 \\
\hline$[0,23]$ & -34.66 & -1.78 & -1.75 & -111.51 & $-3.35^{*}$ & $-3.28 *$ & 62.21 & 0.18 & 0.18 \\
\hline$[0,24]$ & -41.54 & -2.13 & -2.09 & -135.08 & $-4.05 *$ & $-3.98 *$ & 323.90 & 0.94 & 0.92 \\
\hline$[0,25]$ & -92.08 & $-4.72 * *$ & $-4.64 * *$ & -134.52 & $-4.04 *$ & $-3.96 *$ & 166.00 & 0.48 & 0.47 \\
\hline$[0,26]$ & -95.05 & $-4.88^{* *}$ & $-4.75^{* *}$ & -171.26 & $-5.14^{* *}$ & $-5.01^{* *}$ & 213.08 & 0.62 & 0.60 \\
\hline$[0,27]$ & -116.14 & $-5.96 * *$ & $-5.76^{* *}$ & -183.47 & $-5.51 * *$ & $-5.33^{* *}$ & 73.60 & 0.21 & 0.21 \\
\hline$[0,28]$ & -111.86 & $-5.74^{* *}$ & $-5.64 * *$ & -158.44 & $-4.75^{* *}$ & $-4.67^{* *}$ & 120.17 & 0.35 & 0.34 \\
\hline$[0,29]$ & -146.96 & $-7.54^{* *}$ & $-7.41^{* *}$ & -185.59 & $-5.57^{* *}$ & $-5.47^{* *}$ & 178.42 & 0.52 & 0.51 \\
\hline$[0,30]$ & -89.93 & $-4.61^{* *}$ & $-4.54^{* *}$ & -127.41 & $-3.82 *$ & $-3.76^{*}$ & 203.13 & 0.59 & 0.58 \\
\hline
\end{tabular}


Table A36. Case IX: EGARCH(1,1)—Cumulative abnormal change rate of Chinese tourist arrivals.

\begin{tabular}{|c|c|c|c|c|c|c|c|c|c|}
\hline \multirow{3}{*}{ Event Period $\left[\tau_{1}, \tau_{2}\right]$} & \multicolumn{3}{|c|}{ Group-Type } & \multicolumn{3}{|c|}{ Individual-Type } & \multicolumn{3}{|c|}{ Medical-Type } \\
\hline & \multirow{2}{*}{ CAR } & \multicolumn{2}{|c|}{ t-Value } & \multirow{2}{*}{ CAR } & \multicolumn{2}{|c|}{ t-Value } & \multirow{2}{*}{ CAR } & \multicolumn{2}{|c|}{ t-Value } \\
\hline & & TM & SRM & & TM & SRM & & TM & SRM \\
\hline$[0,0]$ & -2.24 & -0.05 & -0.05 & -11.21 & -0.35 & -0.34 & -2.21 & -0.01 & -0.01 \\
\hline$[0,1]$ & -18.52 & -0.41 & -0.40 & -24.90 & -0.77 & -0.76 & -159.93 & -0.39 & -0.39 \\
\hline$[0,2]$ & -8.30 & -0.18 & -0.18 & -23.93 & -0.74 & -0.73 & -174.35 & -0.43 & -0.42 \\
\hline$[0,3]$ & -1.10 & -0.02 & -0.02 & -1.65 & -0.05 & -0.05 & 1.13 & 0.00 & 0.00 \\
\hline$[0,4]$ & -19.78 & -0.43 & -0.43 & -10.93 & -0.34 & -0.33 & 28.66 & 0.07 & 0.07 \\
\hline$[0,5]$ & -13.24 & -0.29 & -0.29 & -34.66 & -1.07 & -1.05 & -45.55 & -0.11 & -0.11 \\
\hline$[0,6]$ & -21.96 & -0.48 & -0.47 & -42.92 & -1.32 & -1.29 & 4.36 & 0.01 & 0.01 \\
\hline$[0,7]$ & -33.27 & -0.73 & -0.72 & -33.41 & -1.03 & -1.01 & 2.08 & 0.01 & 0.01 \\
\hline$[0,8]$ & -72.04 & -1.58 & -1.55 & -43.79 & -1.35 & -1.32 & -7.33 & -0.02 & -0.02 \\
\hline$[0,9]$ & -70.42 & -1.55 & -1.52 & -39.90 & -1.23 & -1.21 & 67.32 & 0.17 & 0.16 \\
\hline$[0,10]$ & -70.01 & -1.54 & -1.50 & -45.54 & -1.40 & -1.37 & 41.71 & 0.10 & 0.10 \\
\hline$[0,11]$ & -69.02 & -1.52 & -1.45 & -16.99 & -0.52 & -0.50 & 147.19 & 0.36 & 0.34 \\
\hline$[0,12]$ & -53.61 & -1.18 & -1.15 & -2.00 & -0.06 & -0.06 & 240.02 & 0.59 & 0.58 \\
\hline$[0,13]$ & -61.81 & -1.36 & -1.33 & 1.92 & 0.06 & 0.06 & 262.69 & 0.64 & 0.63 \\
\hline$[0,14]$ & -74.13 & -1.63 & -1.51 & -9.62 & -0.30 & -0.28 & 87.19 & 0.21 & 0.20 \\
\hline$[0,15]$ & -41.07 & -0.90 & -0.89 & 48.05 & 1.48 & 1.46 & 39.30 & 0.10 & 0.09 \\
\hline$[0,16]$ & -7.27 & -0.16 & -0.15 & 57.07 & 1.76 & 1.70 & 162.33 & 0.40 & 0.38 \\
\hline$[0,17]$ & -22.11 & -0.49 & -0.47 & 20.86 & 0.64 & 0.62 & 199.65 & 0.49 & 0.48 \\
\hline$[0,18]$ & -47.14 & -1.04 & -1.02 & -0.83 & -0.03 & -0.03 & 303.91 & 0.75 & 0.73 \\
\hline$[0,19]$ & -50.07 & -1.10 & -1.08 & -46.22 & -1.42 & -1.40 & 295.31 & 0.72 & 0.71 \\
\hline$[0,20]$ & -39.52 & -0.87 & -0.82 & -57.66 & -1.78 & -1.68 & 252.91 & 0.62 & 0.59 \\
\hline$[0,21]$ & -38.20 & -0.84 & -0.81 & -77.05 & -2.37 & -2.28 & 278.79 & 0.68 & 0.66 \\
\hline$[0,22]$ & -59.78 & -1.31 & -1.29 & -98.24 & $-3.02 *$ & $-2.98 *$ & 245.04 & 0.60 & 0.59 \\
\hline$[0,23]$ & -70.93 & -1.56 & -1.53 & -110.17 & $-3.39 *$ & $-3.33 *$ & 118.20 & 0.29 & 0.28 \\
\hline$[0,24]$ & -78.56 & -1.73 & -1.70 & -133.84 & $-4.12 *$ & $-4.05 *$ & 381.27 & 0.93 & 0.92 \\
\hline$[0,25]$ & -131.31 & -2.88 & -2.83 & -133.08 & $-4.10 *$ & $-4.02 *$ & 226.58 & 0.56 & 0.55 \\
\hline$[0,26]$ & -137.09 & $-3.01 *$ & $-2.93 *$ & -169.52 & $-5.22 * *$ & $-5.09 * *$ & 277.60 & 0.68 & 0.66 \\
\hline$[0,27]$ & -161.40 & -3.55 * & $-3.43 *$ & -181.35 & $-5.58 * *$ & $-5.40 * *$ & 142.57 & 0.35 & 0.34 \\
\hline$[0,28]$ & -159.15 & $-3.50 *$ & $-3.44^{*}$ & -156.17 & $-4.81^{* *}$ & $-4.73 *$ & 192.13 & 0.47 & 0.46 \\
\hline$[0,29]$ & -195.05 & $-4.28 *$ & $-4.21 *$ & -183.39 & $-5.65^{* *}$ & $-5.55^{* *}$ & 251.82 & 0.62 & 0.61 \\
\hline$[0,30]$ & -139.62 & $-3.07 *$ & $-3.02 *$ & -125.14 & $-3.85^{*}$ & $-3.79 *$ & 278.97 & 0.68 & 0.67 \\
\hline
\end{tabular}


Table A37. Case X: OLS—Cumulative abnormal change rate of Chinese tourist arrivals.

\begin{tabular}{|c|c|c|c|c|c|c|c|c|c|}
\hline \multirow{3}{*}{ Event Period $\left[\tau_{1}, \tau_{2}\right]$} & \multicolumn{3}{|c|}{ Group-Type } & \multicolumn{3}{|c|}{ Individual-Type } & \multicolumn{3}{|c|}{ Medical-Type } \\
\hline & \multirow{2}{*}{ CAR } & \multicolumn{2}{|c|}{ t-Value } & \multirow{2}{*}{ CAR } & \multicolumn{2}{|c|}{ t-Value } & \multirow{2}{*}{ CAR } & \multicolumn{2}{|c|}{ t-Value } \\
\hline & & TM & SRM & & TM & SRM & & TM & SRM \\
\hline$[0,0]$ & 18.83 & 0.54 & 0.53 & -13.96 & -0.49 & -0.49 & 10.03 & 0.15 & 0.15 \\
\hline$[0,1]$ & 3.86 & 0.11 & 0.11 & 12.71 & 0.45 & 0.44 & 9.46 & 0.14 & 0.14 \\
\hline$[0,2]$ & 56.09 & 1.61 & 1.57 & 74.82 & 2.65 & 2.59 & -108.42 & -1.64 & -1.61 \\
\hline$[0,3]$ & 75.46 & 2.16 & 2.12 & 67.11 & 2.38 & 2.33 & 12.35 & 0.19 & 0.18 \\
\hline$[0,4]$ & 80.23 & 2.30 & 2.26 & 49.13 & 1.74 & 1.71 & 20.73 & 0.31 & 0.31 \\
\hline$[0,5]$ & 47.51 & 1.36 & 1.34 & 16.40 & 0.58 & 0.57 & 37.70 & 0.57 & 0.56 \\
\hline$[0,6]$ & 47.67 & 1.37 & 1.33 & 9.08 & 0.32 & 0.31 & 3.11 & 0.05 & 0.05 \\
\hline$[0,7]$ & 70.01 & 2.01 & 1.95 & -20.97 & -0.74 & -0.72 & 11.20 & 0.17 & 0.16 \\
\hline$[0,8]$ & 43.58 & 1.25 & 1.22 & -59.91 & -2.12 & -2.07 & -80.58 & -1.22 & -1.19 \\
\hline$[0,9]$ & 63.34 & 1.81 & 1.79 & -39.46 & -1.40 & -1.37 & 10.01 & 0.15 & 0.15 \\
\hline$[0,10]$ & 60.68 & 1.74 & 1.70 & -63.20 & -2.24 & -2.19 & -36.33 & -0.55 & -0.54 \\
\hline$[0,11]$ & 59.42 & 1.70 & 1.66 & -95.49 & $-3.38 *$ & $-3.29 *$ & -119.72 & -1.81 & -1.76 \\
\hline$[0,12]$ & 29.16 & 0.84 & 0.81 & -126.85 & $-4.49^{* *}$ & $-4.34^{* *}$ & -46.99 & -0.71 & -0.69 \\
\hline$[0,13]$ & 19.27 & 0.55 & 0.54 & -122.76 & $-4.35^{*}$ & $-4.21 *$ & -108.72 & -1.64 & -1.59 \\
\hline$[0,14]$ & 27.11 & 0.78 & 0.75 & -118.11 & $-4.18^{*}$ & $-4.06 *$ & -164.76 & -2.49 & -2.42 \\
\hline$[0,15]$ & -5.40 & -0.15 & -0.15 & -153.50 & $-5.43^{* *}$ & $-5.26^{* *}$ & -227.77 & $-3.44 *$ & -3.33 * \\
\hline$[0,16]$ & 12.31 & 0.35 & 0.34 & -188.65 & $-6.68^{* *}$ & $-6.46^{* *}$ & -287.11 & $-4.34^{* *}$ & $-4.20^{* *}$ \\
\hline$[0,17]$ & 19.17 & 0.55 & 0.54 & -131.37 & $-4.65^{* *}$ & $-4.55^{* *}$ & -272.49 & $-4.12 *$ & -4.03 * \\
\hline$[0,18]$ & 39.32 & 1.13 & 1.10 & -134.67 & $-4.77^{* *}$ & $-4.66^{* *}$ & -116.81 & -1.77 & -1.73 \\
\hline$[0,19]$ & 19.16 & 0.55 & 0.53 & -147.38 & $-5.22 * *$ & $-5.06^{* *}$ & -172.01 & -2.60 & -2.52 \\
\hline$[0,20]$ & 20.69 & 0.59 & 0.58 & -156.30 & $-5.53 * *$ & $-5.40 * *$ & -188.53 & -2.85 & -2.78 \\
\hline$[0,21]$ & 34.44 & 0.99 & 0.96 & -149.10 & $-5.28^{* *}$ & $-5.13^{* *}$ & -87.51 & -1.32 & -1.29 \\
\hline$[0,22]$ & 26.75 & 0.77 & 0.75 & -150.47 & $-5.33^{* *}$ & $-5.24^{* *}$ & -87.63 & -1.32 & -1.30 \\
\hline$[0,23]$ & 23.29 & 0.67 & 0.66 & -155.27 & $-5.50 * *$ & $-5.41^{* *}$ & -77.14 & -1.17 & -1.15 \\
\hline$[0,24]$ & 20.42 & 0.58 & 0.57 & -134.70 & $-4.77^{* *}$ & $-4.66^{* *}$ & -49.66 & -0.75 & -0.73 \\
\hline$[0,25]$ & 41.49 & 1.19 & 1.16 & -130.28 & $-4.61 * *$ & $-4.51^{* *}$ & -106.32 & -1.61 & -1.57 \\
\hline$[0,26]$ & 20.13 & 0.58 & 0.56 & -153.79 & $-5.44^{* *}$ & $-5.32 * *$ & -32.29 & -0.49 & -0.48 \\
\hline$[0,27]$ & 30.01 & 0.86 & 0.84 & -137.81 & $-4.88^{* *}$ & $-4.77^{* *}$ & -35.92 & -0.54 & -0.53 \\
\hline$[0,28]$ & 56.25 & 1.61 & 1.58 & -125.99 & $-4.46^{* *}$ & $-4.37^{* *}$ & -174.26 & -2.63 & -2.58 \\
\hline$[0,29]$ & 28.02 & 0.80 & 0.78 & -156.93 & $-5.56^{* *}$ & $-5.43^{* *}$ & -84.12 & -1.27 & -1.24 \\
\hline$[0,30]$ & 56.56 & 1.62 & 1.58 & -166.06 & $-5.88 * *$ & $-5.75^{* *}$ & -85.31 & -1.29 & -1.26 \\
\hline
\end{tabular}

Note: ${ }^{* *}$ and $*$ denote significance at the $5 \%$ and $10 \%$ levels, respectively. 
Table A38. Case X: GARCH(1,1)—Cumulative abnormal change rate of Chinese tourist arrivals.

\begin{tabular}{|c|c|c|c|c|c|c|c|c|c|}
\hline \multirow{3}{*}{ Event Period $\left[\tau_{1}, \tau_{2}\right]$} & \multicolumn{3}{|c|}{ Group-Type } & \multicolumn{3}{|c|}{ Individual-Type } & \multicolumn{3}{|c|}{ Medical-Type } \\
\hline & \multirow{2}{*}{ CAR } & \multicolumn{2}{|c|}{ t-Value } & \multirow{2}{*}{ CAR } & \multicolumn{2}{|c|}{ t-Value } & \multirow{2}{*}{ CAR } & \multicolumn{2}{|c|}{ t-Value } \\
\hline & & TM & SRM & & TM & SRM & & TM & SRM \\
\hline$[0,0]$ & 23.11 & 0.55 & 0.55 & -13.33 & -0.34 & -0.34 & 29.21 & 0.35 & 0.35 \\
\hline$[0,1]$ & 7.16 & 0.17 & 0.17 & 12.21 & 0.32 & 0.31 & 23.92 & 0.29 & 0.29 \\
\hline$[0,2]$ & 56.87 & 1.37 & 1.34 & 72.68 & 1.88 & 1.84 & -105.60 & -1.28 & -1.25 \\
\hline$[0,3]$ & 77.66 & 1.86 & 1.83 & 64.64 & 1.67 & 1.64 & 21.33 & 0.26 & 0.25 \\
\hline$[0,4]$ & 82.66 & 1.98 & 1.95 & 45.95 & 1.19 & 1.17 & 30.55 & 0.37 & 0.36 \\
\hline$[0,5]$ & 51.49 & 1.24 & 1.22 & 12.93 & 0.33 & 0.33 & 54.28 & 0.66 & 0.65 \\
\hline$[0,6]$ & 49.00 & 1.18 & 1.15 & 3.93 & 0.10 & 0.10 & 7.45 & 0.09 & 0.09 \\
\hline$[0,7]$ & 71.57 & 1.72 & 1.67 & -26.84 & -0.69 & -0.68 & 16.31 & 0.20 & 0.19 \\
\hline$[0,8]$ & 45.93 & 1.10 & 1.07 & -66.32 & -1.72 & -1.67 & -72.10 & -0.87 & -0.85 \\
\hline$[0,9]$ & 70.78 & 1.70 & 1.67 & -44.97 & -1.16 & -1.15 & 41.31 & 0.50 & 0.49 \\
\hline$[0,10]$ & 70.56 & 1.69 & 1.66 & -68.70 & -1.78 & -1.74 & 5.74 & 0.07 & 0.07 \\
\hline$[0,11]$ & 70.86 & 1.70 & 1.66 & -101.27 & -2.62 & -2.55 & -70.82 & -0.86 & -0.83 \\
\hline$[0,12]$ & 41.96 & 1.01 & 0.97 & -132.97 & $-3.44 *$ & $-3.33 *$ & 7.84 & 0.09 & 0.09 \\
\hline$[0,13]$ & 32.23 & 0.77 & 0.75 & -129.63 & $-3.35^{*}$ & $-3.25 *$ & -53.42 & -0.65 & -0.63 \\
\hline$[0,14]$ & 40.36 & 0.97 & 0.94 & -125.69 & $-3.25^{*}$ & $-3.16 *$ & -108.39 & -1.31 & -1.27 \\
\hline$[0,15]$ & 8.74 & 0.21 & 0.20 & -161.58 & $-4.18^{*}$ & $-4.04 *$ & -167.57 & -2.03 & -1.96 \\
\hline$[0,16]$ & 26.84 & 0.64 & 0.62 & -197.40 & $-5.11^{* *}$ & $-4.94^{* *}$ & -225.40 & -2.73 & -2.64 \\
\hline$[0,17]$ & 32.43 & 0.78 & 0.76 & -141.33 & $-3.66^{*}$ & $-3.58 *$ & -216.77 & -2.62 & -2.57 \\
\hline$[0,18]$ & 53.02 & 1.27 & 1.24 & -145.29 & $-3.76^{*}$ & $-3.68 *$ & -59.33 & -0.72 & -0.70 \\
\hline$[0,19]$ & 34.71 & 0.83 & 0.81 & -158.19 & $-4.09 *$ & $-3.97 *$ & -106.43 & -1.29 & -1.25 \\
\hline$[0,20]$ & 35.62 & 0.86 & 0.83 & -168.10 & $-4.35^{* *}$ & $-4.25 *$ & -125.97 & -1.53 & -1.49 \\
\hline$[0,21]$ & 50.58 & 1.21 & 1.18 & -161.31 & -4.17 * & $-4.06^{*}$ & -19.69 & -0.24 & -0.23 \\
\hline$[0,22]$ & 40.64 & 0.98 & 0.96 & -164.22 & $-4.25^{* *}$ & $-4.18 *$ & -30.26 & -0.37 & -0.36 \\
\hline$[0,23]$ & 36.63 & 0.88 & 0.87 & -170.01 & $-4.40^{* *}$ & $-4.33 * *$ & -22.53 & -0.27 & -0.27 \\
\hline$[0,24]$ & 37.17 & 0.89 & 0.87 & -149.10 & $-3.86 *$ & $-3.77^{*}$ & 20.16 & 0.24 & 0.24 \\
\hline$[0,25]$ & 58.13 & 1.40 & 1.37 & -145.52 & $-3.76^{*}$ & $-3.69 *$ & -37.23 & -0.45 & -0.44 \\
\hline$[0,26]$ & 37.66 & 0.90 & 0.88 & -169.53 & $-4.39 * *$ & $-4.29 * *$ & 40.60 & 0.49 & 0.48 \\
\hline$[0,27]$ & 47.78 & 1.15 & 1.12 & -154.26 & $-3.99 *$ & $-3.90 *$ & 37.79 & 0.46 & 0.45 \\
\hline$[0,28]$ & 74.20 & 1.78 & 1.74 & -143.19 & $-3.70 *$ & $-3.63 *$ & -99.94 & -1.21 & -1.19 \\
\hline$[0,29]$ & 46.88 & 1.13 & 1.10 & -174.63 & $-4.52^{* *}$ & $-4.42 * *$ & -5.96 & -0.07 & -0.07 \\
\hline$[0,30]$ & 75.67 & 1.82 & 1.78 & -184.47 & $-4.77^{* *}$ & $-4.67^{* *}$ & -6.27 & -0.08 & -0.07 \\
\hline
\end{tabular}


Table A39. Case X: GJR(1,1)—Cumulative abnormal change rate of Chinese tourist arrivals.

\begin{tabular}{|c|c|c|c|c|c|c|c|c|c|}
\hline \multirow{3}{*}{ Event Period $\left[\tau_{1}, \tau_{2}\right]$} & \multicolumn{3}{|c|}{ Group-Type } & \multicolumn{3}{|c|}{ Individual-Type } & \multicolumn{3}{|c|}{ Medical-Type } \\
\hline & \multirow{2}{*}{ CAR } & \multicolumn{2}{|c|}{ t-Value } & \multirow{2}{*}{ CAR } & \multicolumn{2}{|c|}{ t-Value } & \multirow{2}{*}{ CAR } & \multicolumn{2}{|c|}{ t-Value } \\
\hline & & TM & SRM & & TM & SRM & & TM & SRM \\
\hline$[0,0]$ & 7.00 & 0.10 & 0.10 & -10.96 & -0.17 & -0.17 & 28.74 & 0.42 & 0.42 \\
\hline$[0,1]$ & -7.33 & -0.10 & -0.10 & 12.33 & 0.20 & 0.19 & 22.21 & 0.33 & 0.32 \\
\hline$[0,2]$ & 49.14 & 0.69 & 0.68 & 69.21 & 1.10 & 1.08 & -108.78 & -1.61 & -1.57 \\
\hline$[0,3]$ & 63.49 & 0.89 & 0.88 & 61.03 & 0.97 & 0.95 & 17.27 & 0.26 & 0.25 \\
\hline$[0,4]$ & 65.98 & 0.93 & 0.91 & 41.15 & 0.65 & 0.64 & 25.43 & 0.38 & 0.37 \\
\hline$[0,5]$ & 27.92 & 0.39 & 0.39 & 8.11 & 0.13 & 0.13 & 48.30 & 0.71 & 0.70 \\
\hline$[0,6]$ & 32.64 & 0.46 & 0.45 & -4.60 & -0.07 & -0.07 & -0.02 & 0.00 & 0.00 \\
\hline$[0,7]$ & 52.75 & 0.74 & 0.72 & -36.56 & -0.58 & -0.56 & 7.77 & 0.11 & 0.11 \\
\hline$[0,8]$ & 22.74 & 0.32 & 0.31 & -76.73 & -1.22 & -1.19 & -81.62 & -1.21 & -1.17 \\
\hline$[0,9]$ & 28.77 & 0.41 & 0.40 & -52.30 & -0.83 & -0.82 & 31.45 & 0.46 & 0.46 \\
\hline$[0,10]$ & 18.68 & 0.26 & 0.26 & -75.29 & -1.19 & -1.17 & -4.86 & -0.07 & -0.07 \\
\hline$[0,11]$ & 12.02 & 0.17 & 0.16 & -107.87 & -1.71 & -1.67 & -82.28 & -1.22 & -1.18 \\
\hline$[0,12]$ & -23.15 & -0.33 & -0.32 & -139.77 & -2.22 & -2.15 & -4.52 & -0.07 & -0.06 \\
\hline$[0,13]$ & -35.11 & -0.49 & -0.48 & -137.67 & -2.18 & -2.12 & -66.86 & -0.99 & -0.96 \\
\hline$[0,14]$ & -29.65 & -0.42 & -0.41 & -134.86 & -2.14 & -2.08 & -122.88 & -1.82 & -1.76 \\
\hline$[0,15]$ & -65.99 & -0.93 & -0.90 & -171.35 & -2.72 & -2.63 & -183.02 & -2.70 & -2.62 \\
\hline$[0,16]$ & -50.89 & -0.72 & -0.69 & -208.22 & $-3.30 *$ & $-3.20 *$ & -241.89 & $-3.57^{*}$ & $-3.46^{*}$ \\
\hline$[0,17]$ & -42.73 & -0.60 & -0.59 & -154.65 & -2.45 & -2.40 & -234.54 & $-3.47^{*}$ & $-3.39 *$ \\
\hline$[0,18]$ & -25.33 & -0.36 & -0.35 & -159.60 & -2.53 & -2.48 & -78.13 & -1.15 & -1.13 \\
\hline$[0,19]$ & -51.52 & -0.73 & -0.70 & -172.27 & -2.73 & -2.65 & -126.06 & -1.86 & -1.81 \\
\hline$[0,20]$ & -50.25 & -0.71 & -0.69 & -184.11 & $-2.92 *$ & -2.85 & -146.78 & -2.17 & -2.12 \\
\hline$[0,21]$ & -41.07 & -0.58 & -0.56 & -177.64 & -2.82 & -2.74 & -41.42 & -0.61 & -0.59 \\
\hline$[0,22]$ & -45.13 & -0.64 & -0.63 & -183.92 & -2.92 & -2.87 & -53.42 & -0.79 & -0.78 \\
\hline$[0,23]$ & -48.97 & -0.69 & -0.68 & -191.57 & $-3.04 *$ & $-2.99 *$ & -46.86 & -0.69 & -0.68 \\
\hline$[0,24]$ & -61.61 & -0.87 & -0.85 & -169.06 & -2.68 & -2.62 & -4.76 & -0.07 & -0.07 \\
\hline$[0,25]$ & -41.98 & -0.59 & -0.58 & -166.95 & -2.65 & -2.59 & -63.26 & -0.93 & -0.92 \\
\hline$[0,26]$ & -67.14 & -0.95 & -0.92 & -191.57 & $-3.04 *$ & $-2.97 *$ & 13.60 & 0.20 & 0.20 \\
\hline$[0,27]$ & -59.52 & -0.84 & -0.82 & -177.49 & -2.82 & -2.75 & 9.73 & 0.14 & 0.14 \\
\hline$[0,28]$ & -35.41 & -0.50 & -0.49 & -167.63 & -2.66 & -2.61 & -129.07 & -1.91 & -1.87 \\
\hline$[0,29]$ & -67.47 & -0.95 & -0.93 & -199.67 & $-3.17^{*}$ & $-3.10 *$ & -36.05 & -0.53 & -0.52 \\
\hline$[0,30]$ & -41.21 & -0.58 & -0.57 & -210.68 & $-3.34 *$ & $-3.27 *$ & -37.42 & -0.55 & -0.54 \\
\hline
\end{tabular}

Note: * denotes significance at the $10 \%$ level. 
Table A40. Case X: EGARCH(1,1)—Cumulative abnormal change rate of Chinese tourist arrivals.

\begin{tabular}{|c|c|c|c|c|c|c|c|c|c|}
\hline \multirow{3}{*}{ Event Period $\left[\tau_{1}, \tau_{2}\right]$} & \multicolumn{3}{|c|}{ Group-Type } & \multicolumn{3}{|c|}{ Individual-Type } & \multicolumn{3}{|c|}{ Medical-Type } \\
\hline & \multirow{2}{*}{ CAR } & \multicolumn{2}{|c|}{ t-Value } & \multirow{2}{*}{ CAR } & \multicolumn{2}{|c|}{ t-Value } & \multirow{2}{*}{ CAR } & \multicolumn{2}{|c|}{ t-Value } \\
\hline & & TM & SRM & & TM & SRM & & TM & SRM \\
\hline$[0,0]$ & 12.98 & 0.29 & 0.28 & -15.89 & -0.16 & -0.15 & 19.29 & 0.11 & 0.11 \\
\hline$[0,1]$ & -2.07 & -0.05 & -0.05 & 7.31 & 0.07 & 0.07 & 22.72 & 0.13 & 0.13 \\
\hline$[0,2]$ & 51.73 & 1.15 & 1.13 & 65.49 & 0.65 & 0.63 & -92.69 & -0.54 & -0.53 \\
\hline$[0,3]$ & 68.40 & 1.52 & 1.49 & 55.01 & 0.54 & 0.53 & 34.48 & 0.20 & 0.20 \\
\hline$[0,4]$ & 71.74 & 1.59 & 1.57 & 33.91 & 0.33 & 0.33 & 48.08 & 0.28 & 0.27 \\
\hline$[0,5]$ & 36.17 & 0.80 & 0.79 & -1.55 & -0.02 & -0.02 & 71.58 & 0.41 & 0.41 \\
\hline$[0,6]$ & 38.06 & 0.85 & 0.82 & -12.83 & -0.13 & -0.12 & 39.33 & 0.23 & 0.22 \\
\hline$[0,7]$ & 58.99 & 1.31 & 1.27 & -46.00 & -0.45 & -0.44 & 52.62 & 0.30 & 0.30 \\
\hline$[0,8]$ & 30.52 & 0.68 & 0.66 & -87.90 & -0.87 & -0.84 & -33.37 & -0.19 & -0.19 \\
\hline$[0,9]$ & 43.55 & 0.97 & 0.95 & -69.14 & -0.68 & -0.67 & 67.27 & 0.39 & 0.38 \\
\hline$[0,10]$ & 37.07 & 0.82 & 0.81 & -95.35 & -0.94 & -0.92 & 28.34 & 0.16 & 0.16 \\
\hline$[0,11]$ & 32.94 & 0.73 & 0.71 & -130.37 & -1.29 & -1.25 & -48.51 & -0.28 & -0.27 \\
\hline$[0,12]$ & 0.02 & 0.00 & 0.00 & -164.51 & -1.62 & -1.57 & 30.56 & 0.18 & 0.17 \\
\hline$[0,13]$ & -11.20 & -0.25 & -0.24 & -163.56 & -1.61 & -1.56 & -26.03 & -0.15 & -0.15 \\
\hline$[0,14]$ & -4.84 & -0.11 & -0.10 & -162.02 & -1.60 & -1.55 & -76.79 & -0.44 & -0.43 \\
\hline$[0,15]$ & -39.50 & -0.88 & -0.85 & -200.33 & -1.98 & -1.91 & -133.92 & -0.77 & -0.75 \\
\hline$[0,16]$ & -23.38 & -0.52 & -0.50 & -238.55 & -2.35 & -2.28 & -187.90 & -1.09 & -1.05 \\
\hline$[0,17]$ & -16.30 & -0.36 & -0.35 & -184.82 & -1.82 & -1.78 & -169.56 & -0.98 & -0.96 \\
\hline$[0,18]$ & 2.20 & 0.05 & 0.05 & -191.18 & -1.89 & -1.84 & -8.45 & -0.05 & -0.05 \\
\hline$[0,19]$ & -21.13 & -0.47 & -0.46 & -206.54 & -2.04 & -1.98 & -56.83 & -0.33 & -0.32 \\
\hline$[0,20]$ & -20.11 & -0.45 & -0.44 & -218.82 & -2.16 & -2.11 & -68.98 & -0.40 & -0.39 \\
\hline$[0,21]$ & -8.85 & -0.20 & -0.19 & -214.46 & -2.12 & -2.06 & 38.24 & 0.22 & 0.22 \\
\hline$[0,22]$ & -15.24 & -0.34 & -0.33 & -219.67 & -2.17 & -2.13 & 40.86 & 0.24 & 0.23 \\
\hline$[0,23]$ & -19.26 & -0.43 & -0.42 & -227.83 & -2.25 & -2.21 & 55.78 & 0.32 & 0.32 \\
\hline$[0,24]$ & -27.02 & -0.60 & -0.59 & -209.43 & -2.07 & -2.02 & 91.64 & 0.53 & 0.52 \\
\hline$[0,25]$ & -7.00 & -0.16 & -0.15 & -208.23 & -2.05 & -2.01 & 39.86 & 0.23 & 0.23 \\
\hline$[0,26]$ & -30.50 & -0.68 & -0.66 & -234.67 & -2.32 & -2.26 & 119.76 & 0.69 & 0.68 \\
\hline$[0,27]$ & -22.04 & -0.49 & -0.48 & -221.80 & -2.19 & -2.14 & 121.35 & 0.70 & 0.69 \\
\hline$[0,28]$ & 2.83 & 0.06 & 0.06 & -213.12 & -2.10 & -2.06 & -11.82 & -0.07 & -0.07 \\
\hline$[0,29]$ & -27.55 & -0.61 & -0.60 & -246.98 & -2.44 & -2.38 & 84.20 & 0.49 & 0.48 \\
\hline$[0,30]$ & -0.44 & -0.01 & -0.01 & -259.23 & -2.56 & -2.50 & 88.25 & 0.51 & 0.50 \\
\hline
\end{tabular}


Table A41. Case XI: OLS-Cumulative abnormal change rate of Chinese tourist arrivals.

\begin{tabular}{|c|c|c|c|c|c|c|c|c|c|}
\hline \multirow{3}{*}{ Event Period $\left[\tau_{1}, \tau_{2}\right]$} & \multicolumn{3}{|c|}{ Group-Type } & \multicolumn{3}{|c|}{ Individual-Type } & \multicolumn{3}{|c|}{ Medical-Type } \\
\hline & \multirow{2}{*}{ CAR } & \multicolumn{2}{|c|}{ t-Value } & \multirow{2}{*}{ CAR } & \multicolumn{2}{|c|}{ t-Value } & \multirow{2}{*}{ CAR } & \multicolumn{2}{|c|}{ t-Value } \\
\hline & & TM & SRM & & TM & SRM & & TM & SRM \\
\hline$[0,0]$ & -15.18 & -0.65 & -0.64 & 37.05 & 1.66 & 1.63 & -38.37 & -0.40 & -0.39 \\
\hline$[0,1]$ & -25.75 & -1.11 & -1.09 & 28.73 & 1.28 & 1.26 & -76.77 & -0.79 & -0.78 \\
\hline$[0,2]$ & -16.16 & -0.70 & -0.68 & 15.61 & 0.70 & 0.69 & -65.08 & -0.67 & -0.66 \\
\hline$[0,3]$ & -21.25 & -0.91 & -0.90 & -5.39 & -0.24 & -0.24 & -10.93 & -0.11 & -0.11 \\
\hline$[0,4]$ & -5.59 & -0.24 & -0.24 & 12.96 & 0.58 & 0.57 & 91.70 & 0.95 & 0.93 \\
\hline$[0,5]$ & 2.68 & 0.12 & 0.11 & 8.99 & 0.40 & 0.40 & -24.27 & -0.25 & -0.25 \\
\hline$[0,6]$ & -35.12 & -1.51 & -1.48 & 2.74 & 0.12 & 0.12 & 8.42 & 0.09 & 0.09 \\
\hline$[0,7]$ & -47.73 & -2.05 & -1.97 & -43.28 & -1.94 & -1.85 & 48.04 & 0.50 & 0.47 \\
\hline$[0,8]$ & 22.10 & 0.95 & 0.93 & 63.05 & 2.82 & 2.76 & 217.40 & 2.24 & 2.20 \\
\hline$[0,9]$ & 9.98 & 0.43 & 0.42 & 36.07 & 1.61 & 1.59 & 123.78 & 1.28 & 1.26 \\
\hline$[0,10]$ & -11.06 & -0.48 & -0.47 & 29.23 & 1.31 & 1.29 & 60.51 & 0.62 & 0.61 \\
\hline$[0,11]$ & 12.52 & 0.54 & 0.53 & 33.31 & 1.49 & 1.47 & 14.20 & 0.15 & 0.14 \\
\hline$[0,12]$ & 15.91 & 0.68 & 0.67 & 29.51 & 1.32 & 1.30 & -43.43 & -0.45 & -0.44 \\
\hline$[0,13]$ & -13.19 & -0.57 & -0.56 & 15.65 & 0.70 & 0.69 & -10.34 & -0.11 & -0.11 \\
\hline$[0,14]$ & 1.13 & 0.05 & 0.05 & 51.29 & 2.29 & 2.25 & 1.27 & 0.01 & 0.01 \\
\hline$[0,15]$ & 1.18 & 0.05 & 0.05 & 35.71 & 1.60 & 1.56 & -62.95 & -0.65 & -0.63 \\
\hline$[0,16]$ & 22.49 & 0.97 & 0.95 & 26.35 & 1.18 & 1.16 & 151.59 & 1.56 & 1.54 \\
\hline$[0,17]$ & 9.23 & 0.40 & 0.39 & 24.21 & 1.08 & 1.07 & 93.86 & 0.97 & 0.95 \\
\hline$[0,18]$ & 14.84 & 0.64 & 0.63 & 32.07 & 1.43 & 1.41 & 36.54 & 0.38 & 0.37 \\
\hline$[0,19]$ & 22.60 & 0.97 & 0.96 & 25.33 & 1.13 & 1.12 & 121.02 & 1.25 & 1.23 \\
\hline$[0,20]$ & 6.75 & 0.29 & 0.29 & 18.06 & 0.81 & 0.79 & -40.94 & -0.42 & -0.42 \\
\hline$[0,21]$ & 12.30 & 0.53 & 0.52 & 42.30 & 1.89 & 1.86 & 42.88 & 0.44 & 0.44 \\
\hline$[0,22]$ & 8.82 & 0.38 & 0.37 & 43.77 & 1.96 & 1.93 & 177.69 & 1.83 & 1.80 \\
\hline$[0,23]$ & 12.65 & 0.54 & 0.54 & 24.49 & 1.09 & 1.08 & 20.75 & 0.21 & 0.21 \\
\hline$[0,24]$ & 7.81 & 0.34 & 0.33 & 12.43 & 0.56 & 0.55 & 53.90 & 0.56 & 0.55 \\
\hline$[0,25]$ & 5.87 & 0.25 & 0.25 & 9.74 & 0.44 & 0.43 & 150.81 & 1.56 & 1.53 \\
\hline$[0,26]$ & 11.97 & 0.52 & 0.51 & 4.52 & 0.20 & 0.20 & 175.23 & 1.81 & 1.78 \\
\hline$[0,27]$ & -11.84 & -0.51 & -0.50 & 9.38 & 0.42 & 0.41 & 58.07 & 0.60 & 0.59 \\
\hline$[0,28]$ & 8.80 & 0.38 & 0.37 & 27.92 & 1.25 & 1.23 & 37.34 & 0.39 & 0.38 \\
\hline$[0,29]$ & -1.65 & -0.07 & -0.07 & 31.26 & 1.40 & 1.37 & 186.99 & 1.93 & 1.89 \\
\hline$[0,30]$ & 6.98 & 0.30 & 0.29 & 18.47 & 0.83 & 0.80 & 35.78 & 0.37 & 0.36 \\
\hline
\end{tabular}


Table A42. Case XI: GARCH(1,1)—Cumulative abnormal change rate of Chinese tourist arrivals.

\begin{tabular}{|c|c|c|c|c|c|c|c|c|c|}
\hline \multirow{3}{*}{ Event Period $\left[\tau_{1}, \tau_{2}\right]$} & \multicolumn{3}{|c|}{ Group-Type } & \multicolumn{3}{|c|}{ Individual-Type } & \multicolumn{3}{|c|}{ Medical-Type } \\
\hline & \multirow{2}{*}{ CAR } & \multicolumn{2}{|c|}{ t-Value } & \multirow{2}{*}{ CAR } & \multicolumn{2}{|c|}{ t-Value } & \multirow{2}{*}{ CAR } & \multicolumn{2}{|c|}{ t-Value } \\
\hline & & TM & SRM & & TM & SRM & & TM & SRM \\
\hline$[0,0]$ & -15.10 & -0.82 & -0.68 & 36.24 & 1.18 & 1.16 & -41.43 & -0.38 & -0.38 \\
\hline$[0,1]$ & -25.42 & -1.39 & -1.14 & 27.41 & 0.89 & 0.87 & -83.77 & -0.78 & -0.76 \\
\hline$[0,2]$ & -15.62 & -0.85 & -0.70 & 13.71 & 0.45 & 0.44 & -75.86 & -0.70 & -0.69 \\
\hline$[0,3]$ & -20.56 & -1.12 & -0.92 & -7.95 & -0.26 & -0.25 & -25.20 & -0.23 & -0.23 \\
\hline$[0,4]$ & -5.03 & -0.27 & -0.23 & 9.22 & 0.30 & 0.29 & 75.49 & 0.70 & 0.69 \\
\hline$[0,5]$ & 3.54 & 0.19 & 0.16 & 4.83 & 0.16 & 0.15 & -44.73 & -0.41 & -0.41 \\
\hline$[0,6]$ & -35.04 & -1.91 & -1.56 & -3.67 & -0.12 & -0.12 & -10.70 & -0.10 & -0.10 \\
\hline$[0,7]$ & -48.38 & -2.64 & -2.11 & -51.86 & -1.68 & -1.61 & 30.01 & 0.28 & 0.27 \\
\hline$[0,8]$ & 24.15 & 1.32 & 1.08 & 58.11 & 1.89 & 1.85 & 182.77 & 1.69 & 1.66 \\
\hline$[0,9]$ & 11.70 & 0.64 & 0.53 & 29.62 & 0.96 & 0.95 & 88.23 & 0.82 & 0.80 \\
\hline$[0,10]$ & -8.89 & -0.49 & -0.40 & 22.60 & 0.73 & 0.72 & 19.96 & 0.18 & 0.18 \\
\hline$[0,11]$ & 14.36 & 0.78 & 0.64 & 25.19 & 0.82 & 0.81 & -27.34 & -0.25 & -0.25 \\
\hline$[0,12]$ & 17.96 & 0.98 & 0.81 & 20.82 & 0.68 & 0.67 & -88.73 & -0.82 & -0.81 \\
\hline$[0,13]$ & -10.42 & -0.57 & -0.47 & 7.22 & 0.23 & 0.23 & -61.98 & -0.57 & -0.57 \\
\hline$[0,14]$ & 4.55 & 0.25 & 0.20 & 43.03 & 1.40 & 1.37 & -56.38 & -0.52 & -0.51 \\
\hline$[0,15]$ & 5.10 & 0.28 & 0.23 & 27.36 & 0.89 & 0.87 & -125.86 & -1.17 & -1.14 \\
\hline$[0,16]$ & 25.86 & 1.41 & 1.16 & 16.13 & 0.52 & 0.52 & 88.88 & 0.82 & 0.81 \\
\hline$[0,17]$ & 12.64 & 0.69 & 0.57 & 13.14 & 0.43 & 0.42 & 28.23 & 0.26 & 0.26 \\
\hline$[0,18]$ & 18.02 & 0.98 & 0.81 & 19.65 & 0.64 & 0.63 & -30.55 & -0.28 & -0.28 \\
\hline$[0,19]$ & 26.30 & 1.44 & 1.18 & 12.88 & 0.42 & 0.41 & 48.52 & 0.45 & 0.44 \\
\hline$[0,20]$ & 11.03 & 0.60 & 0.50 & 5.65 & 0.18 & 0.18 & -119.08 & -1.10 & -1.09 \\
\hline$[0,21]$ & 16.89 & 0.92 & 0.76 & 29.47 & 0.96 & 0.94 & -39.51 & -0.37 & -0.36 \\
\hline$[0,22]$ & 13.52 & 0.74 & 0.61 & 30.19 & 0.98 & 0.97 & 92.06 & 0.85 & 0.84 \\
\hline$[0,23]$ & 17.47 & 0.95 & 0.78 & 10.17 & 0.33 & 0.33 & -68.14 & -0.63 & -0.62 \\
\hline$[0,24]$ & 12.97 & 0.71 & 0.58 & -2.25 & -0.07 & -0.07 & -39.42 & -0.37 & -0.36 \\
\hline$[0,25]$ & 10.89 & 0.59 & 0.49 & -6.10 & -0.20 & -0.20 & 55.50 & 0.51 & 0.51 \\
\hline$[0,26]$ & 17.48 & 0.95 & 0.78 & -11.45 & -0.37 & -0.37 & 74.80 & 0.69 & 0.68 \\
\hline$[0,27]$ & -5.72 & -0.31 & -0.26 & -6.49 & -0.21 & -0.21 & -48.20 & -0.45 & -0.44 \\
\hline$[0,28]$ & 15.12 & 0.83 & 0.68 & 11.46 & 0.37 & 0.37 & -72.64 & -0.67 & -0.66 \\
\hline$[0,29]$ & 4.98 & 0.27 & 0.22 & 14.39 & 0.47 & 0.46 & 72.72 & 0.67 & 0.66 \\
\hline$[0,30]$ & 13.61 & 0.74 & 0.60 & 0.65 & 0.02 & 0.02 & -81.10 & -0.75 & -0.73 \\
\hline
\end{tabular}


Table A43. Case XI: GJR (1,1)—Cumulative abnormal change rate of Chinese tourist arrivals.

\begin{tabular}{|c|c|c|c|c|c|c|c|c|c|}
\hline \multirow{3}{*}{ Event Period $\left[\tau_{1}, \tau_{2}\right]$} & \multicolumn{3}{|c|}{ Group-Type } & \multicolumn{3}{|c|}{ Individual-Type } & \multicolumn{3}{|c|}{ Medical-Type } \\
\hline & \multirow{2}{*}{ CAR } & \multicolumn{2}{|c|}{ t-Value } & \multirow{2}{*}{ CAR } & \multicolumn{2}{|c|}{ t-Value } & \multirow{2}{*}{ CAR } & \multicolumn{2}{|c|}{ t-Value } \\
\hline & & TM & SRM & & TM & SRM & & TM & SRM \\
\hline$[0,0]$ & -16.17 & -0.37 & -0.36 & 35.63 & 0.63 & 0.62 & -26.36 & -0.07 & -0.07 \\
\hline$[0,1]$ & -27.80 & -0.63 & -0.62 & 25.65 & 0.45 & 0.45 & -53.46 & -0.14 & -0.14 \\
\hline$[0,2]$ & -19.26 & -0.44 & -0.43 & 10.92 & 0.19 & 0.19 & -30.33 & -0.08 & -0.08 \\
\hline$[0,3]$ & -25.38 & -0.58 & -0.57 & -11.62 & -0.21 & -0.20 & 35.49 & 0.09 & 0.09 \\
\hline$[0,4]$ & -10.64 & -0.24 & -0.24 & 5.61 & 0.10 & 0.10 & 151.04 & 0.39 & 0.39 \\
\hline$[0,5]$ & -3.45 & -0.08 & -0.08 & -0.10 & 0.00 & 0.00 & 46.12 & 0.12 & 0.12 \\
\hline$[0,6]$ & -41.93 & -0.95 & -0.93 & -6.56 & -0.12 & -0.11 & 94.38 & 0.24 & 0.24 \\
\hline$[0,7]$ & -55.24 & -1.26 & -1.20 & -52.87 & -0.93 & -0.89 & 149.37 & 0.39 & 0.37 \\
\hline$[0,8]$ & 12.62 & 0.29 & 0.28 & 48.33 & 0.85 & 0.84 & 319.80 & 0.83 & 0.81 \\
\hline$[0,9]$ & -0.34 & -0.01 & -0.01 & 20.52 & 0.36 & 0.36 & 239.92 & 0.62 & 0.61 \\
\hline$[0,10]$ & -22.51 & -0.51 & -0.50 & 11.72 & 0.21 & 0.20 & 187.10 & 0.48 & 0.48 \\
\hline$[0,11]$ & 0.22 & 0.00 & 0.00 & 14.95 & 0.26 & 0.26 & 154.48 & 0.40 & 0.39 \\
\hline$[0,12]$ & 2.56 & 0.06 & 0.06 & 9.53 & 0.17 & 0.17 & 108.30 & 0.28 & 0.28 \\
\hline$[0,13]$ & -27.77 & -0.63 & -0.62 & -6.65 & -0.12 & -0.12 & 150.75 & 0.39 & 0.38 \\
\hline$[0,14]$ & -14.66 & -0.33 & -0.33 & 26.77 & 0.47 & 0.46 & 171.99 & 0.45 & 0.44 \\
\hline$[0,15]$ & -15.76 & -0.36 & -0.35 & 9.16 & 0.16 & 0.16 & 118.01 & 0.31 & 0.30 \\
\hline$[0,16]$ & 4.79 & 0.11 & 0.11 & -0.72 & -0.01 & -0.01 & 347.20 & 0.90 & 0.89 \\
\hline$[0,17]$ & -9.46 & -0.22 & -0.21 & -4.24 & -0.07 & -0.07 & 301.59 & 0.78 & 0.77 \\
\hline$[0,18]$ & -4.73 & -0.11 & -0.11 & 2.63 & 0.05 & 0.05 & 257.58 & 0.67 & 0.66 \\
\hline$[0,19]$ & 1.86 & 0.04 & 0.04 & -6.17 & -0.11 & -0.11 & 352.18 & 0.91 & 0.90 \\
\hline$[0,20]$ & -15.17 & -0.35 & -0.34 & -15.56 & -0.27 & -0.27 & 200.15 & 0.52 & 0.51 \\
\hline$[0,21]$ & -10.70 & -0.24 & -0.24 & 6.92 & 0.12 & 0.12 & 295.02 & 0.76 & 0.75 \\
\hline$[0,22]$ & -15.19 & -0.35 & -0.34 & 6.93 & 0.12 & 0.12 & 441.70 & 1.14 & 1.13 \\
\hline$[0,23]$ & -12.37 & -0.28 & -0.28 & -13.82 & -0.24 & -0.24 & 296.62 & 0.77 & 0.76 \\
\hline$[0,24]$ & -18.30 & -0.42 & -0.41 & -27.68 & -0.49 & -0.48 & 340.67 & 0.88 & 0.87 \\
\hline$[0,25]$ & -21.16 & -0.48 & -0.47 & -31.50 & -0.56 & -0.55 & 450.46 & 1.17 & 1.15 \\
\hline$[0,26]$ & -16.20 & -0.37 & -0.36 & -38.70 & -0.68 & -0.67 & 485.23 & 1.26 & 1.24 \\
\hline$[0,27]$ & -41.21 & -0.94 & -0.92 & -36.03 & -0.64 & -0.62 & 377.83 & 0.98 & 0.96 \\
\hline$[0,28]$ & -21.62 & -0.49 & -0.48 & -19.09 & -0.34 & -0.33 & 368.60 & 0.96 & 0.94 \\
\hline$[0,29]$ & -33.15 & -0.75 & -0.74 & -17.50 & -0.31 & -0.30 & 529.27 & 1.37 & 1.35 \\
\hline$[0,30]$ & -25.48 & -0.58 & -0.56 & -31.59 & -0.56 & -0.54 & 390.43 & 1.01 & 0.99 \\
\hline
\end{tabular}


Table A44. Case XI: EGARCH(1,1)—Cumulative abnormal change rate of Chinese tourist arrivals.

\begin{tabular}{|c|c|c|c|c|c|c|c|c|c|}
\hline \multirow{3}{*}{ Event Period $\left[\tau_{1}, \tau_{2}\right]$} & \multicolumn{3}{|c|}{ Group-Type } & \multicolumn{3}{|c|}{ Individual-Type } & \multicolumn{3}{|c|}{ Medical-Type } \\
\hline & \multirow{2}{*}{ CAR } & \multicolumn{2}{|c|}{ t-Value } & \multirow{2}{*}{ CAR } & \multicolumn{2}{|c|}{ t-Value } & \multirow{2}{*}{ CAR } & \multicolumn{2}{|c|}{ t-Value } \\
\hline & & TM & SRM & & TM & SRM & & TM & SRM \\
\hline$[0,0]$ & -15.06 & -0.35 & -0.34 & 36.23 & 1.06 & 1.04 & -27.65 & -0.08 & -0.08 \\
\hline$[0,1]$ & -26.85 & -0.63 & -0.61 & 27.21 & 0.80 & 0.78 & -55.83 & -0.16 & -0.15 \\
\hline$[0,2]$ & -18.22 & -0.42 & -0.42 & 13.36 & 0.39 & 0.38 & -33.83 & -0.10 & -0.09 \\
\hline$[0,3]$ & -23.86 & -0.56 & -0.55 & -8.40 & -0.25 & -0.24 & 30.80 & 0.09 & 0.09 \\
\hline$[0,4]$ & -6.37 & -0.15 & -0.15 & 8.97 & 0.26 & 0.26 & 144.80 & 0.41 & 0.40 \\
\hline$[0,5]$ & 0.21 & 0.00 & 0.00 & 4.34 & 0.13 & 0.13 & 38.86 & 0.11 & 0.11 \\
\hline$[0,6]$ & -30.78 & -0.72 & -0.70 & -3.30 & -0.10 & -0.09 & 84.80 & 0.24 & 0.23 \\
\hline$[0,7]$ & -36.97 & -0.86 & -0.82 & -50.69 & -1.49 & -1.42 & 137.52 & 0.39 & 0.37 \\
\hline$[0,8]$ & 12.42 & 0.29 & 0.28 & 56.59 & 1.66 & 1.63 & 309.84 & 0.87 & 0.86 \\
\hline$[0,9]$ & 3.66 & 0.09 & 0.08 & 28.52 & 0.84 & 0.82 & 228.17 & 0.64 & 0.63 \\
\hline$[0,10]$ & -20.19 & -0.47 & -0.46 & 21.11 & 0.62 & 0.61 & 174.51 & 0.49 & 0.48 \\
\hline$[0,11]$ & 6.65 & 0.15 & 0.15 & 24.09 & 0.71 & 0.70 & 140.11 & 0.40 & 0.39 \\
\hline$[0,12]$ & 9.10 & 0.21 & 0.21 & 19.56 & 0.57 & 0.56 & 92.81 & 0.26 & 0.26 \\
\hline$[0,13]$ & -24.86 & -0.58 & -0.57 & 5.31 & 0.16 & 0.15 & 134.74 & 0.38 & 0.37 \\
\hline$[0,14]$ & -14.91 & -0.35 & -0.34 & 40.52 & 1.19 & 1.16 & 155.39 & 0.44 & 0.43 \\
\hline$[0,15]$ & -18.07 & -0.42 & -0.41 & 24.40 & 0.72 & 0.70 & 100.63 & 0.28 & 0.28 \\
\hline$[0,16]$ & 8.31 & 0.19 & 0.19 & 13.80 & 0.40 & 0.40 & 327.76 & 0.93 & 0.91 \\
\hline$[0,17]$ & -4.62 & -0.11 & -0.11 & 10.83 & 0.32 & 0.31 & 280.83 & 0.79 & 0.78 \\
\hline$[0,18]$ & 3.55 & 0.08 & 0.08 & 17.65 & 0.52 & 0.51 & 235.15 & 0.66 & 0.65 \\
\hline$[0,19]$ & 7.85 & 0.18 & 0.18 & 10.40 & 0.30 & 0.30 & 329.01 & 0.93 & 0.91 \\
\hline$[0,20]$ & -11.79 & -0.27 & -0.27 & 2.65 & 0.08 & 0.08 & 176.30 & 0.50 & 0.49 \\
\hline$[0,21]$ & -7.92 & -0.18 & -0.18 & 26.22 & 0.77 & 0.76 & 270.16 & 0.76 & 0.75 \\
\hline$[0,22]$ & -11.56 & -0.27 & -0.27 & 26.89 & 0.79 & 0.78 & 415.58 & 1.17 & 1.15 \\
\hline$[0,23]$ & -7.91 & -0.18 & -0.18 & 6.82 & 0.20 & 0.20 & 269.26 & 0.76 & 0.75 \\
\hline$[0,24]$ & -14.70 & -0.34 & -0.34 & -5.88 & -0.17 & -0.17 & 312.35 & 0.88 & 0.87 \\
\hline$[0,25]$ & -14.90 & -0.35 & -0.34 & -9.53 & -0.28 & -0.28 & 420.59 & 1.19 & 1.17 \\
\hline$[0,26]$ & -11.81 & -0.28 & -0.27 & -15.30 & -0.45 & -0.44 & 454.55 & 1.28 & 1.26 \\
\hline$[0,27]$ & -39.72 & -0.93 & -0.91 & -10.90 & -0.32 & -0.31 & 346.52 & 0.98 & 0.96 \\
\hline$[0,28]$ & -19.95 & -0.46 & -0.46 & 6.90 & 0.20 & 0.20 & 336.14 & 0.95 & 0.93 \\
\hline$[0,29]$ & -32.14 & -0.75 & -0.73 & 9.58 & 0.28 & 0.28 & 495.81 & 1.40 & 1.37 \\
\hline$[0,30]$ & -22.72 & -0.53 & -0.52 & -4.08 & -0.12 & -0.12 & 355.58 & 1.00 & 0.98 \\
\hline
\end{tabular}


Table A45. Case XII: OLS—Cumulative abnormal change rate of Chinese tourist arrivals.

\begin{tabular}{|c|c|c|c|c|c|c|c|c|c|}
\hline \multirow{3}{*}{ Event Period $\left[\tau_{1}, \tau_{2}\right]$} & \multicolumn{3}{|c|}{ Group-Type } & \multicolumn{3}{|c|}{ Individual-Type } & \multicolumn{3}{|c|}{ Medical-Type } \\
\hline & \multirow{2}{*}{ CAR } & \multicolumn{2}{|c|}{ t-Value } & \multirow{2}{*}{ CAR } & \multicolumn{2}{|c|}{ t-Value } & \multirow{2}{*}{ CAR } & \multicolumn{2}{|c|}{ t-Value } \\
\hline & & TM & SRM & & TM & SRM & & TM & SRM \\
\hline$[0,0]$ & 8.05 & 0.35 & 0.34 & 12.44 & 0.55 & 0.54 & -53.37 & -0.64 & -0.62 \\
\hline$[0,1]$ & 14.20 & 0.62 & 0.61 & 2.72 & 0.12 & 0.12 & 26.11 & 0.31 & 0.31 \\
\hline$[0,2]$ & -3.48 & -0.15 & -0.15 & -7.99 & -0.36 & -0.35 & -141.36 & -1.68 & -1.66 \\
\hline$[0,3]$ & 1.66 & 0.07 & 0.07 & 15.48 & 0.69 & 0.68 & -59.91 & -0.71 & -0.70 \\
\hline$[0,4]$ & -1.21 & -0.05 & -0.05 & 18.12 & 0.81 & 0.79 & 74.80 & 0.89 & 0.88 \\
\hline$[0,5]$ & 3.22 & 0.14 & 0.14 & -0.03 & 0.00 & 0.00 & -82.26 & -0.98 & -0.96 \\
\hline$[0,6]$ & -2.22 & -0.10 & -0.09 & -13.19 & -0.59 & -0.57 & -51.88 & -0.62 & -0.60 \\
\hline$[0,7]$ & -2.27 & -0.10 & -0.10 & -12.32 & -0.55 & -0.54 & 47.77 & 0.57 & 0.56 \\
\hline$[0,8]$ & 2.53 & 0.11 & 0.11 & -19.99 & -0.89 & -0.87 & 67.84 & 0.81 & 0.79 \\
\hline$[0,9]$ & -23.33 & -1.01 & -1.00 & -18.95 & -0.84 & -0.83 & -55.30 & -0.66 & -0.65 \\
\hline$[0,10]$ & -2.55 & -0.11 & -0.11 & -0.14 & -0.01 & -0.01 & -77.17 & -0.92 & -0.90 \\
\hline$[0,11]$ & -13.45 & -0.59 & -0.56 & 2.36 & 0.11 & 0.10 & 70.02 & 0.83 & 0.80 \\
\hline$[0,12]$ & -3.57 & -0.16 & -0.15 & -8.07 & -0.36 & -0.35 & -79.87 & -0.95 & -0.93 \\
\hline$[0,13]$ & -27.30 & -1.19 & -1.16 & -8.14 & -0.36 & -0.36 & -90.11 & -1.07 & -1.05 \\
\hline$[0,14]$ & -16.73 & -0.73 & -0.68 & -4.12 & -0.18 & -0.17 & -117.74 & -1.40 & -1.30 \\
\hline$[0,15]$ & -2.52 & -0.11 & -0.11 & -12.69 & -0.57 & -0.56 & -69.08 & -0.82 & -0.81 \\
\hline$[0,16]$ & -10.96 & -0.48 & -0.46 & -14.44 & -0.64 & -0.62 & -59.47 & -0.71 & -0.69 \\
\hline$[0,17]$ & 7.21 & 0.31 & 0.31 & 23.28 & 1.04 & 1.01 & -69.59 & -0.83 & -0.81 \\
\hline$[0,18]$ & -3.88 & -0.17 & -0.17 & 17.19 & 0.77 & 0.75 & -76.65 & -0.91 & -0.90 \\
\hline$[0,19]$ & -14.73 & -0.64 & -0.63 & -4.20 & -0.19 & -0.18 & 63.98 & 0.76 & 0.75 \\
\hline$[0,20]$ & -17.16 & -0.75 & -0.71 & -12.63 & -0.56 & -0.53 & -3.35 & -0.04 & -0.04 \\
\hline$[0,21]$ & -37.37 & -1.63 & -1.57 & -19.16 & -0.85 & -0.82 & -57.94 & -0.69 & -0.66 \\
\hline$[0,22]$ & -19.02 & -0.83 & -0.81 & -23.06 & -1.03 & -1.01 & -160.49 & -1.91 & -1.88 \\
\hline$[0,23]$ & -59.82 & -2.60 & -2.56 & -35.14 & -1.57 & -1.54 & 7.46 & 0.09 & 0.09 \\
\hline$[0,24]$ & -55.08 & -2.40 & -2.35 & -6.83 & -0.30 & -0.30 & -10.33 & -0.12 & -0.12 \\
\hline$[0,25]$ & -25.88 & -1.13 & -1.10 & 2.68 & 0.12 & 0.12 & -9.90 & -0.12 & -0.12 \\
\hline$[0,26]$ & -29.25 & -1.27 & -1.24 & -25.59 & -1.14 & -1.11 & -67.43 & -0.80 & -0.78 \\
\hline$[0,27]$ & -50.64 & -2.20 & -2.13 & -32.17 & -1.43 & -1.39 & -64.33 & -0.77 & -0.74 \\
\hline$[0,28]$ & -39.20 & -1.71 & -1.68 & -28.83 & -1.29 & -1.26 & 74.36 & 0.89 & 0.87 \\
\hline$[0,29]$ & -25.79 & -1.12 & -1.10 & -37.21 & -1.66 & -1.63 & -16.04 & -0.19 & -0.19 \\
\hline$[0,30]$ & -32.86 & -1.43 & -1.41 & -33.75 & -1.50 & -1.48 & -56.65 & -0.67 & -0.66 \\
\hline
\end{tabular}


Table A46. Case XII: GARCH(1,1)—Cumulative abnormal change rate of Chinese tourist arrivals.

\begin{tabular}{|c|c|c|c|c|c|c|c|c|c|}
\hline \multirow{3}{*}{ Event Period $\left[\tau_{1}, \tau_{2}\right]$} & \multicolumn{3}{|c|}{ Group-Type } & \multicolumn{3}{|c|}{ Individual-Type } & \multicolumn{3}{|c|}{ Medical-Type } \\
\hline & \multirow{2}{*}{ CAR } & \multicolumn{2}{|c|}{ t-Value } & \multirow{2}{*}{ CAR } & \multicolumn{2}{|c|}{ t-Value } & \multirow{2}{*}{ CAR } & \multicolumn{2}{|c|}{ t-Value } \\
\hline & & TM & SRM & & TM & SRM & & TM & SRM \\
\hline$[0,0]$ & 7.57 & 0.30 & 0.29 & 7.48 & 0.22 & 0.21 & -53.62 & -0.56 & -0.54 \\
\hline$[0,1]$ & 13.68 & 0.54 & 0.53 & -0.17 & 0.00 & 0.00 & 24.05 & 0.25 & 0.25 \\
\hline$[0,2]$ & -4.03 & -0.16 & -0.16 & -8.37 & -0.25 & -0.24 & -145.33 & -1.51 & -1.49 \\
\hline$[0,3]$ & 0.94 & 0.04 & 0.04 & 15.11 & 0.44 & 0.44 & -65.23 & -0.68 & -0.67 \\
\hline$[0,4]$ & -2.22 & -0.09 & -0.09 & 15.97 & 0.47 & 0.46 & 68.53 & 0.71 & 0.70 \\
\hline$[0,5]$ & 1.93 & 0.08 & 0.07 & -3.93 & -0.12 & -0.11 & -89.50 & -0.93 & -0.92 \\
\hline$[0,6]$ & -3.66 & -0.14 & -0.14 & -16.76 & -0.49 & -0.48 & -60.55 & -0.63 & -0.61 \\
\hline$[0,7]$ & -4.13 & -0.16 & -0.16 & -19.91 & -0.59 & -0.58 & 38.64 & 0.40 & 0.39 \\
\hline$[0,8]$ & 0.59 & 0.02 & 0.02 & -25.99 & -0.77 & -0.75 & 57.02 & 0.59 & 0.58 \\
\hline$[0,9]$ & -25.26 & -0.99 & -0.97 & -22.10 & -0.65 & -0.64 & -68.10 & -0.71 & -0.70 \\
\hline$[0,10]$ & -4.72 & -0.19 & -0.18 & -4.24 & -0.12 & -0.12 & -91.11 & -0.95 & -0.93 \\
\hline$[0,11]$ & -15.79 & -0.62 & -0.59 & -1.65 & -0.05 & -0.05 & 54.71 & 0.57 & 0.54 \\
\hline$[0,12]$ & -6.27 & -0.25 & -0.24 & -14.98 & -0.44 & -0.43 & -95.89 & -1.00 & -0.98 \\
\hline$[0,13]$ & -29.98 & -1.18 & -1.15 & -12.10 & -0.36 & -0.35 & -108.14 & -1.13 & -1.10 \\
\hline$[0,14]$ & -19.92 & -0.78 & -0.73 & -13.43 & -0.40 & -0.37 & -135.94 & -1.41 & -1.31 \\
\hline$[0,15]$ & -5.73 & -0.22 & -0.22 & -19.57 & -0.58 & -0.57 & -89.15 & -0.93 & -0.91 \\
\hline$[0,16]$ & -14.33 & -0.56 & -0.54 & -20.98 & -0.62 & -0.60 & -80.98 & -0.84 & -0.81 \\
\hline$[0,17]$ & 3.53 & 0.14 & 0.13 & 14.33 & 0.42 & 0.41 & -91.91 & -0.96 & -0.93 \\
\hline$[0,18]$ & -7.83 & -0.31 & -0.30 & 6.80 & 0.20 & 0.20 & -100.00 & -1.04 & -1.02 \\
\hline$[0,19]$ & -18.89 & -0.74 & -0.73 & -15.14 & -0.45 & -0.44 & 39.40 & 0.41 & 0.40 \\
\hline$[0,20]$ & -21.60 & -0.85 & -0.80 & -25.28 & -0.74 & -0.70 & -28.91 & -0.30 & -0.28 \\
\hline$[0,21]$ & -42.10 & -1.65 & -1.59 & -33.61 & -0.99 & -0.95 & -84.45 & -0.88 & -0.85 \\
\hline$[0,22]$ & -23.47 & -0.92 & -0.91 & -30.21 & -0.89 & -0.88 & -189.95 & -1.98 & -1.95 \\
\hline$[0,23]$ & -64.08 & -2.52 & -2.47 & -36.36 & -1.07 & -1.05 & -24.66 & -0.26 & -0.25 \\
\hline$[0,24]$ & -60.00 & -2.36 & -2.31 & -15.87 & -0.47 & -0.46 & -42.08 & -0.44 & -0.43 \\
\hline$[0,25]$ & -31.07 & -1.22 & -1.20 & -8.04 & -0.24 & -0.23 & -42.62 & -0.44 & -0.44 \\
\hline$[0,26]$ & -34.71 & -1.36 & -1.33 & -37.69 & -1.11 & -1.08 & -101.21 & -1.05 & -1.03 \\
\hline$[0,27]$ & -56.42 & -2.21 & -2.14 & -46.83 & -1.38 & -1.33 & -98.89 & -1.03 & -1.00 \\
\hline$[0,28]$ & -45.31 & -1.78 & -1.75 & -45.91 & -1.35 & -1.33 & 38.99 & 0.41 & 0.40 \\
\hline$[0,29]$ & -32.05 & -1.26 & -1.24 & -54.02 & -1.59 & -1.56 & -52.82 & -0.55 & -0.54 \\
\hline$[0,30]$ & -39.31 & -1.54 & -1.52 & -50.67 & -1.49 & -1.47 & -94.76 & -0.99 & -0.97 \\
\hline
\end{tabular}


Table A47. Case XII: GJR(1,1)—Cumulative abnormal change rate of Chinese tourist arrivals.

\begin{tabular}{|c|c|c|c|c|c|c|c|c|c|}
\hline \multirow{3}{*}{ Event Period $\left[\tau_{1}, \tau_{2}\right]$} & \multicolumn{3}{|c|}{ Group-Type } & \multicolumn{3}{|c|}{ Individual-Type } & \multicolumn{3}{|c|}{ Medical-Type } \\
\hline & \multirow{2}{*}{ CAR } & \multicolumn{2}{|c|}{ t-Value } & \multirow{2}{*}{ CAR } & \multicolumn{2}{|c|}{ t-Value } & \multirow{2}{*}{ CAR } & \multicolumn{2}{|c|}{ t-Value } \\
\hline & & TM & SRM & & TM & SRM & & TM & SRM \\
\hline$[0,0]$ & 7.92 & 0.34 & 0.33 & 8.95 & 0.38 & 0.37 & -44.93 & -0.18 & -0.18 \\
\hline$[0,1]$ & 15.00 & 0.64 & 0.63 & 1.31 & 0.06 & 0.06 & 43.30 & 0.17 & 0.17 \\
\hline$[0,2]$ & -1.69 & -0.07 & -0.07 & -6.97 & -0.30 & -0.29 & -115.41 & -0.46 & -0.46 \\
\hline$[0,3]$ & 4.07 & 0.17 & 0.17 & 16.95 & 0.72 & 0.71 & -25.30 & -0.10 & -0.10 \\
\hline$[0,4]$ & 1.55 & 0.07 & 0.07 & 18.61 & 0.79 & 0.78 & 117.99 & 0.47 & 0.47 \\
\hline$[0,5]$ & 6.33 & 0.27 & 0.27 & -0.48 & -0.02 & -0.02 & -30.49 & -0.12 & -0.12 \\
\hline$[0,6]$ & 1.56 & 0.07 & 0.07 & -12.94 & -0.55 & -0.54 & 8.56 & 0.03 & 0.03 \\
\hline$[0,7]$ & 1.52 & 0.07 & 0.06 & -14.81 & -0.63 & -0.62 & 116.69 & 0.47 & 0.46 \\
\hline$[0,8]$ & 7.18 & 0.31 & 0.30 & -20.78 & -0.89 & -0.87 & 145.49 & 0.58 & 0.57 \\
\hline$[0,9]$ & -17.64 & -0.76 & -0.74 & -17.05 & -0.73 & -0.71 & 31.13 & 0.12 & 0.12 \\
\hline$[0,10]$ & 3.61 & 0.16 & 0.15 & 1.45 & 0.06 & 0.06 & 17.87 & 0.07 & 0.07 \\
\hline$[0,11]$ & -6.66 & -0.29 & -0.27 & 4.46 & 0.19 & 0.18 & 173.72 & 0.70 & 0.67 \\
\hline$[0,12]$ & 3.40 & 0.15 & 0.14 & -7.82 & -0.33 & -0.33 & 32.36 & 0.13 & 0.13 \\
\hline$[0,13]$ & -19.27 & -0.83 & -0.81 & -5.12 & -0.22 & -0.21 & 30.90 & 0.12 & 0.12 \\
\hline$[0,14]$ & -8.88 & -0.38 & -0.35 & -4.90 & -0.21 & -0.19 & 11.70 & 0.05 & 0.04 \\
\hline$[0,15]$ & 6.31 & 0.27 & 0.27 & -11.10 & -0.47 & -0.47 & 69.13 & 0.28 & 0.27 \\
\hline$[0,16]$ & -1.47 & -0.06 & -0.06 & -12.14 & -0.52 & -0.50 & 87.40 & 0.35 & 0.34 \\
\hline$[0,17]$ & 16.97 & 0.73 & 0.71 & 24.11 & 1.03 & 1.00 & 85.84 & 0.34 & 0.34 \\
\hline$[0,18]$ & 6.27 & 0.27 & 0.26 & 17.32 & 0.74 & 0.72 & 87.38 & 0.35 & 0.34 \\
\hline$[0,19]$ & -4.05 & -0.17 & -0.17 & -4.06 & -0.17 & -0.17 & 236.64 & 0.95 & 0.94 \\
\hline$[0,20]$ & -6.11 & -0.26 & -0.25 & -13.41 & -0.57 & -0.54 & 177.89 & 0.71 & 0.67 \\
\hline$[0,21]$ & -25.98 & -1.11 & -1.07 & -20.93 & -0.89 & -0.86 & 131.88 & 0.53 & 0.51 \\
\hline$[0,22]$ & -5.92 & -0.25 & -0.25 & -18.61 & -0.79 & -0.78 & 38.30 & 0.15 & 0.15 \\
\hline$[0,23]$ & -45.22 & -1.94 & -1.90 & -25.56 & -1.09 & -1.07 & 215.15 & 0.86 & 0.85 \\
\hline$[0,24]$ & -41.03 & -1.76 & -1.73 & -2.99 & -0.13 & -0.13 & 205.69 & 0.83 & 0.81 \\
\hline$[0,25]$ & -11.46 & -0.49 & -0.48 & 5.62 & 0.24 & 0.23 & 214.70 & 0.86 & 0.85 \\
\hline$[0,26]$ & -14.43 & -0.62 & -0.60 & -23.29 & -0.99 & -0.97 & 165.77 & 0.67 & 0.65 \\
\hline$[0,27]$ & -35.58 & -1.53 & -1.48 & -31.47 & -1.34 & -1.30 & 177.41 & 0.71 & 0.69 \\
\hline$[0,28]$ & -23.89 & -1.02 & -1.01 & -29.60 & -1.26 & -1.24 & 324.66 & 1.30 & 1.28 \\
\hline$[0,29]$ & -9.81 & -0.42 & -0.41 & -37.33 & -1.59 & -1.56 & 242.93 & 0.97 & 0.96 \\
\hline$[0,30]$ & -16.29 & -0.70 & -0.69 & -33.52 & -1.43 & -1.41 & 210.96 & 0.85 & 0.83 \\
\hline
\end{tabular}


Table A48. Case XII: EGARCH(1,1)—Cumulative abnormal change rate of Chinese tourist arrivals.

\begin{tabular}{|c|c|c|c|c|c|c|c|c|c|}
\hline \multirow{3}{*}{ Event Period $\left[\tau_{1}, \tau_{2}\right]$} & \multicolumn{3}{|c|}{ Group-Type } & \multicolumn{3}{|c|}{ Individual-Type } & \multicolumn{3}{|c|}{ Medical-Type } \\
\hline & \multirow{2}{*}{ CAR } & \multicolumn{2}{|c|}{$\mathrm{t}$-Value } & \multirow{2}{*}{ CAR } & \multicolumn{2}{|c|}{$\mathrm{t}$-Value } & \multirow{2}{*}{ CAR } & \multicolumn{2}{|c|}{ t-Value } \\
\hline & & TM & SRM & & TM & SRM & & TM & SRM \\
\hline$[0,0]$ & 7.52 & 0.34 & 0.33 & 9.07 & 0.32 & 0.31 & -51.44 & -0.62 & -0.60 \\
\hline$[0,1]$ & 14.31 & 0.65 & 0.64 & 2.88 & 0.10 & 0.10 & 27.08 & 0.33 & 0.32 \\
\hline$[0,2]$ & -2.66 & -0.12 & -0.12 & -3.87 & -0.14 & -0.13 & -141.52 & -1.70 & -1.67 \\
\hline$[0,3]$ & 2.78 & 0.13 & 0.12 & 21.11 & 0.74 & 0.73 & -60.17 & -0.72 & -0.71 \\
\hline$[0,4]$ & -0.10 & 0.00 & 0.00 & 23.49 & 0.82 & 0.81 & 75.17 & 0.90 & 0.89 \\
\hline$[0,5]$ & 4.34 & 0.20 & 0.19 & 5.13 & 0.18 & 0.18 & -81.28 & -0.98 & -0.96 \\
\hline$[0,6]$ & -0.75 & -0.03 & -0.03 & -6.21 & -0.22 & -0.21 & -51.15 & -0.61 & -0.60 \\
\hline$[0,7]$ & -1.17 & -0.05 & -0.05 & -7.78 & -0.27 & -0.27 & 50.05 & 0.60 & 0.59 \\
\hline$[0,8]$ & 4.18 & 0.19 & 0.19 & -12.40 & -0.43 & -0.43 & 69.37 & 0.83 & 0.82 \\
\hline$[0,9]$ & -20.91 & -0.95 & -0.94 & -7.06 & -0.25 & -0.24 & -55.04 & -0.66 & -0.65 \\
\hline$[0,10]$ & 0.01 & 0.00 & 0.00 & 12.31 & 0.43 & 0.42 & -76.62 & -0.92 & -0.90 \\
\hline$[0,11]$ & -10.59 & -0.48 & -0.46 & 16.39 & 0.57 & 0.55 & 70.43 & 0.85 & 0.81 \\
\hline$[0,12]$ & -0.89 & -0.04 & -0.04 & 4.62 & 0.16 & 0.16 & -78.38 & -0.94 & -0.92 \\
\hline$[0,13]$ & -23.84 & -1.09 & -1.06 & 8.94 & 0.31 & 0.31 & -89.94 & -1.08 & -1.06 \\
\hline$[0,14]$ & -13.86 & -0.63 & -0.59 & 9.21 & 0.32 & 0.30 & -115.48 & -1.39 & -1.29 \\
\hline$[0,15]$ & 1.05 & 0.05 & 0.05 & 4.51 & 0.16 & 0.16 & -67.91 & -0.82 & -0.80 \\
\hline$[0,16]$ & -7.05 & -0.32 & -0.31 & 4.60 & 0.16 & 0.16 & -58.55 & -0.70 & -0.68 \\
\hline$[0,17]$ & 11.03 & 0.50 & 0.49 & 41.46 & 1.45 & 1.41 & -67.78 & -0.81 & -0.79 \\
\hline$[0,18]$ & -0.02 & 0.00 & 0.00 & 35.44 & 1.24 & 1.22 & -74.35 & -0.89 & -0.88 \\
\hline$[0,19]$ & -10.66 & -0.49 & -0.48 & 15.02 & 0.53 & 0.52 & 66.40 & 0.80 & 0.79 \\
\hline$[0,20]$ & -13.08 & -0.60 & -0.56 & 6.41 & 0.22 & 0.21 & -0.34 & 0.00 & 0.00 \\
\hline$[0,21]$ & -33.30 & -1.52 & -1.46 & -0.40 & -0.01 & -0.01 & -54.29 & -0.65 & -0.63 \\
\hline$[0,22]$ & -13.44 & -0.61 & -0.60 & 4.36 & 0.15 & 0.15 & -159.93 & -1.92 & -1.89 \\
\hline$[0,23]$ & -52.97 & -2.41 & -2.37 & -0.40 & -0.01 & -0.01 & 5.48 & 0.07 & 0.06 \\
\hline$[0,24]$ & -49.23 & -2.24 & -2.20 & 21.74 & 0.76 & 0.75 & -9.21 & -0.11 & -0.11 \\
\hline$[0,25]$ & -20.00 & -0.91 & -0.89 & 31.09 & 1.09 & 1.07 & -8.19 & -0.10 & -0.10 \\
\hline$[0,26]$ & -23.32 & -1.06 & -1.04 & 2.97 & 0.10 & 0.10 & -65.27 & -0.78 & -0.76 \\
\hline$[0,27]$ & -44.83 & -2.04 & -1.98 & -4.63 & -0.16 & -0.16 & -61.22 & -0.74 & -0.71 \\
\hline$[0,28]$ & -33.50 & -1.53 & -1.50 & -2.16 & -0.08 & -0.07 & 78.36 & 0.94 & 0.93 \\
\hline$[0,29]$ & -19.75 & -0.90 & -0.88 & -8.78 & -0.31 & -0.30 & -12.25 & -0.15 & -0.14 \\
\hline$[0,30]$ & -26.55 & -1.21 & -1.19 & -3.93 & -0.14 & -0.14 & -52.92 & -0.64 & -0.63 \\
\hline
\end{tabular}

\section{References}

1. McAleer, M. The Fundamental Equation in Tourism Finance. J. Risk Financ. Manag. 2015, 8, 369-374. [CrossRef]

2. Dolley, J.C. Characteristics and Procedure of Common Stock Split-ups. Harvard Bus. Rev. 1933, 11, 316-326.

3. Ball, R.; Brown, P. An Empirical Evaluation of Accounting Index Numbers. J. Acc. Res. 1968, 6, 159-178. [CrossRef]

4. Fama, E.F.; Fisher, L.; Jensen, M.C.; Roll, R. The Adjustment of Stock Prices to New Information. Int. Econ. Rev. 1969, 10, 1-21. [CrossRef]

5. Fama, E.F. Efficient Capital Markets: A Review of Theory and Empirical Work. J. Financ. 1970, 25, $383-420$. [CrossRef]

6. Boehmer, E.; Masumeci, J.; Poulsen, A.B. Event-study Methodology under Conditions of Event-induced Variance. J. Financ. Econ. 1991, 30, 253-272. [CrossRef]

7. MacKinlay, A.C. Event Studies in Economics and Finance. J. Econ. Lit. 1997, 35, 13-39.

8. Binder, J. The Event Study Methodology Since 1969. Rev. Quant. Financ. Acc. 1998, 11, 111-137. [CrossRef]

9. Corrado, C.J. A Nonparametric Test for Abnormal Security-price Performance in Event Studies. J. Financ. Econ. 1989, 23, 385-395. [CrossRef]

10. Mazzocchi, M.; Montini, A. Earthquake Effects on Tourism in Central Italy. Ann. Tour. Res. 2001, 28, 1031-1046. [CrossRef]

11. Patell, J. M Corporate Forecasts of Earnings Per Share and Stock Price Behavior: Empirical Test. J. Acc. Res. 1976, 14, 246-276. [CrossRef] 
12. Tao, Z. Short-term Economic Effect of the M7. 0 Lushan Earthquake. Nat. Hazards 2014, 70, 1247-1261. [CrossRef]

13. Nicolau, J.L. Assessing New Hotel Openings Through an Event Study. Tour. Manag. 2002, 23, 47-54. [CrossRef]

14. Corrado, C.J. Event Studies: A Methodology Review. Acc. Financ. 2011, 51, 207-234. [CrossRef]

15. Chen, M.H.; Jang, S.S.; Kim, W.G. The Impact of the SARS Outbreak on Taiwanese Hotel Stock Performance: An Event-study Approach. Int. J. Hosp. Manag. 2007, 26, 200-212. [CrossRef]

16. Dick, C.D.; Wang, Q. The Economic Impact of the Olympic Games: Evidence from Stock Markets. Appl. Econ. Lett. 2010, 17, 861-864. [CrossRef]

17. Ogawa, R. Using REIT Data to Assess the Economic Worth of Mega-events: The Case of the 2020 Tokyo Olympics; MPRA Working Paper; University Library of Munich: Munich, Germany, 2017.

18. Szutowski, D.; Bednarska, M.A. Short-term Effects of Innovations on tourism Enterprise Market Value: Event Study Approach. In New Trends in Tourism Research-A Polish Perspective; Dias, F., Oliveira, S., Kosmaczewska, J., Pereira, Â., Eds.; GITUR-Tourism Research Group of Polytechnic Institute of Leiria: Leiria, Portugal, 2014; pp. 205-217.

19. Szyszka, A. Efektywność Giełdy Papierów Wartościowych w Warszawie na tle Rynków Dojrzatych; Efficiency of the Warsaw Stock Exchange in Comparison to Developed Markets, Wyd; Akademii Ekonomicznej w Poznaniu: Poznań, Poland, 2003; p. 64.

20. Johnson, M.; Singh, A.J.; Ma, Q. The impact of authorization of the travel promotion act on hotel firm stock returns. Cornell Hosp. Q. 2015, 56, 29-40. [CrossRef]

21. McWilliams, A.; Siegel, D. Event Studies in Management Research: Theoretical and Empirical Issues. Acad. Manag. J. 1997, 40, 626-657.

22. Sharpe, W.F. Capital Asset Prices: A Theory of Market Equilibrium under Conditions of Risk. J. Financ. 1964, 19, 425-442.

23. Engle, R.F. Autoregressive Conditional Heteroscedasticity with Estimates of the Variance of United Kingdom inflation. Econometrica 1982, 50, 987-1007. [CrossRef]

24. McAleer, M. Asymmetry and Leverage in Conditional Volatility Models. Econometrics 2014, 2, 145-150. [CrossRef]

25. Chang, C.L.; McAleer, M.; Wang, Y.A. Modelling Volatility Spillovers for Bio-ethanol, Sugarcane and Corn Spot and Futures Prices. Renew. Sustain. Energy Rev. 2018, 81, 1002-1018. [CrossRef]

26. Bollerslev, T. Generalized Autoregressive Conditional Heteroskedasticity. J. Econ. 1986, 31, 307-327. [CrossRef]

27. Tsay, R.S. Conditional Heteroscedastic Time Series Models. J. Am. Stat. Assoc. 1987, 82, 590-604. [CrossRef]

28. Ling, S.; McAleer, M. Asymptotic Theory for a Vector ARMA-GARCH Model. Econ. Theory 2003, 19, $280-310$. [CrossRef]

29. Glosten, L.; Jagannathan, R.; Runkle, D. On the Relation Between the Expected Value and Volatility of Nominal Excess Return on Stocks. J. Financ. 1993, 48, 1779-1801. [CrossRef]

30. Nelson, D.B. Conditional Heteroscedasticity in Asset Returns: A New Approach. Econometrica 1991, 59, 347-370. [CrossRef]

31. McAleer, M.; Hafner, C.M. A One Line Derivation of EGARCH. Econometrics 2014, 2, 92-97. [CrossRef]

32. Brown, S.J.; Warner, J.B. Using Daily Stock Returns: The Case of Event Studies. J. Financ. Econ. 1985, 14, 3-31. [CrossRef]

(C) 2018 by the authors. Licensee MDPI, Basel, Switzerland. This article is an open access article distributed under the terms and conditions of the Creative Commons Attribution (CC BY) license (http:/ / creativecommons.org/licenses/by/4.0/). 